

\title{
The Unsettled Landscape
}

\author{
The Core to Coastal Fabrics
}

A 120 point thesis submitted to the Victoria University of Wellington in fulfilment of the requirements for the degree of Masters of Landscape Architecture.

Victoria University of Wellington

By Oliver Chan

2015 


\section{Acknowledgements}

Without the assistance of many individuals, this thesis would not have been possible.

Firstly, I would like to thank Martin Bryant and Penny Allan, who have supervised this research, and have also guided me for the duration of my study at Victoria University.Your continual input has pushed my learning and furthered my interest in design. I would also like to thank Sam Kebbell, who has offered insight during this research.

I extend my gratitude to my colleagues and friends, who have somehow survived five years of my presence, and have also provided support, constructive advice, and good company. I'm not sure how they managed.

To Dad and Sue, I am grateful for your support, encouragement, advice, and in particular the numerous free dinners at the Majestic. To my Mum and Terry, your continued reassurance and faith has kept me confident. To each of you, I am immensely grateful for all the support you have given. Lastly, to my partner, Jolene, whose encouragement, willingness to listen, and ability to motivate me on a daily routine has provided me with immeasurable support, which has meant a lot to me. 


\section{Abstract}

'The Unsettled Landscape' considers an alternative sustainable manner in which communities can settle New Zealand's coastland. Living at the ocean edge is ingrained in the way many of our urban settlements have formed, and is intricately linked with how we define ourselves. Unfortunately the way these places have manifested in reality has produced ecological barriers to natural cycles paramount to ecosystem health. Sea walls, housing, roads and many other infrastructural typologies resist the natural 'flux' of these areas, which results in dysfunctional ecosystems as well as putting residents of these places at risk of numerous threats which occur along these interface sites. Earthquakes, river movement, erosion, sea level rise, flooding and the continual movement of the dunes are just some of the issues coastal settlements face. The conflict forms where the sought after coastal environments are applied to in a permanent manner that is irresponsive of a landscape which functions in a most dynamic way.
This thesis looks towards the geomorphological patterns in the coast as an indicator for how a complete shift in infrastructural application might occur responsively. This new fabric distinguishes stable components in this shifting landscape, utilising them as a stable network from which settlement can develop. This network could become the basis of more responsive settlements, stronger communities, and will act as a way to future proof inhabitation of these fragile yet hazardous places. Design research explores the physical as well as intangible aspects of settlement application, and focuses on communities forming the 'real' foundation of these temporal environments. Responsive communities arise 'reactively' avoiding hazards, and allowing inhabitants to take advantage of what these precious sites offer. 


\section{Contents}

1. Introduction

1.1. The Coastal Problem

1.2. Research Aims

1.3. Research Method

1.4. A Global Issue

1.5. Typical Responses

2. Case Studies

2.1. The Maritime Youth House

2.2. The Retreating Village

2.3. Floating Villages of Ha Long Bay

2.4. Dauphin Island

2.5. Svalbard Global Seed Vault

2.6. Chand Baori Step Well

2.7. Parc de la Villette

2.8. DIY Urban Furniture

Experiment

3. Literature Review

3.1. Responsive Architecture

3.2. Settlement Structure

3.3. Place and Community

4. Test Site: Waikawa

4.1. Context

47
7 5. Processes and Threats

51

5.1. River Movement 52

5.2. River Consistency 54

5.3. Flooding 56

5.4. Sea Level Rise 58

5.5. Fore Dune Movement 60

5.6. Parabolic Dunes 62

5.7. Earthquakes 64

6. A History of Inhabitation 67

6.1. Early Settlement: Pre 1800's 68

6.2. Maori Settlement: 1800-1843 70

6.3. European/

MaoriSettlement:1844-1874 72

6.4. European Colonisation: 1875$1915 \quad 74$

6.5. The Beginning of Baches: 1916$1950 \quad 76$

6.6. Contemporary Waikawa: 19512014 78

6.7. Waikawa Today 80

6.8. Relation to Surrounding

Settlements

82

6.9. Community at Waikawa 84

7. Concept Design: Zone-Making 87

7.1. Patterns in the Land 88

7.2. Applying Zones 90

7.3. Habitable, Sacrificial, and Anticipated

7.4 Evaluation 


\section{Alternative Concept Design: Cores}

8.1. What is a 'Core'?

8.2. Core Location

8.3. Settlement Under Core Notion

8.4. Determining Form

8.5. Evaluation

9. Design: Core Networks

9.1. Of Points, Paths, and Peripheries

9.2. Core Logic

9.3. Periphery Expansion

9.4. Working with Farmers

9.5. Phasing

9.6. Long-term Resilience

9.7. Exploration Summary

10. Design Types: Form and

Community

10.1. Communal Platforms

10.2. Activity Typologies

10.3. Form/Activities: A Summation of Context
109
11. Final Development

11.1. Core Variant One

11.1.1. Contextual Activity Drivers

11.1.2. Design

11.1.3. Activity Matrix

11.2. Core Variant Two

11.2.1. Contextual Activity Drivers

11.2.2. Design

152

11.2.3. Activity Matrix

12. Discussion

12.1. Cores as a Method of Settling 166

12.2. Communities as Infrastructure

12.3. Geomorphology as an Indicator

12.4. Benefits for Existing Land Owners

12.5. Form as a Required Amalgamation

13. Conclusion

14. Figure List 174

15. Bibliography 176 
Humanity has always longed to settle on the coast. These sites provide an abundance of rich resources, and have given numerous forms of opportunity to inhabitants since initial occupation. Globally, coastal sites have significance to a diverse range of people. Culturally, productively, or for lifestyle reasons these sites have become incredibly valuable and sought after. Coastal areas are continually popular for development, and are becoming ever more populated. Being on the land-sea threshold has meant that these sites, though abundant with life, are unstable and dangerous if populations apply themselves in manners irresponsive to the complex patterns of the coast.

Currently, the majority of settlements in coastal areas are fashioned in a 'one size fits all' manner, applied defensively, and avoiding opportunity to work with the landscape.

"Every square foot built by conventional means is already obsolete.” (Russel, 2011 )
This irresponsive, static way of occupying land prevents natural movements from occurring and has degraded system health, impeding opportunities that were once plentiful.

"Until economic activity accurately prices the value of natural resources, the forests, fisheries, and agricultural land will continue a spiralling decline, exploited beyond the point of no return by unprecedented levels of world demand." (Russel, 2011)

This thesis looks towards patterns in the coast as an indicator for how settlement might form responsively. Design research considers stable and shifting elements of this complex system to plan for an infrastructural system for developing settlements. 
By proposing an alternative settlement pattern, the aim is to confront traditional manners of settling on the coast.

In doing this the objective is to explore how landscape architecture can be at the forefront of settlement planning, beginning a new way of occupying fragile landscapes. The goal is to create a meaningful relationship between land and settlement.The intention of this thesis is to recognise the importance of coastal living and the value of a functional coastal system, and to explore how the two may mutually benefit from one another. Proposals can be tested against important criteria; in particular, application of settlements which do not adversely disturb coastal processes, the avoidance of threats/preparedness to deal with disaster events, the level of density, and the ability of settlement structure to form strong communities.

To achieve this, design research occurred on several scales, designing on large system scales, and on detailed scales which reveal how alternative settlements function on the ground. 
The research method is design led; priority into achieving a holistically viable coastal settlement scheme is the overarching theme. Research conducted is not focused on scientific, or calculated exploration, but rather makes use of several design tools which focus not only on the pragmatics of settlement planning, but also on intangible factors such as community, aesthetics and historic influence, aiding in exploring a more encompassing response.

Investigation analysed issues, and the current theories and trends in dealing with them as well as some unique responses. Research here will enquire into underlying principles behind the standard and unconventional responses, determining successful and unsuccessful facets.

Design investigation has been carried out in an iteratively guided process; explorations are applied and evaluated based on objectives. From here, faults, or important unanswered topics will be addressed in new lines of investigation. This constant re-evaluation refined the design response so that it 'answers' the numerous issues related with settling the coast. 


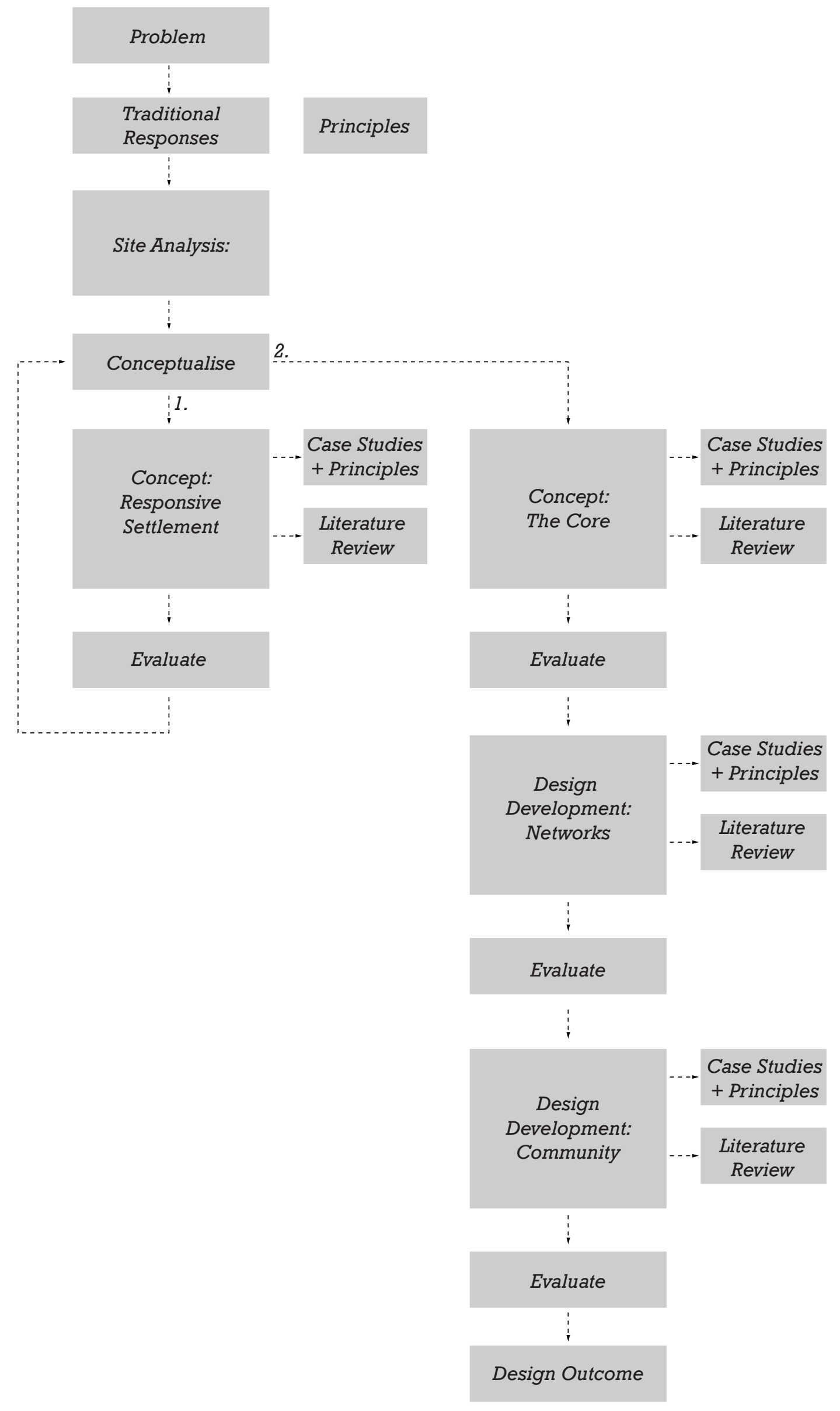

Figure 01 Methodology of design process 
With populations increasing and a constant allure of the coast, there is pressure for seaside landscapes to be developed. Environmental issues associated with development occur on many scales ranging from sparsely populated rural land to high density urban areas.

Devastation occurs along these delicate lands given certain circumstances, the Japanese earthquake and Tsunami of 2011 is a reminder of the potential cost of living in a fragile landscape. The magnitude 9 earthquake caused a tsunami which reached $10 \mathrm{~km}$ inland, consuming sea defences. Over 18,000 people lost their lives in the event (Fig.02).

"The waves overtopped and destroyed protective tsunami seawalls at several locations." (Oskin, 2013) 


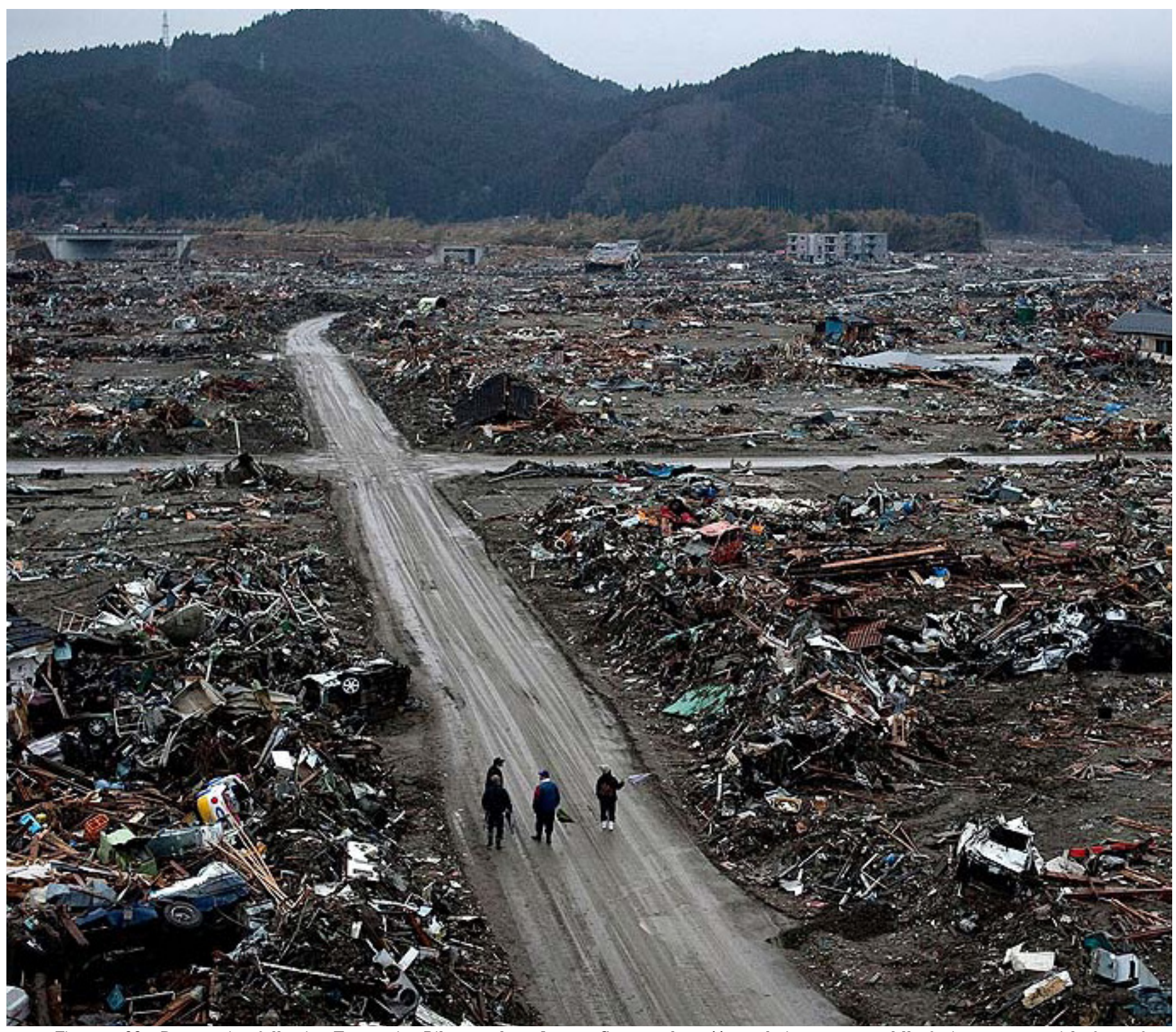

Figure 02 Destruction following Tsunami at Rikuzentakata, Japan - Source - http://www.latimes.comworldla-fg-japan-tsunami-before-afterslider-htmlstory.htm I 
Loss also transpires over long timescales. Happisburgh, located on England's North Sea coast; a town home to 1400 residents lies on the brink of ruin due to erosive forces (Fig.03).

"Although now a coastal village, Happisburgh was once some distance from the sea." (BGS Landslides team, 2014)

Within 250 years, $250 \mathrm{~m}$ of land has been lost. Until recently one property has been relinquished annually. Typical coastal defences have slowed the rate of erosion since, however many areas lie beyond repair (BGS Landslides team, 2014). 


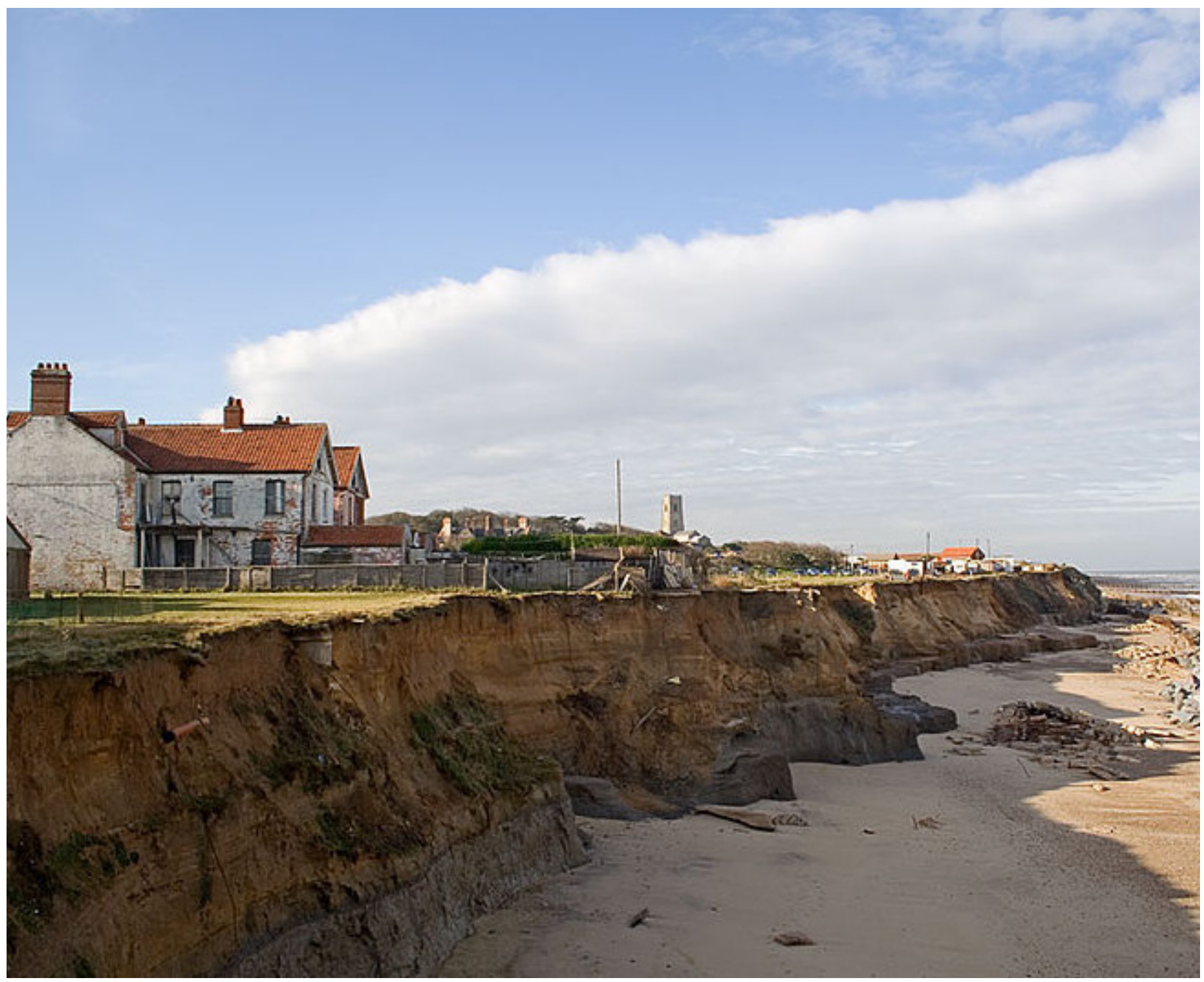

Figure 03 Crumbling cliff at Happisburgh, England - Source - http://www.andrewdunnphoto.com/ 
Coastal protection is catered to by two predominant methods. Neither adopt an approach where settlements respond to movements. Both methods take a defensive stance, effectively separating and limiting interaction between movements and settlements.

Harden: Strengthening the edge thereby stabilising developed areas. Traditionally this is done with structures such as sea walls, groynes, and revetments. In high energy environments these measures can mitigate the danger to development (Fig.03). These structures are often expensive to build and maintain and can cause places such as beaches to dissipate rendering them unusable. These structures can 'disrupt' shoreline processes and destroy important habitats such as wetlands and intertidal beaches damaging the very landscape which they are often attempting to protect. 


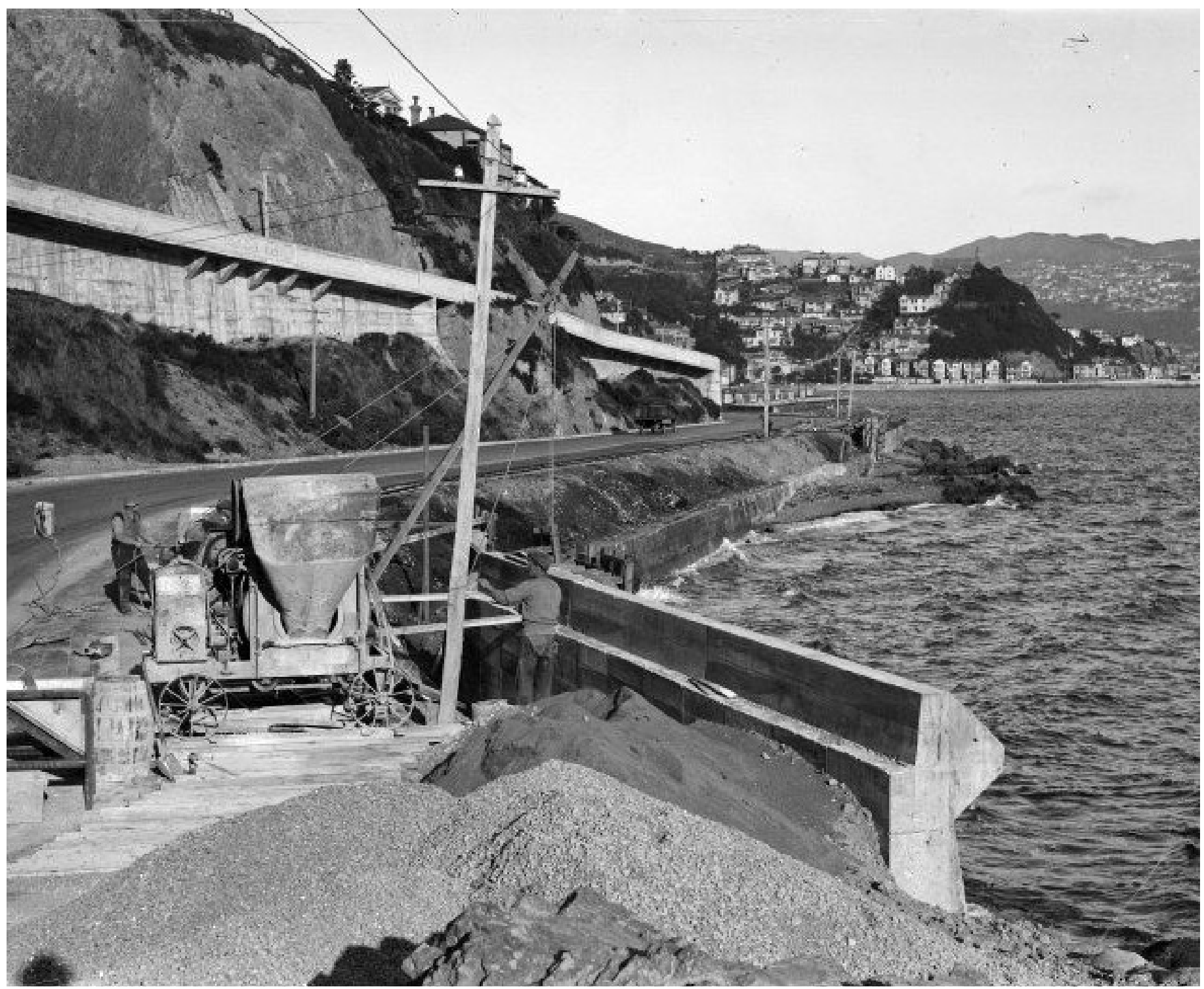

Figure 04 Construction of sea wall at Oriental Bay, Wellington, $1930-$ Source - http://mp.natlib.govt.nz/detail/?id=21778\&l=en 
Soften: This involves restricting development on the shoreline and allowing natural cycles to regenerate without human presence. A common example is sand dune restoration, which allows processes to occur undisturbed, and in return acts as a buffer (Fig.05). These options are often initiated using vegetation to stabilise and build dunes (Nature Space, n.d.). These approaches restrict access to the shoreline, and make attractive land unavailable.

Neither response shows an understanding of the natural systems in play. Are there alternatives to these standardised approaches? 


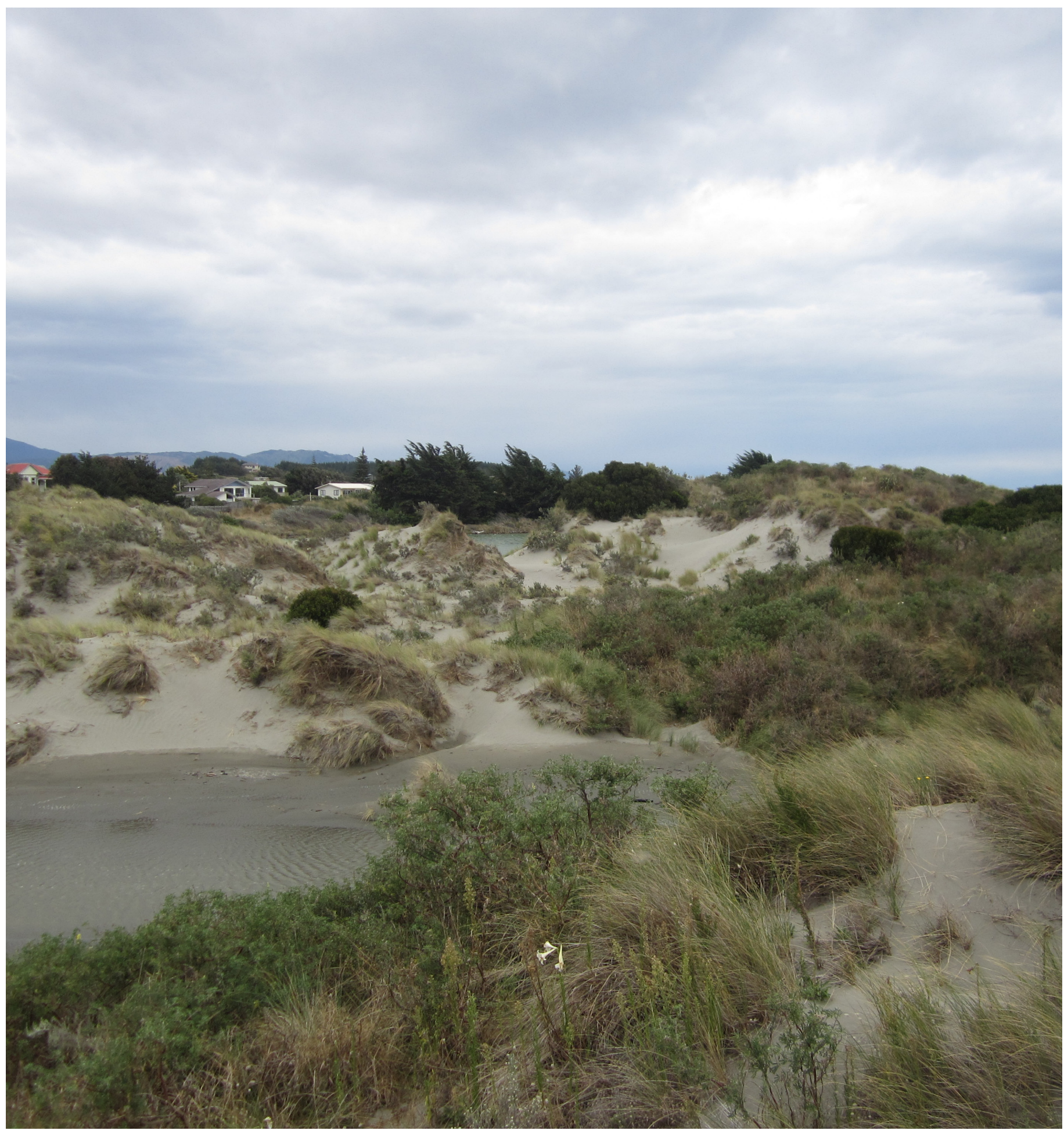


Exploration into alternative methods of dealing with uncertainty has occurred, but is less resolved than standard responses. Each response deals with change but is not necessarily coastal. The implications of principles of such responses have potential to change the way we inhabit the shoreline. These case studies have been selected as interesting approaches which have not been fully explored, but provide several strengths and weaknesses. 
The Maritime Youth House is located in Copenhagen on an industrial maritime area. The project seeks to provide for two distinct user groups; the sailing club, requiring mooring space, and a youth group which needed outdoor areas for recreation. The project achieves this while avoiding the polluted landscape below. The structure is propped up on piles, separating it from the landscape (MIMOA Community, n.d.). The deck-structure becomes a substitute for the unusable land beneath, forming various spaces which allow mooring and a diverse platform for recreation (Fig.07).

This project mitigates the issues of the landscape simply by removing it from the equation, separating structure and landscape. The construction of a separated substitute allows an 'ideal' replacement (Fig.08).

On a small scale separating inhabitants from the land beneath may be viable; however on a large coastal settlement scale, this would prove extremely cost and labour ineffective. The structure also avoids any connection to the land, preventing any exchange that may be mutually beneficial, and attempts to 'dodge' the problem rather than resolve it. Significant changes in the landscape may also reveal the inability for schemes like this to adapt (Fig.06).

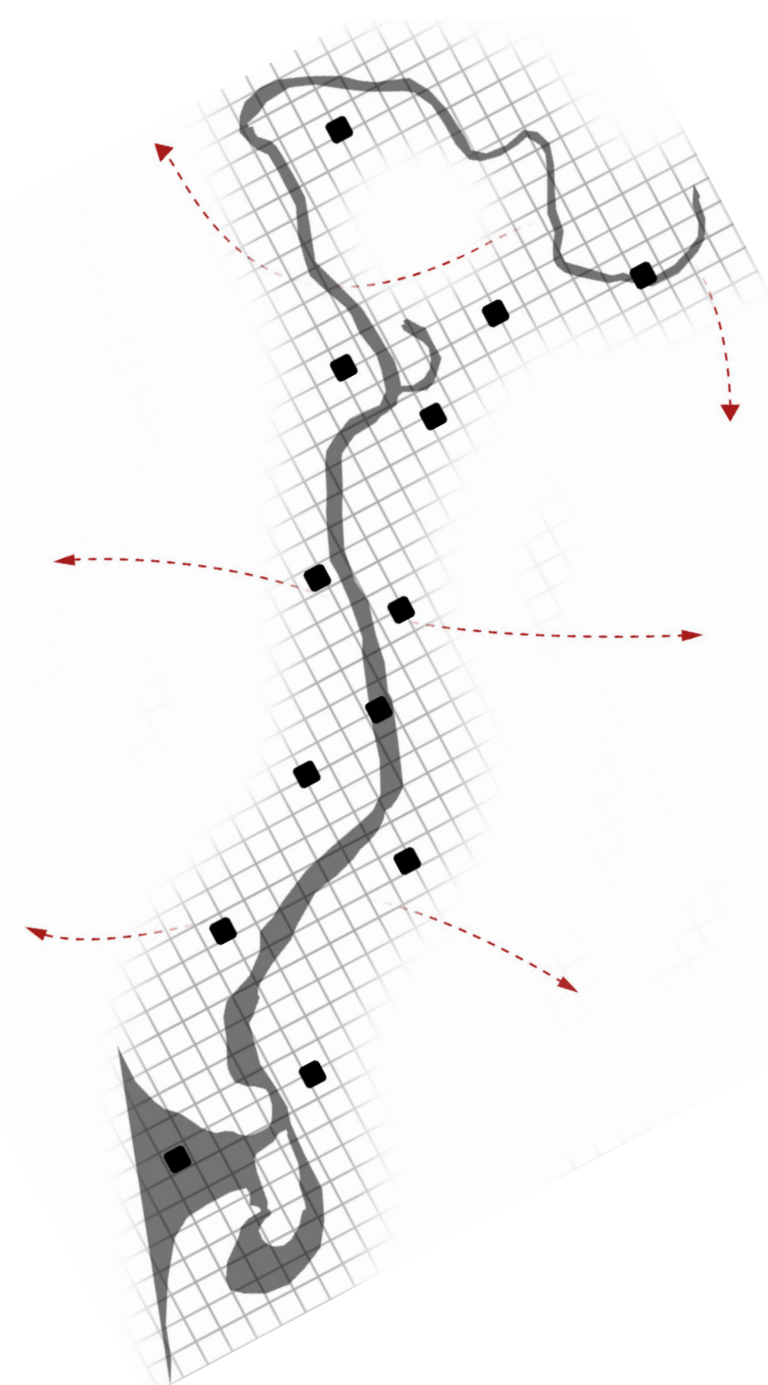

Figure 06 Diagrammatic application of 'substitute' principle over Waikawa River 


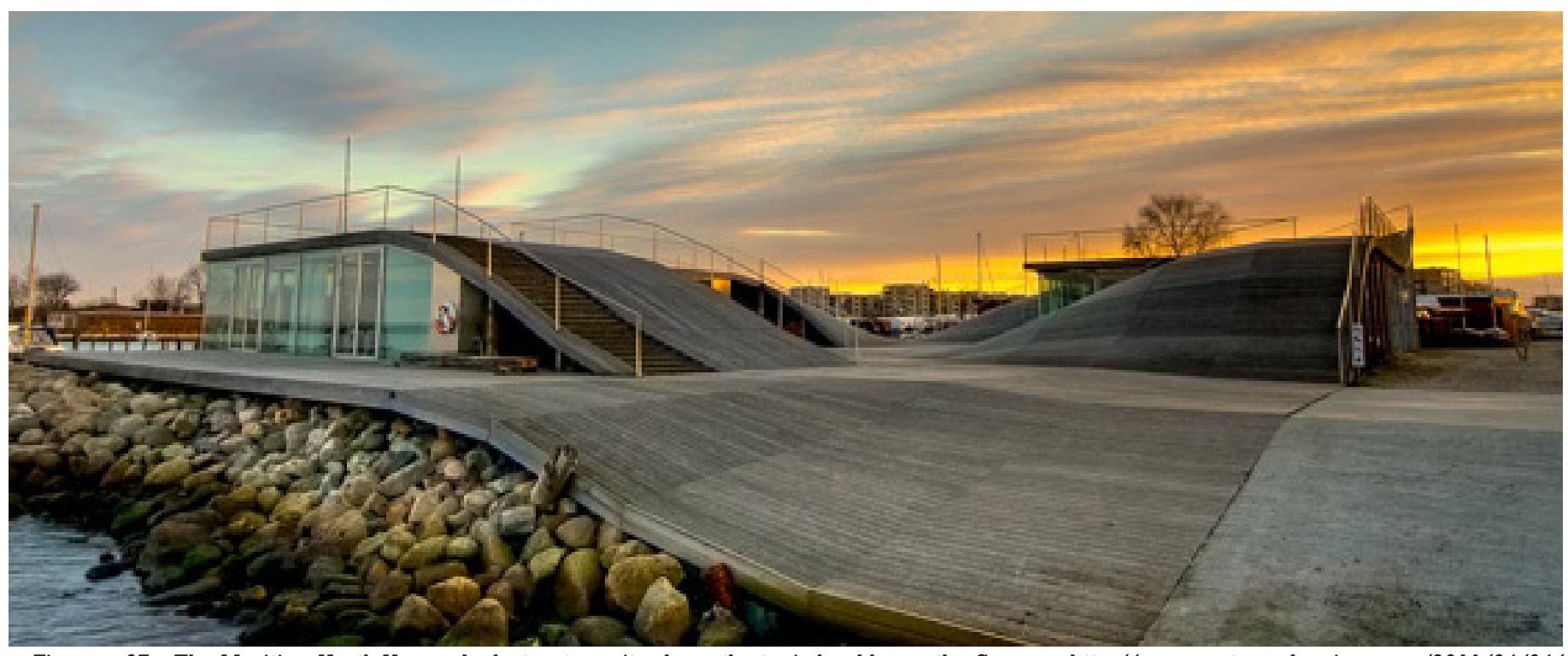

Figure 07 The Maritime Youth House deck structure sits above the toxic land beneath - Source - http://www.metamodernism.com/201 1/04/04/ bjarke-ingels-ii-at-warpspeed/maritime-youth-house-copenhagen-denmark_0/
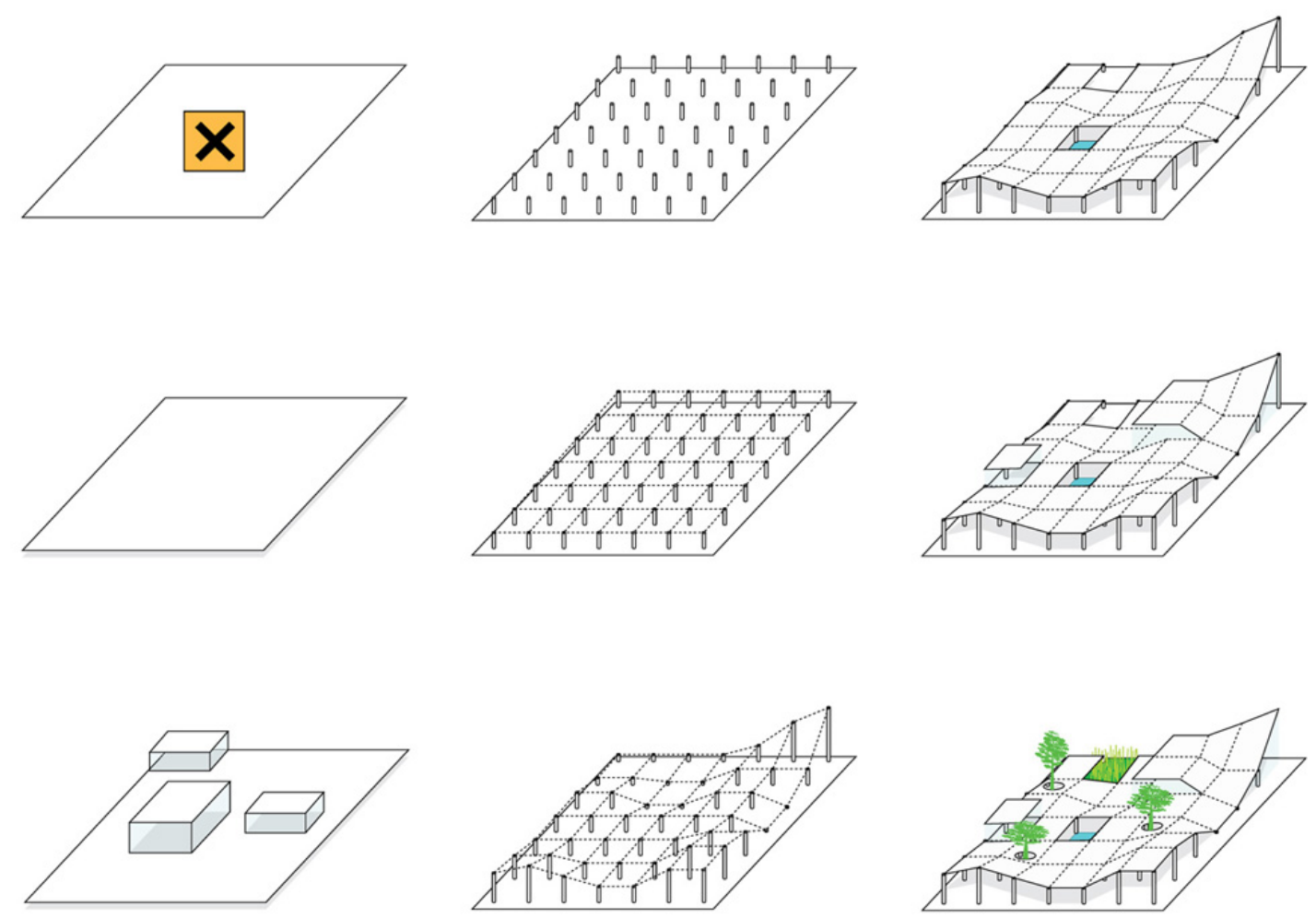

Figure 08 Diagram of substitution of toxic land with new deck structure - Source - http://www.archdaily.com/1 1232/maritime-youth-house- 
The Retreating Village is a hypothetical solution to erosive forces threatening the town of Happisburgh. Several buildings have been abandoned or lie meters from the cliff face. The project occupies this unstable space using a managed retreat system, responding directly to changes in the cliff. This is realised using mechanical devices which mimic the cliff, continually adjusting building positions, retreating as the coast retreats (Allen \& Smout, 2008). (Fig. 11).

This project responds directly to erosion, allowing structures to remain safe while occupying the most dangerous locations. Further, this removes a necessity for buffers which are often found in landscapes such as Happisburghs'. The impermanent nature of the project means reformatting the settlement is unproblematic (Fig.11).

Practicalities such as continued maintenance of machinery, and mechanical issues associated with small debris prevent this response from being totally feasible on the coast. The response deals with a single movement, but there are often several major processes in play at coastal locations (Fig.09). On a settlement scale, huge amounts of machinery would prove costly, and would require large portions of land to be placed; valuable land situated on the coastal edge.

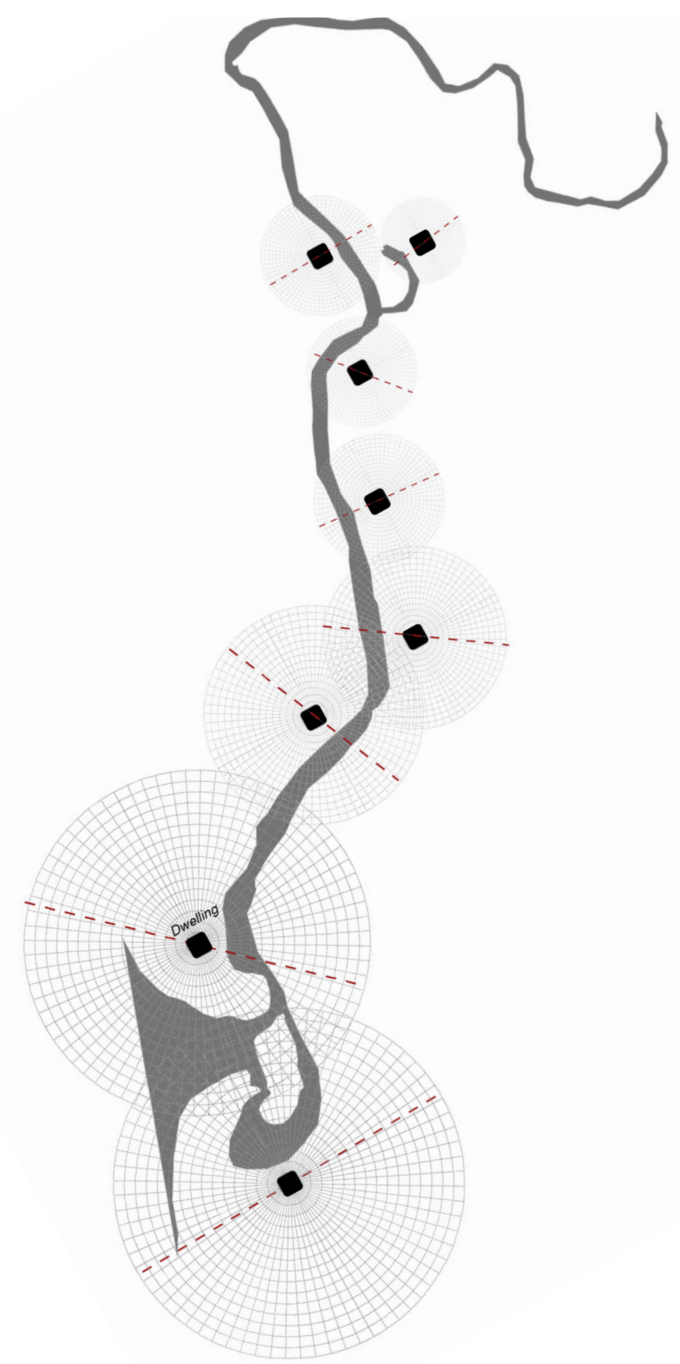

Figure 09 Diagrammatic application of 'retreat' principle over Waikawa River 


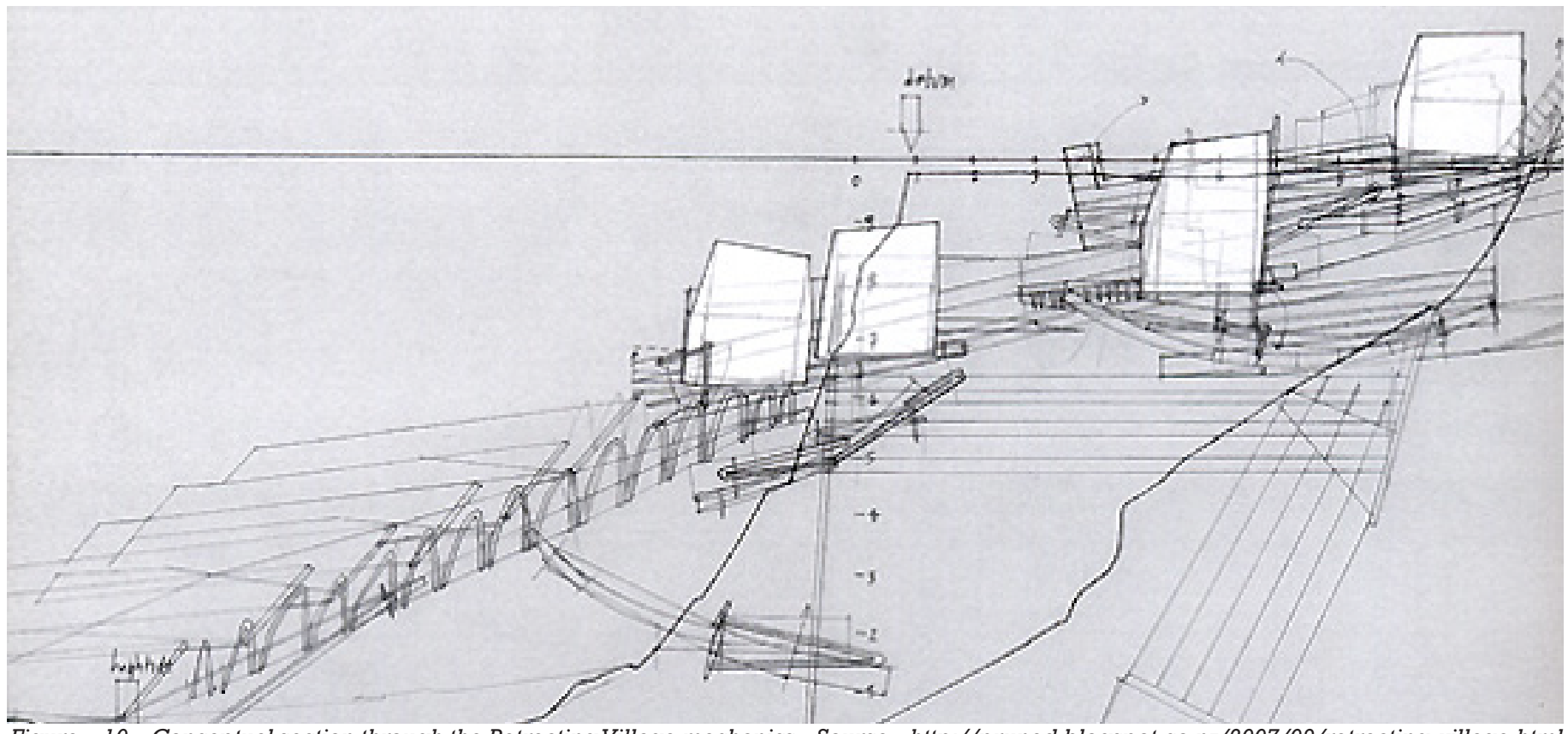

Figure 10 Conceptual section through the Retreating Village mechanics - Source - http://pruned.blogspot.co.nz/2007/09/retreating-village.html

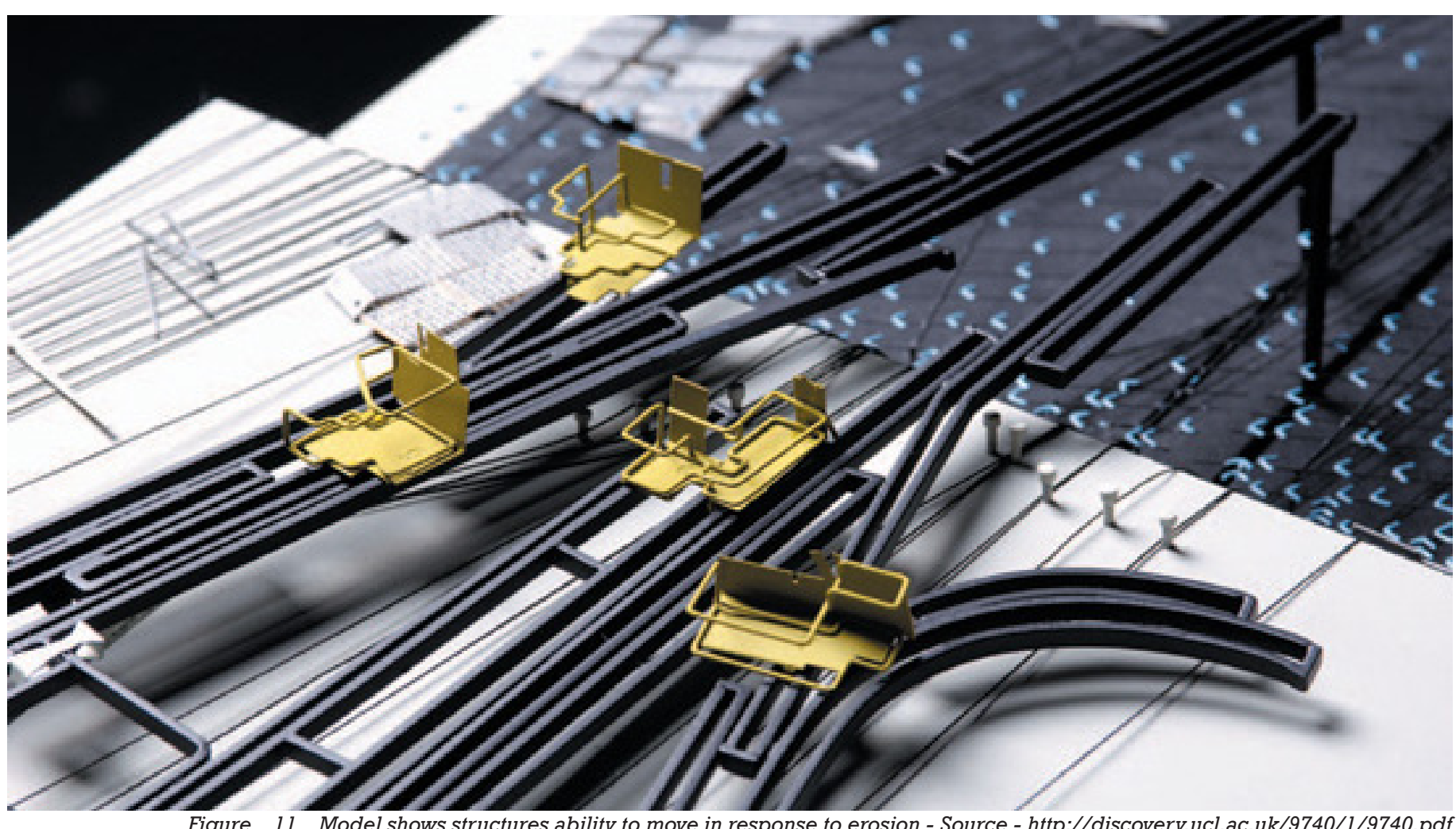

Figure 11 Model shows structures ability to move in response to erosion - Source - http://discovery.ucl.ac.uk/9740/1/9740.pdf 
Four fishing villages reside on the water within $\mathrm{Ha}$ Long Bay, Vietnam. Approximately 1,000 occupants live on a number of interconnecting boats/households several kilometres from land (Fig.13). No land ownership is required, and inhabitants make a living from aquaculture and fishing. Initially these villages formed during the 19th Century when rising waters forced people to make their boats homes. Today the villages form a network of timber frames, supported by floatation devices, accommodating households and pathways (Fig. 14).

Structuring settlements under these parameters permits continual fluctuation. The re-structuring capability allows residents to reorganise their community in line with traditions, culture or seasonal fluctuation. Placement offshore aligns the settlement with a single movement, while granting access to these valuable locations (Fig.12). Communally, the lack of land ownership creates an equality between occupants.

On a large scale, the degree of infrastructure and maintenance would prove challenging. Freak events, such as large storms could put many lives in danger and severely damage structures. A truly coastal response should also deal with a range of processes allowing the inhabitation of the land, and not simply the sea.

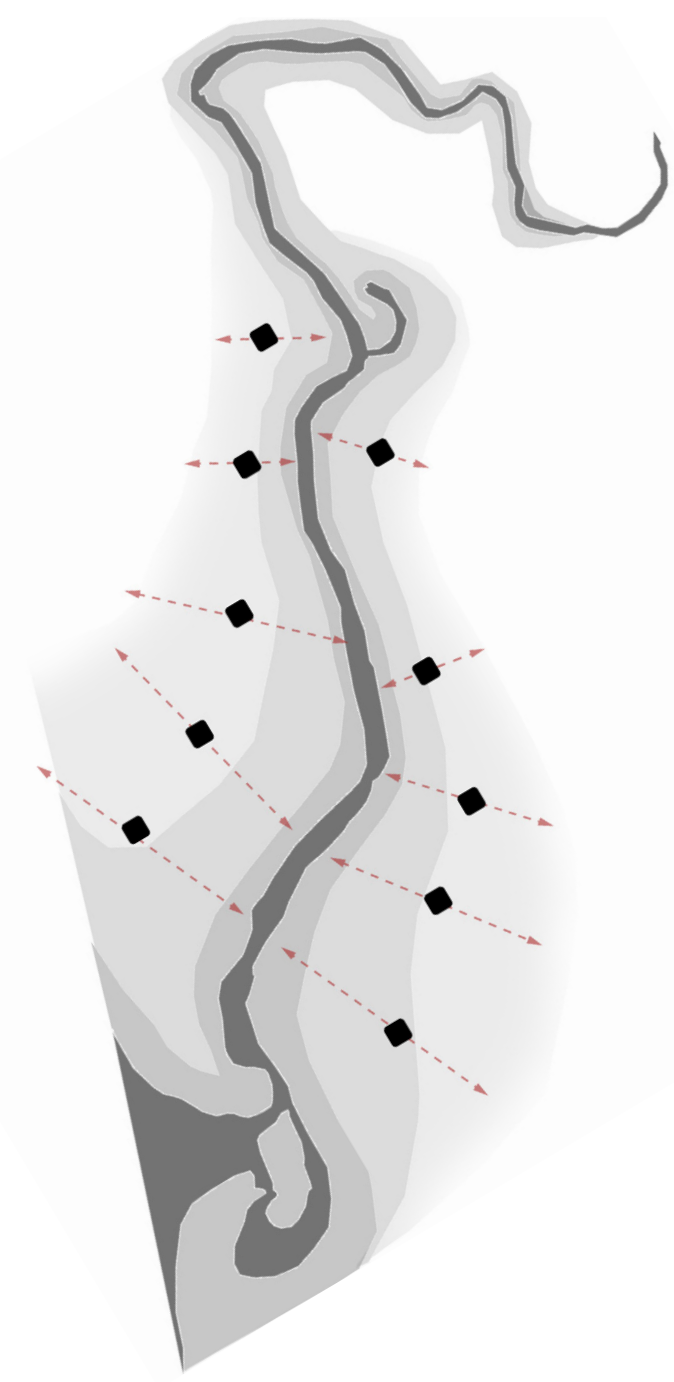

Figure 12 Diagrammatic application of 'mimicry' principle over Waikawa River 


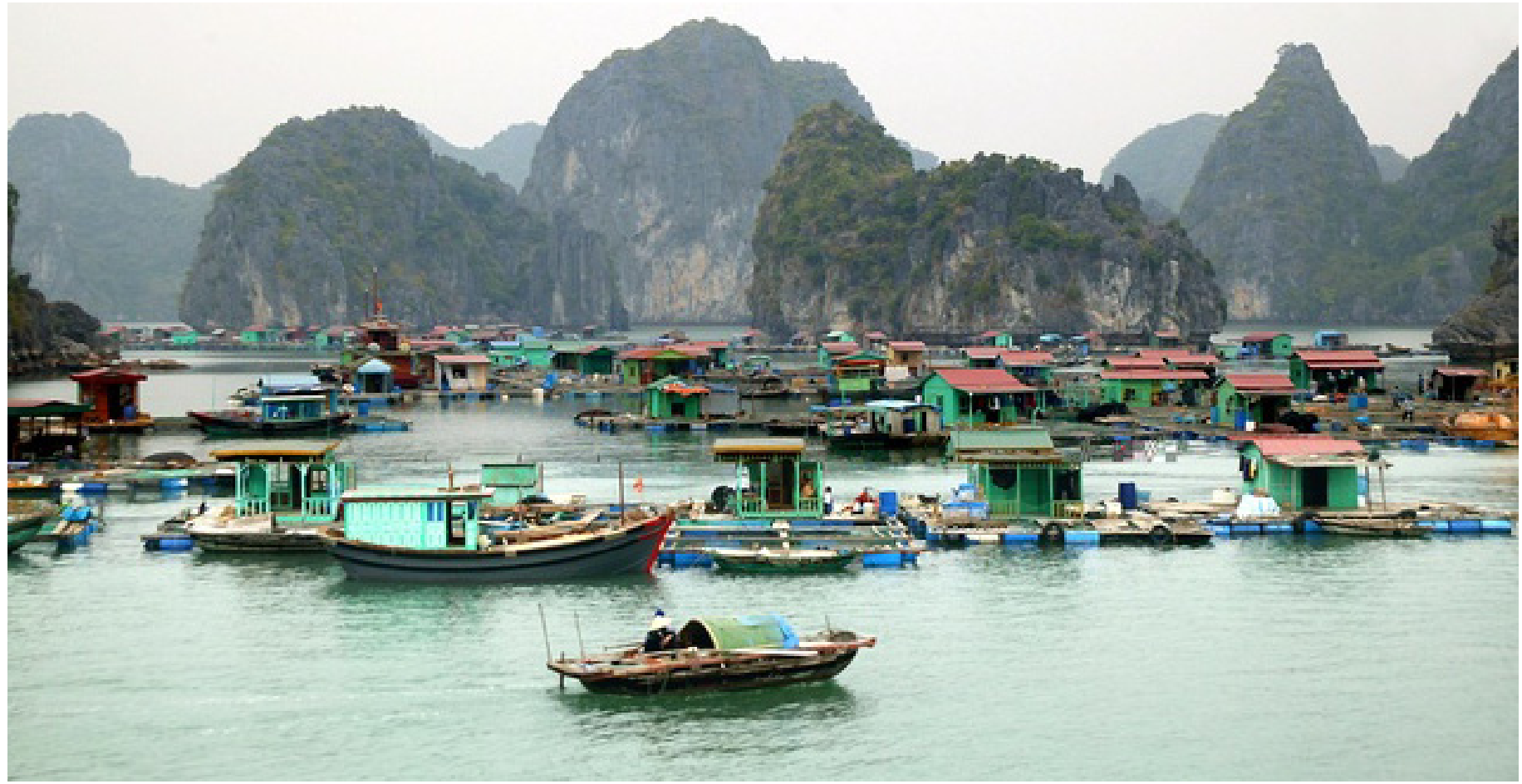

Figure 13 Ha Long Bay's network of connected rafts - Source - http://theclassytraveler.com/ha-long-bay-one-of-the-7-natural-wonders-of-the-

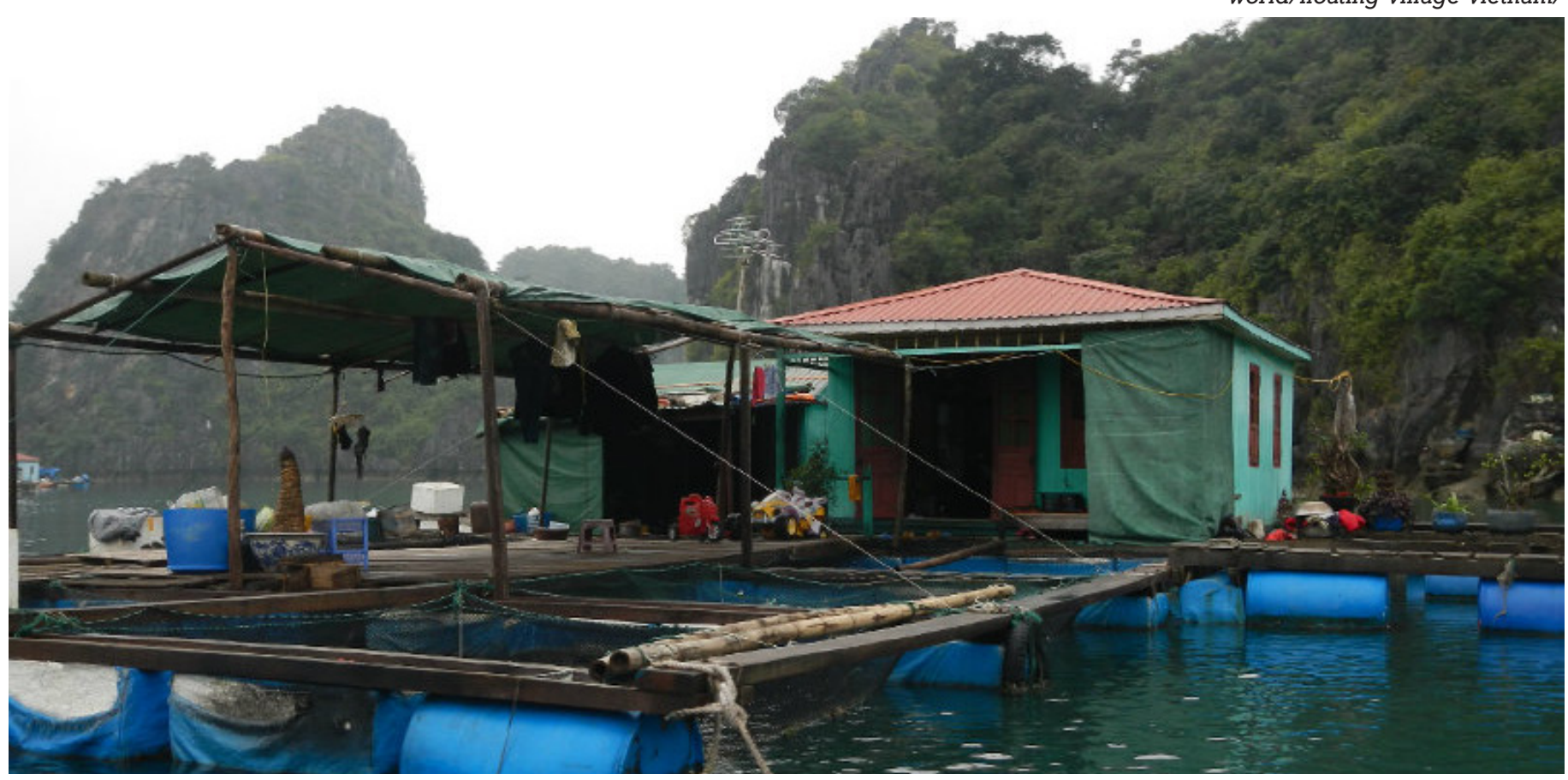

Figure 14 Floatation devices prop the settlement above the sea - Source - http://www.feedmetravel.com/vietnam/vung-vieng-floating-village- 
Dauphin Island is a barrier island located in the Gulf of Mexico. Accessible by a bridge almost five kilometres long, the island is home to 1,300 residents (Fig.18). Structures employ stilts, lifting homes above the reach of the sea (Fig.17). Essentially the first floors of homes are void, and living occurs where the second story would normally begin. Density is very sparse, but dwellings are able to extend over areas such as the waters edge, which would not normally be habitable (Town of Dauphin Island, 2014). (Fig. 16).

This method of separation disconnects the landscape from dwellings. Potentially this technique allows occupation of any land. The distance between water and household allows for predictable change, and the sparse placement prevents collateral damage (Fig.15).

This system relies on access from the bridge, in the event of damage, residents would find themselves stranded. In the event of a large storm, or tsunami, there is little safety offered to residents, and no way to protect dwellings. In smaller events houses are protected, but infrastructure such as roads are not, making them more vulnerable.

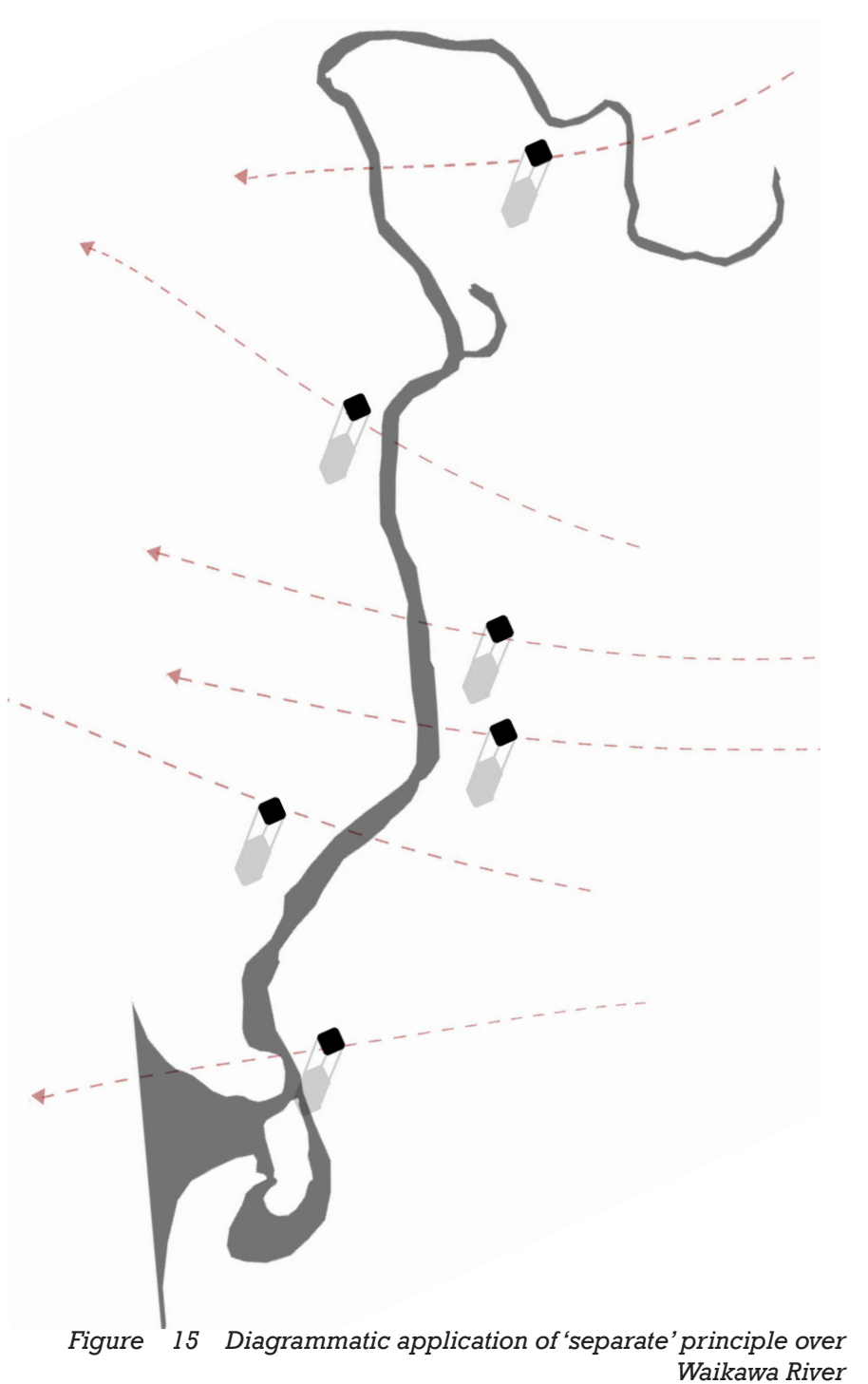




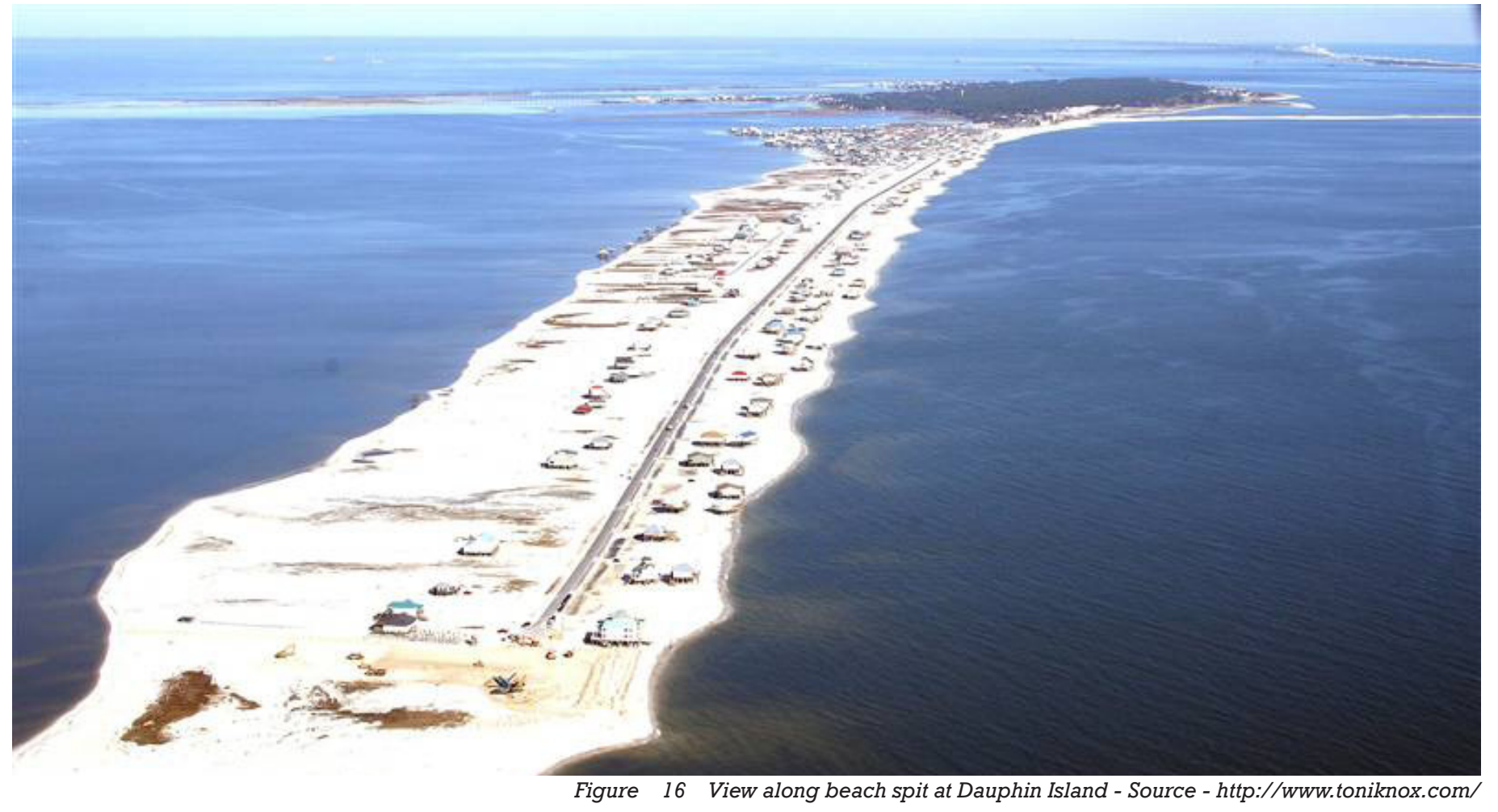

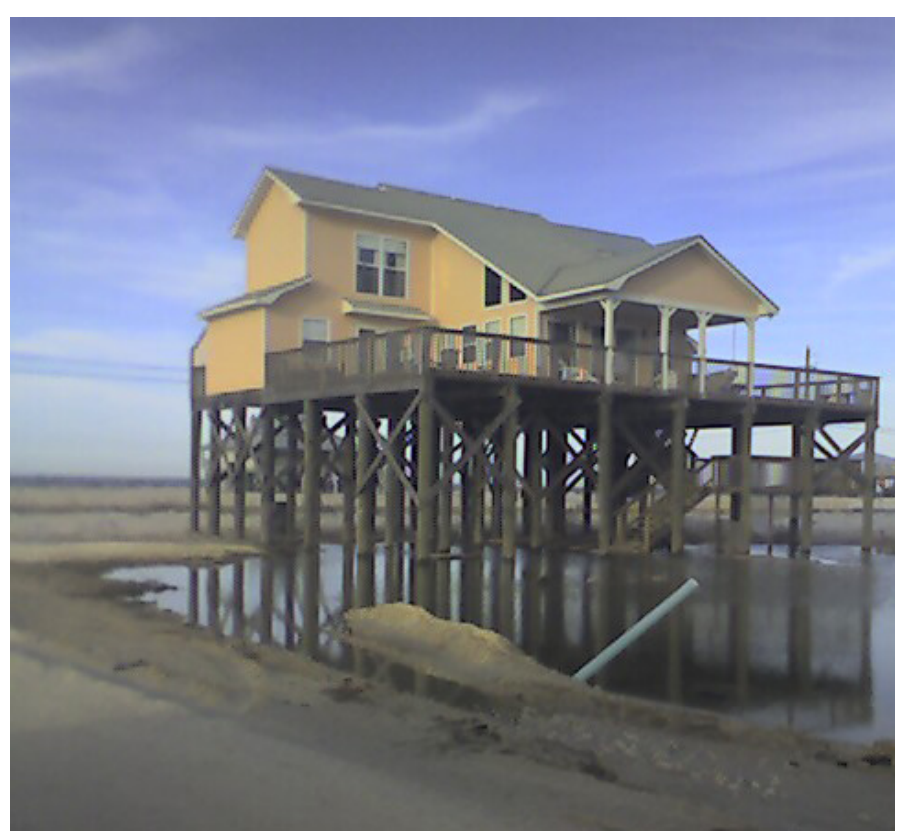

Figure $\quad 17$ Typical stilt house at Dauphin Island - Source -http:// onegreatjourney.blogspot.co.nz/2009/02/dauphin-island-stormdamage-end.htm

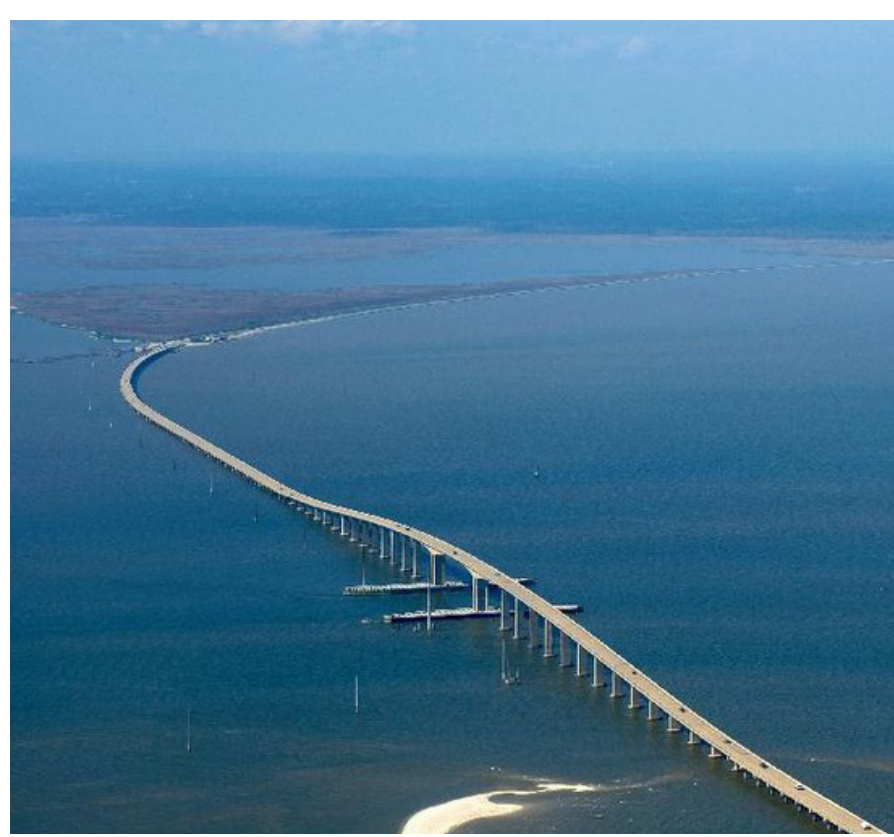

Figure 18 Five kilometre Access Bridge to Dauphin Island - Source http://www.panoramio.com/photo/20404172 
Located within a mountain on an Island in the Svalbard archipelago, lies the Global Seed Vault. This facility stores seeds, and protects them against natural or man-made disaster (Global Crop Diversity Trust, n.d.). The vault contains two thirds of the worlds' stored crop biodiversity, preserving the genetic code that one day might be vital (Fig.21). The vault is burrowed 160 meters into permafrost through a tunnel system, protecting it from the exterior (Fig.20). In the event of the loss of electricity, it would take 200 years for the vault to warm to freezing point (The Economist Newspaper, 2012).

The vault utilises the stability of its environmental conditions to perform much of the effort (Fig.22). The system keeps the seeds safe from fire or flooding where others have failed.

Svalbard seed vault offers little to its immediate community. There is little relationship between it and the nearby town, Longyearbyen. The vault cannot operate as a heart of the community, to do so the vault would in some manner have to provide services to the community in the event of disaster. Storage of food, building material, or shelter are some of the opportunities missed (Fig.19).

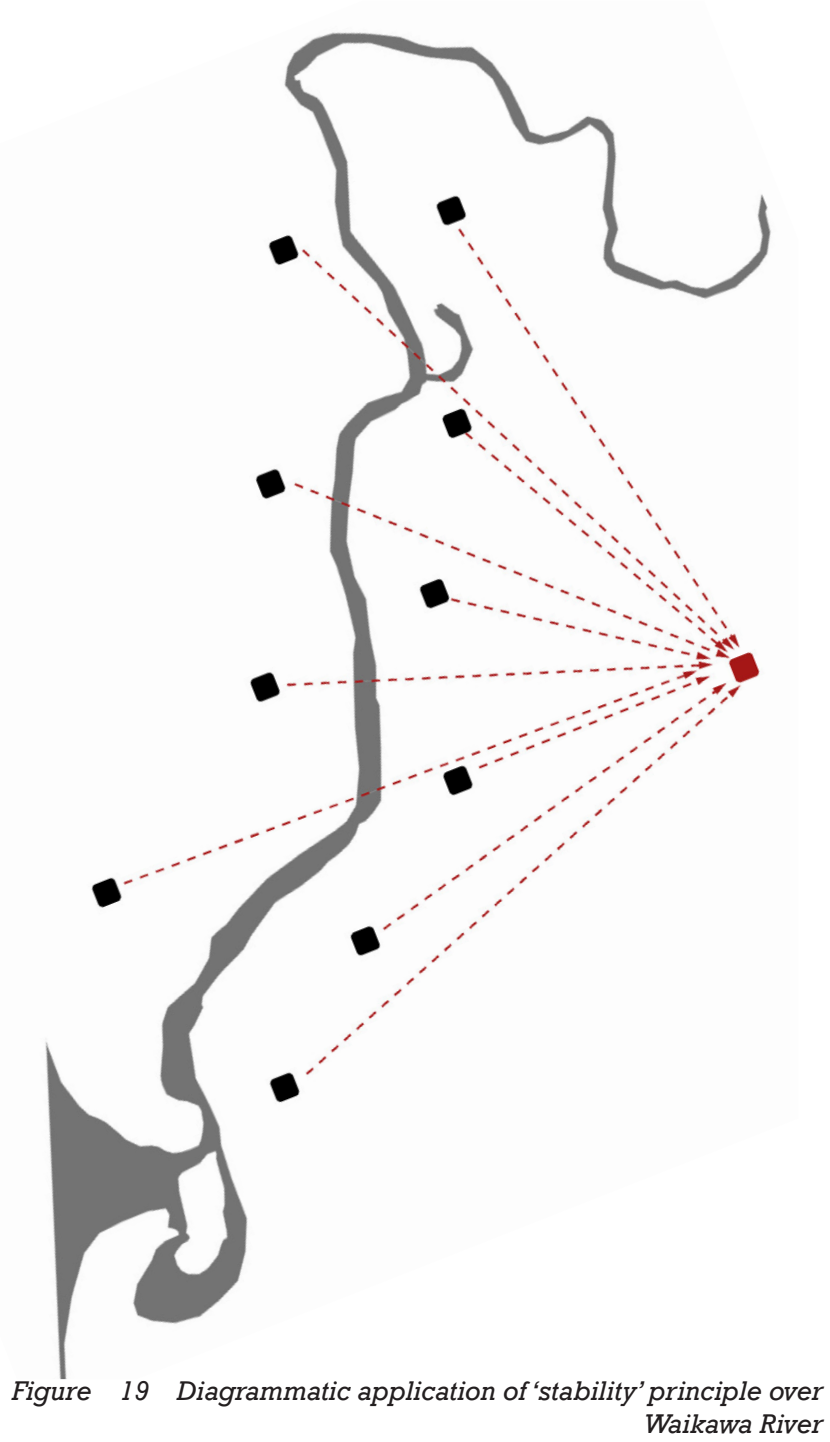




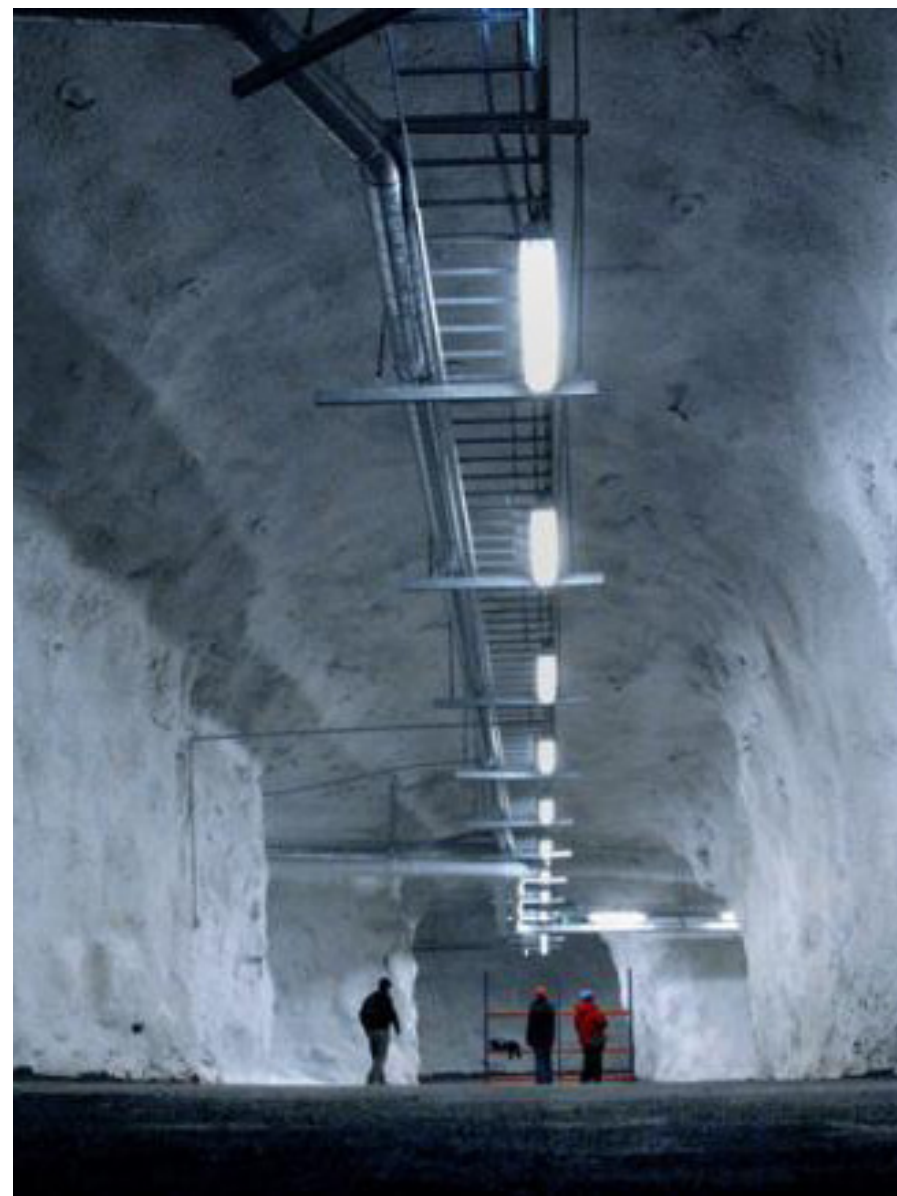

Figure 20 Interior tunnel system - Source - http://www. caravanmagazine.in/periscope/saving-our-seeds

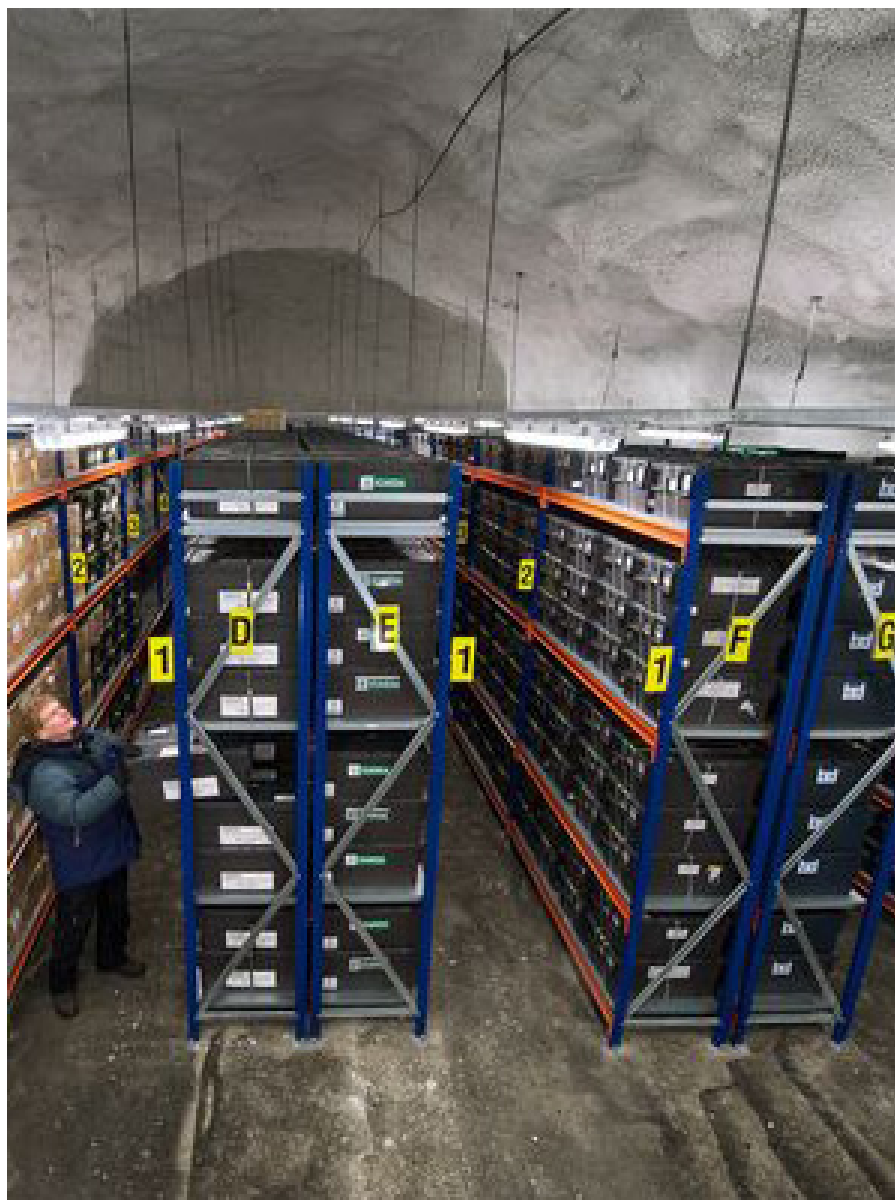

Figure 21 Storage space inside vaults - Source - http://news. nationalgeographic.com/news/pictures/2012/07/120702-svalbarddoomsday-seed-vault-food-supply/\#/rio-20-seed-bank-svalbardracks_55733_600x450.jpg

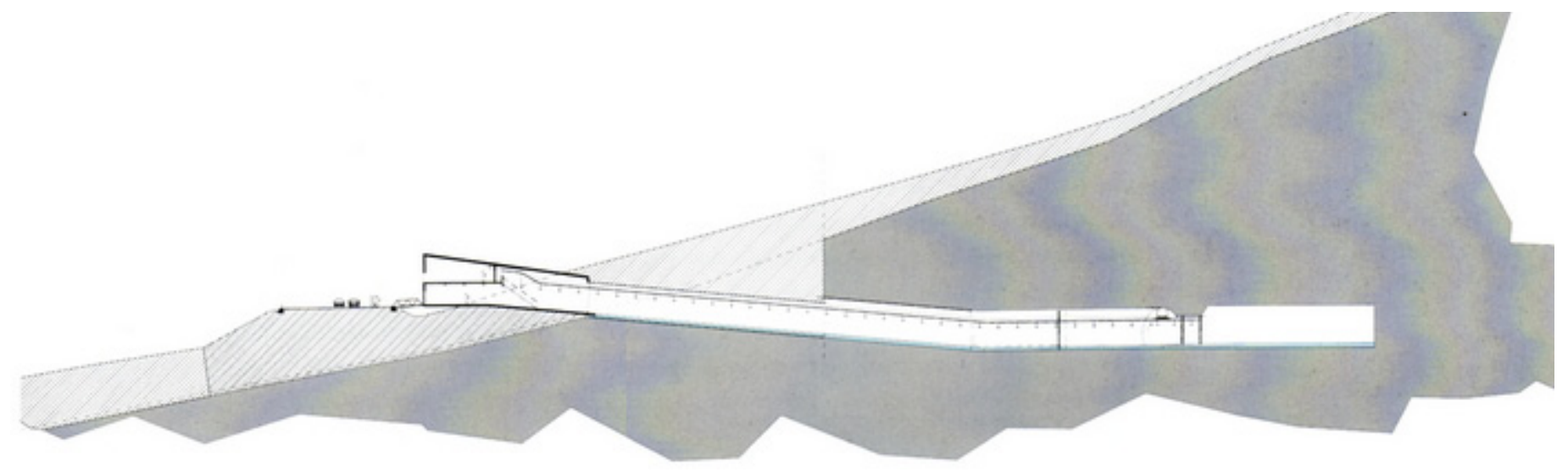

Figure 22 Section of Svalbard Global Seed Vault - Source - http://climatechange.thinkaboutit.eu/think4/post/global_seed_vault_the_food_ protector.htm 
The Chand Baori step well is located in Rajasthan, India. This massive structure was built during the 8th and 9th Century and was used to access ground water in dry seasons. The well descends thirteen stories into the ground, where year round, ground water is available (Amusing Planet, 2012). These sites were used to supply drinking water and recreation, but also became significant community landmarks and gathering places for the locals (Fig.24). The temperature at the lowest point is five degrees cooler than at the surface, increasing its popularity (Livingstone, 2002).

The four accessible sides made the Chand Baori a popular gathering spot, open to all members of the community, it was an effective centre (Fig.25). The permanence of the structure acted like an anchor to the surrounding community. The nature of this meant that despite harsh climatic conditions, inhabitants were able to remain fixed.

The fluctuation this structure deals with is seasonal, and not landform (Fig.23). It is difficult transplanting this to a coastal condition therefor it is more important to consider the aspects which guide the well to being a successful centre. Firstly, there is a necessity for this site, and secondly, there is a communal benefit provided. The integration of these makes the Chand Baori successful.

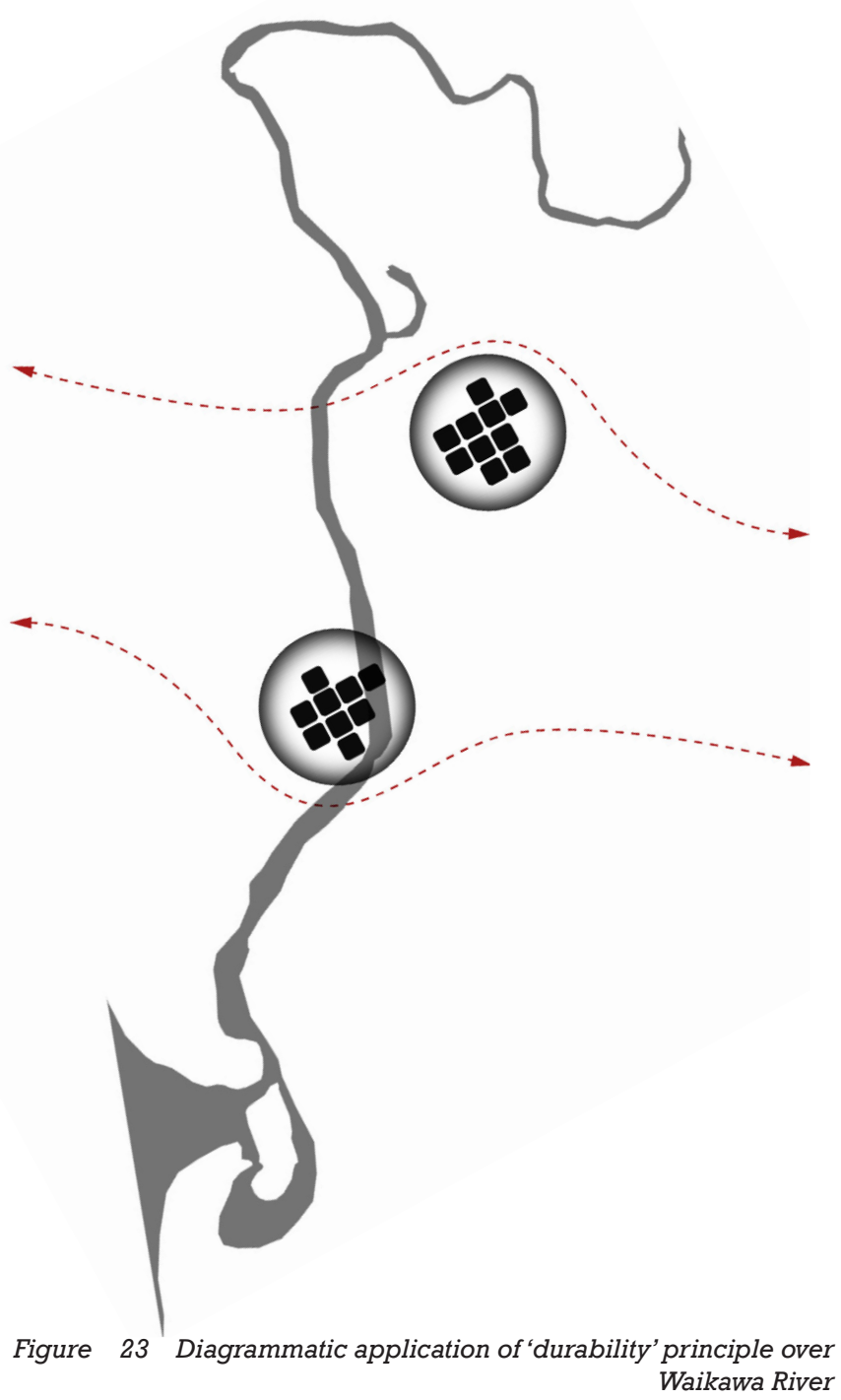




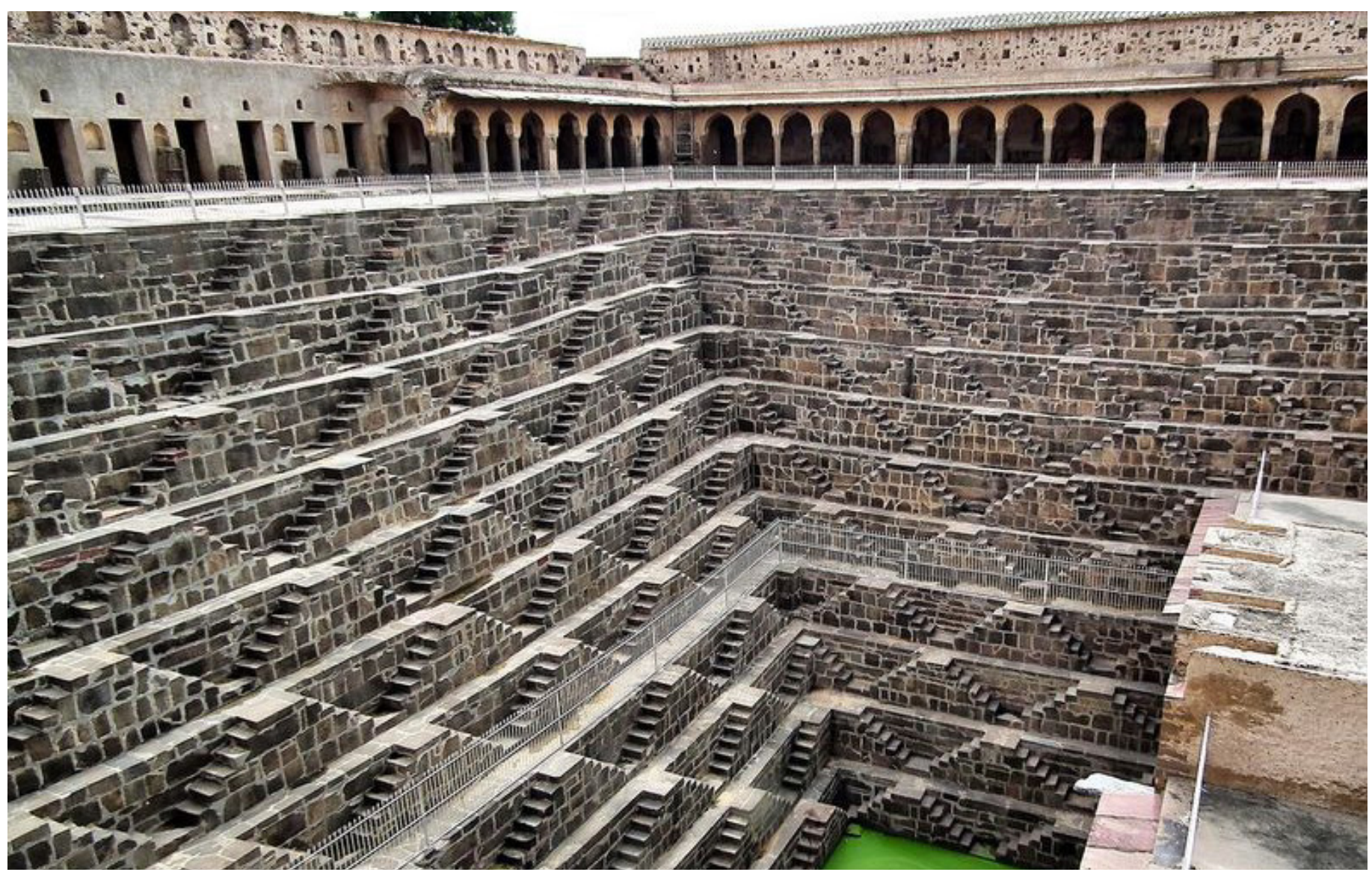

Figure 24 View across Chand Baori structure - Source - http://www.amusingplanet.com/2012/10/chand-baori-step-well-in-rajasthan-india.
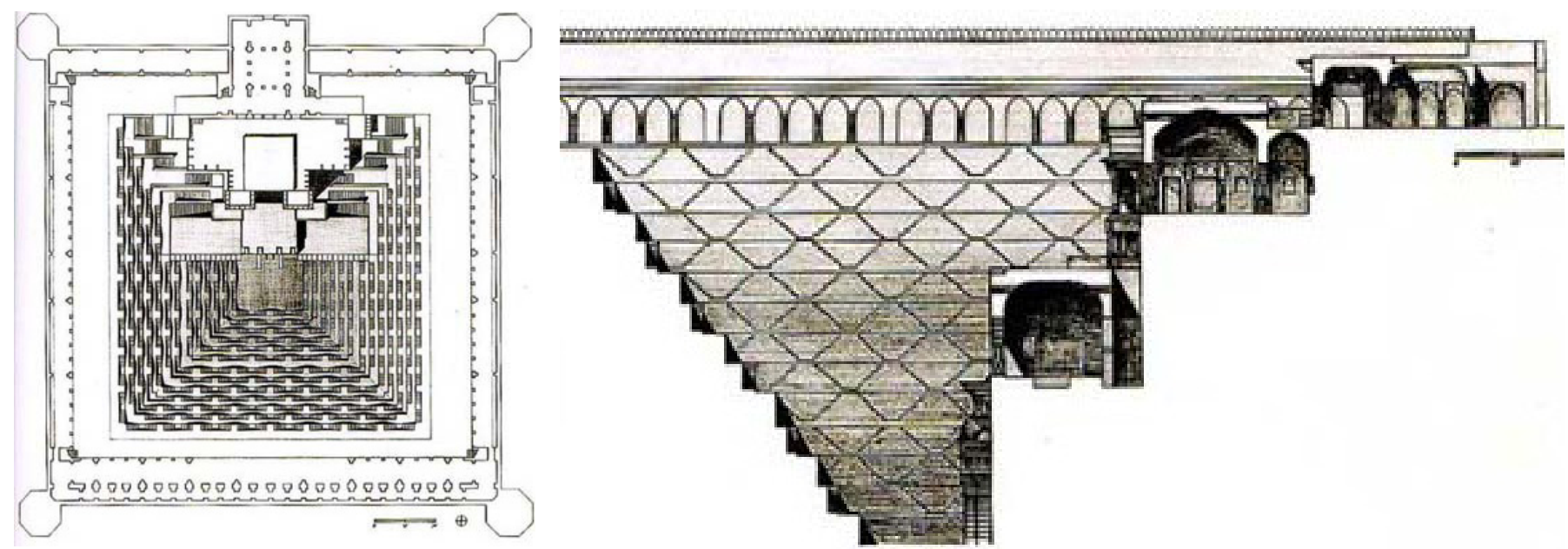

Figure 25 Plan/Section of Chand Baori step well - Source - http://socks-studio.com/2014/03/13/inhabiting-infrastructures-indian-stepwells/ 
Constructed between 1982 and 1998, Parc de la Villette is an urban park in Paris design by architect Bernard Tschumi (Bernard Tschumi Architects, n.d.). The 125 acre plan is organised using three principles categorized as points, lines, and surfaces (Fig.28). Points are arranged in a grid-like fashion and are a series of 'un-programmed' follies acting as positioning markers. Lines are distinguishable paths across the park. Surfaces are the open spaces dedicated to recreation. The project attempts to create a 'platform' which adapts to communal needs by refraining from allocating 'use' to space. In particular, the formally diverse follies have been utilised differently, from cafes to performance stages (Kroll, 2011). (Fig.29).

"He denied any possibility of inherent meaning or commonly understood symbolism in architecture and argued that his design for Villette 'means nothing'... "(Landscapelover, 2010)

Points are aesthetically coherent, creating a strong legibility within the park. The flexibility of the points can fulfil many aspirations which the community might have.

The structure of Villette is an interesting concept in its settlement application, where components are undefined and pertain to an unspecific role (Fig. 26). Despite creating a decipherable landscape, points do not relate or take advantage of any contextual drivers, or cues for placement; rather they are placed ambiguously as if designed purely aerially. Variation between folly forms is insignificant in the assumption that there is an ability for points to be re-imagined according to future aspirations.

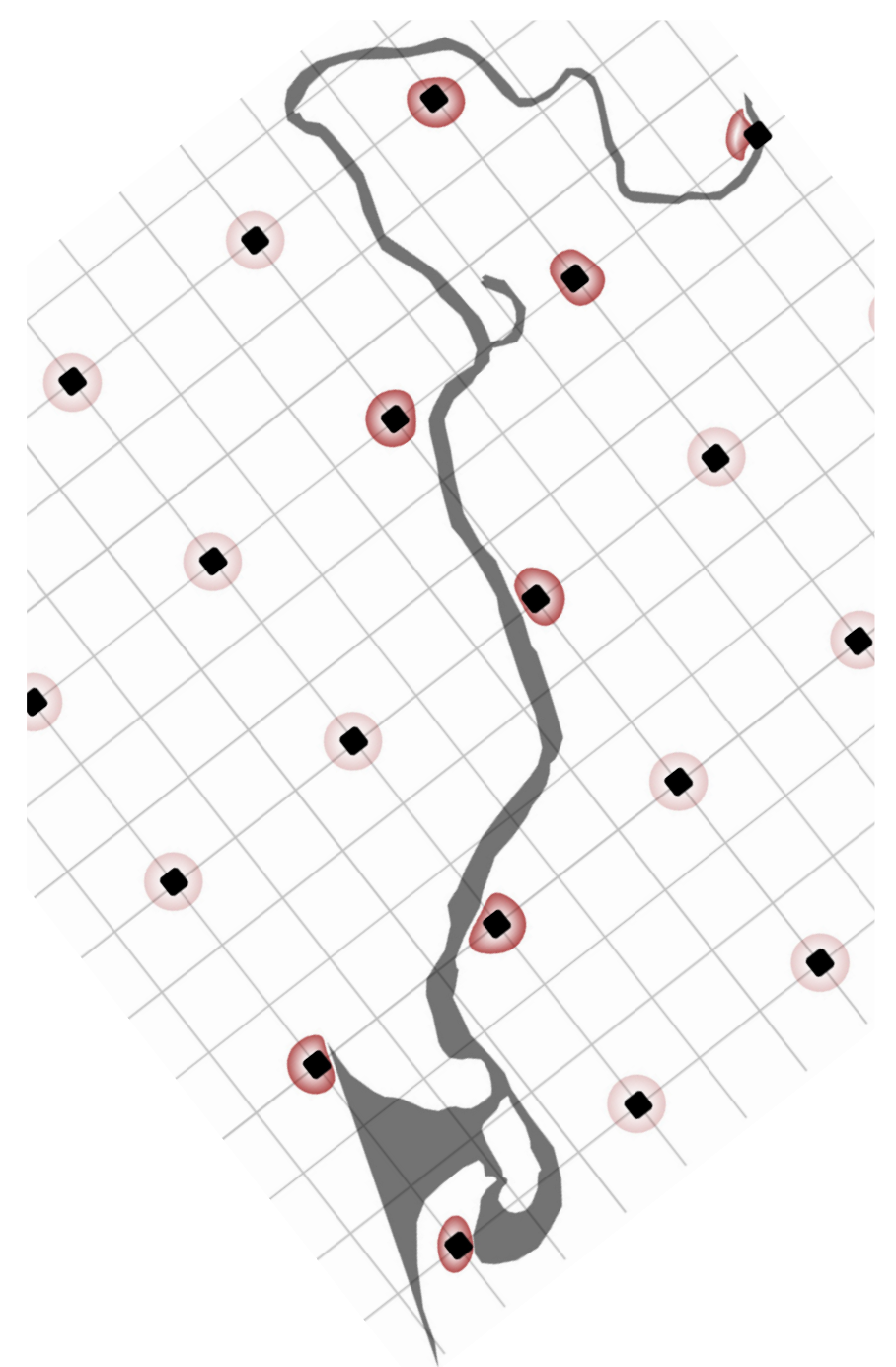

Figure 26 Diagrammatic application of 'adaptability" principle over Waikawa Rive 


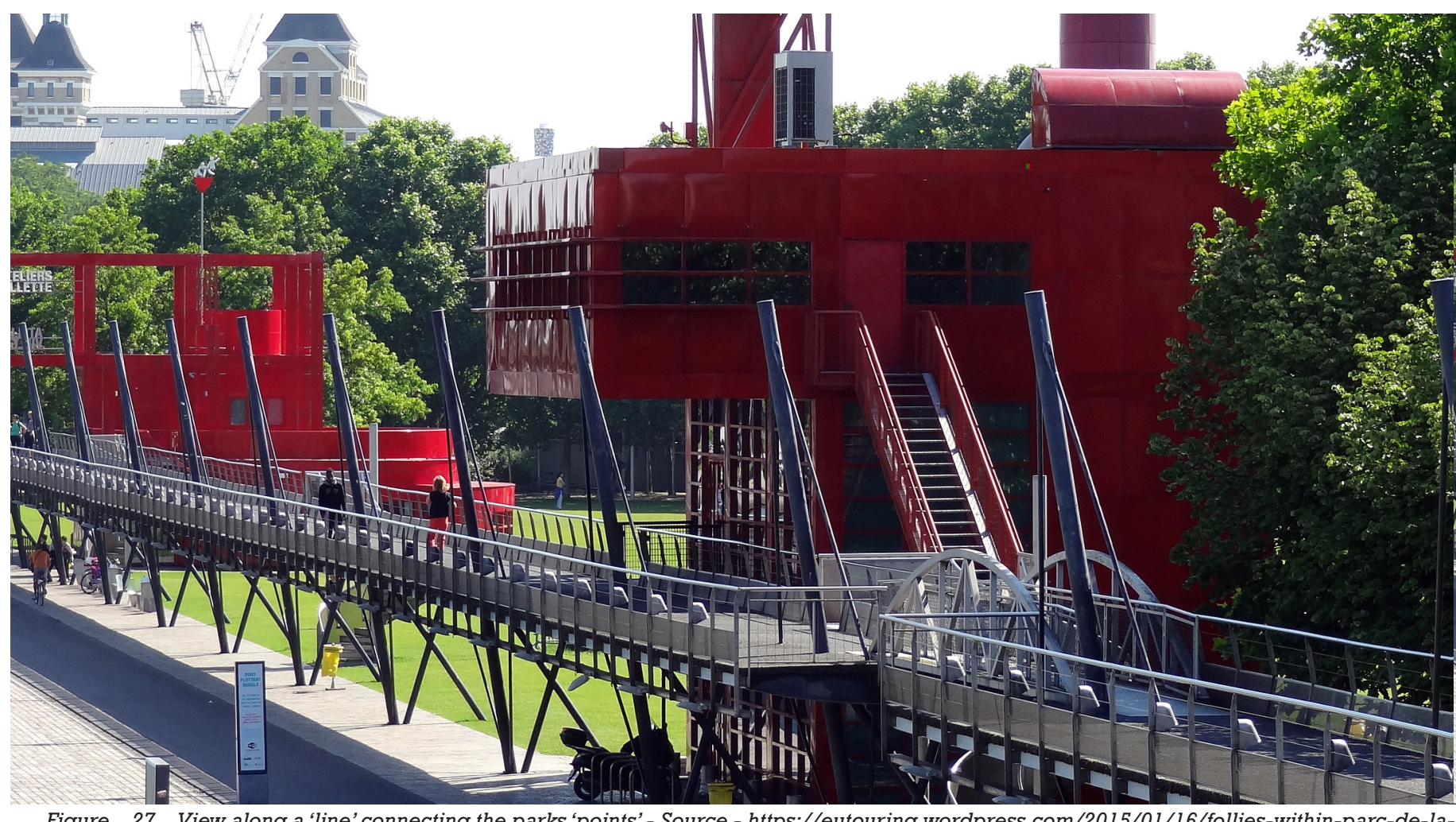

Figure 27 View along a 'line' connecting the parks 'points' - Source - https://eutouring.wordpress.com/2015/01/16/follies-within-parc-de-la-

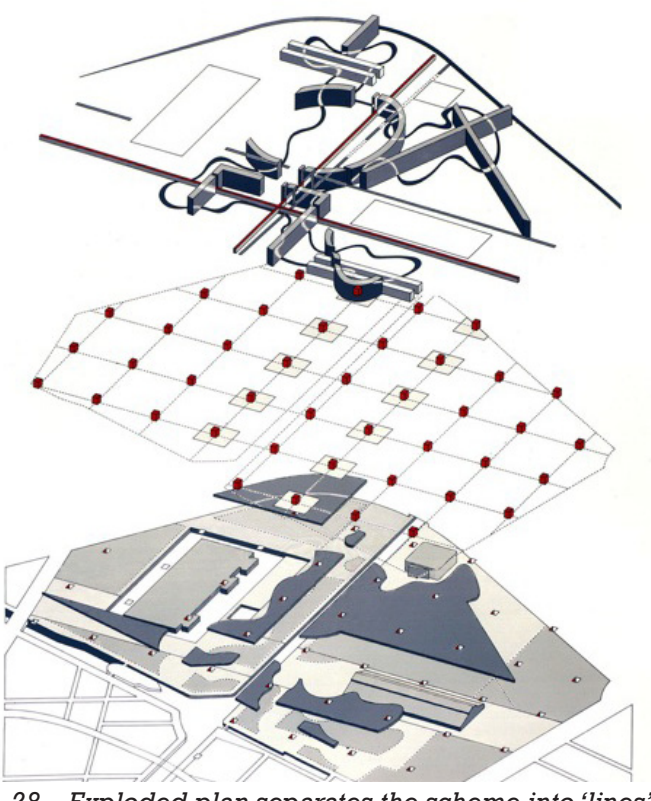

Figure 28 Exploded plan separates the scheme into 'lines', 'points', and 'surfaces' - Source - https://landscapelover.wordpress. com/2010/11/30/parc-de-la-villette/

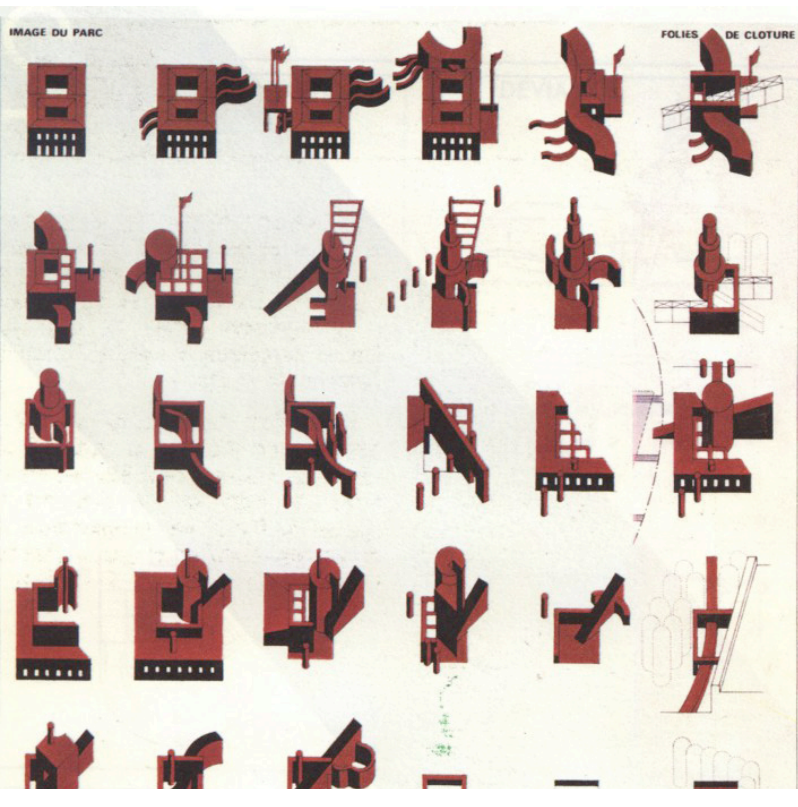

Figure 29 Diagram showing the various forms follies may acquire Source - http://plusacne.org/2014/01/03/la-villette/ 
In Strasburg, France, students have transformed a campus forecourt into public space. Module-like furniture is placed in a number of layouts, with 33 different applications (Fig.33). Modules are based off the foundation of a pallet, which can be shifted using a truck, this flexibility allows the space to be continually re-worked conforming to on site aspirations (Fig.31). Configurations are tested, with the objective of discovering the sites potential to accommodate several ambitions (Landezine, 2011).

This project epitomises flexibility. A single pallet truck can change the layout of a public space. The simplistic modular base allows application for numerous activities (Fig.32). The ease of change, and low cost allows the space to perform as a shared area for a diverse community (Fig.30).

Constant change prevents any connection or familiarity to the site; instead connections are made to temporary modules, which become redundant. The small module size also limits large scale application such as swimming, which is an unlikely possibility. At a small scale, the idea is intriguing; however on a large scale this method could divorce inhabitants from the landscape.

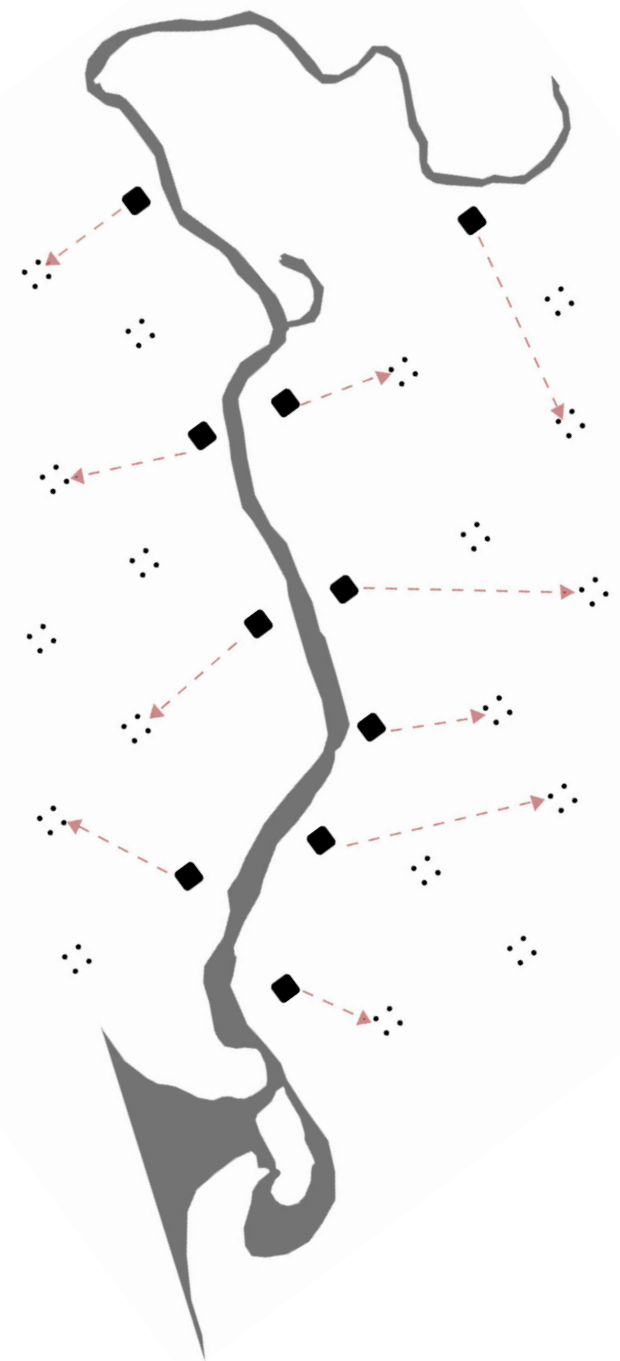

Figure 30 Diagrammatic application of 'flexibility' principle over Waikawa River 


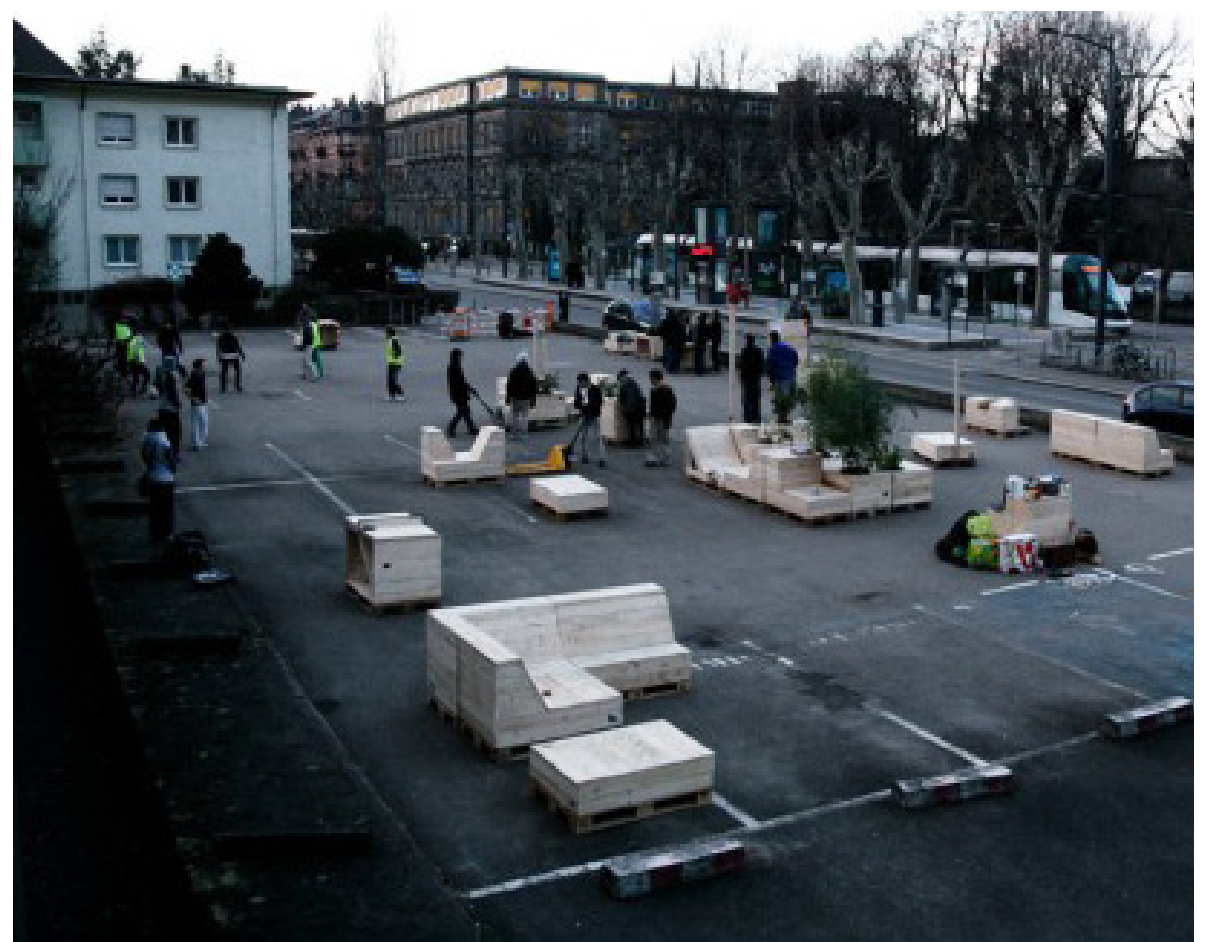

Figure 31 View of various applications transpiring within the space - Source - http://www. landscapeishankin.blogspot.co.nz/201 1/03/blog-post.html

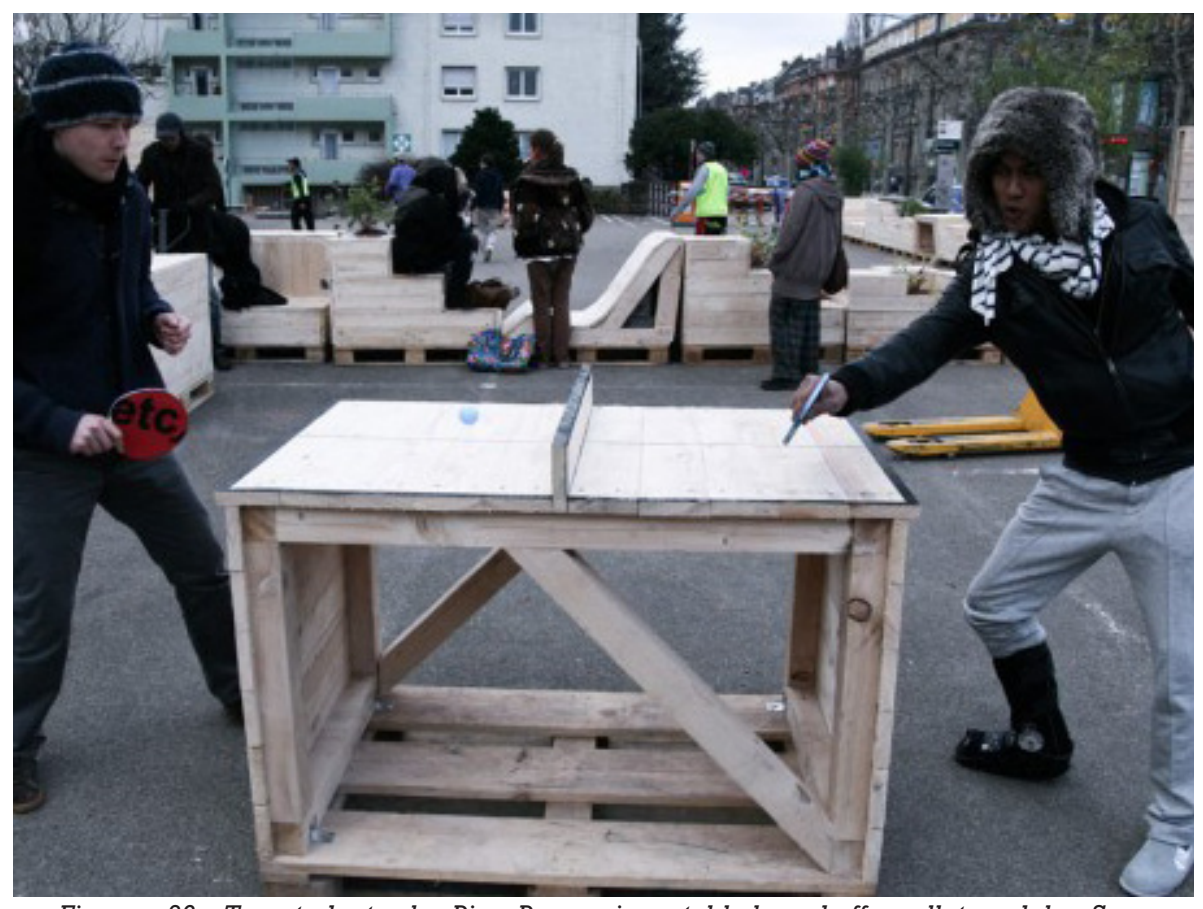

Figure 32 Two students play Ping-Pong using a table based off a pallet module - Source http://www.landscapeishankin.blogspot.co.nz/2011/03/blog-post.html

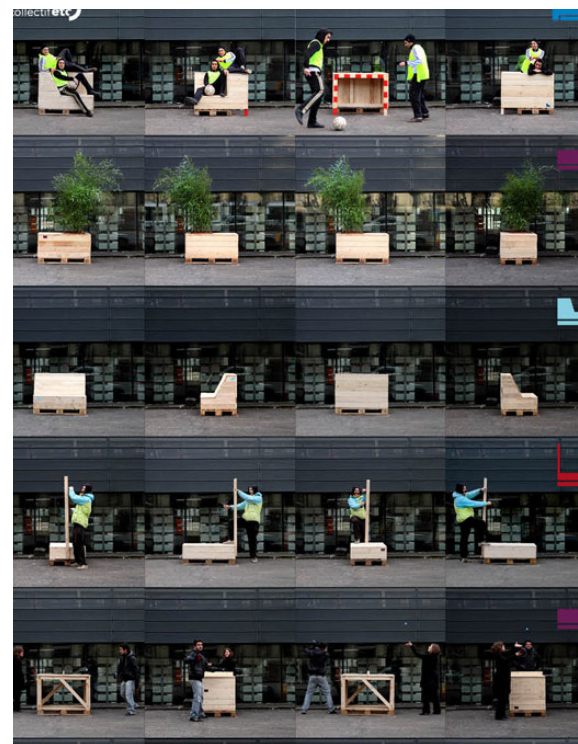

Equ

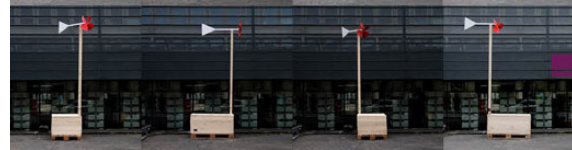

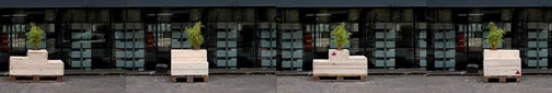

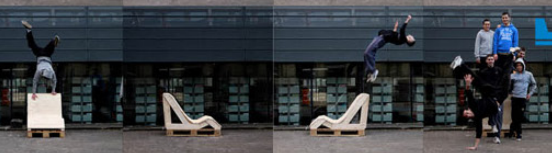

La (A)

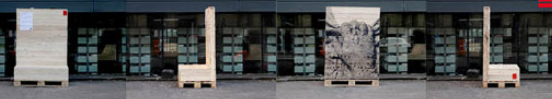

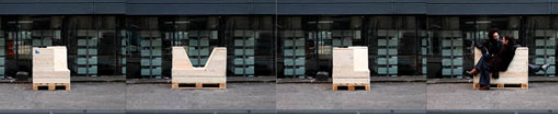

Figure 33 Variation of module form allows for numerous amenities and application Source - http://www.landscapeishankin. blogspot.co.nz/2011/03/blog-post.html 
This segment places the research within a theoretical context. The issues discussed below have relevance to design exploration in the following chapters. Literature is separated into categories of relevance to certain aspects of consideration within the design process. 
It is now widely accepted that settlements should respond to patterns within the landscape. In the past land has been divided and organised into linear geometries, such as squares, lines, or circles, working in utter opposition to complex natural organisations (Zaera-Polo, 2003). Straight lines are used to mark off parcels, but have little to do with the watersheds, wildlife corridors, slopes, and streams which are not static, and unlike property lines, move (Russel, 2011). Movement toward a more sustainable way of settling has demanded analysis of significant processes, particularly in the wake of rapid and sometimes unpredictable change.

"A climate-change era demands we pay closer attention to those natural systems that flow within our tidy land divisions." (Russel, 2011)

Charles Waldheim describes the landscape as a medium capable of responding to temporal change (Waldheim, 2006). This operates conversely to the standard practice of planning where there is an expectation of permanence, where in reality the dynamics mean that application is much more complex. Mohsen Moastafavi, explains the lack of interaction between classic planning techniques and the fluctuating nature found within landscapes.

"The temporality of landscapes renders them forever incomplete, and this incompletion can be seen as an antidote to the implicit finitude of zoning." (Mostafavi, 2003)
James Corner emphasised this further, claiming that complex systems were not only beyond the control of static plans, but because of the lack of certainty he asserts that it is also beyond the control of design.

"Such a dynamic, open-ended matrix can never be operated upon with any certainty as to outcome and effect. It escapes design and, even more so, planning." (Corner, 2003)

From Corners' perspective, this is characteristic is a strength, with the uncontrollable dynamics being opportunities which can be engaged with, rather than finding solutions to 'problems' (Corner, 2003).

A common principle for inhabiting interface sites, such as the coast has been the 'managed retreat system'. The advantages of this system are various, but in particular the sites' ecological and economic values are retained, and settlers are able to inhabit uncertain lands. However as James Russel has pointed out, political and economic issues have made the managed retreat method less than successful, resulting in low pragmatic traction.

"How do you get people to give up their homes and their memories? And who will pay the cost? It's no surprise that few communities have even considered the possibility." (Russel, 2011)

For others, a successful navigation of ever changing landscapes might be called successful if a response leads to some form of stability; this is not to be confused 
with a static application. A response may be judged stable by its ability to evolve in rhythmic manner as Gillian Rose implies.

"Indeed stability might be best sought in a placespecific sense of rhythmic change, rather than in a denial of change through dreams of static and enclosed places."(Rose, 2007)

Or as Corner describes it, stability might be considered as softness, rather than hardness. For in a soft system there is an inherent ability to manage, and absorb change. This 'softness' becomes the stability whether applied to a wetland, or a settlement.

"Its stability and robustness derive from its dynamics in its capacity to handle and process movement." (Corner, 2003) 
The way settlements are structured is continually tested and challenged. The successfulness of reworkings is not always apparent as it takes significant time to observe the effects of arranging components in a multiplicity of orders. It is however extremely important to continue challenging the foundations on which current settlements sit, as they lay the base to how people live out their lives. There is also significant economic value in this infrastructure, with approximately $35 \%$ of a nation's assets being tied up in estate and infrastructure (Russel, 2011).

The modernist approach has largely influenced the way many cities have evolved, and was extremely clear in its planning. Distinct components were separated into groups such as housing, business, industrial zones, and open space. The master plan was a tool which provided a way to hold these functions together but keep them distinctly separate. A landscape urbanism response would accuse this system of arrangement as a way of preventing overlaps of components which in turn afford opportunism (Mostafavi, 2003). The effect of this, as Mostafavi explains, not only restricted spatial diversity, but also human behaviour.
"Citizens' actions were - and are - being played out within spatial frameworks that serve to reduce any diversity of events and to control (and thereby reform) behaviour." (Mostafavi, 2003)

Kevin Lynch judged cities successfulness based on its legibility in his renowned publication 'The Image of the City'. In his beliefs, a clear and perceptual image of the city was beneficial as it allowed the ability to move about and successfully way find based on recognisable patterns which individuals could understand through their current placement and memory.

"But an ordered environment can do more than this; it may serve as a broad frame of reference, an organiser of activity or belief or knowledge." (Lynch, 1960)

Today however, there is a focus on systems, the way they interact and how a cohesive whole might function. Landscape urbanisms' approach works with this, and rather than transplanting a system, uses implementation as an infrastructure for 'potential'. 
"Rather, contemporary landscape urbanism practices recommend the use of infrastructural systems and the public landscape they engender as the very ordering mechanisms of the urban field itself." (Waldheim, 2006)

Essentially the practice of this inserts a catalyst for change, which produces an effect on the landscape.

"Landscape urbanism implants new potential in a given field through the orchestration of infrastructural catalysts - infrastructures that perform and produce, or 'exfoliate' effects (Corner, 2003)

What is clear, is that settlements cannot simply be placed two dimensionally, organised neatly as if on a 'blank canvas'. Instead they should be functional within their own bounds and also in relationship with their context, be that cultural, ecological, or economic. 
To focus only on the physical components involved in settlement design, would exclude important facets which must be addressed. In particular, designing a settlement should not simply be practically viable, but also improve identity and communal value.

It must first be stated that in terms of development, collaboration is key. Individualism in large scale growth and improvement is simply not feasible, and in some opinions has prevented cities from 'moving forward'.

"The privatised, individualist approach is so deeply ingrained in cities, that an attempt to create consensus on growth, planning, or identity can barely be contemplated." (Russel, 2011)

To some looking towards the landscape is a way to inform and approach 'place' and community. Jacky Bowring describes the landscape as a cultural theatre. Within this construct there are two components the composition observed by an audience, and the devices used to prop up the landscape. The landscape is a source of identity.

" $A$ mapping of cultures values into the very heart of its identity - the landscape." (Bowring, 2010)

As Corner states, the landscape has ceased to be a backdrop, and now is a surface of possibilities, a tool to transform place (Corner, 2003). Stan Allen further iterates this, describing the ability of the landscape to inform behaviour. He explains, slope, porosity, and even soil chemistry has a hand in determining the sort of behavioural life the landscape will support (Allen S. , 2011). In taking cues from the landscape, both Corner and Allen suggest projects ought to somewhat emulate their contexts and by doing so extend them.

"The project is validated insofar as it constructs a complete re-description of the place, proposing the invention of topography." (Corner, 2003)

The effect of this adds to the identity of places and potentially connects people with place.

"The ephemeral character of the environment is reflected in the solidity of the artefacts that inhabit it as they take on a local specificity and lend to their surroundings a sense of nature illuminated." (Allen S. , 2007)

Specificity, sameness, and familiarity are all terms which have been immensely popular in describing the essentials of creating a strong sense of community and identity. Juhani Pallasmaa explains the importance of familiarity within a context of identity. Pallasmaa describes familiar objects as having the ability to not only prompt memory of the object itself, but to also evoke other connections such as what and who else was involved (Pallasmaa, 2009).

Likewise Yi-Fu Tuan emphasises the importance of stability in producing an identity. Tuan states that 
places must be static for humans to grasp them; we fixate ourselves on seemingly immovable fixtures such as mountains and lakes. He then compares this to a strong communal sense of home in which there is an expectation for no change. Even in years of absence there is a human condition to grasp at familiarity.

"Whatever sense of place you had before is no longer supported by tangible reality." (Tuan, 2004)

Along with its familiarity, specificity is important; a sense of home is strongest when it has an element of uniqueness.

"It means that sweet sense of home is strongest when home is not only familiar but distinctive as well." (Lynch, 1960)

Building a strong community does not lie purely in the realm of intangible qualities. As Robin Dunbar explains, the size of groups is also important. A conducted study revealed a link between brain size and species group size. For humans, the predicted network size was approximately 150, now recognised as Dunbar's Number. It was revealed that this was the human cognitive limit to form various personalised relationships. A community of around this size would be productive, co-operative, and united. Past this number, it is theorised that a community cannot be run without the implementation of a governing system or police force (Dunbar, 1991). Maintaining a community requires a strong foundation, simply placing 150 people in one area will not ensure co-operation, and this is where there must be a 'centre' to the community; a place of commonality, where all members place value. This centre could tie communities to places. 


\section{Test Site: Waikawa}

Waikawa beach and the surrounding land provide an opportune test site for exploration of alternative coastal settlements. Located within the Horowhenua district, on the West coast of New Zealand's North Island, this setting is host to a number of complex coastal processes (Fig.34). From river movement, to shifting sand dunes, the range of active processes makes Waikawa a challenging environment to inhabit. There is a small existing settlement made up largely of holiday homes. The majority of the landscape here is farm dominated, though development plans show the intent to continue residential expansion along the fluctuating coastline (Horowhenua District Council, 2008). 

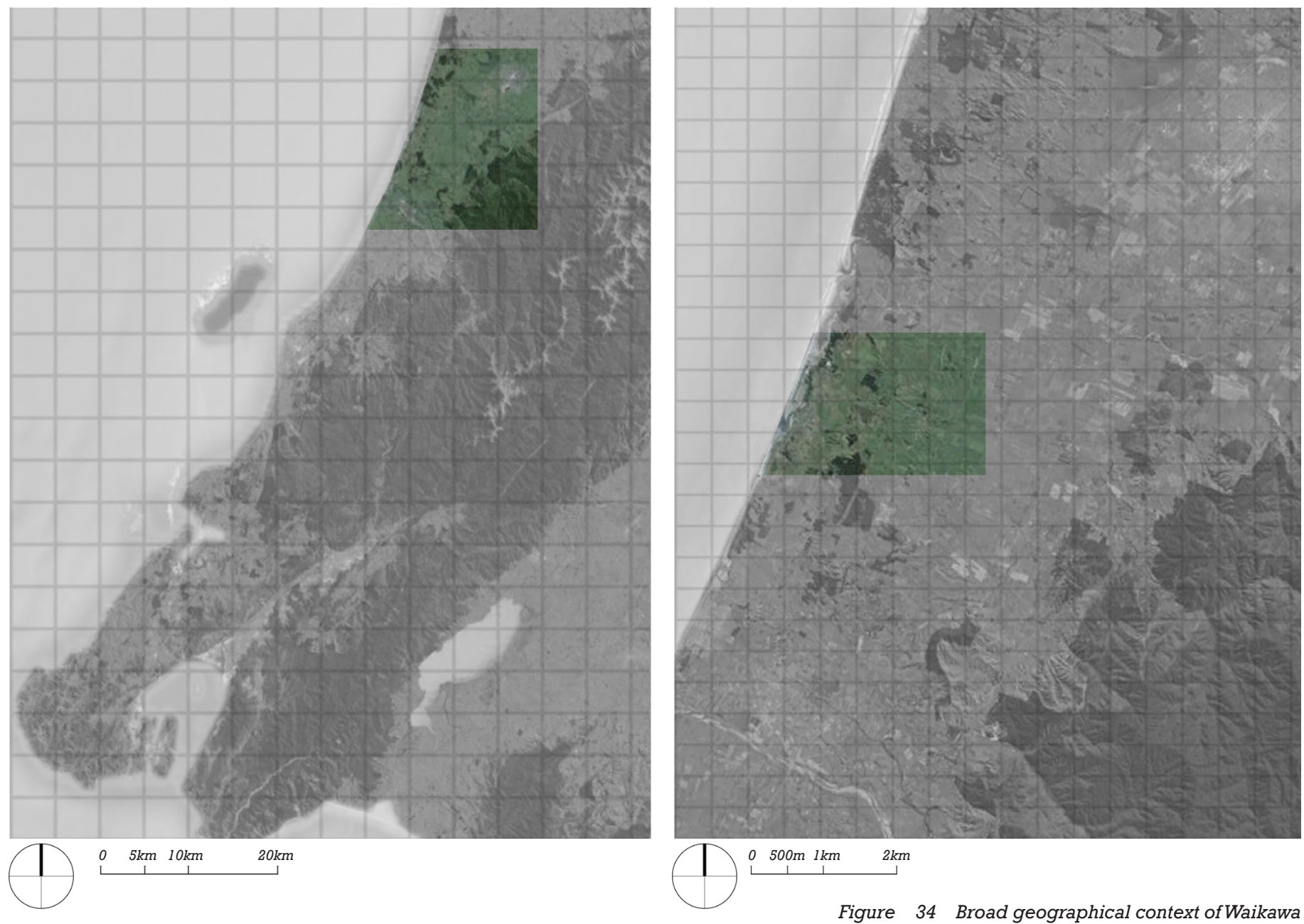


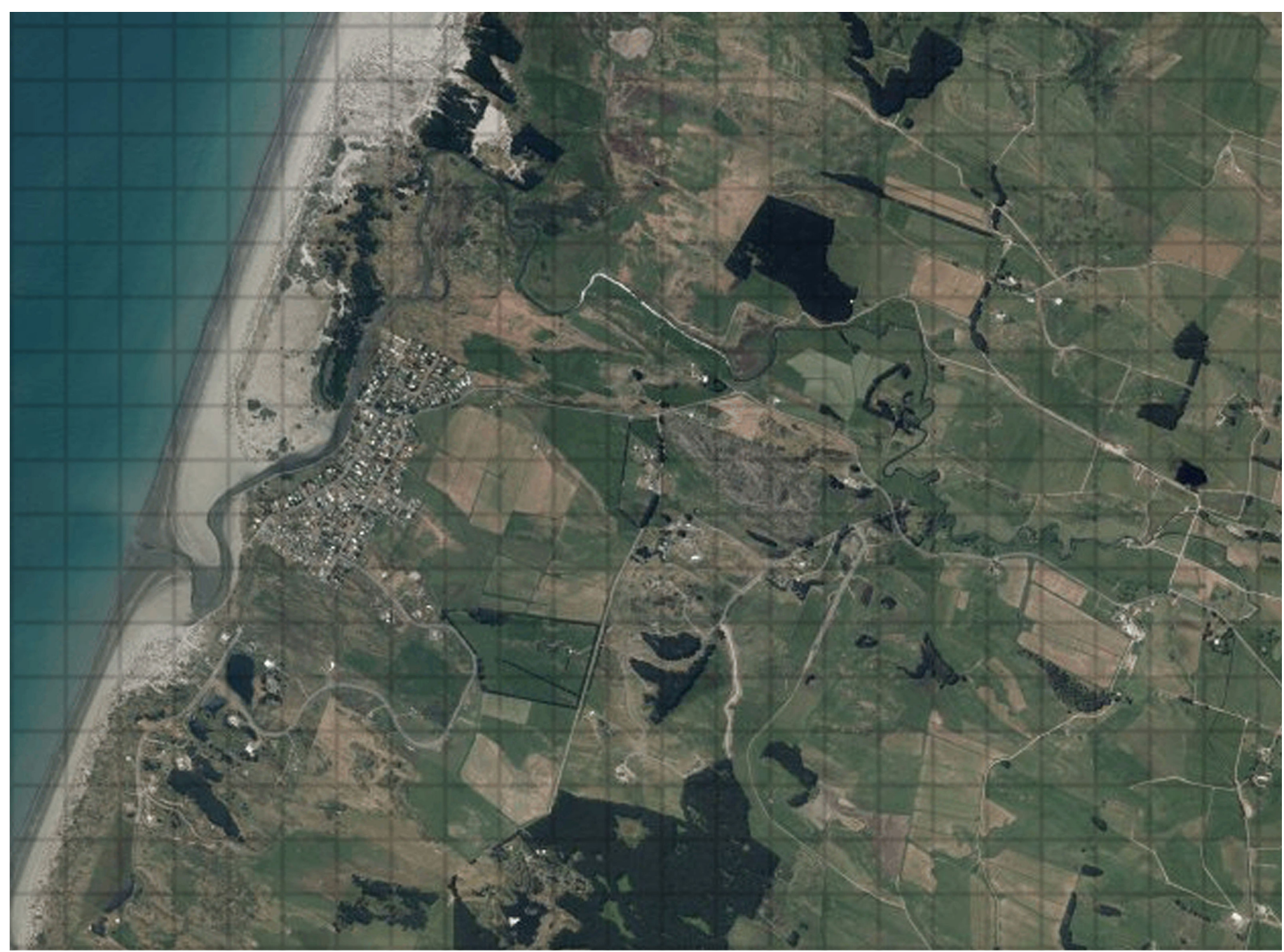
(1) $\begin{array}{cccc}0 & 200 m & 400 m & 1\end{array}$

Figure 35 Immediate geographical context of Waikawa 
The following analysis shows the diversity of coastal movements and processes occurring in the Waikawa area. 
Rivers in Horowhenua have a history of moving. The Waikawa River is particularly dynamic, showing immense activity in the last 150 years. This map shows various locations of the Waikawa River; grey scale images denote photographic evidence, while red images are based on older maps (Fig.39). Originally connected to the Northern Ohau River, the Waikawa has since split, generally moving southward, its speed is unpredictable. A decade may reveal between a few meters and a few kilometres of movement within an envelope of around $10 \mathrm{~km}$. This continual shift has eroded fore-dunes, and endangered residential areas (Shepherd \& Shepherd, 1999).

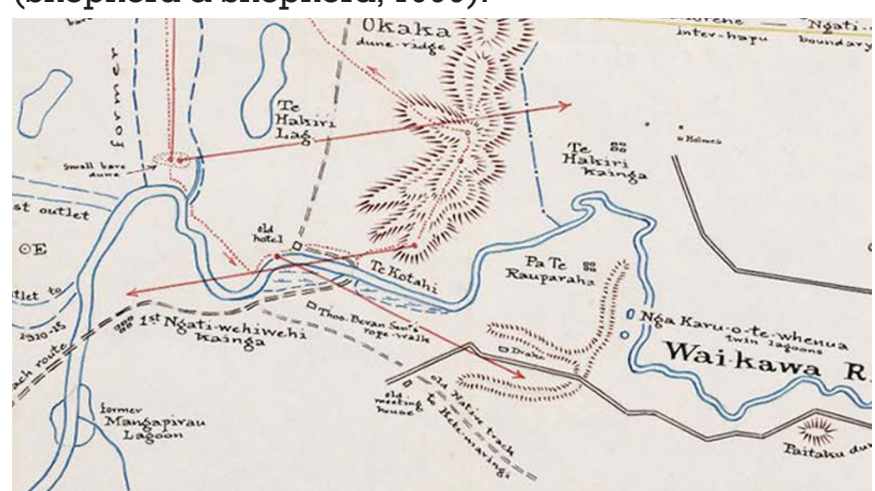

The Former Course of the Ohau River Connecting with the Waikawa Rive
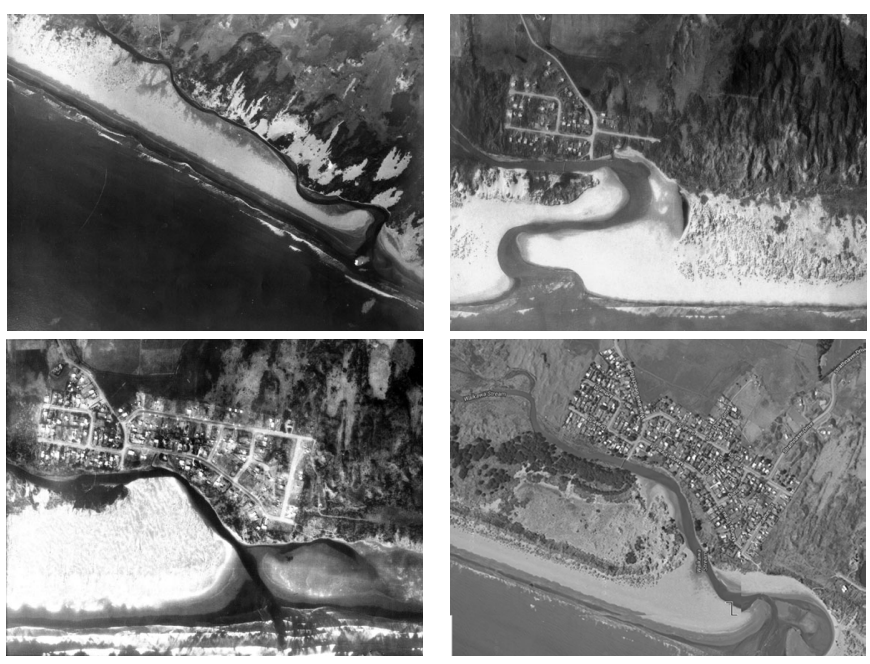

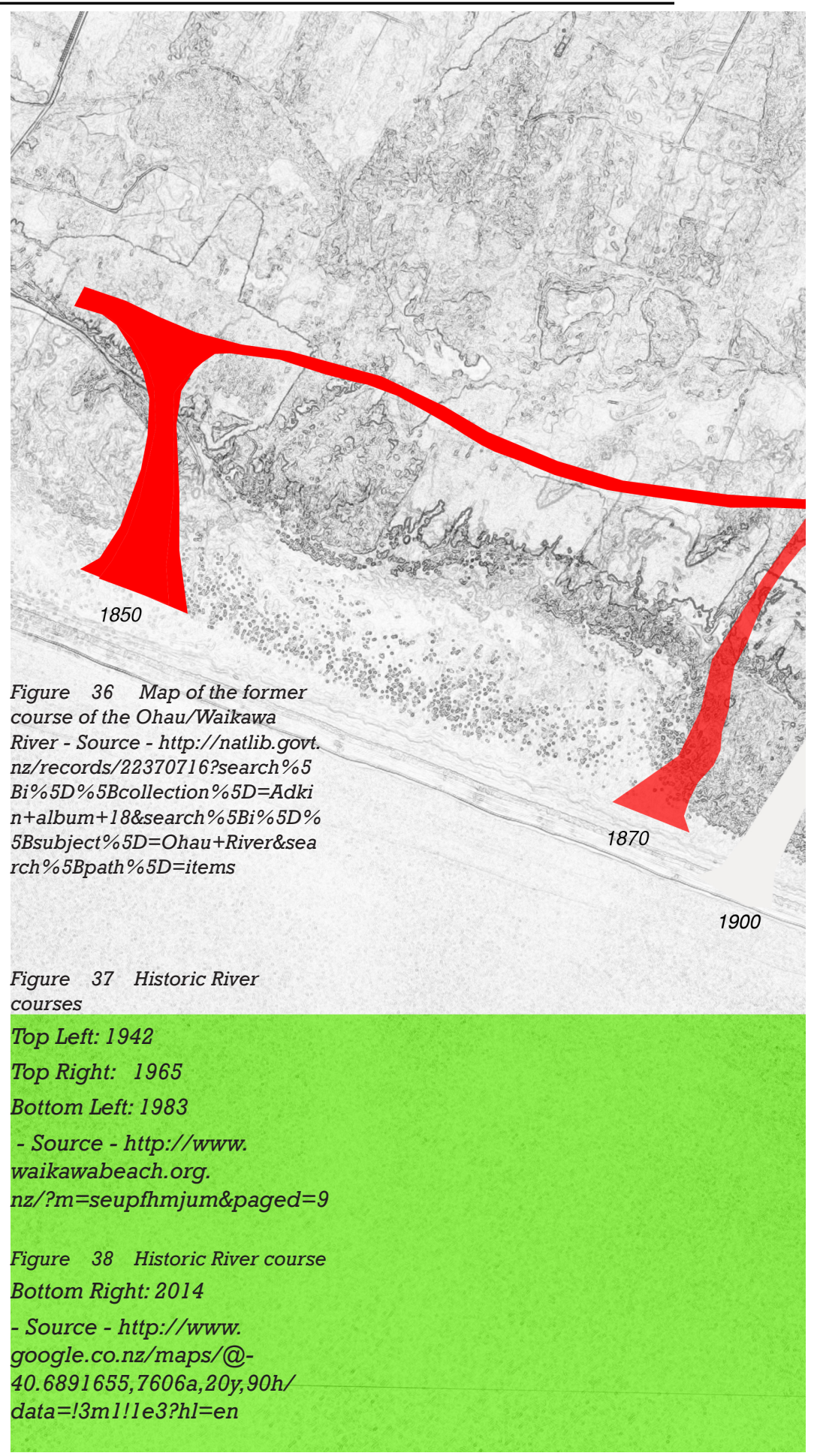




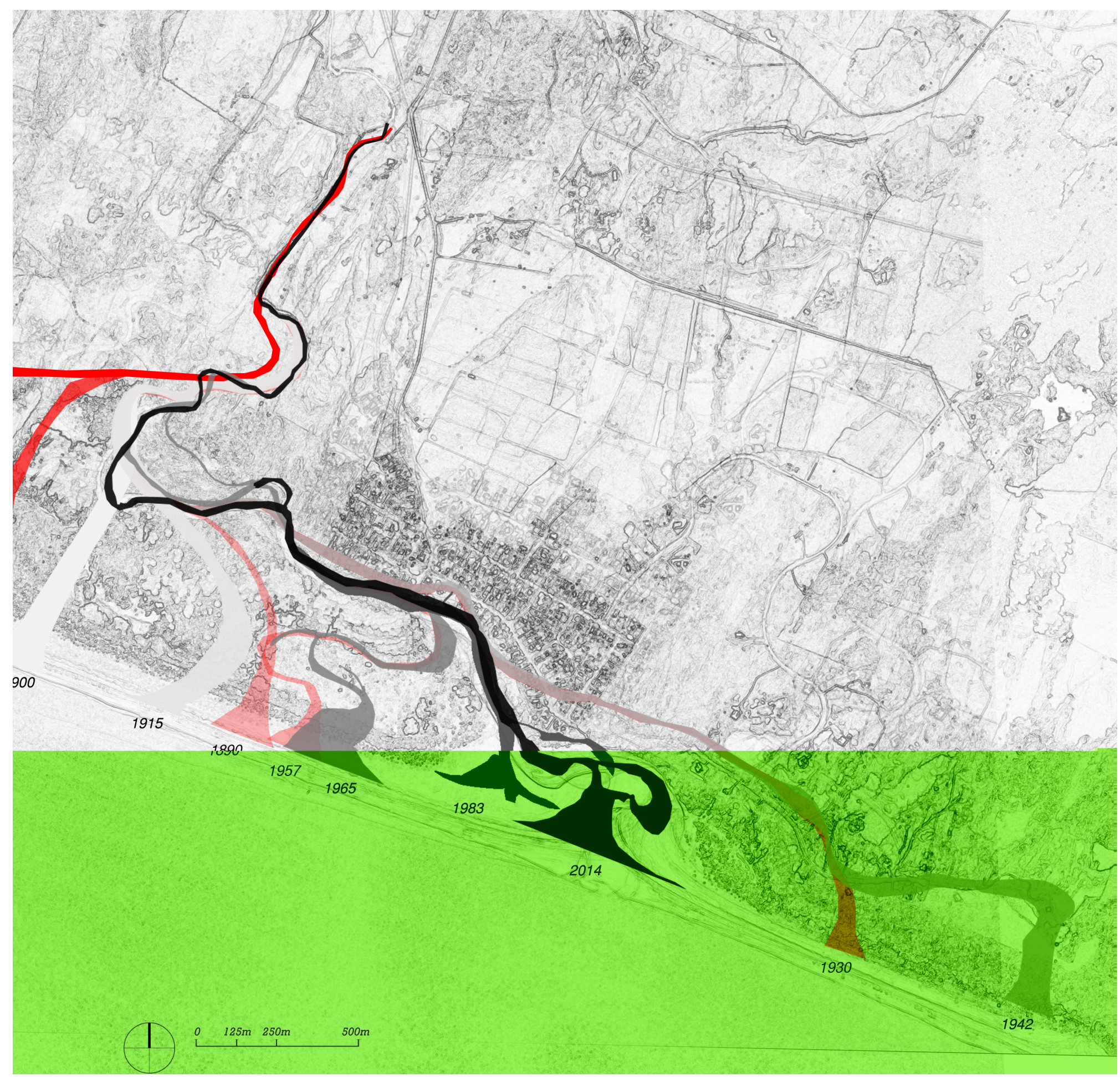


Overlaid instances of river location indicate a pattern. The consistency of placement is more erratic the closer the river moves to the coast. There is a stable-dynamic gradient along the land, making shoreline areas highly unpredictable and inland areas predictable (Fig.43). Property density is placed converse to this, with higher densities placed in less predictable zones, working against the 'gradient' of the land and placing more dwellings in danger.

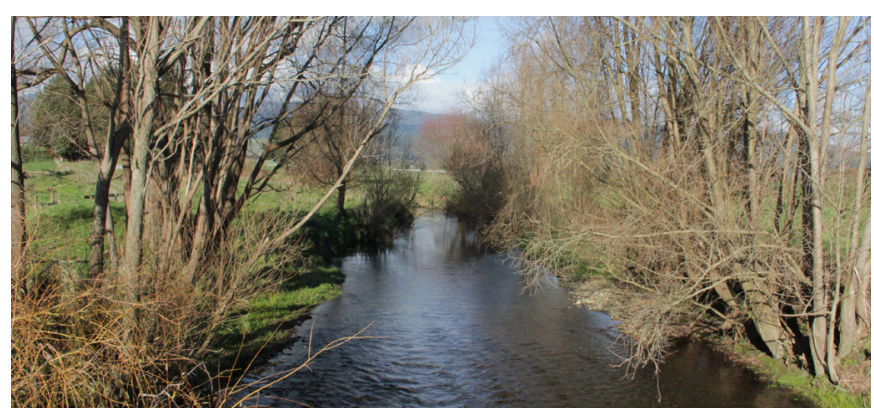

Figure 40 Upper reach of Waikawa River

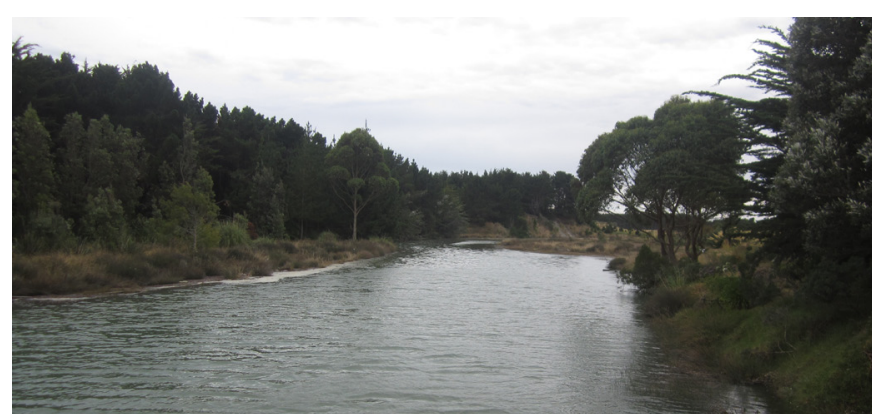

Figure 41 Lower reach of Waikawa River

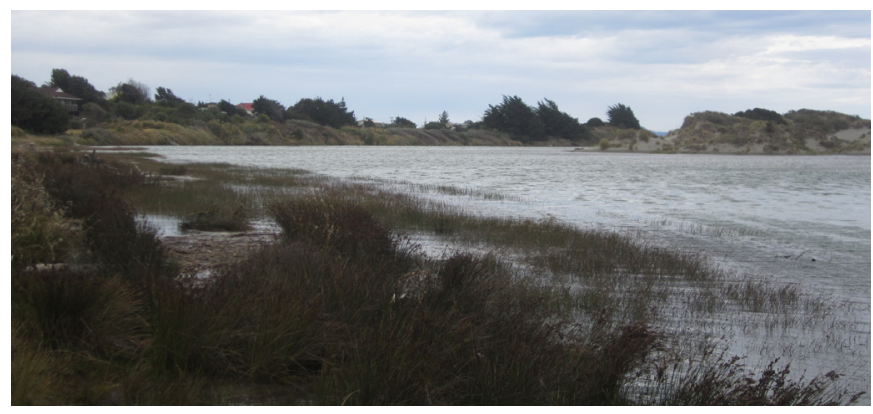

Figure 42 Waikawa River mouth

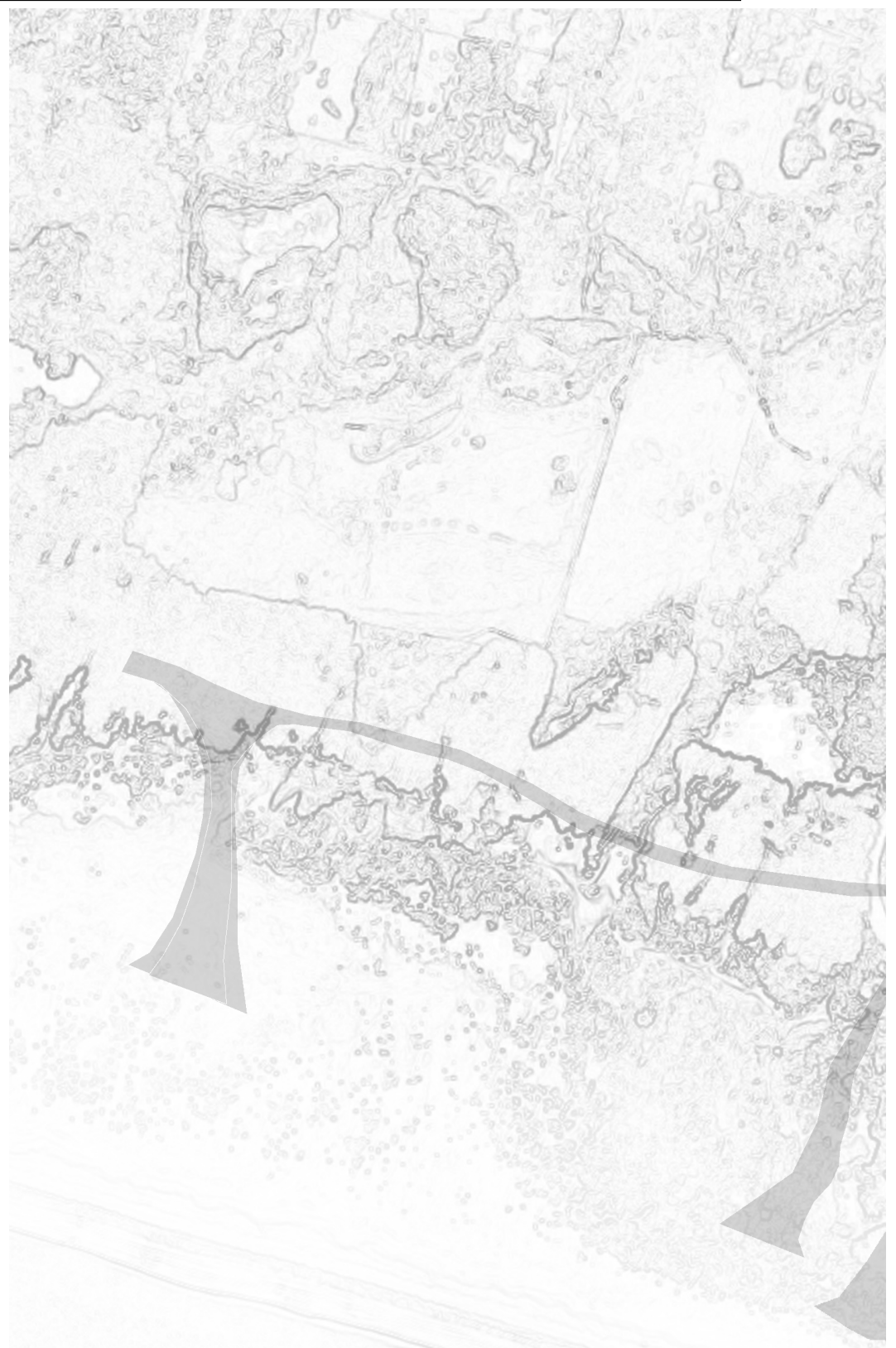




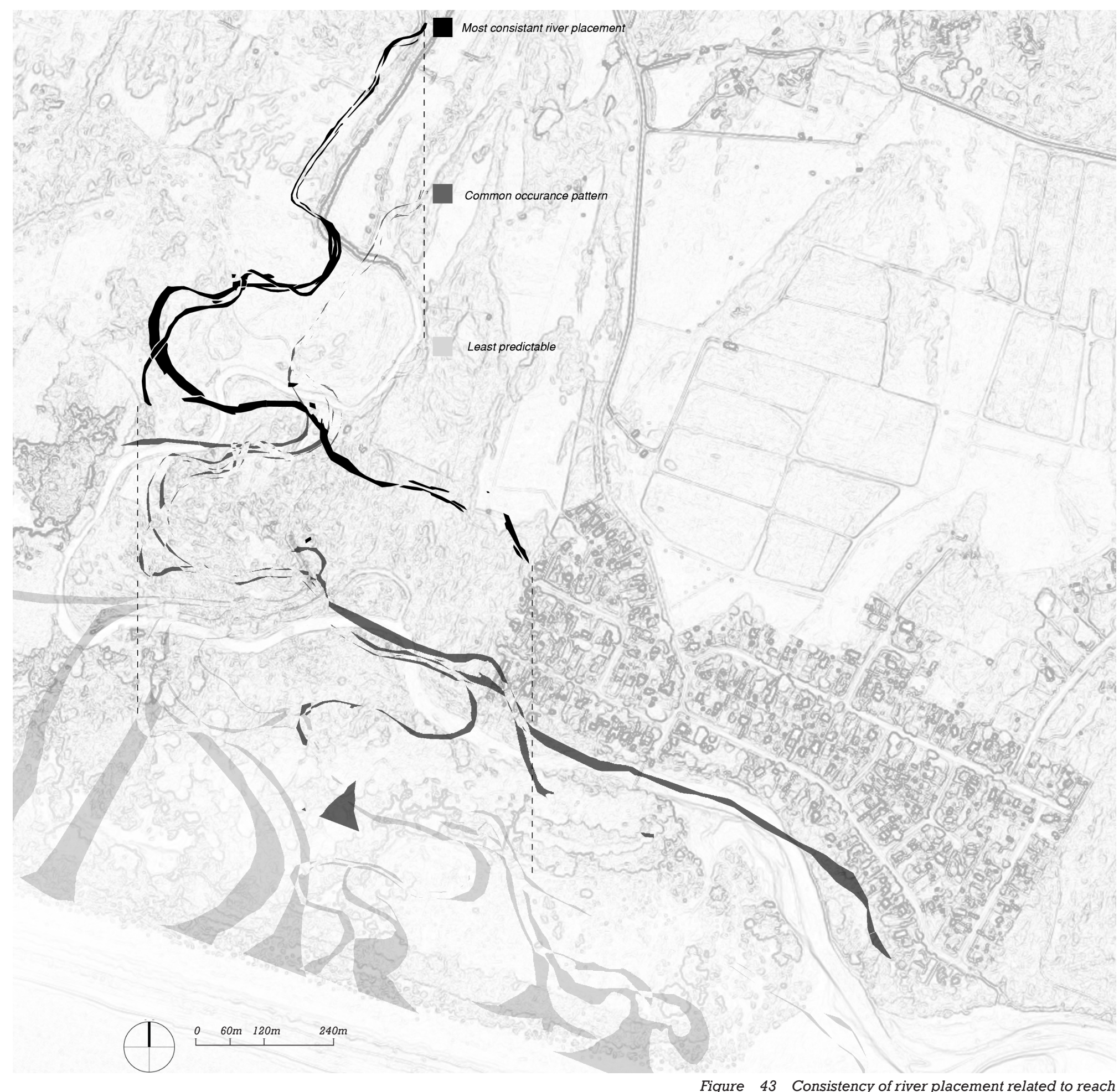


Flood events are common in the Horowhenua region. The eastward Tararua ranges are prone to significant downpour. As rivers swell, they overrun into residential areas, causing damage to property and infrastructure (Fig.45). The district is located on floodplains, and periodic surface flooding is common close to waterways such as the Waikawa (Horowhenua District Council, 2012). Particularly, the front road of Waikawa has had significant floods in 1954 and 1991 (Fig.46). The densification of residential zones along rivers puts more property at risk of floods (Shepherd \& Shepherd, 1999).
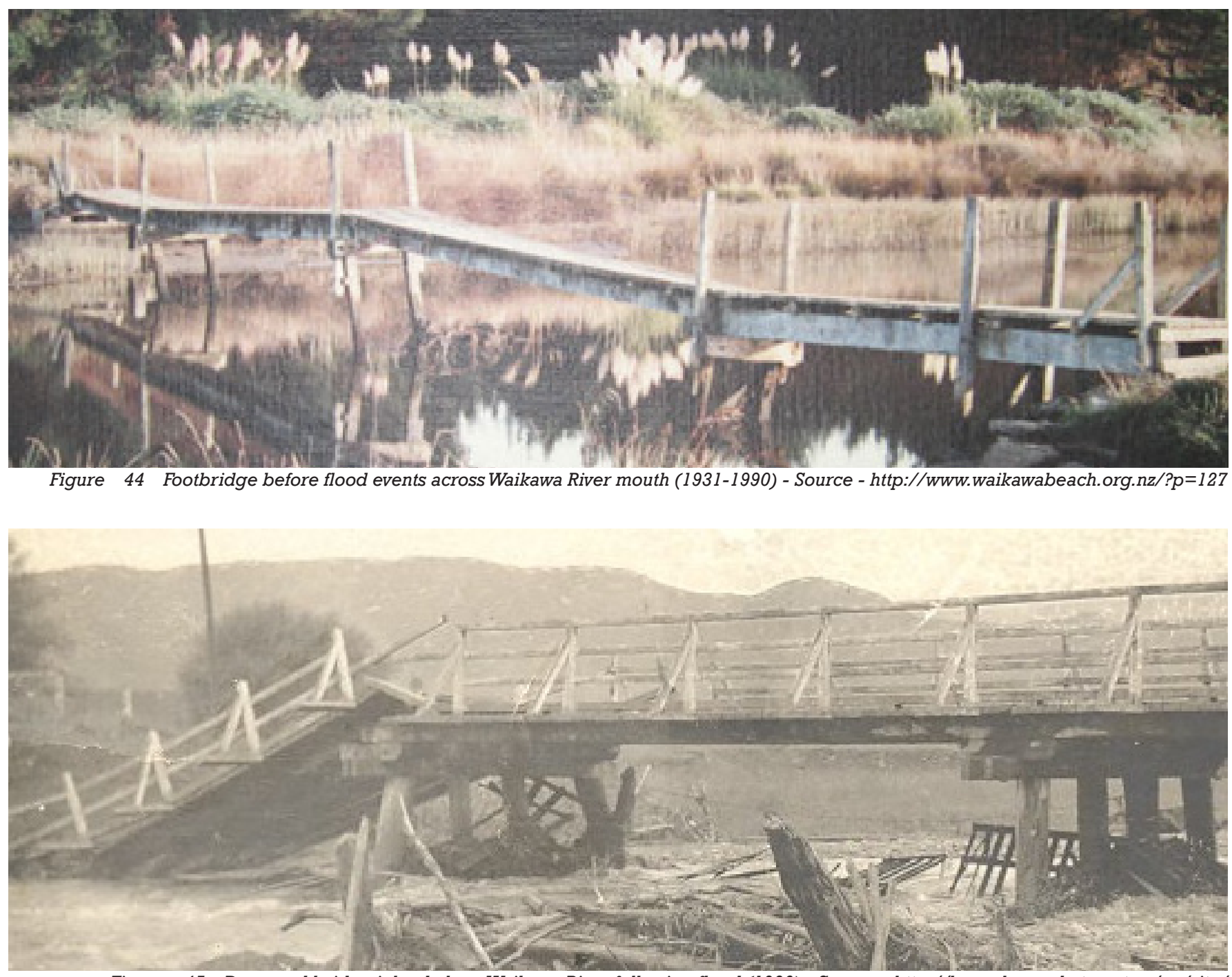

Figure 45 Damaged bridge inland along Waikawa River following flood (1920) - Source - http://horowhenua.kete.net.nz/en/site/ 
Im River Rise

2m River Rise

3m River Rise

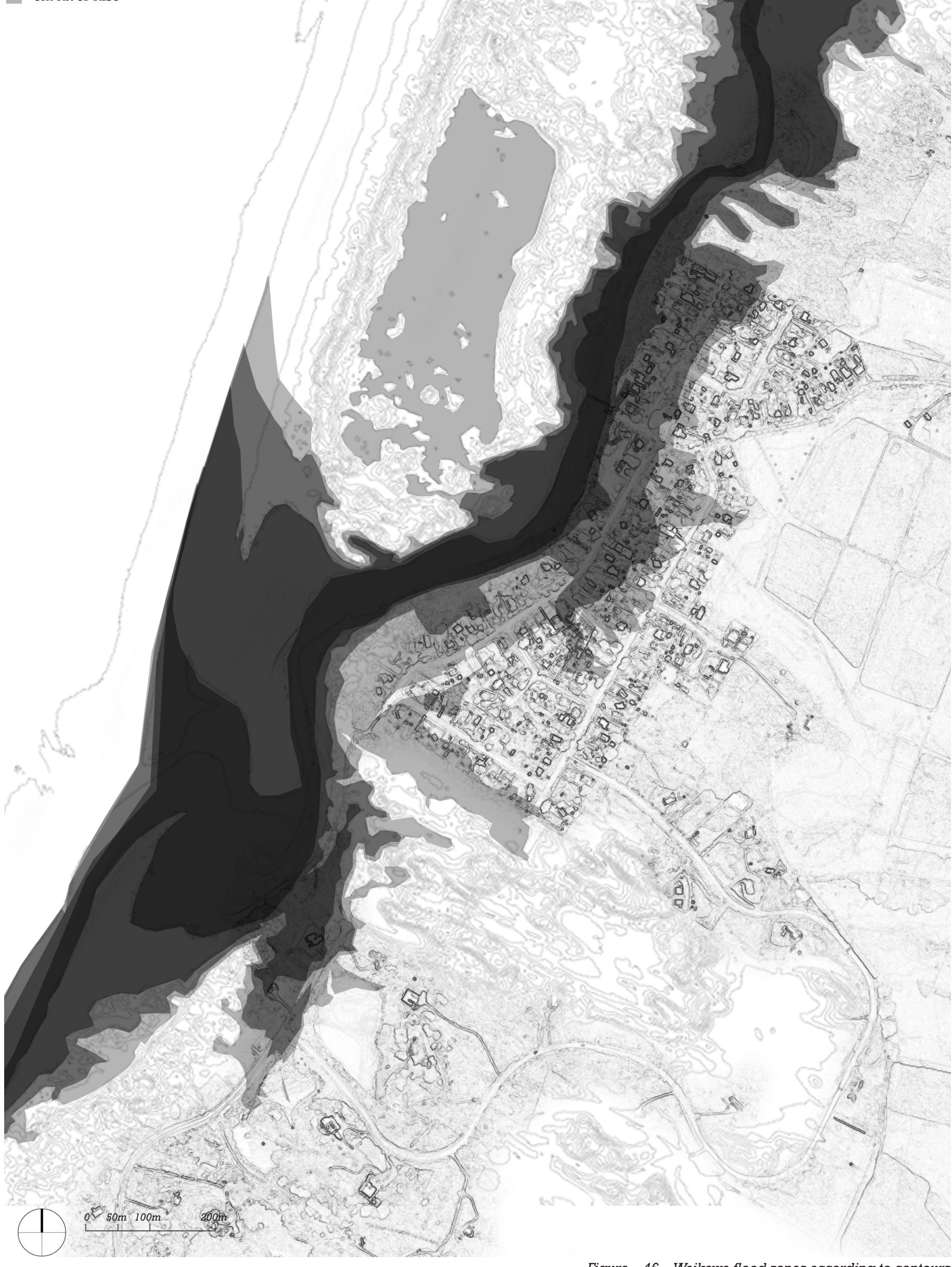


Relative to other processes, sea level rise is less rapid. It is however an important consideration when generating coastal fabric. Poorly planned placement of settlements could mean disaster on a decade or century scale. Globally, sea level rise is expected to claim many coastal areas. These images show land usurped by varying sea levels. For a four metre rise, two kilometres of land is submerged. The edge is nonuniform, where some dune heights break the surface. It is likely that these would eventually erode, although are useful in showing areas safe from short term events such as tsunamis (Fig.52).

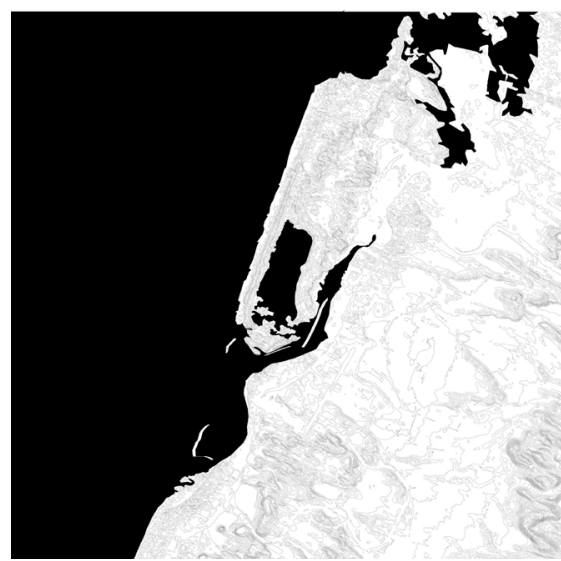

Figure 48 One meter sea level rise

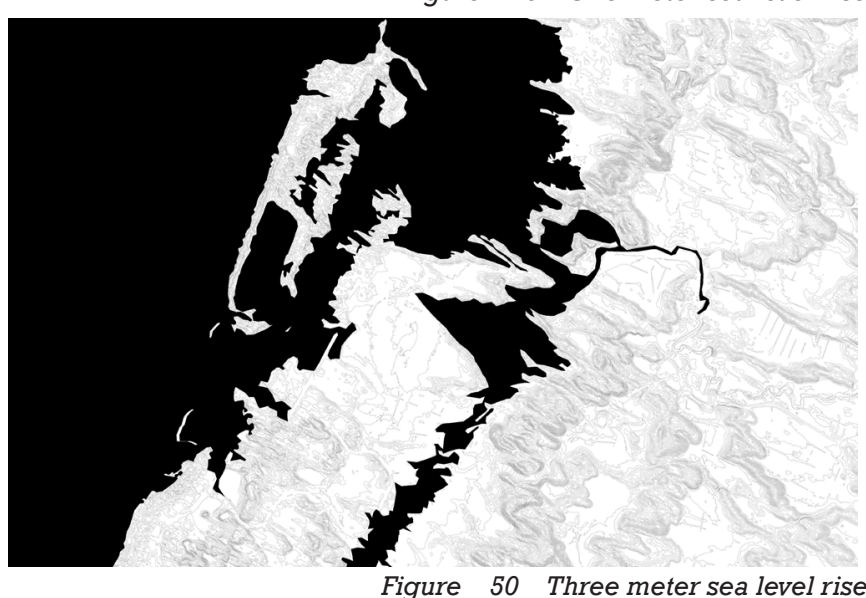

[58]
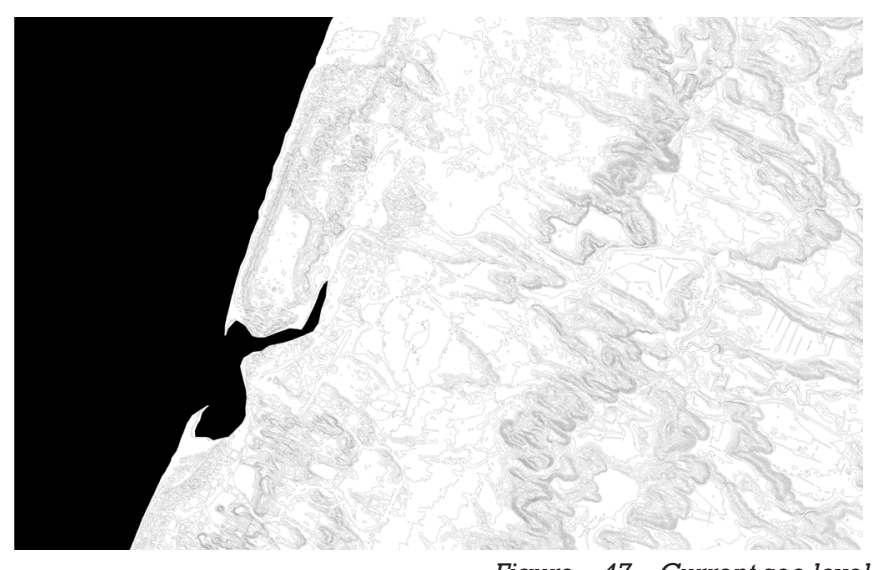

Figure 47 Current sea level
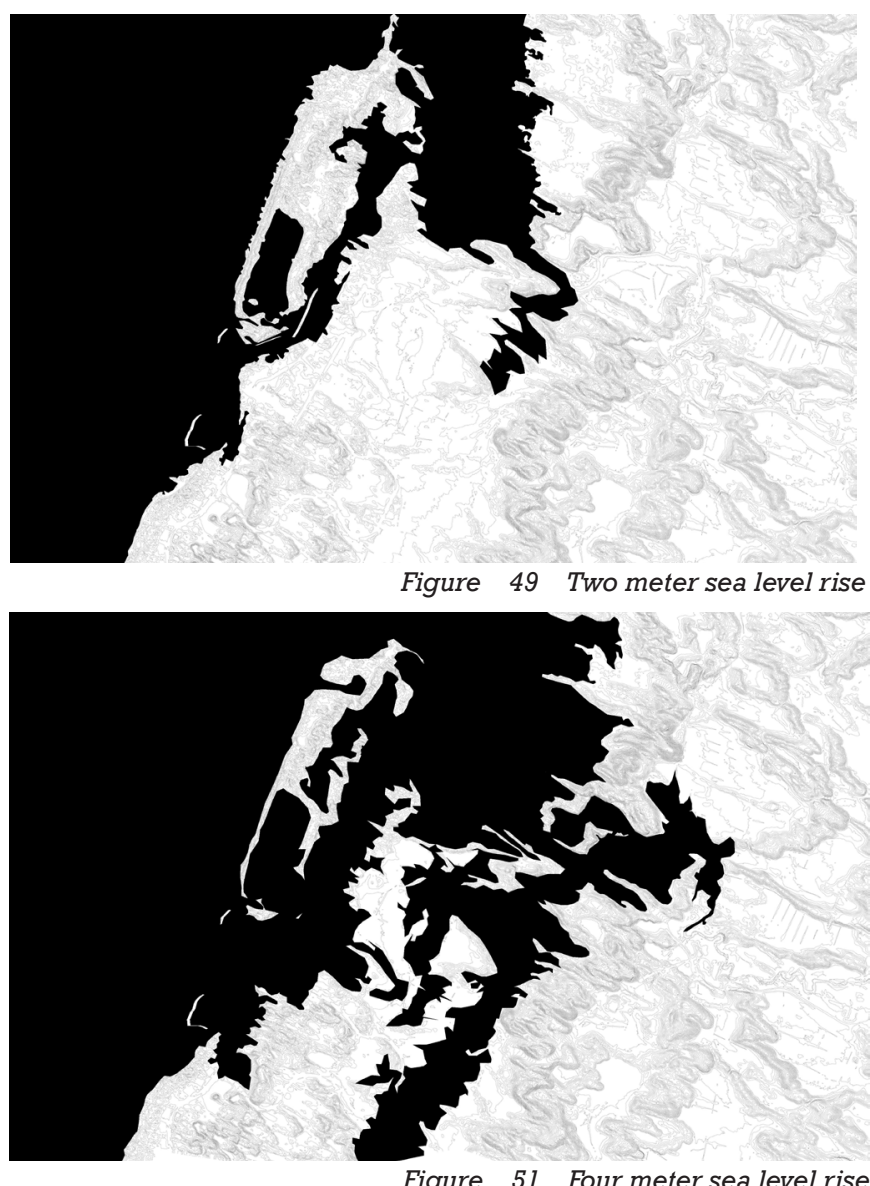

Figure 51 Four meter sea level rise 


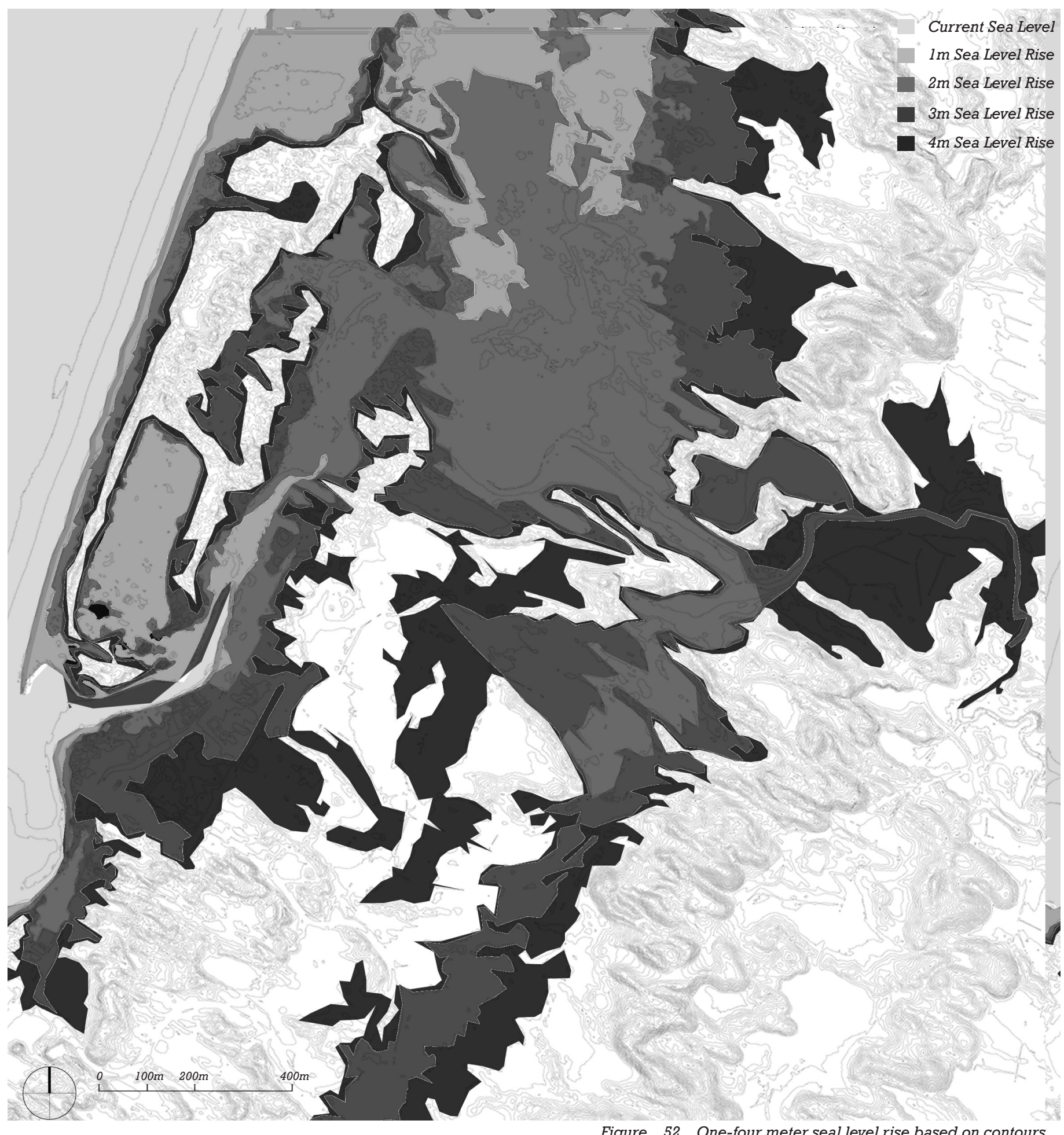


Fore dunes are located on the interface between land-sea. These members of the landscape have the ability to drastically change landform in a short timeframe. Fore dunes consist of sand, and grow by particle accretion. Initial or 'insipient' dunes are formed by windblown sand becoming trapped by small objects and vegetation (Fig.54). These 'insipient' dunes develop into 'established' dunes if enough sand is accumulated; these dunes are larger and are often supported by grasses (Fig.55). As dunes grow, stabilise, and move further inland they become 'back' dunes, often covered by woodier species, but are still subject to sand accretion and erosion over a longer period (Department of Conservation, n.d.). (Fig.56). As shown, these stages occur in a linear pattern heading inland, the diagram shows the speed of sand accretion between 1957 and today (Shepherd \& Shepherd, 1999). (Fig.57)
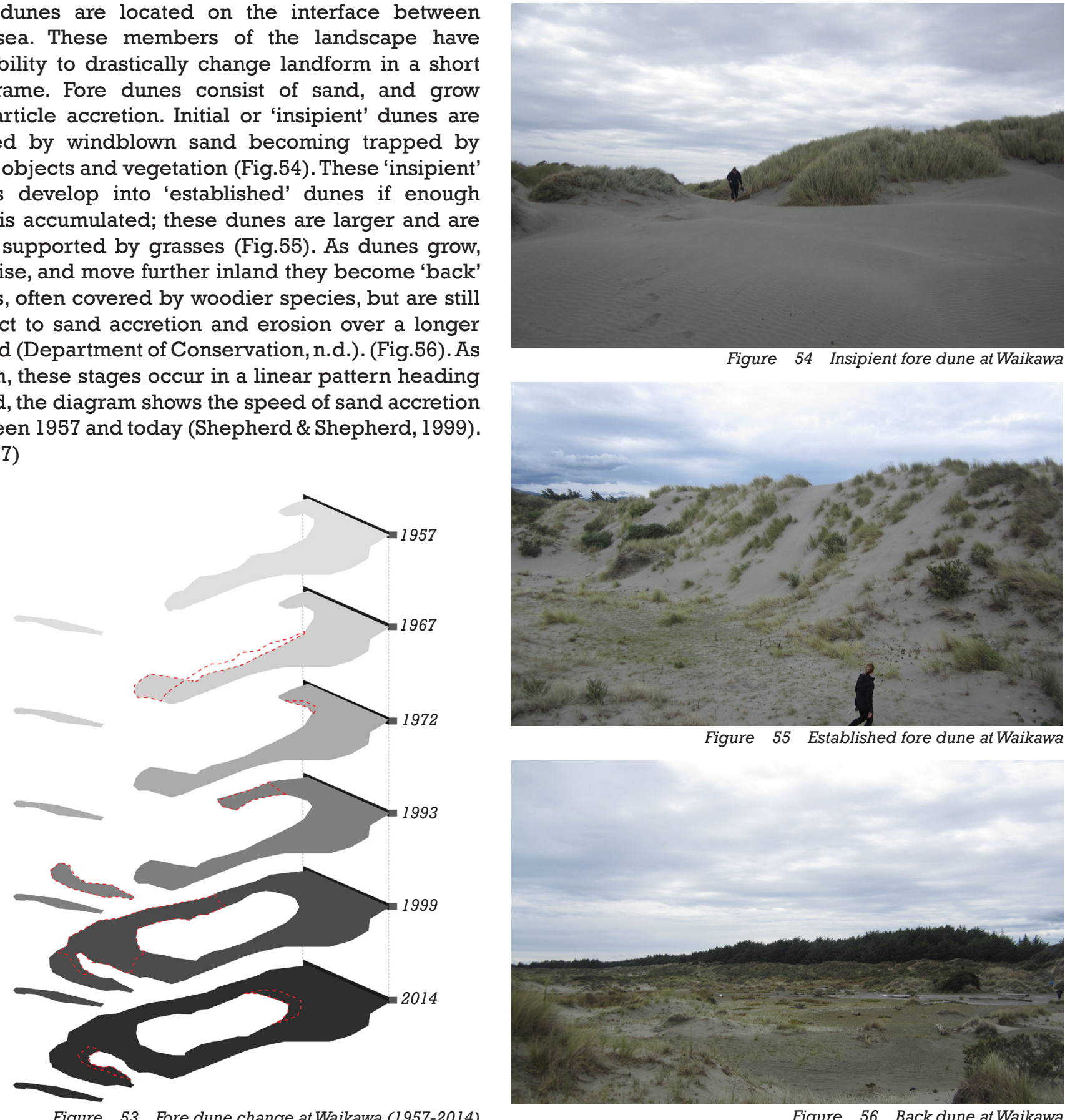

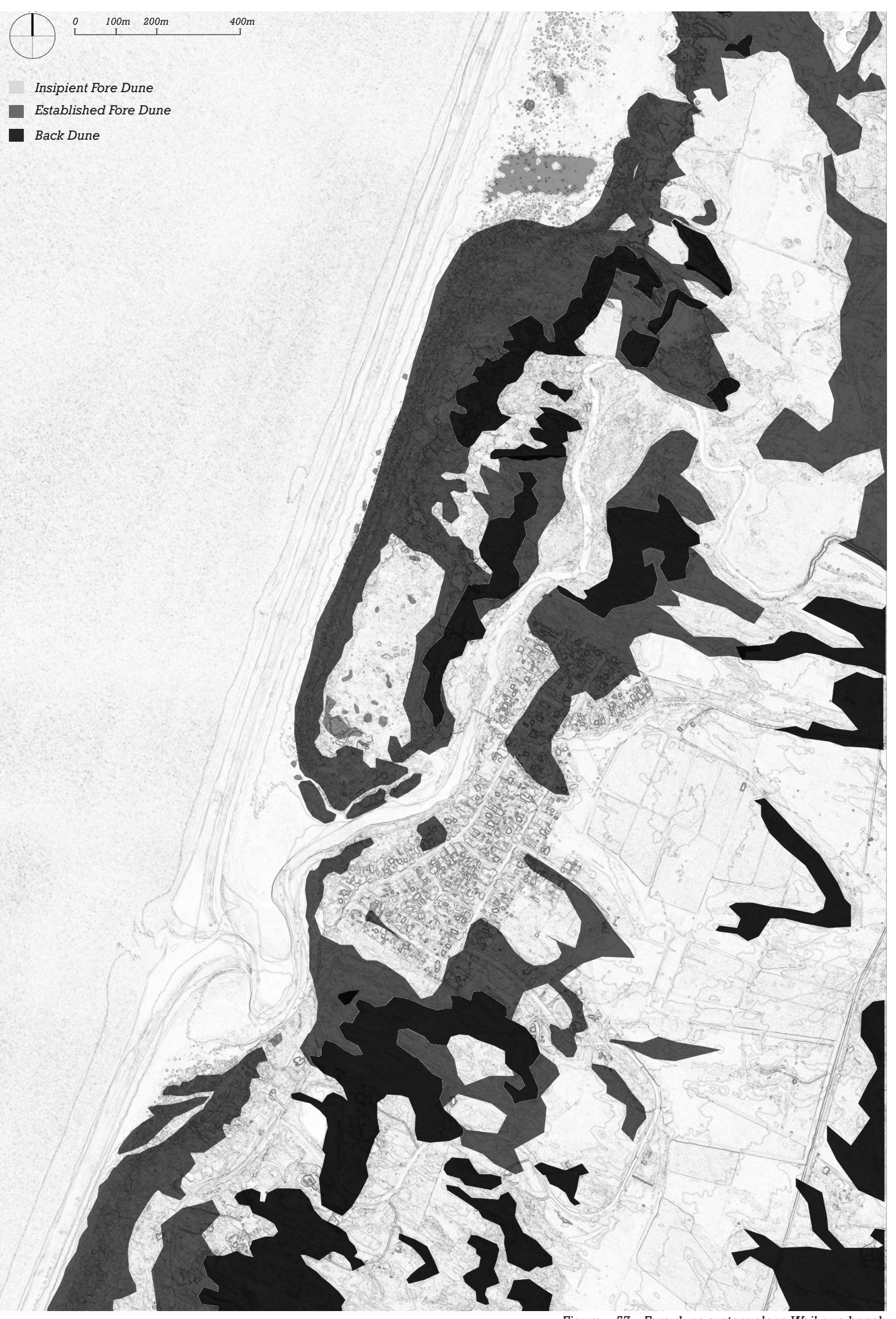
Parabolic dunes are inland, from the ground these members of the landscape might be easily mistaken for hills (Fig.60). These great dunes began accumulating 6500 years ago; as more sand collected, the shoreline grew seaward. The older inland dunes have more developed soils and have resultantly produced more vegetation further stabilising these now static 'remnants'. The unique 'U-shaped' form of parabolic dunes occur when erosive forces remove vegetation necessary for stability; a blowout is formed which migrates with prevailing winds inland, leaving trailing arms (McFadgen, 1997). At Waikawa these 'monuments' are established and stable, which has prompted safe construction on and around the dunes (Fig.59). This map shows a gestural representation of ancient movements (Fig.61).

A study of parabolic dunes conducted at Cape Cod, a North American colony reveals the conditions which facilitate movement. The forest at Cape Cod has long been destroyed, leaving the sand susceptible to Aeolian processes. The study showed dunes moving at a rate of between two and seven meters annually (Fig.58). Drier periods produced more movement, as sand was easily affected by wind (Forman, et al., 2008). The less vegetated areas at Waikawa, closer to the shoreline are therefore much more vulnerable to these movements, while the large remnants inland are almost certainly static.

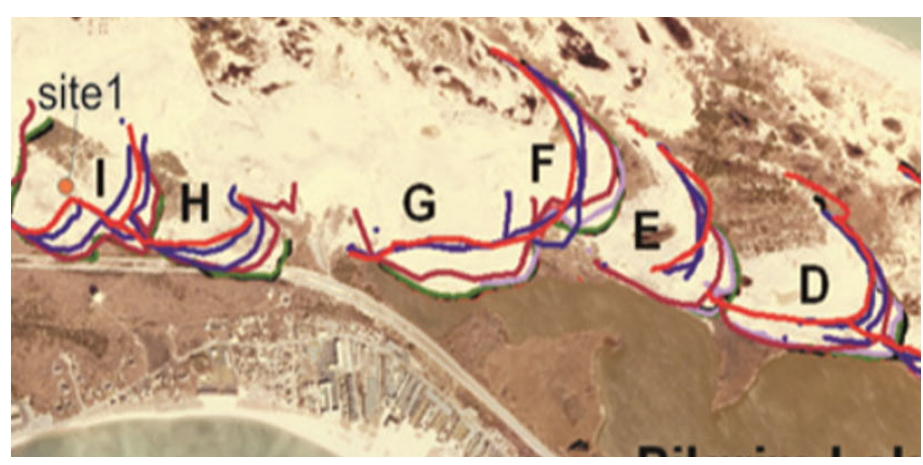

Figure 58 Image of parabolic dune study at Cape Cod-Source - The twentieth-century migration of parabolic dunes and wetland formation at Cape Cod National Sea Shore, Massachusetts, USA
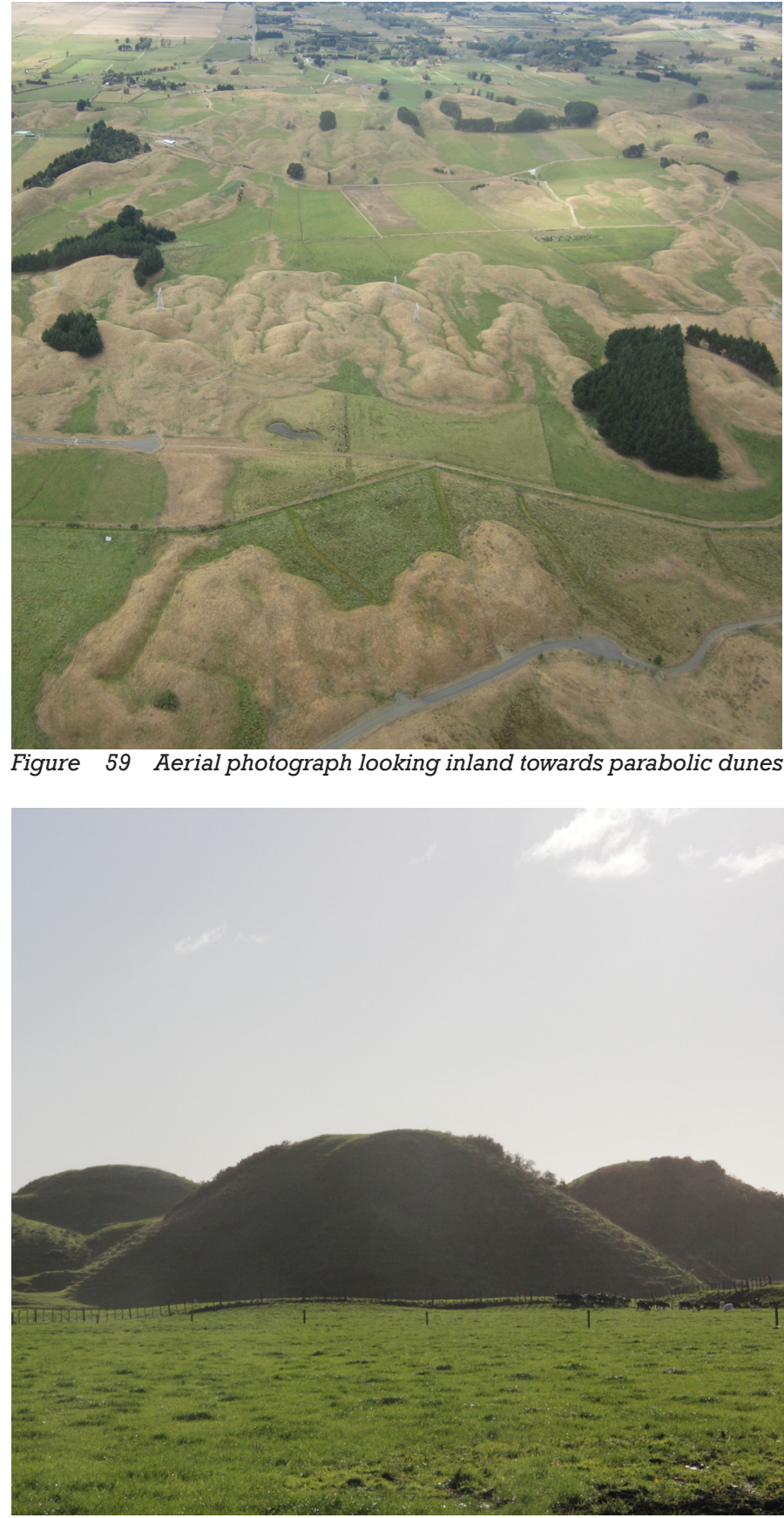

Figure 60 Large parabolic dunes located several kilometres inland 


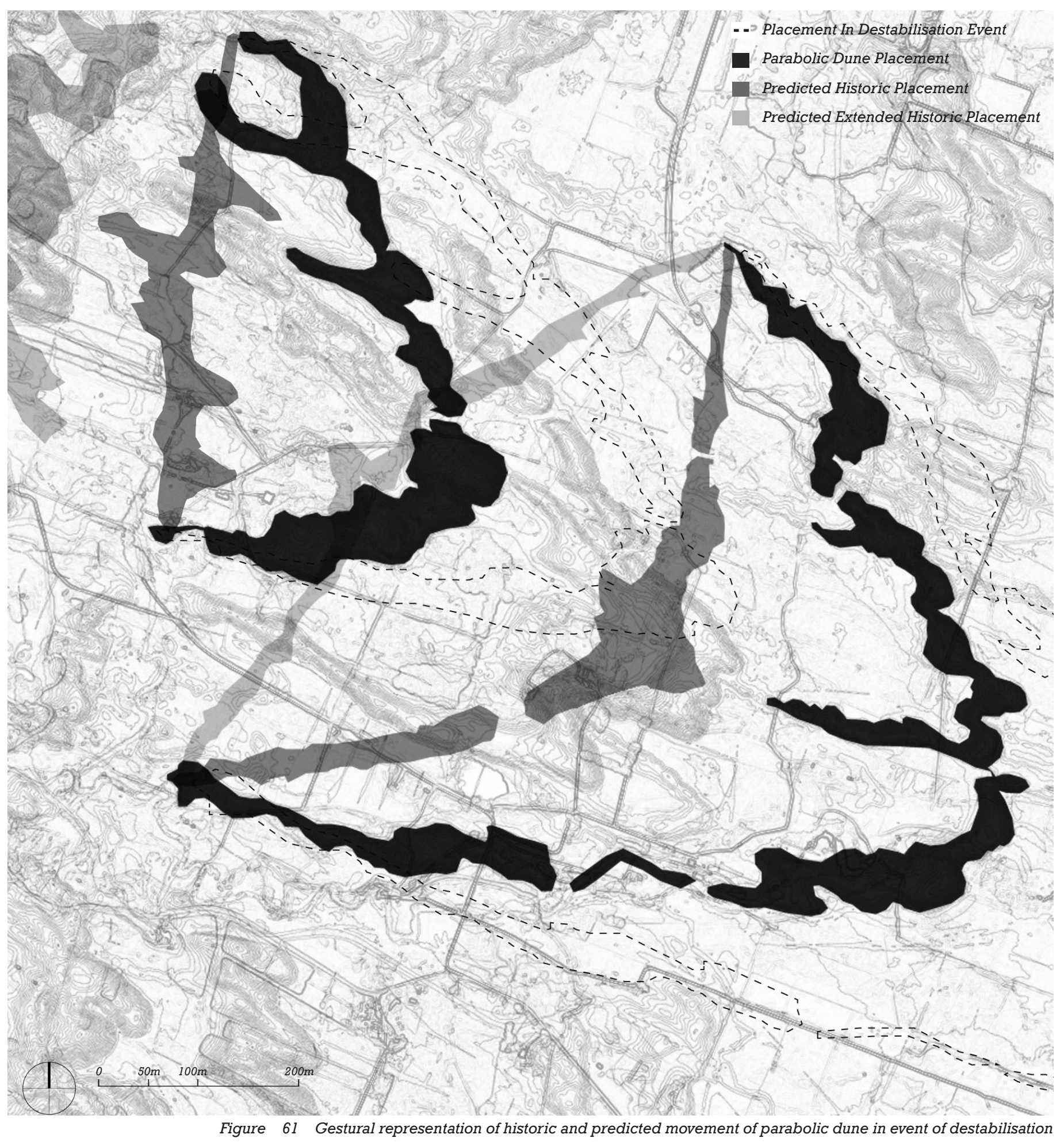


The greater Wellington region is located on several active fault lines. The most notable of these are the Wairarapa Fault, the Wellington Fault, and the Ohariu Fault (Fig.65). The Ohariu fault is closest to Waikawa, however given a large enough earthquake, any fault could see devastation for hundreds of kilometres. Amongst these main faults it is estimated that an extreme earthquake would occur every 150 years

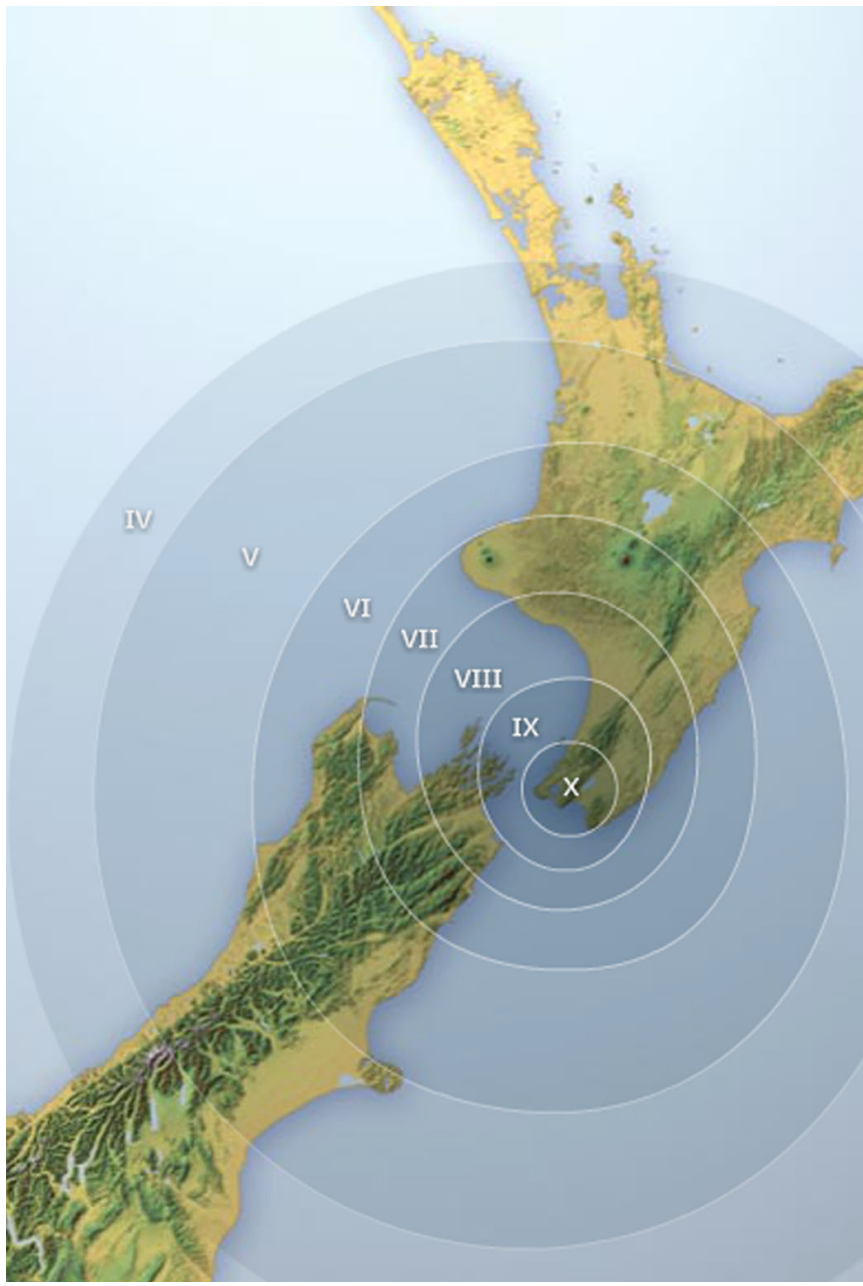

Figure 62 Map showing extent of damage from 1855 Wairarapa earthquake. Waikawa (within second ring) is susceptible to landslides,

liquefaction and cracking - Source - http://www.teara.govt.nz/en/ interactive/4392/extent-of-shaking-wairarapa-earthquake-23
(Fig.62). In 1855 the Wairarapa and Ohariu Faults ruptured triggering an 8.2 magnitude earthquake causing widespread damage (GNS Science, 2009). The threat of earthquakes is notable on the coast due to instability of the land; the risk of earthquakes at Waikawa is not solely in the compromised structural integrity of buildings, but in landslides, liquefaction, and tsunamis.

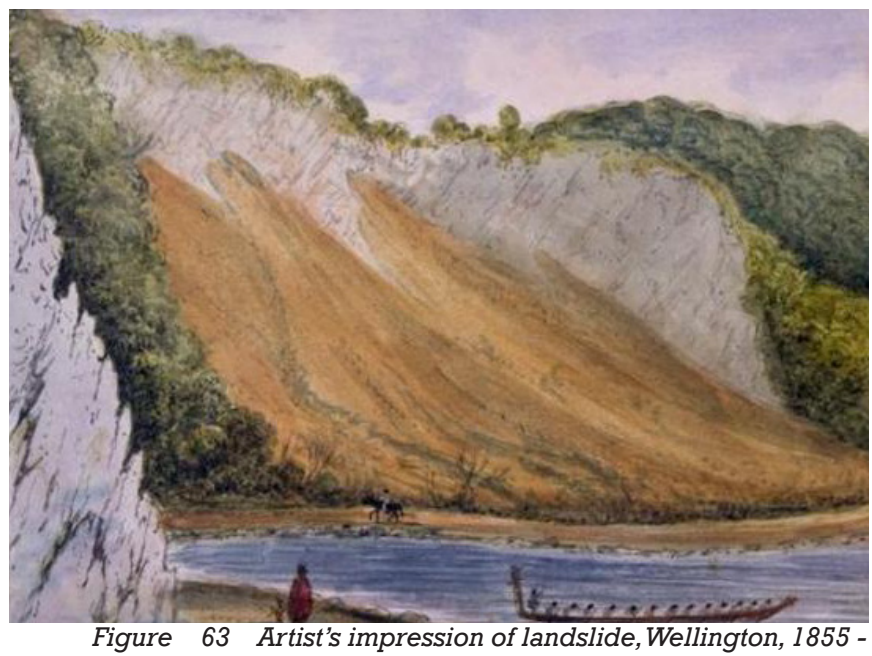

Source - http://info.geonet.org.nz/display/quake/M+8.2+-+8.3,+Wai rarapa,+23+January+1855

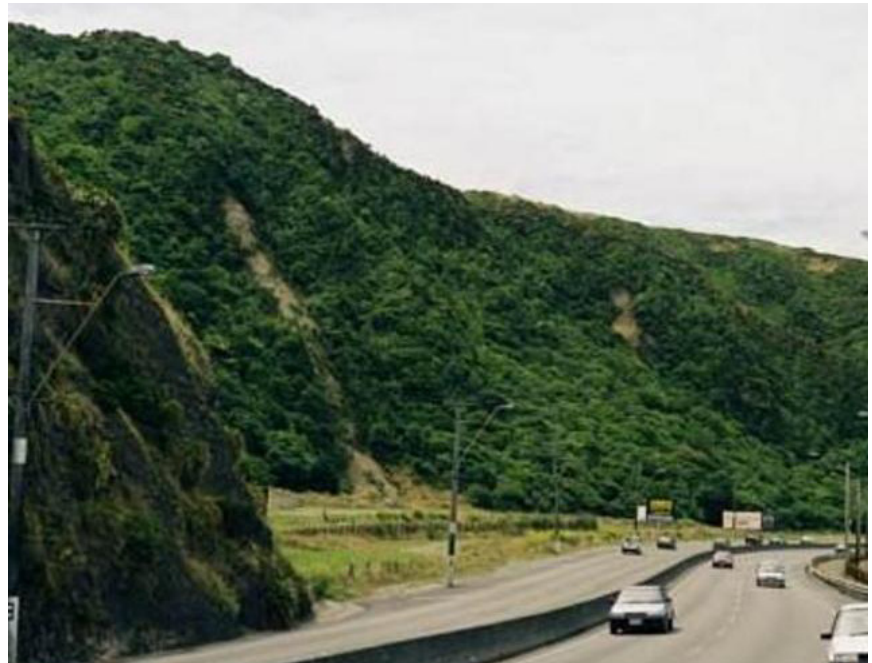

Figure 64 Site of landslide in 1855 -Source - http://info.geonet org.nz/display/quake/M+8.2+-+8.3,+Wairarapa, +23+January+1855 


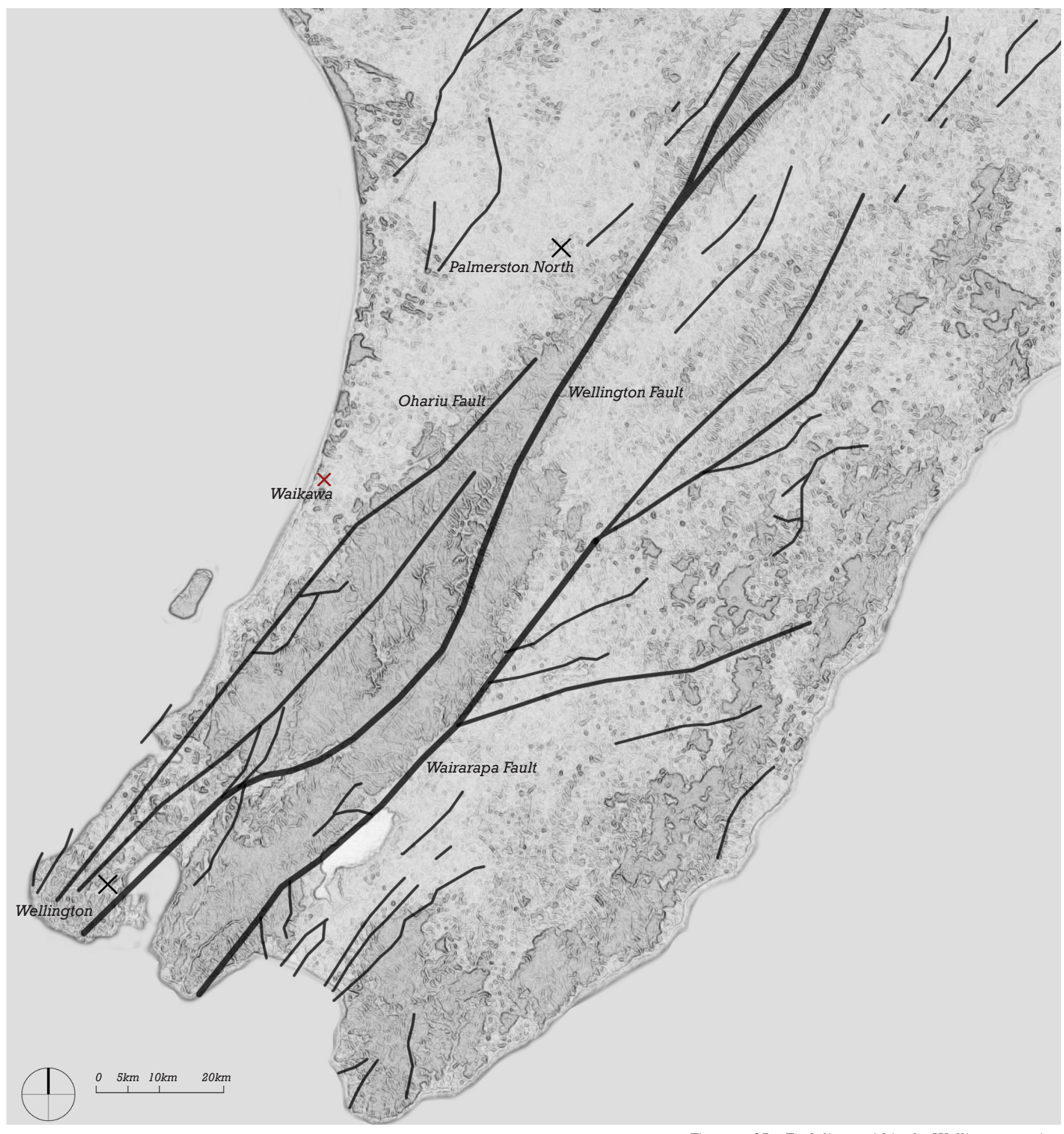


Waikawa has had a long history of occupation, from its earliest settlers dating before the 1800's, through to Maori and European inhabitants. The area has been colonised through several approaches, some making use of opportunities the land creates, while others attempt to reshape the landscape. 
The 'Waitaha' were the first settlers to occupy the Horowhenua region. A number of 'middens' and burial sites are proof of their existence, where it appears they chose to settle directly on the coast to make use of the rich supply of seafood. Other settlers such as early Maori also settled near water bodies to capitalise on their abundance (Shepherd \& Shepherd, 1999). (Fig.66).

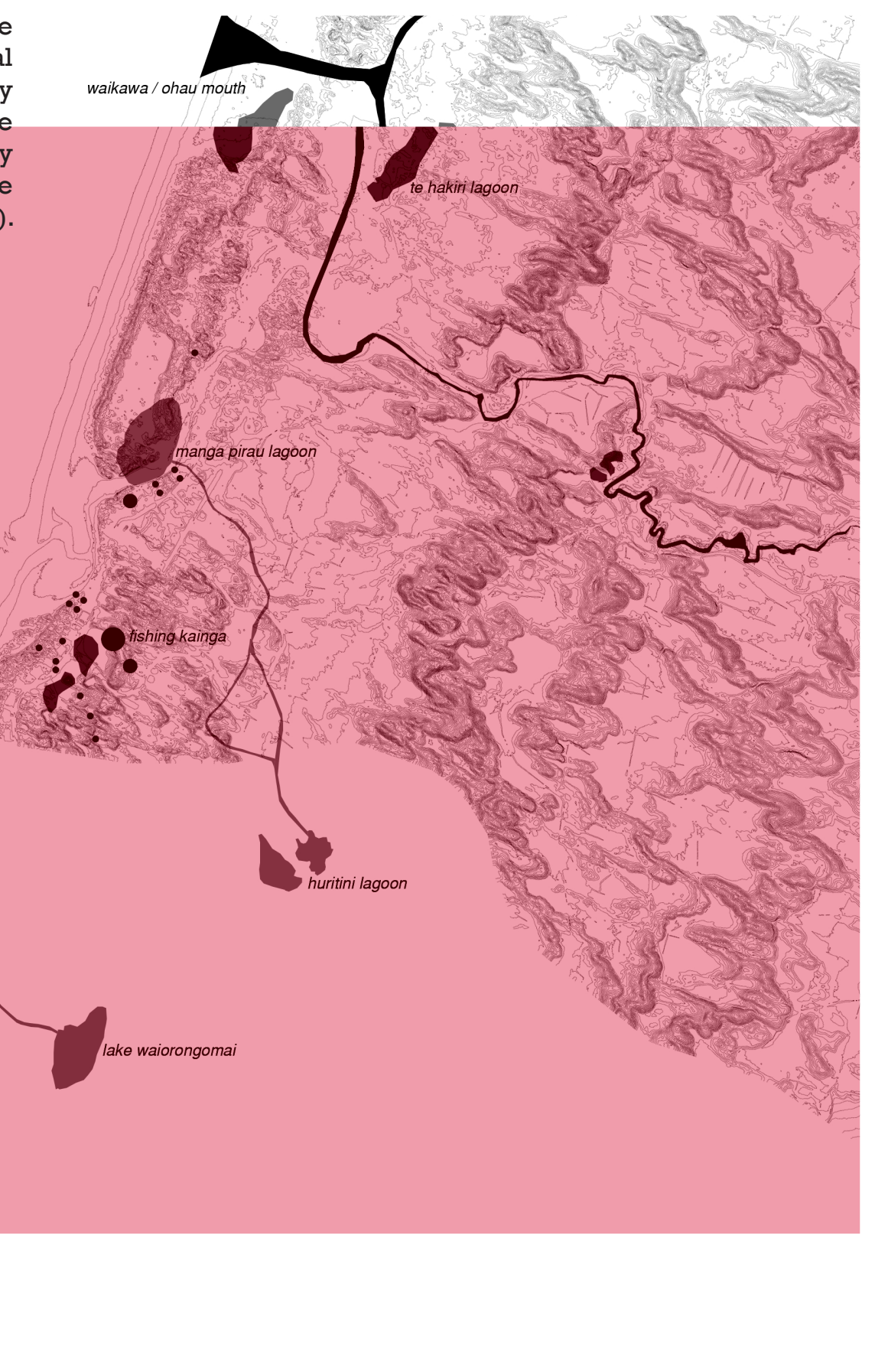


'Pa Te Rauparaha' was a Maori settlement established in the prominent bend of the river. This location secured access to the river - supplying eels, and the Okaka dune ridge; one spot became known as Te Rauparahas' lookout, due to expansive views. Another notable settlement was located near the mouth, adjacent to a lagoon. The location provided access to the ocean, estuary environment, and river, which supplied a range of food (Shepherd \& Shepherd, 1999). (Fig.67)

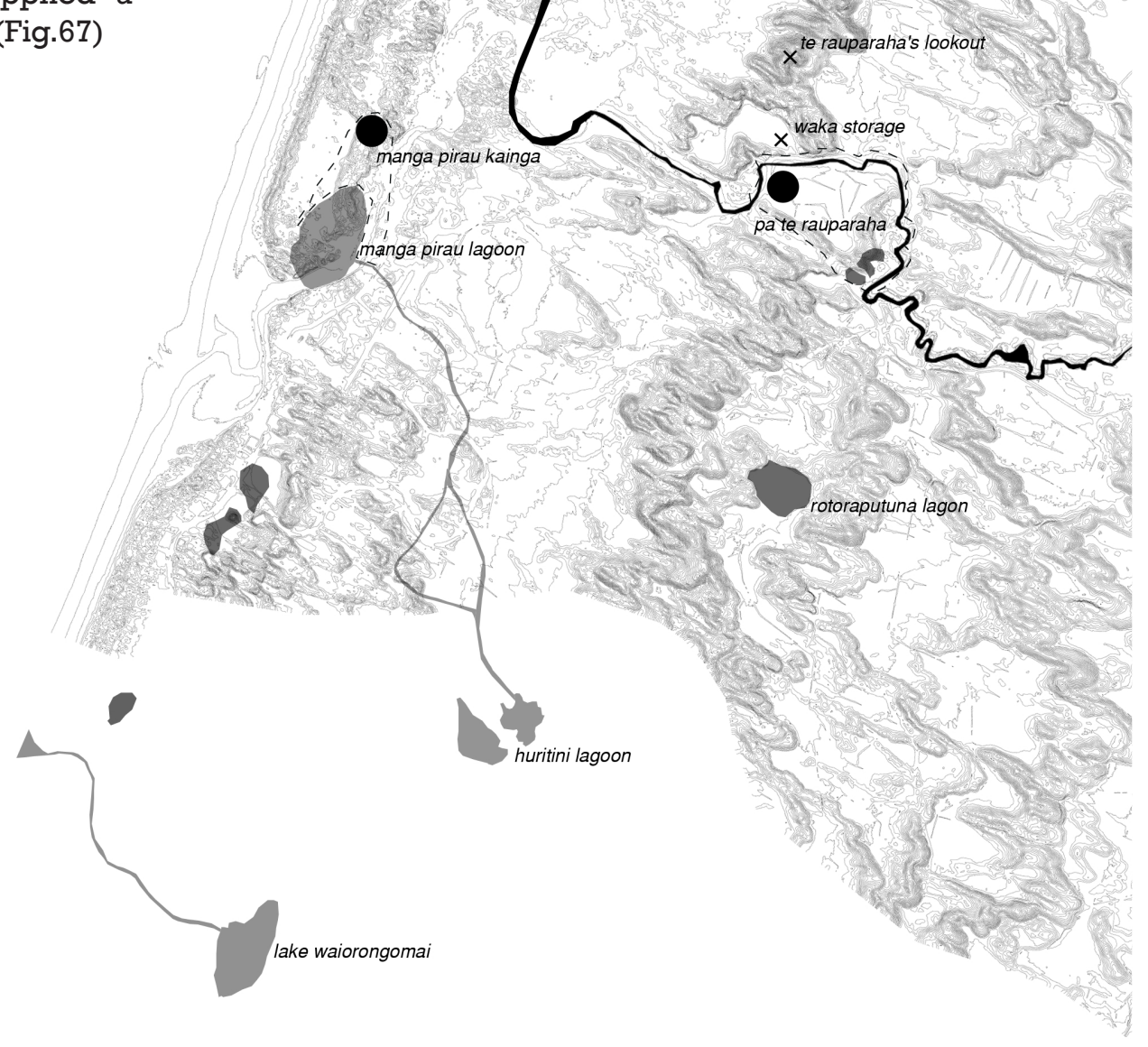


maori occupation: 1800 - 1844

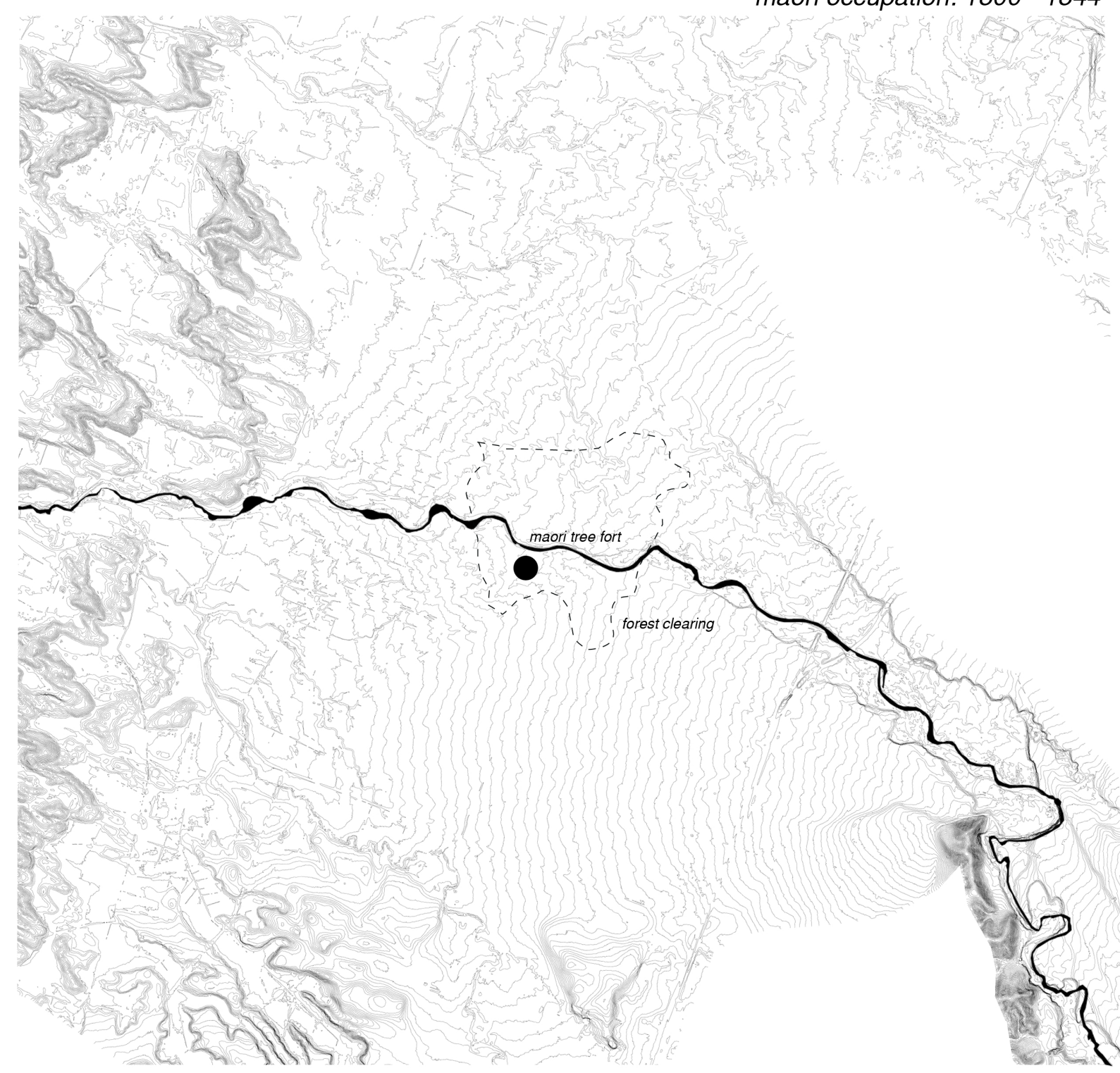

Figure 67 Inhabitation of Waikawa (1800-1843) 
By the 1840's Europeans had occupied land alongside Maori. In Waikawa, an accommodation house was built providing safe passage via ferry across the river. In areas, sheep runs were being set up, and along the river, flax mills were established for the soil moisture which was ideal for growing flax (Shepherd \& Shepherd, 1999). This reveals why settlements followed the form of the river. (Fig.68)

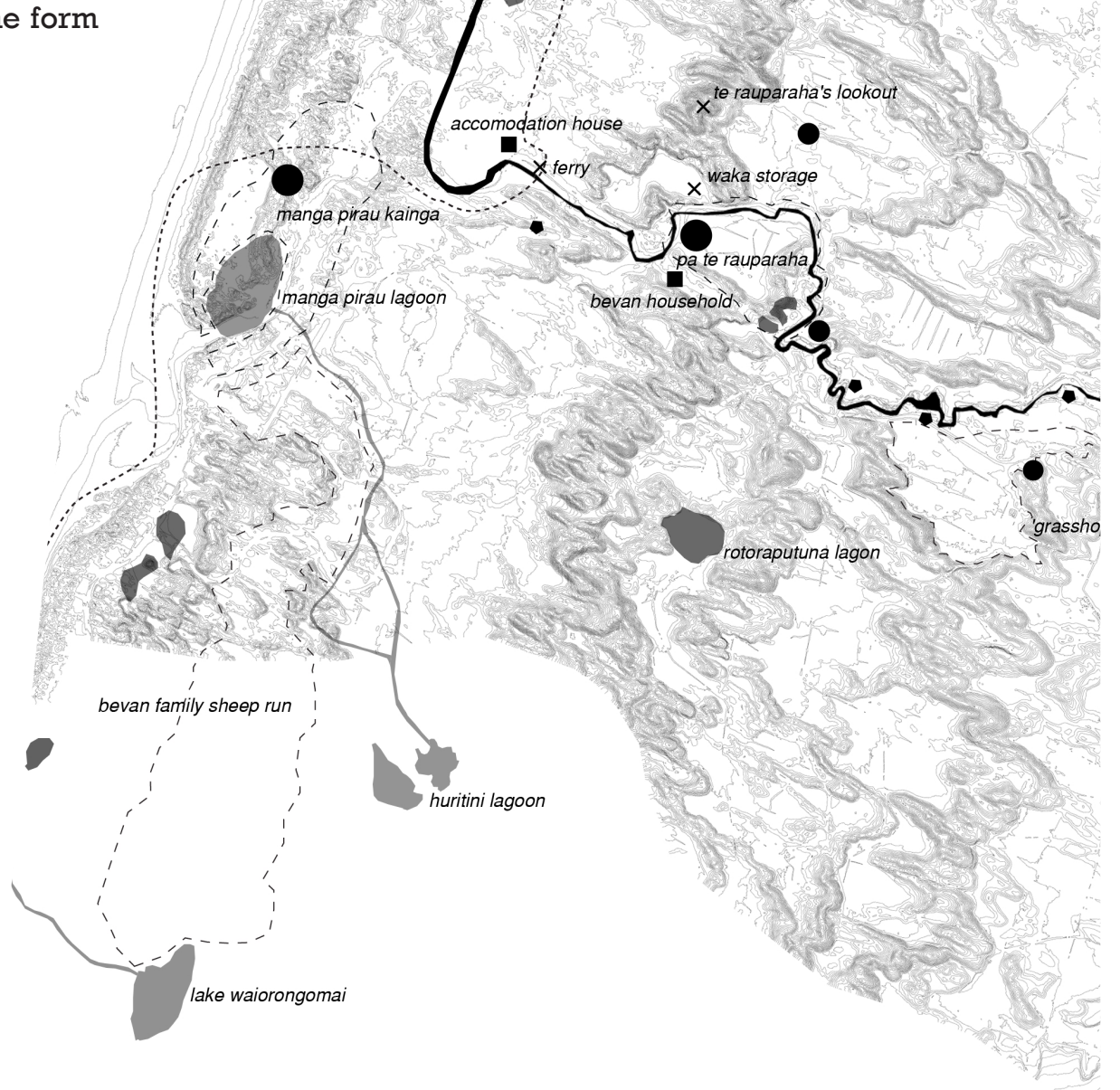




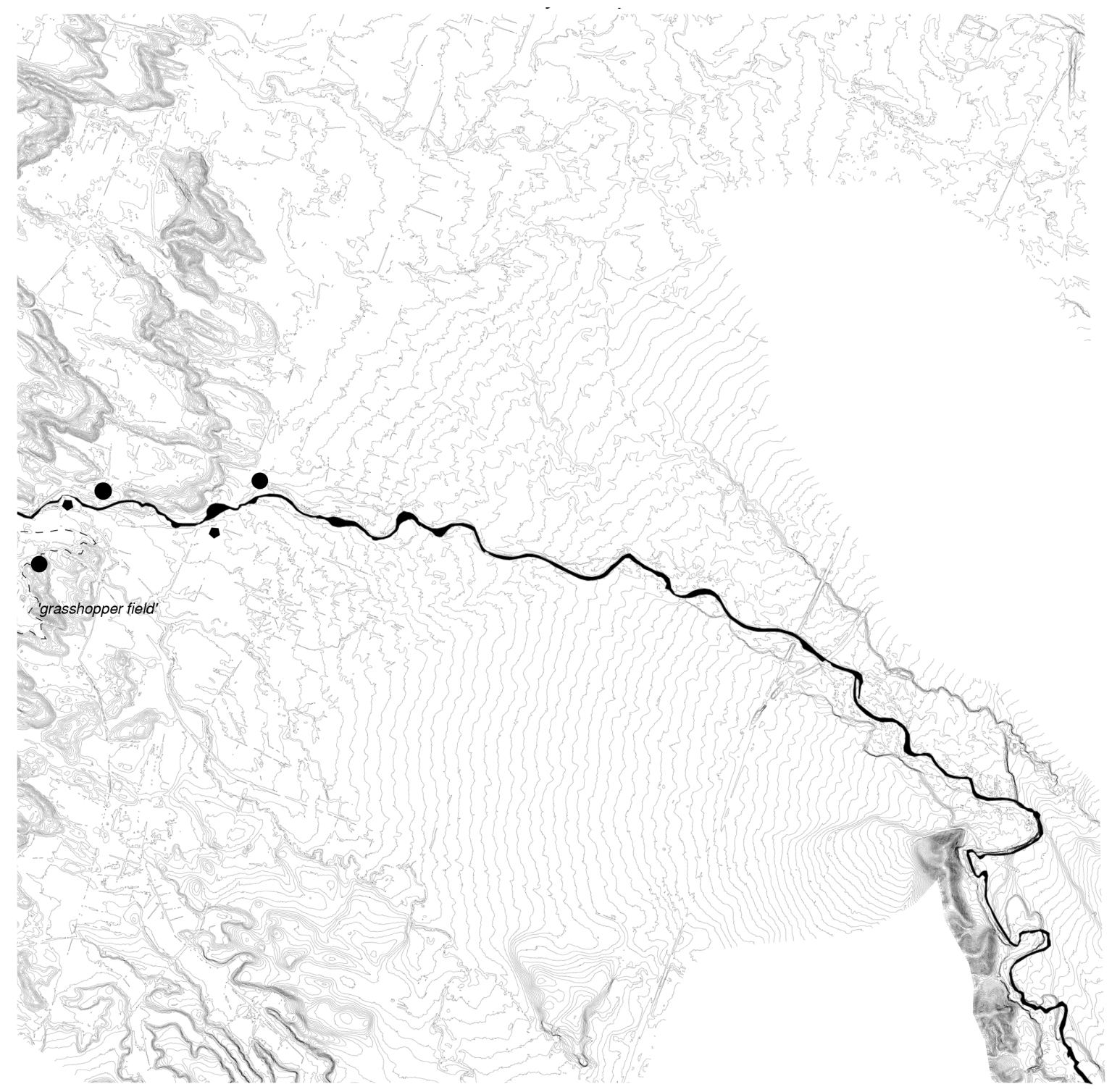

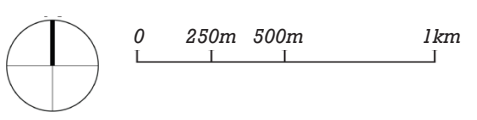


The formation of Manakau, on the Manawatu rail line marked the end of Waikawas' life as a trading settlement, and began its transition to a farmland. In particular a 3000 acre land purchase saw a massive portion of Waikawa dedicated to a single practice, ignoring the opportunities of the landscape. By the 1900's farming was the sole occupation at Waikawa (Shepherd \& Shepherd, 1999). (Fig.69)
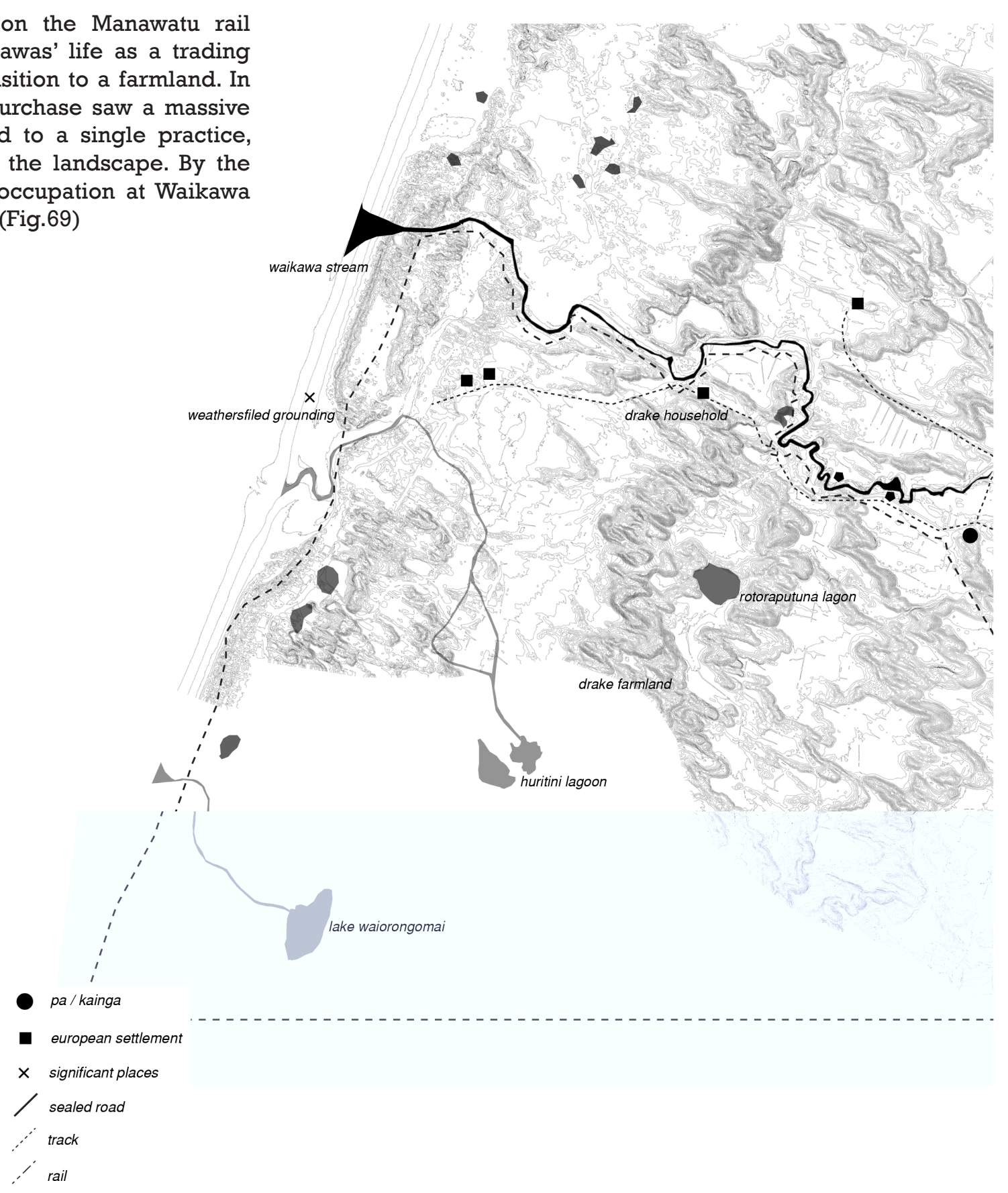


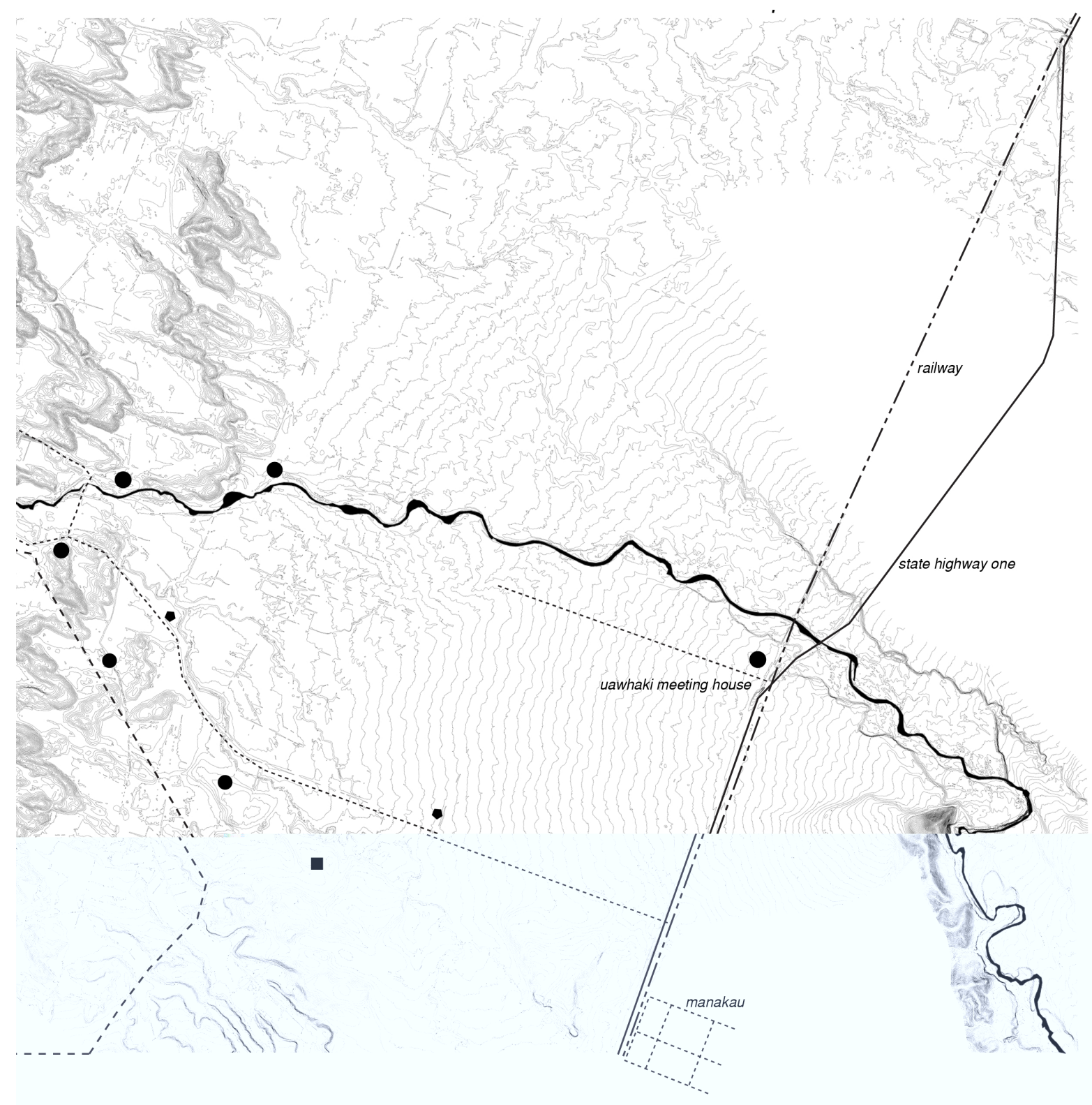

$\bigoplus \begin{array}{cccc}0 & 250 \mathrm{~m} & 500 \mathrm{~m} & 1 \mathrm{~km}\end{array}$ 
Increase in mobility made areas like Waikawa popular holiday destinations. Due to farmland inundation occurring at the coastline, land was released for development, and several stop banks implemented in an unsuccessful attempt to prevent flooding. By 1950 the population had reached 50 (Shepherd \& Shepherd, 1999). (Fig.70).

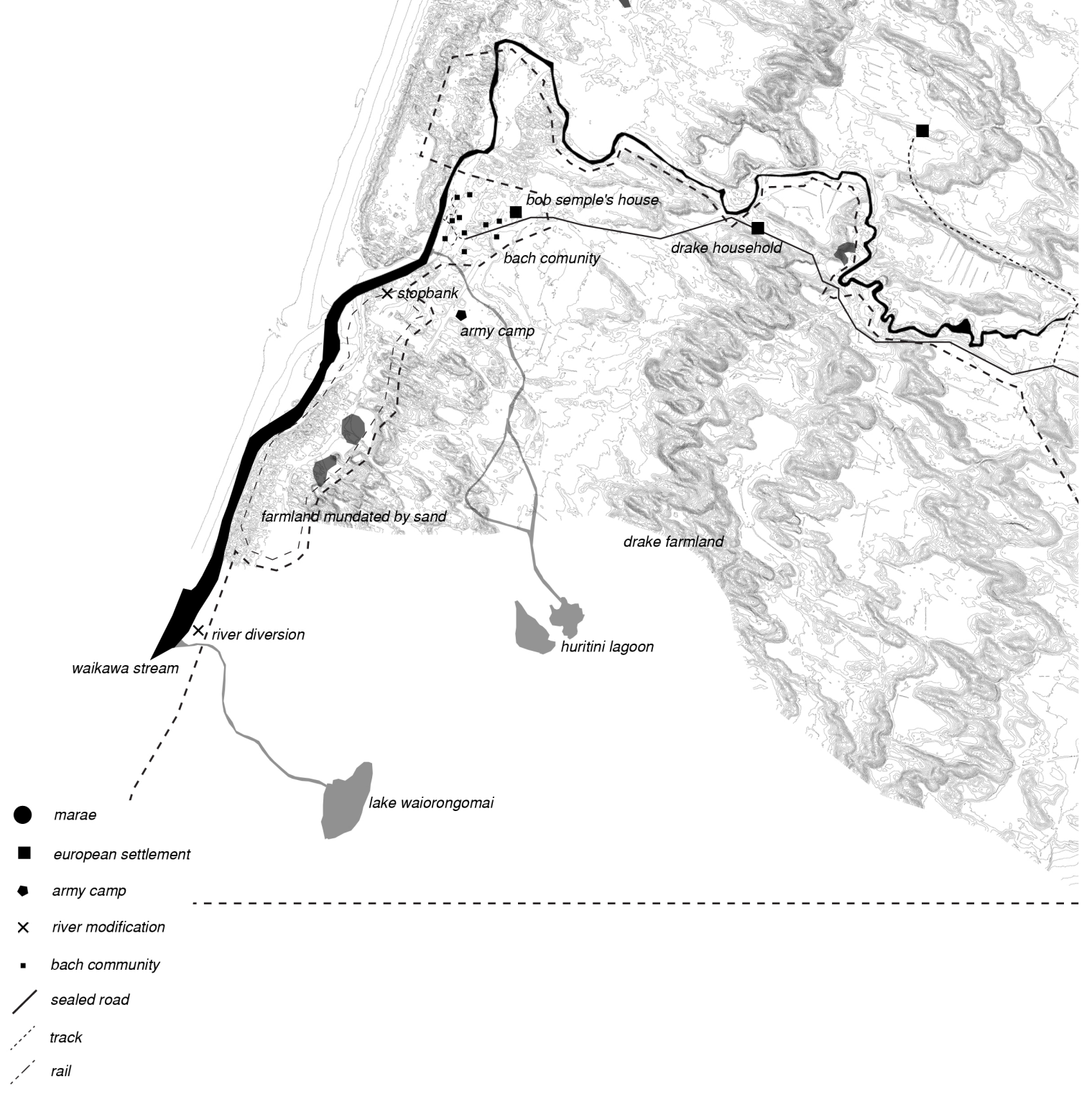




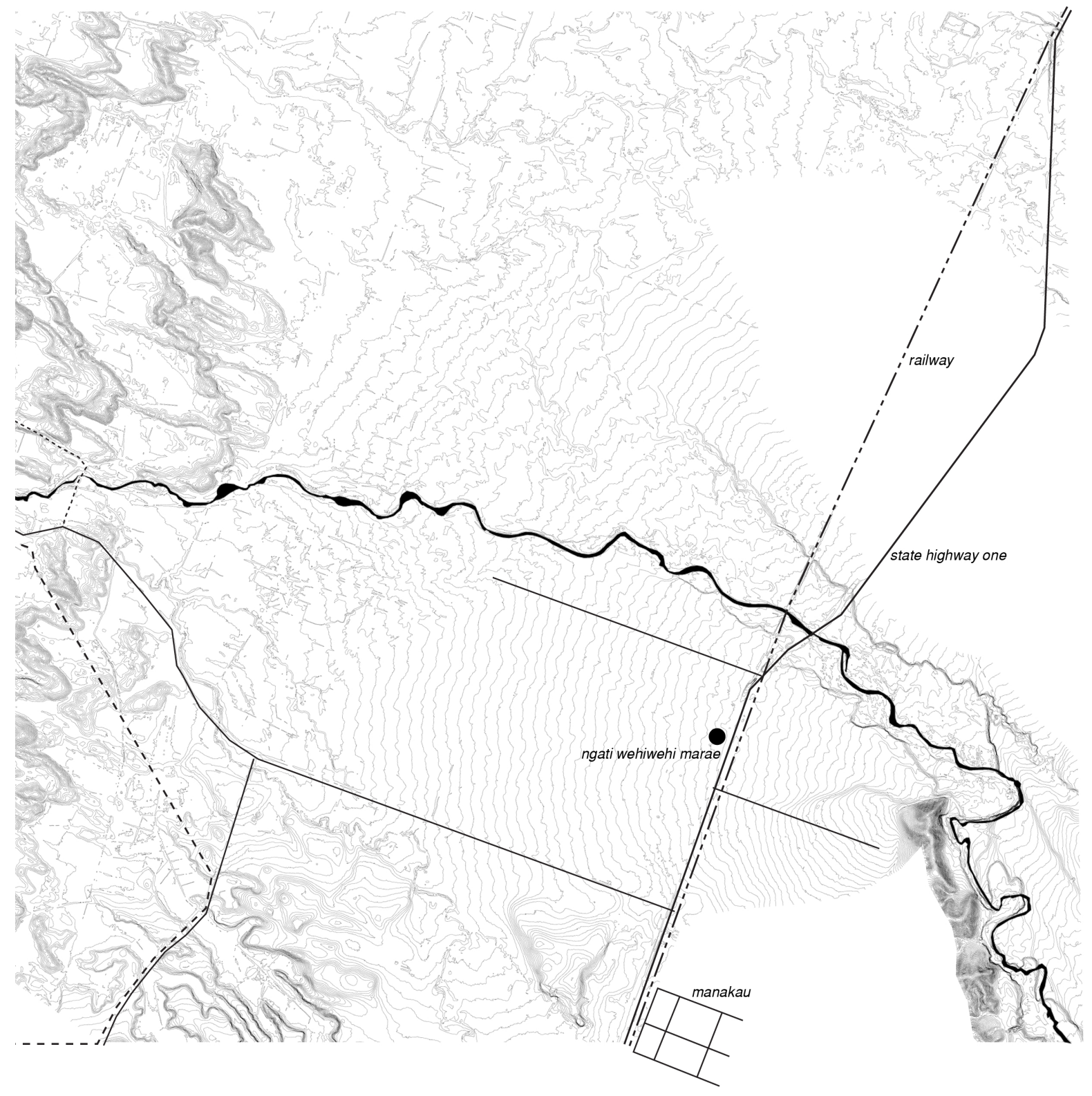

$\bigoplus \begin{array}{cccc}0 & 250 m & 500 m & 1 k m \\ \text { I } & & & \end{array}$ 
Since the 1950's farmers have continued to release land. Several baches have been built, and today, number approximately 200. Other areas have also been developed; specifically the two dune developments (Shepherd \& Shepherd, 1999). The majority of the landscape is still farm dominated, though development plans show the intent to continue residential expansion (Horowhenua District Council, 2008). (Fig.71).

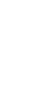

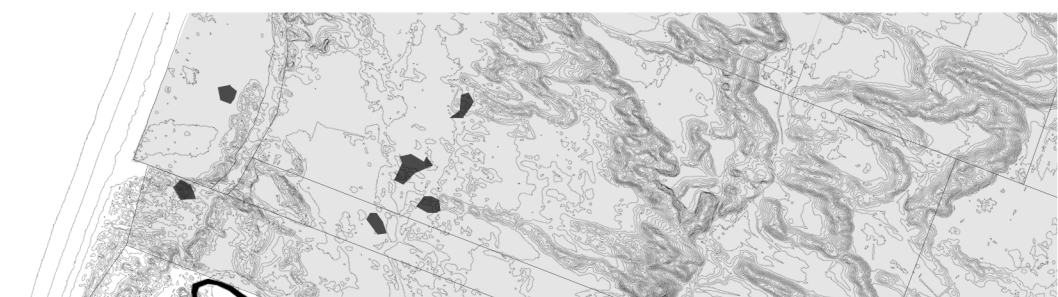




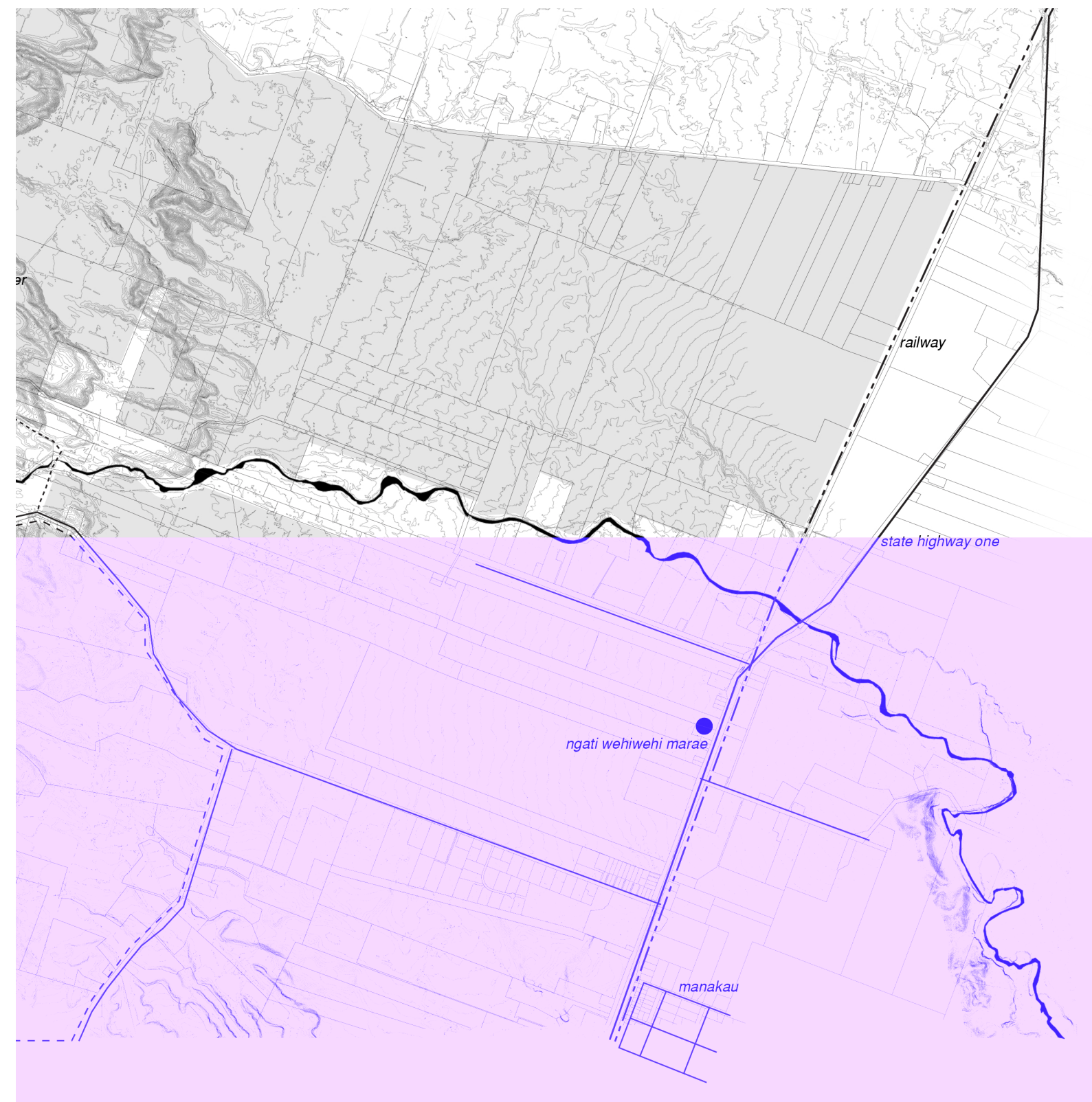

(1) $\stackrel{0}{0} \stackrel{250 m}{5} \underset{I}{1 k m}$ 
Today the landscape at Waikawa is divided two dimensionally, with plot typologies clustered together (Fig.72). The most numerous are Baches which occupy the smallest parcels. The 233 bach plots make up $60 \%$ of plots in Waikawa, but only cover $2 \%$ of the land. Conversely, larger farmland plots make up $7 \%$ of the plots but cover $66 \%$ of the land (Fig.74). The placement of plots reveals mostly un-integrated classifications, where farming is separated from residential zones, which is separated from reserve land and so on. Denser typologies are located closer to the coast while the sparser typologies are inland, making a large portion of the occupants susceptible to the effects of coastal processes.
Farmland

Fore Dune Dwellings

Back Dune Dwellings

Fore Dune Dwellings

Baches

Reserve Land
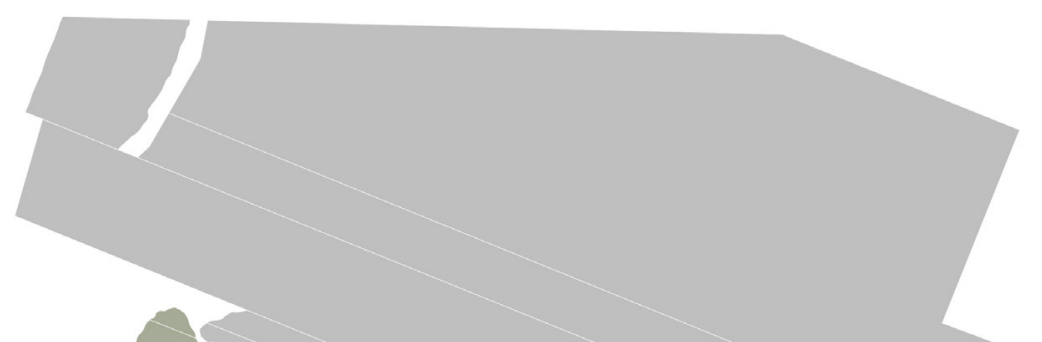


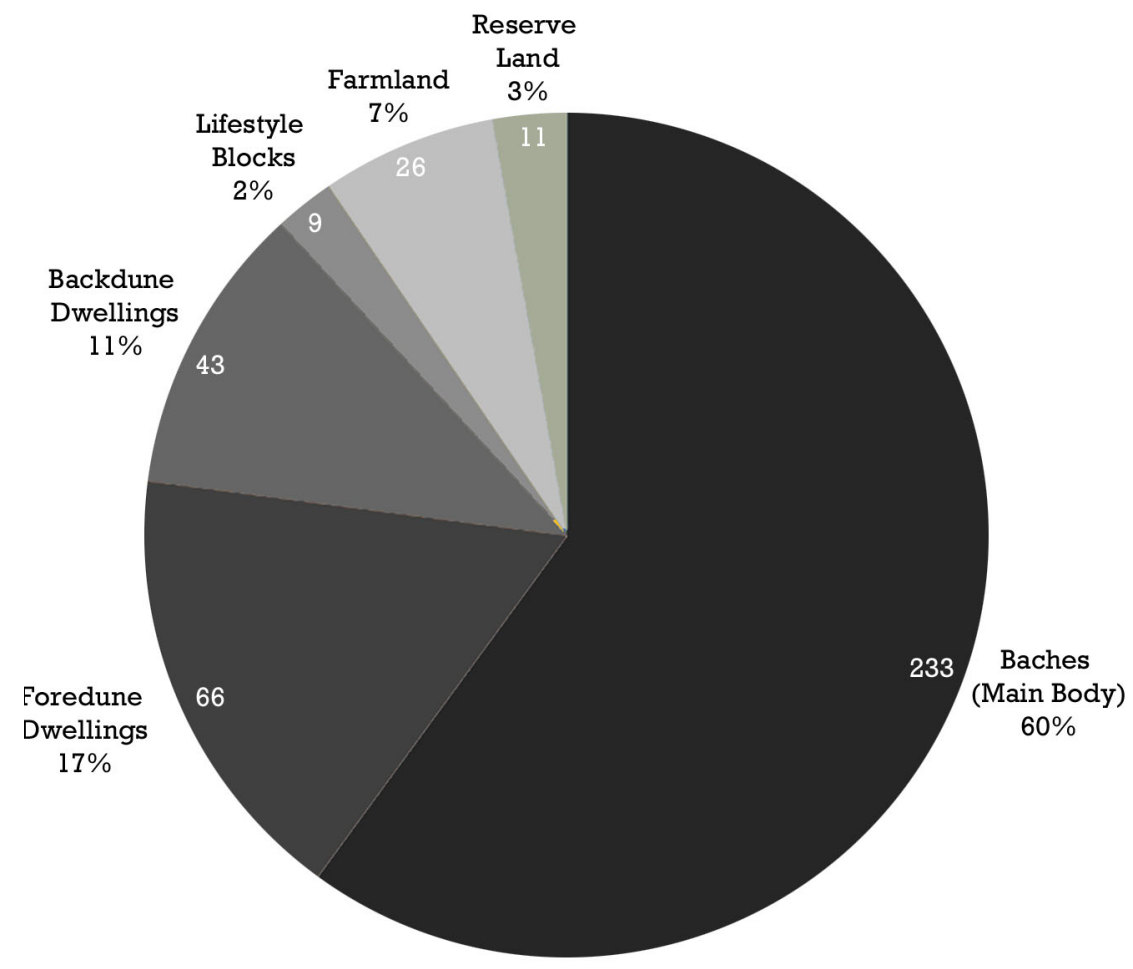

Figure 73 Number of plot typologies

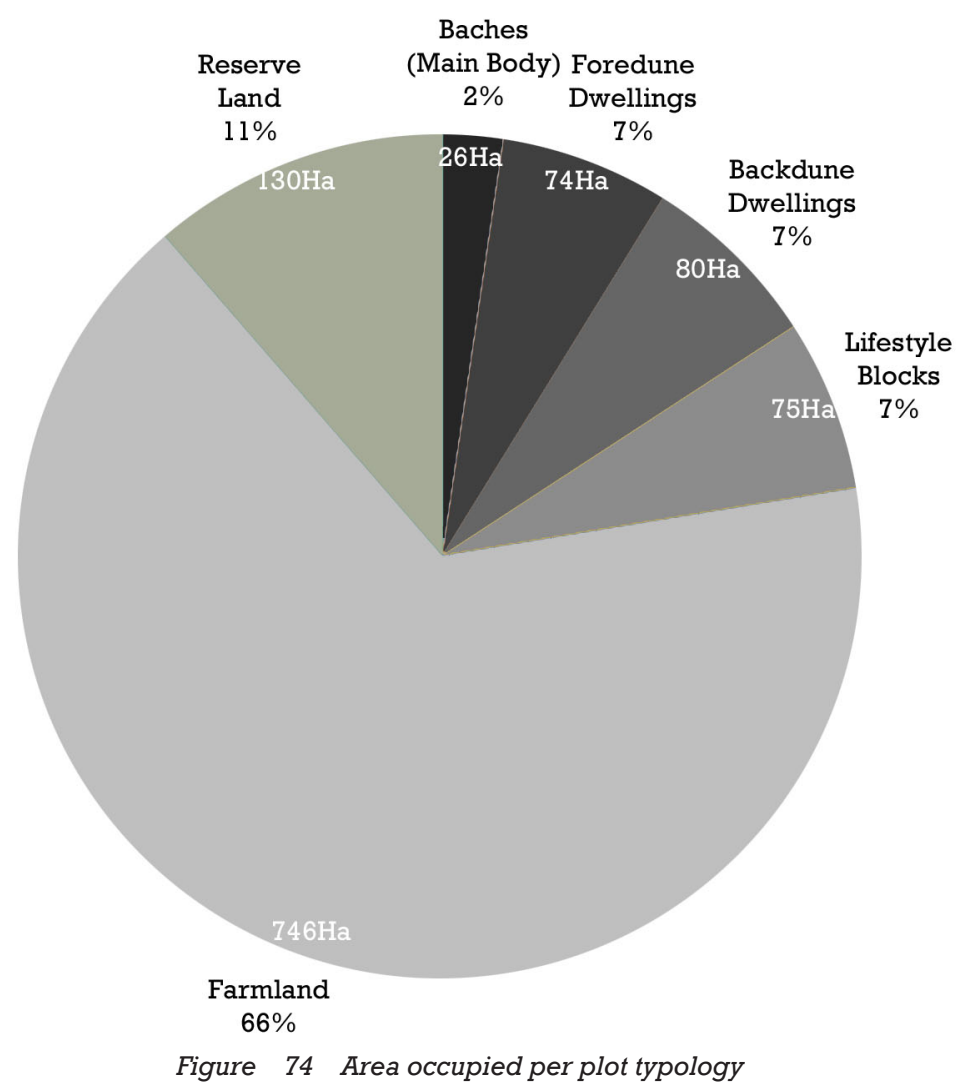


Due to small size, and unstable populations, Waikawa fails to be self-sufficient. Approximately $75 \%$ of dwellings are secondary; leaving only 60 houses permanently occupied (Land Information New Zealand, 2014). This means large amounts of land are dedicated to unoccupied houses, situated in unstable areas and resulting in continued upkeep and maintenance (Fig.75).
Locally, Levin and Otaki which lie North and South respectively, provide residents of Waikawa with basic needs. Beyond this, the most significant settlements are Wellington and Palmerston North. It is likely that these cities are home to many of Waikawas' home owners (Fig.76).

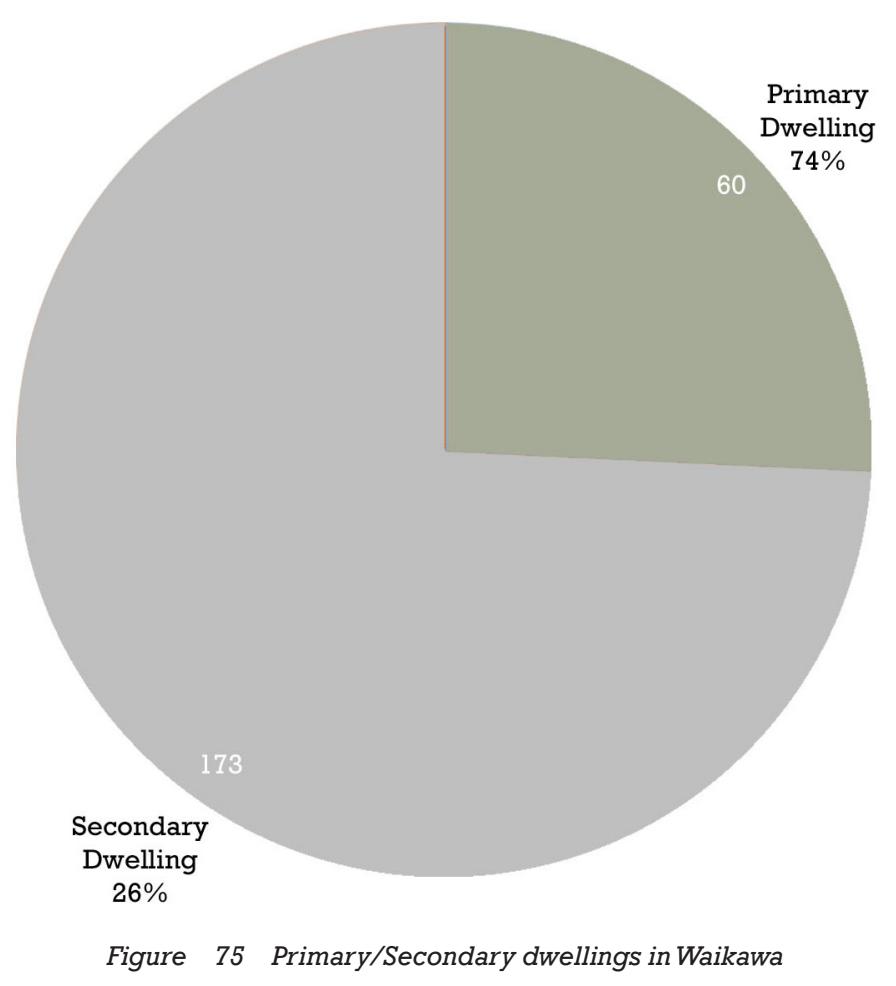




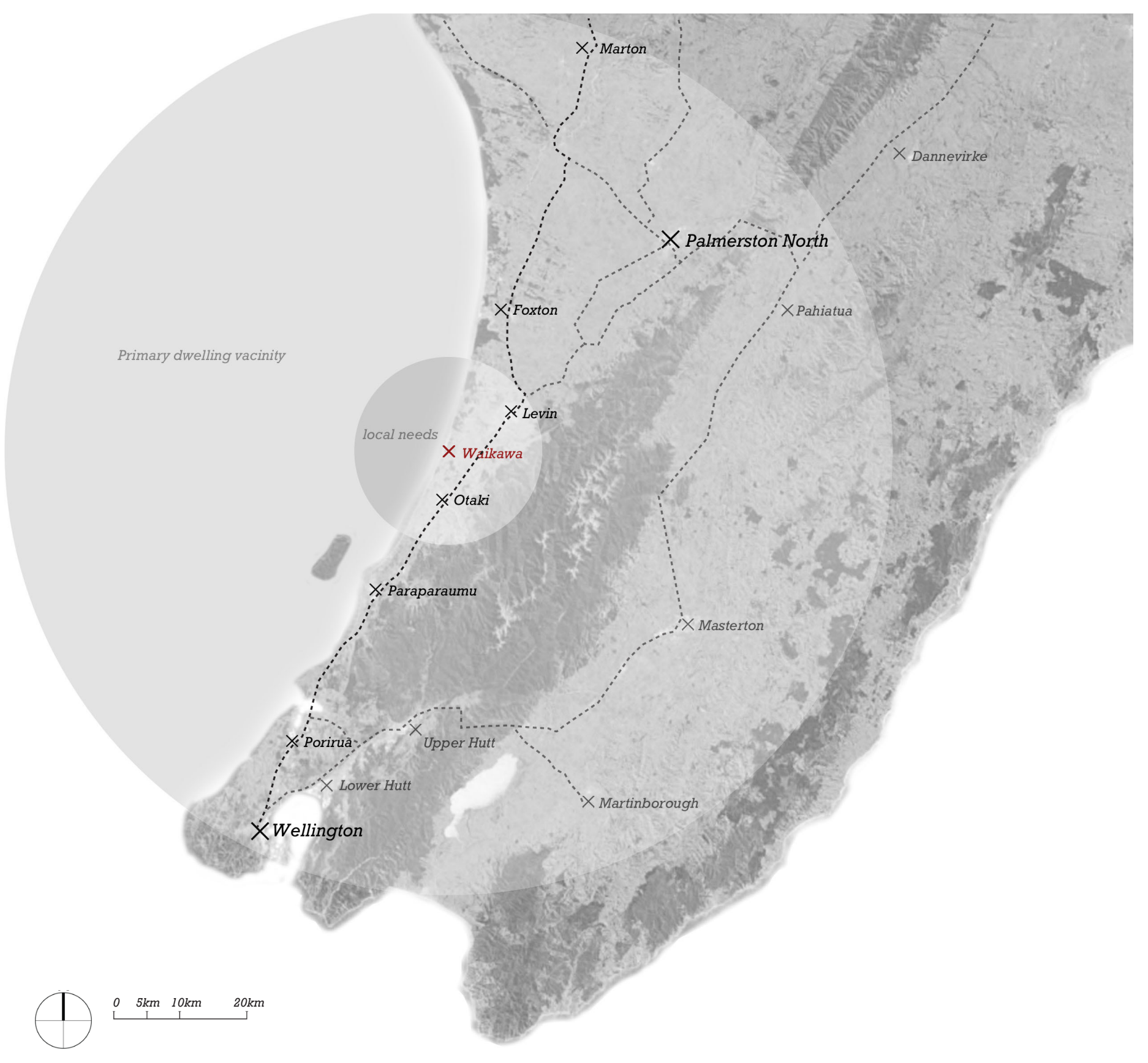

Figure 76 Surrounding settlement relationship 
The fabric of Waikawa is highly monotonous; there is minimal public space, street hierarchy, or sense of centre (Fig.78). A small basketball court and picnic areas are the sole community areas (Fig.77). The 'real' value in Waikawa is the amenity and aesthetic qualities the landscape provides; features such as the river, and rolling dunes bear considerable worth to residents. The Horowhenua District Council plans to extend development to the North and South of the settlement, and in all likelihoods enlarge the problems associated with settling unpredictable land (Horowhenua District Council, 2008). (Fig.79)

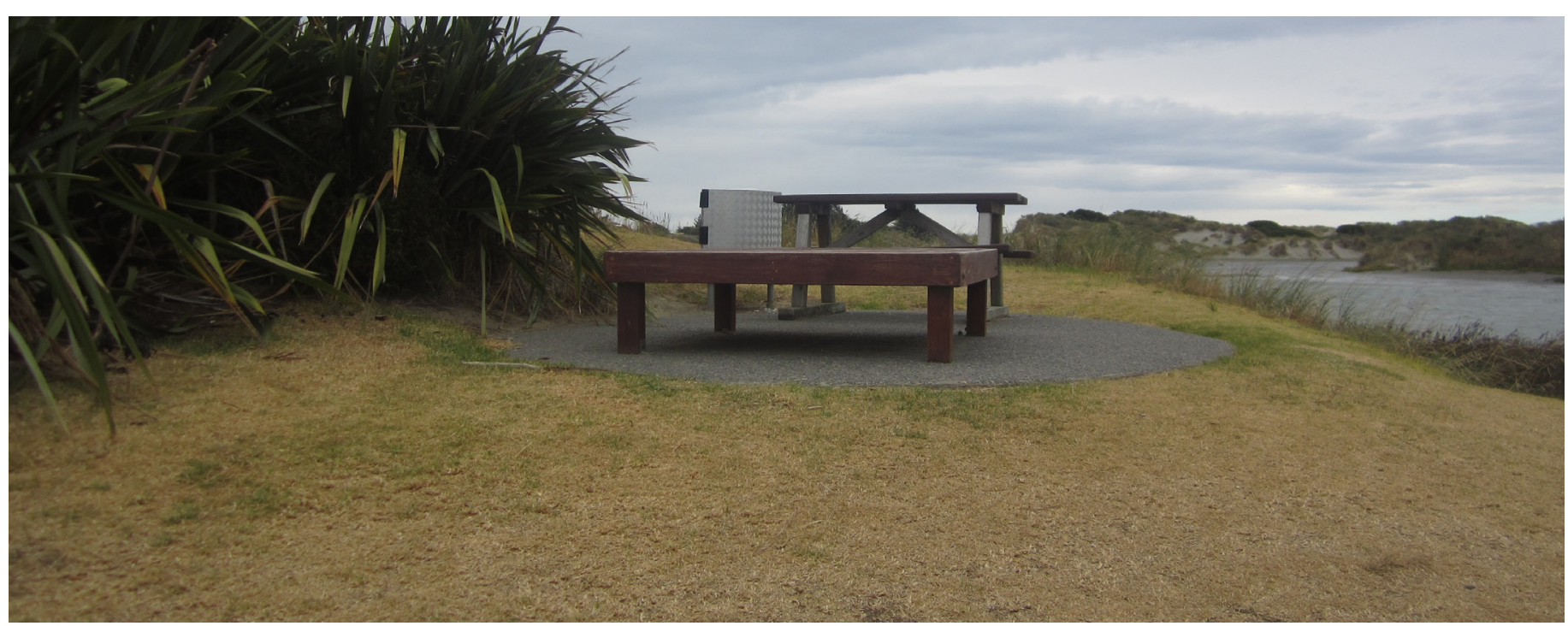

Figure $\quad 77 \quad$ Picnic area at Waikawa beach

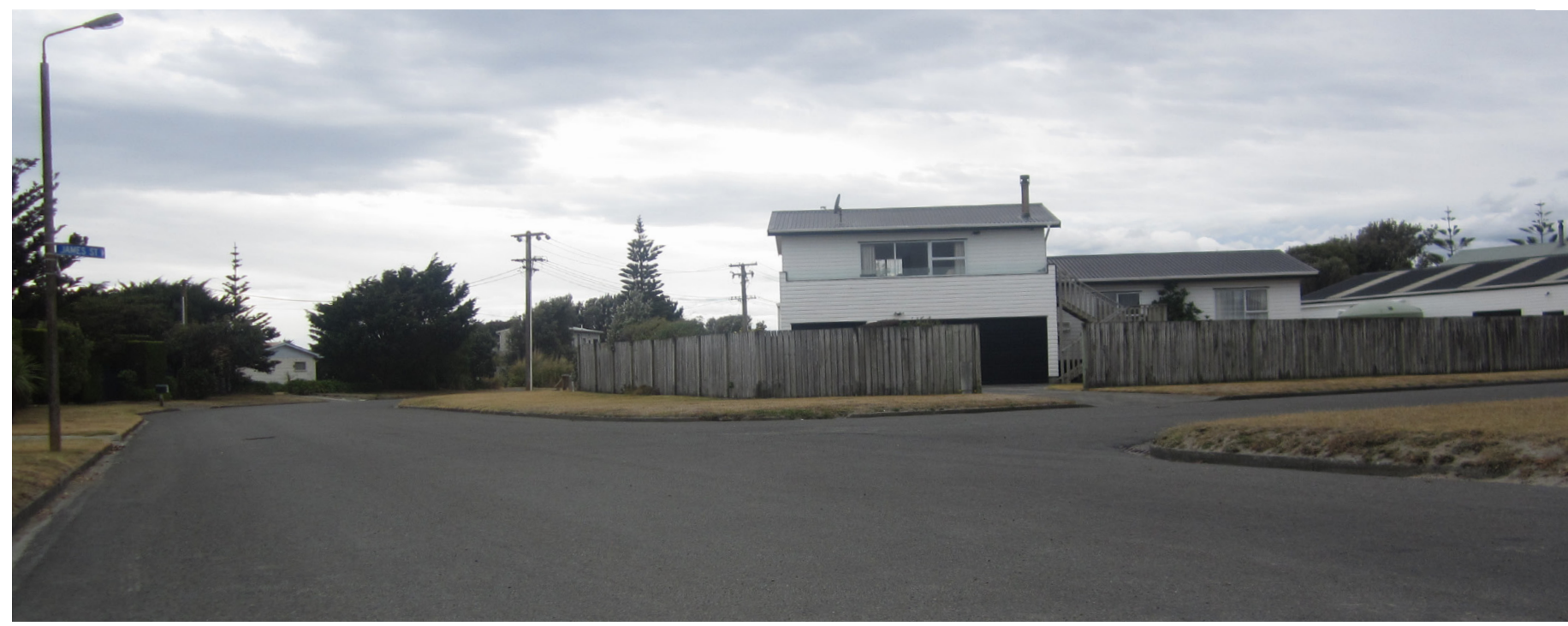

Figure $\quad 78 \quad$ Typical 'grain' within Waikawa streetscape 


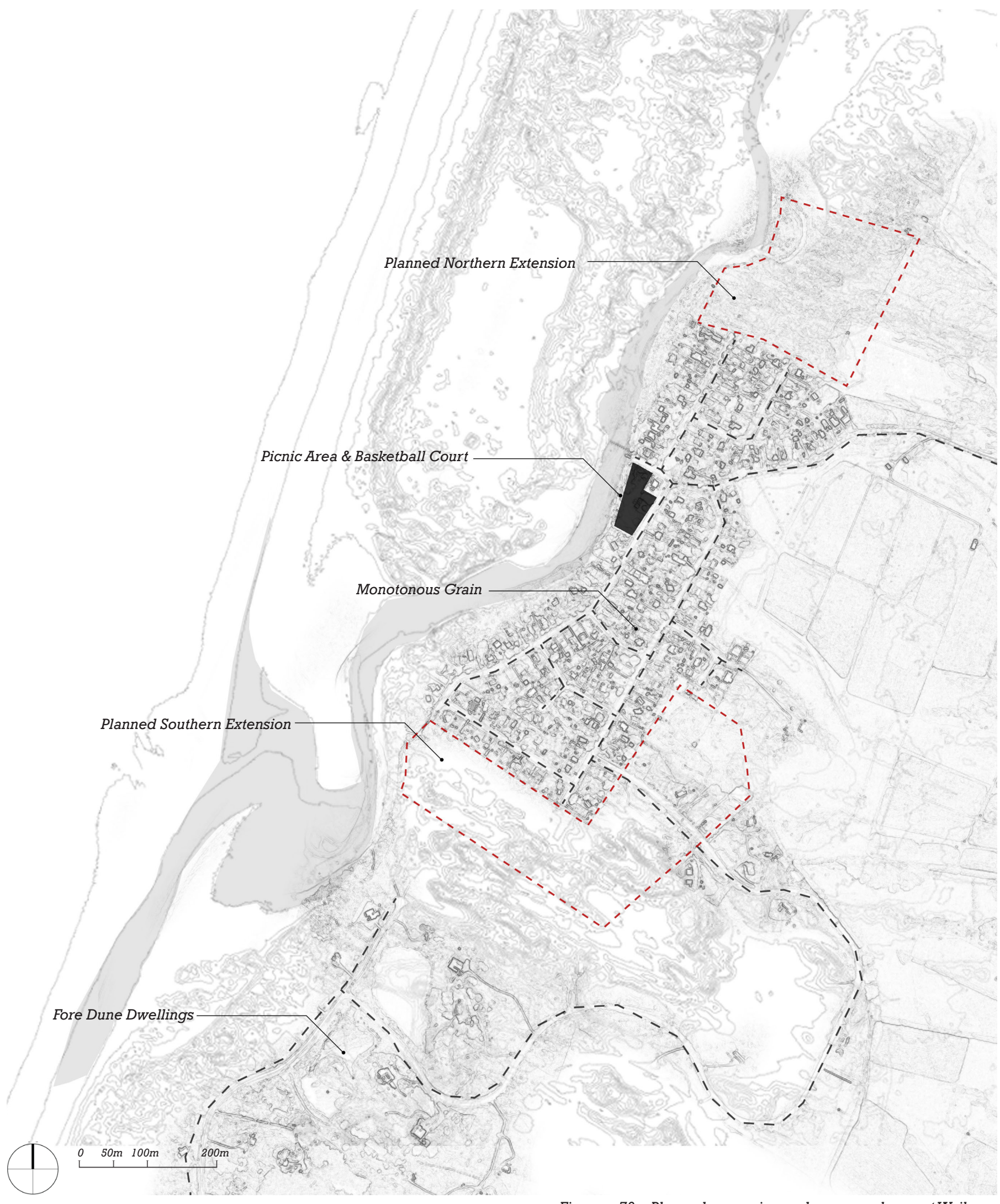


This section explores how applied settlements might be able to directly respond to movements of the landscape using knowledge of coastal processes to predict change. How might the way we organise our settlements enable us to cope with this change? 
In applying settlement to Waikawa which runs in tandem with movements, it is important to recognise stable land is not absolute. These images show the pattern on Waikawa ideal for 'traditional' application. The lands in these areas are flat, but surrounded by moving components of the landscape, the two most predominant of these are the fore dunes, and the unpredictable river. Awareness of these elements may allow planning to plot out suitable areas to settle. The lower reaches offer plenty of ideal space, but are susceptible to rapid change (Fig.80). Ideal land is patchier in the upper reaches, but it less likely to alter (Fig.81).

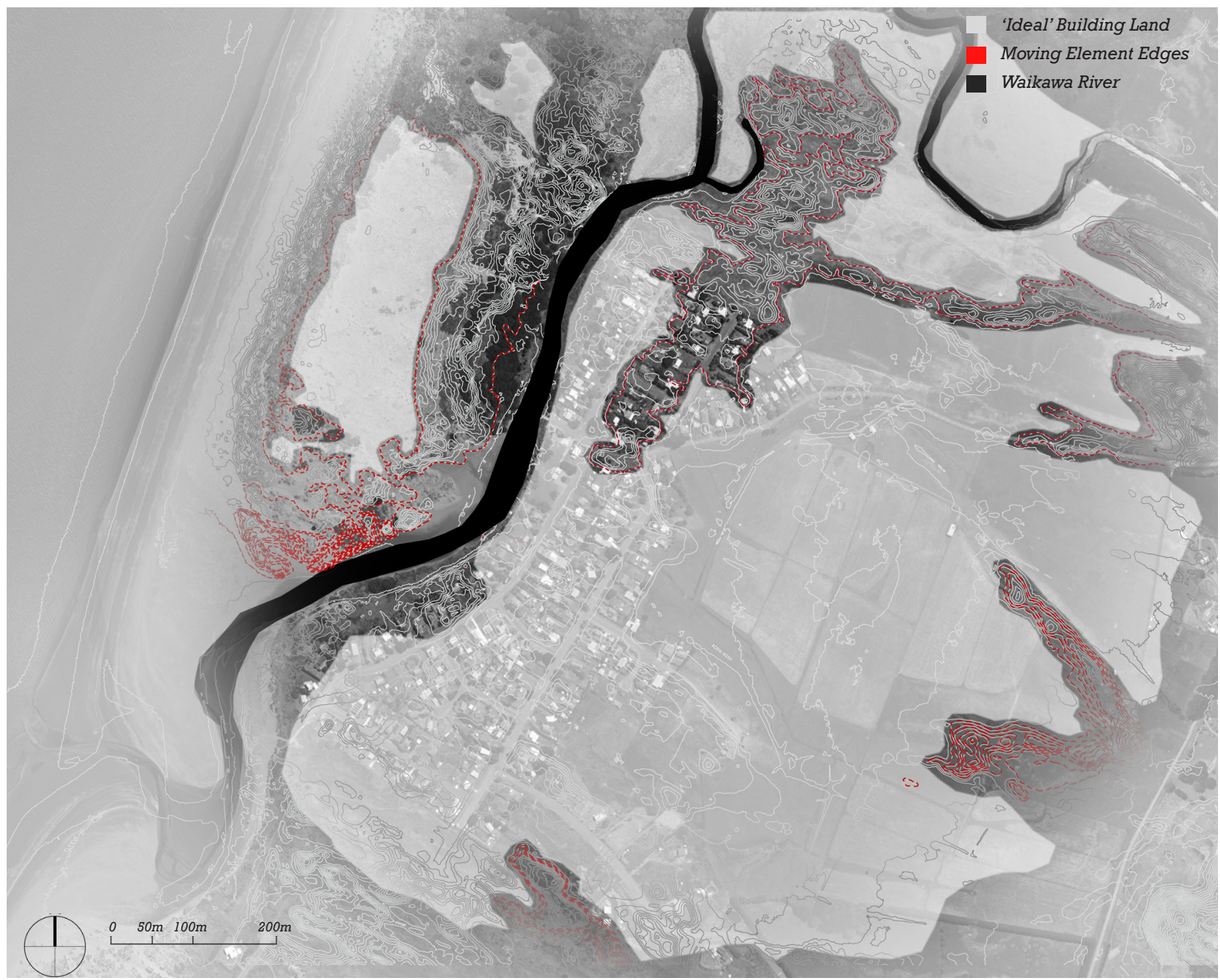

Figure 80 Ideal building land within Waikawas' lower reaches 


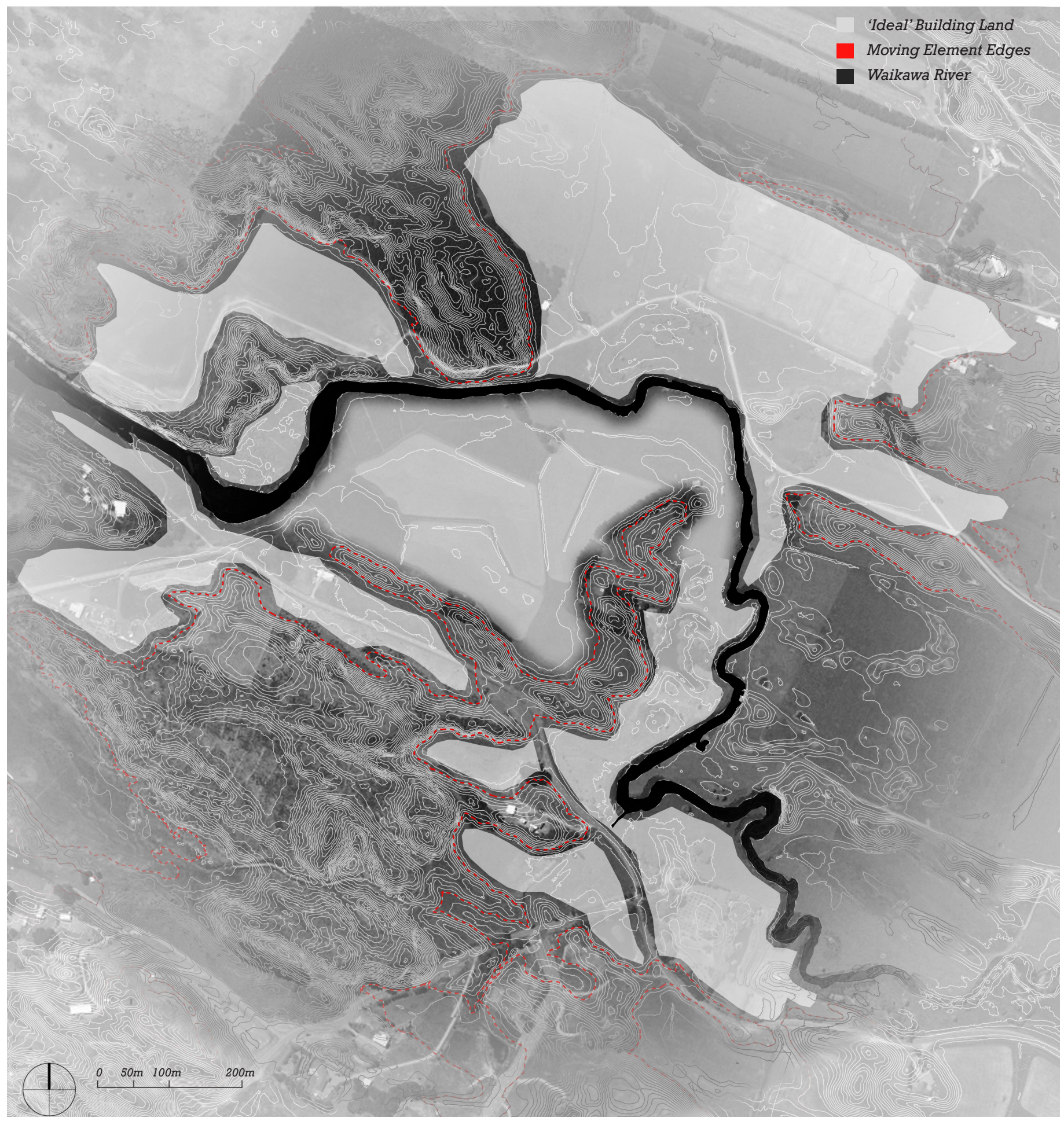

Figure 81 Ideal building land within Waikawas' upper reaches 
Employing basic knowledge of how components move allows exploration into how communities might be organised. Using predictions of dune migration, typologies of settlement can be massed amongst dunes based on the expected longevity as a suitable zone for occupation. This attempt places three distinct zones between dunes. The 'habitable', the 'sacrificial' and the 'anticipated', which act as a gradient that mirrors the temporality of the land. (Fig.82,83)

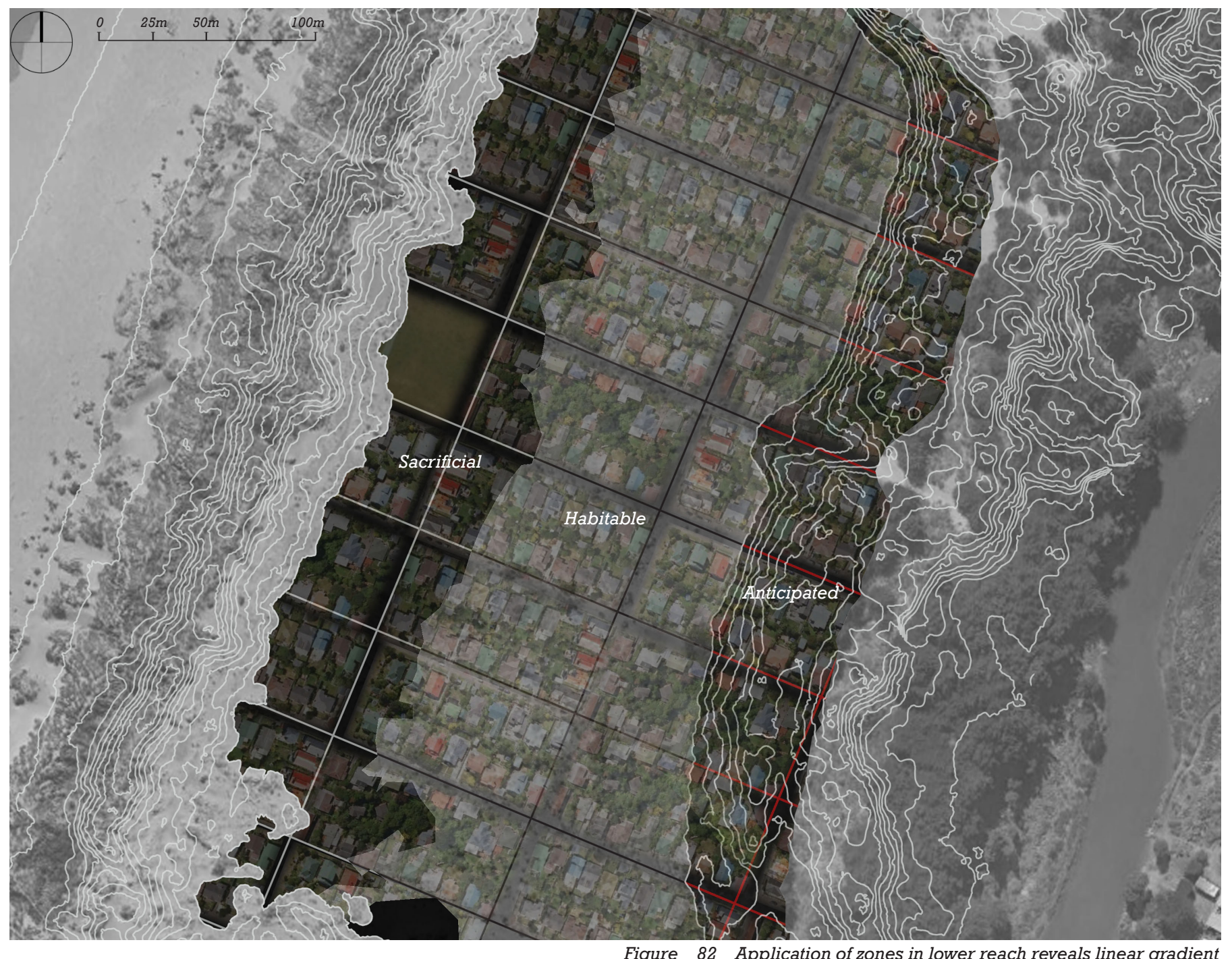




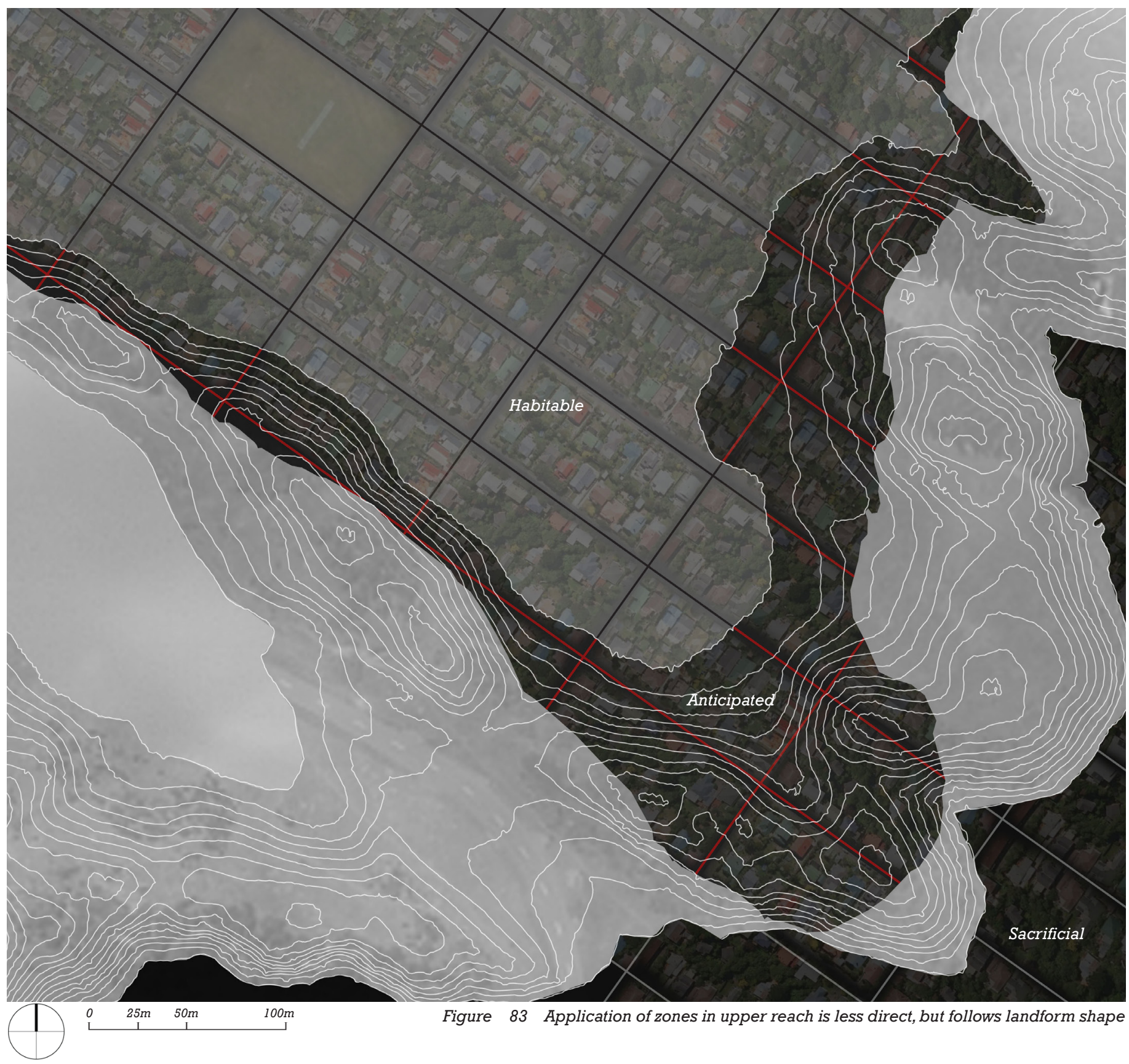


Habitable: Land furthest from active dunes, these areas are placed away from the path of foreseeable movement. Permanent facets of settlement such as sealed roads, and dense residential areas reside here (Fig.84).

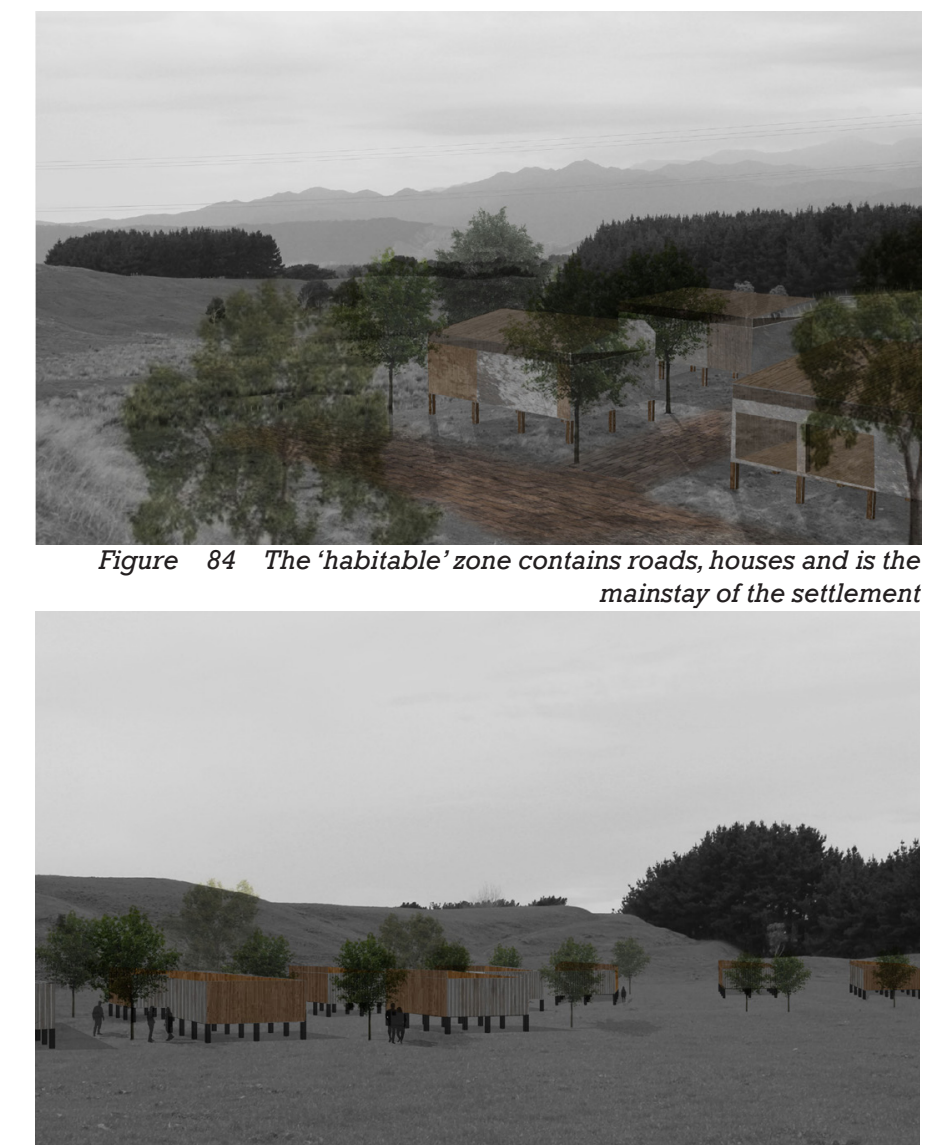

Sacrificial: Located adjacent to dunes and in their path of movement. Temporary structures may inhabit this space, but these areas would likely serve as recreation areas (Fig.85).

Anticipated: These areas are occupied by active elements, and cannot be settled. Expected migration or diminishment allows them to be 'planned' for, making them reliant on expected growth of habitable zones (Fig.86).

Figure 85 The 'sacrificial' zone houses impermanent structures and is predominantly recreationa.

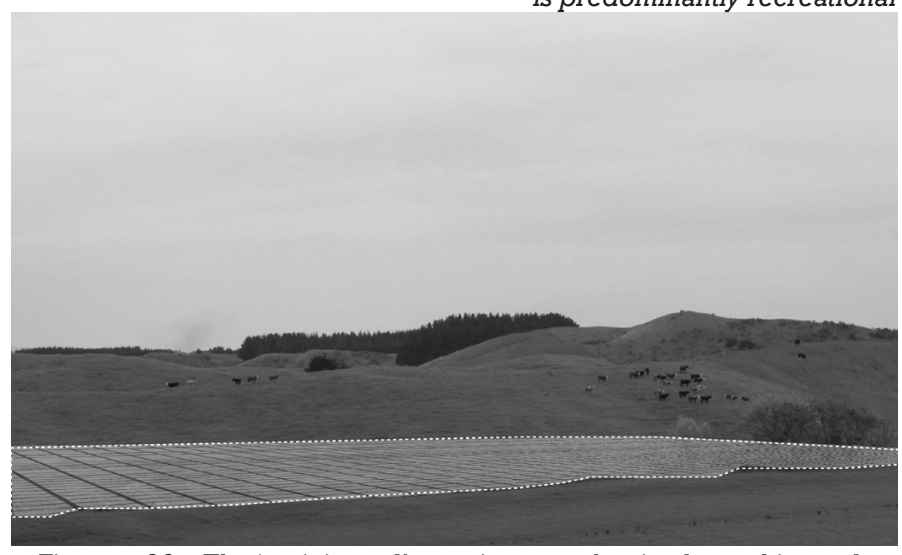

Figure 86 The 'anticipated' zone is empty, but is planned in tandem with habitable zones for expected future use 


\section{Evaluation}

Settlements designed under a 'gradient' method could continually morph to the shape of the land, maintaining access to the coast (Fig.82). However there is significant uncertainty involved, as parts of the landscape which move unexpectedly could nullify planning. This response does not cater for unpredictable events such as Earthquakes or tsunamis which have high damage potential. There is also no defined 'centre' to these settlements, which could tie communities to sites and would be useful in the event of disaster, as well as creating a reference point to the community, preventing sprawl which could eventuate under this method. 


\section{Alternative Concept Design: Cores}

This concept approaches issues within the previous concept, namely the lack of identity, and communal heart. This segment investigates the use of 'cores', situated in stable land, used as hubs for communities. Cores would position settlements in a protected manner and safe-house provisions. 
Defining the 'core'

Character: Distinct/Recognisable elements within the landscape/settlement which coherently tie the site together.

Relationships: Stable set of associations remaining constant despite other changes within the landscape/ settlement.

Origin: Expansion point of settlement. Generally pertains to some significance or use to the community such as a water well (Fig.88).

Heart: Site on landscape/settlement which holds particular communal value and activity (Fig.87).

Foundation: Underlying base of settlement which remains stable, while other components are comparatively temporary.

Refuge: Place of retreat in disaster events. A refuge may be a safe-haven and place where rebuilding can occur.

Intersection: Point where several elements of the landscape/settlement meet and all share in common.

Core is a notion of centrality, a place from which settlement is founded and expanded from. A core should bare communal significance, providing amenity and guaranteeing safety. Each definition describes an aspect of what 'core' means. 


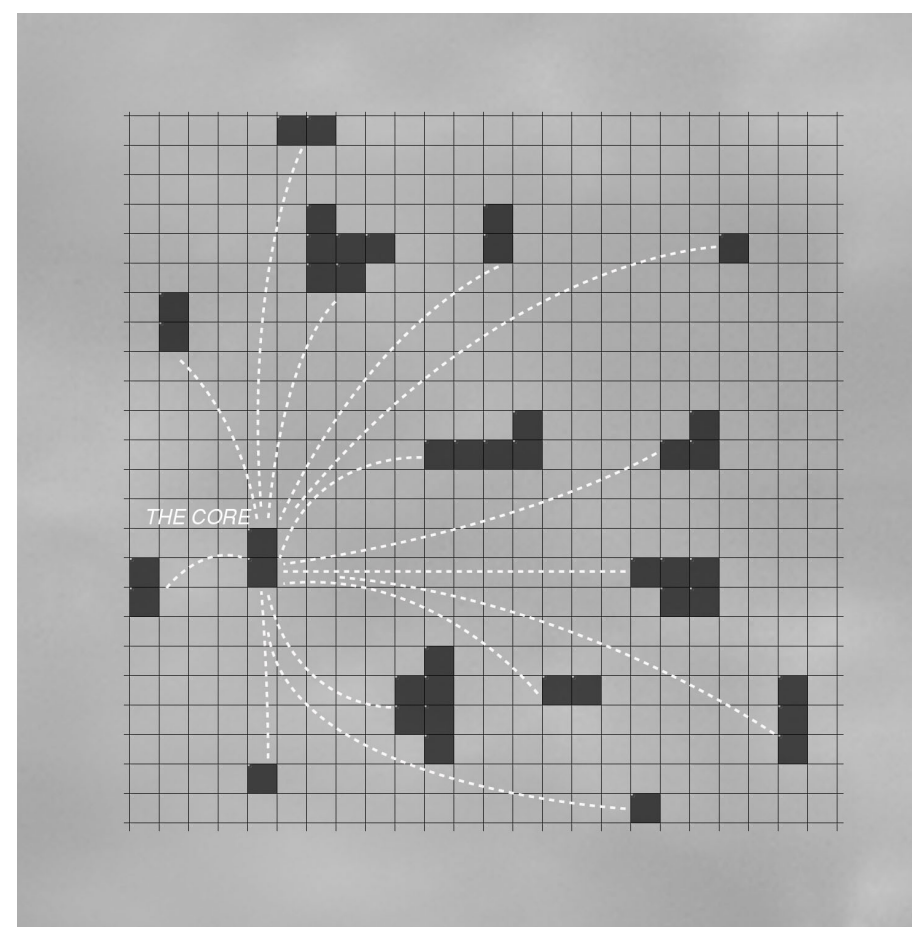

Figure 87 The 'core' as communal heart to settlements

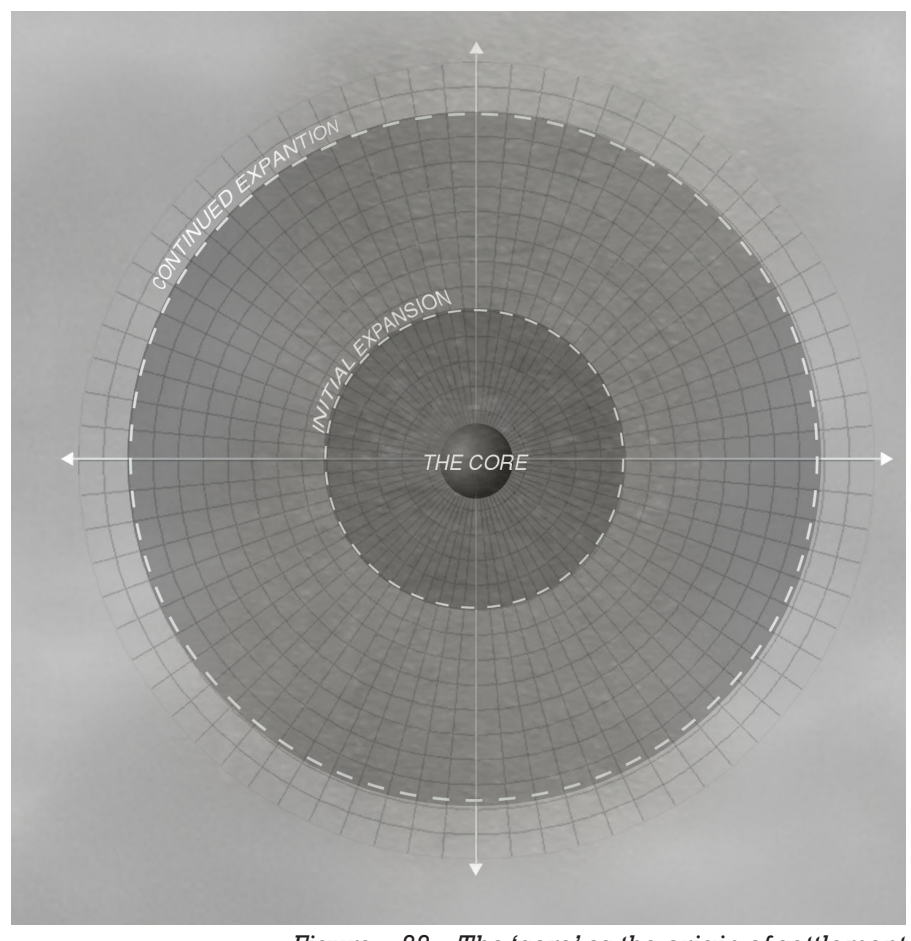

Figure 88 The 'core' as the origin of settlement 
A founding location and place of refuge relies on a stable base. Landscape elements on the coast, however are rarely stable. This map shows elements within segments of the coast, with potential to be used as an origin for 'cores' (Fig.92). Most stable, are inland parabolic dunes; now covered in vegetation and at a safe distance from the shore. (Fig.91)
The height of these remnants makes them ideal for protection, where in the event of disasters, can act as gathering areas, visible from the lowland. In the unlikely event of parabolic dunes moving slightly, the system of cores is still present, preserving the relationship, and maintaining recognition of points as refuges (Fig.93).

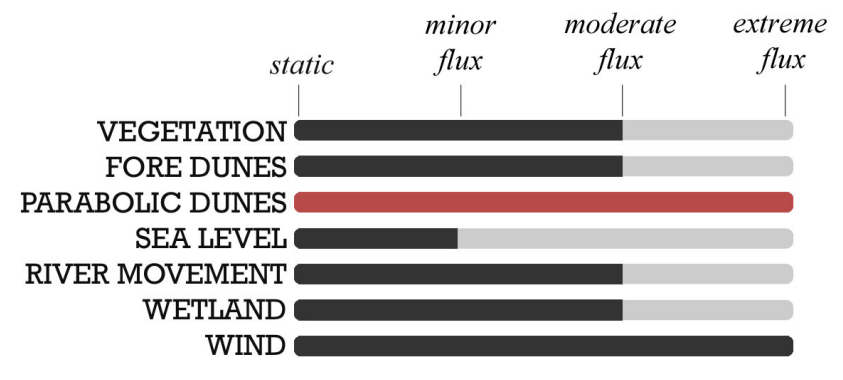

Figure 89 Element movement at the shoreline
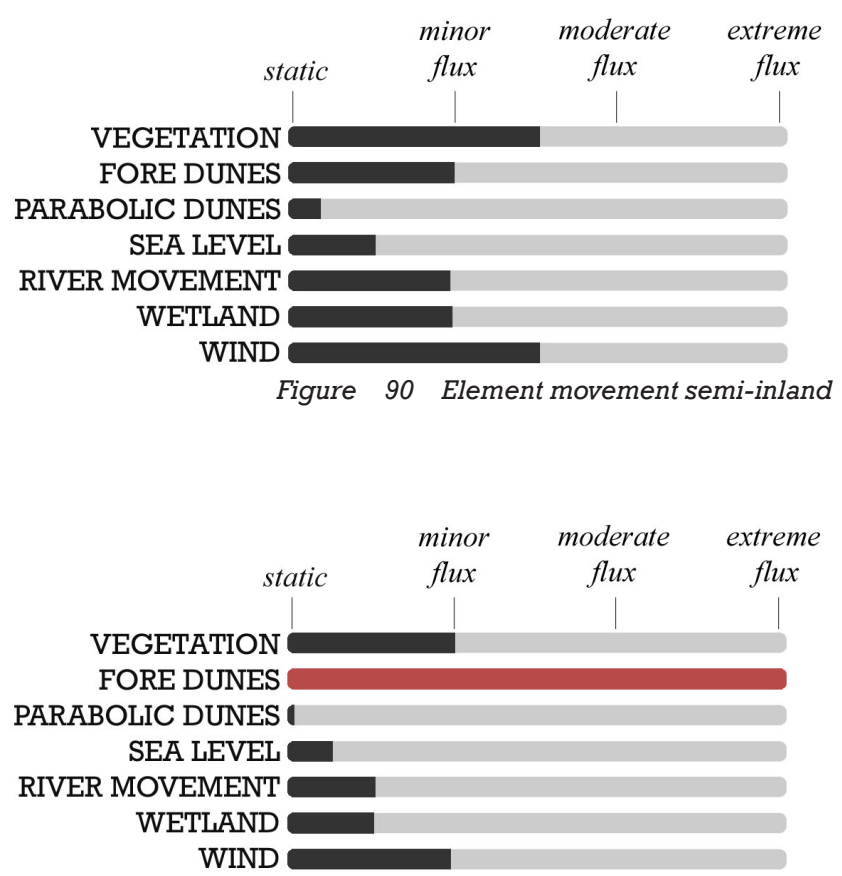

Figure 91 Element movement inland 


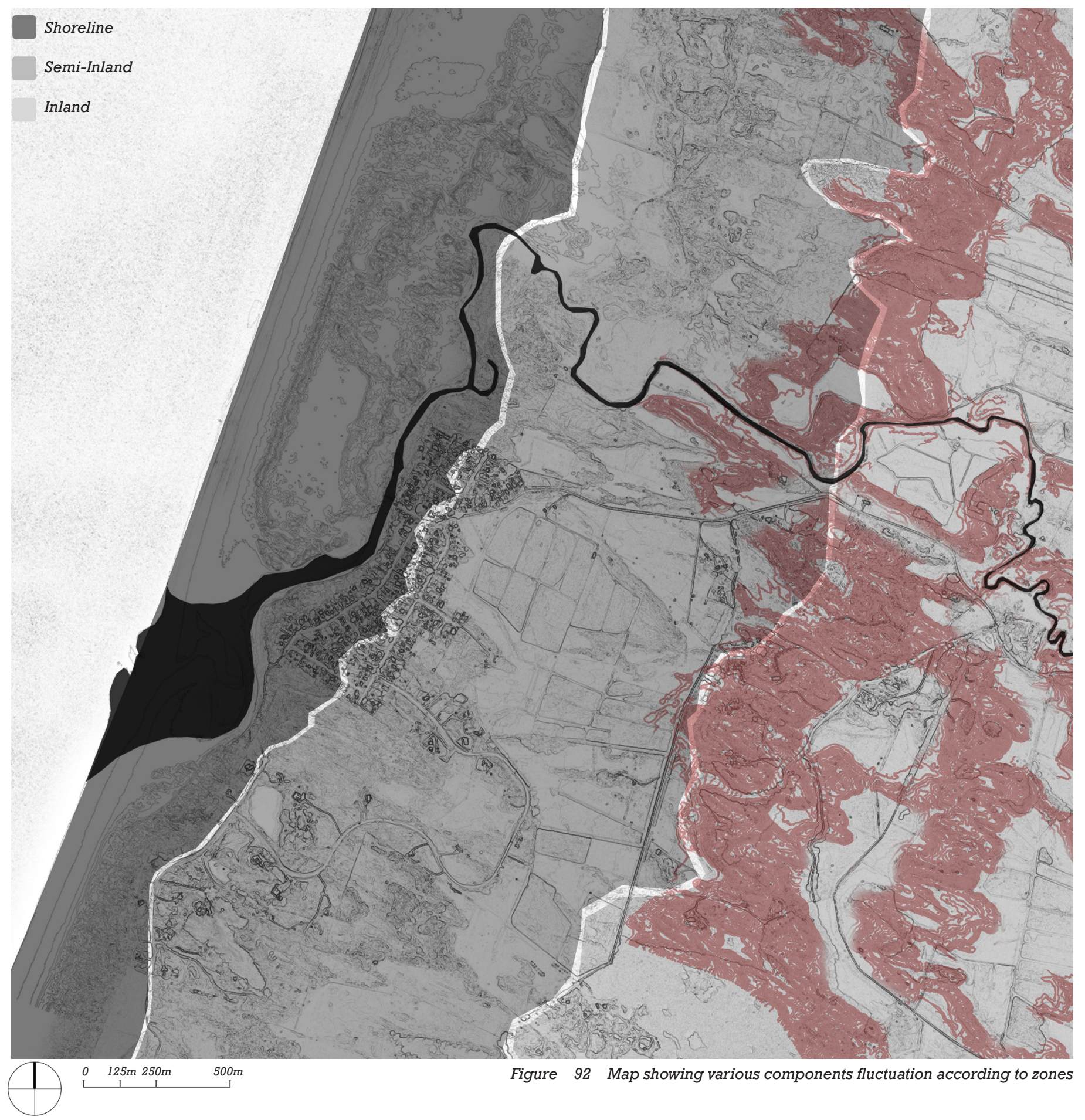




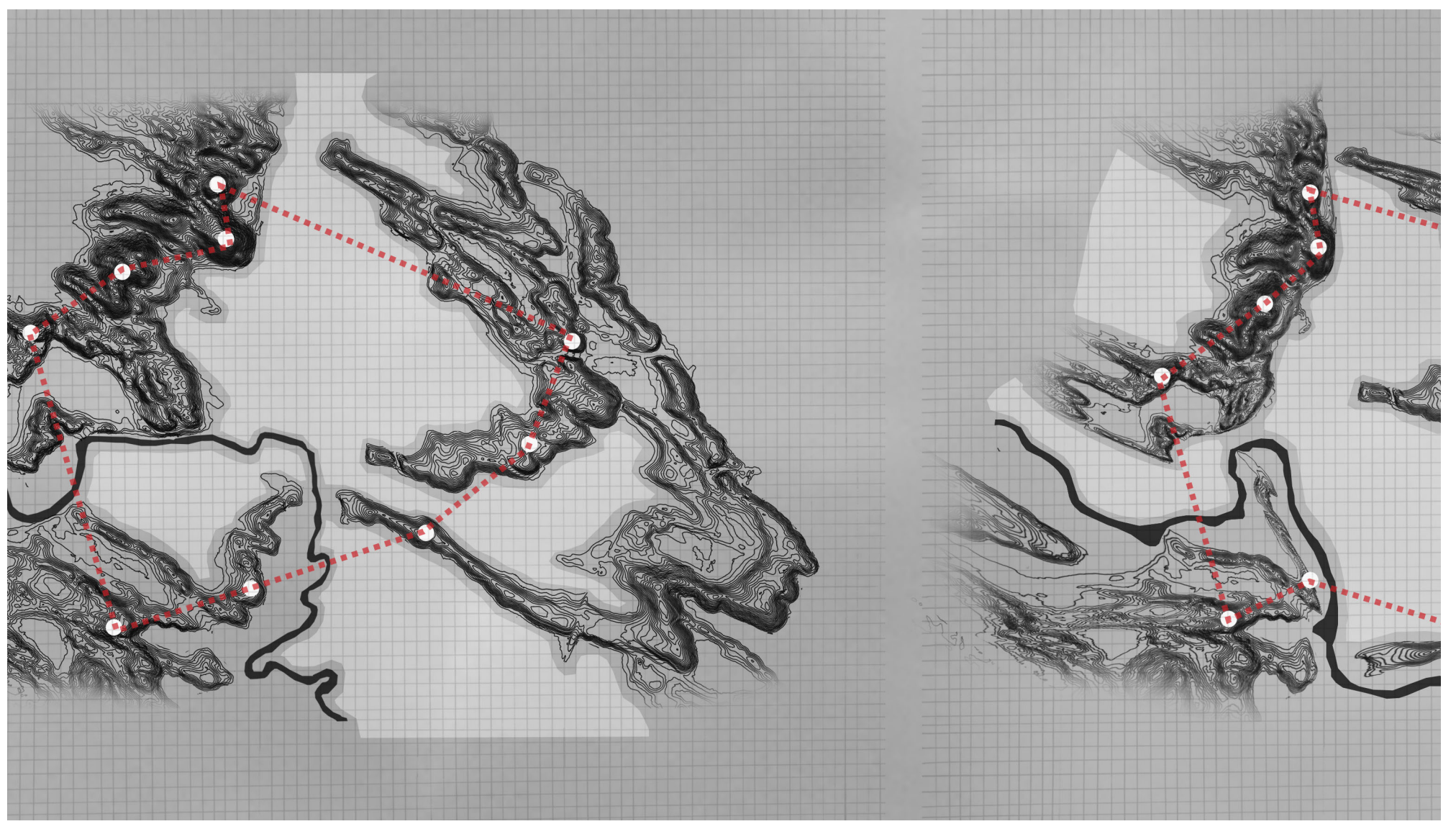




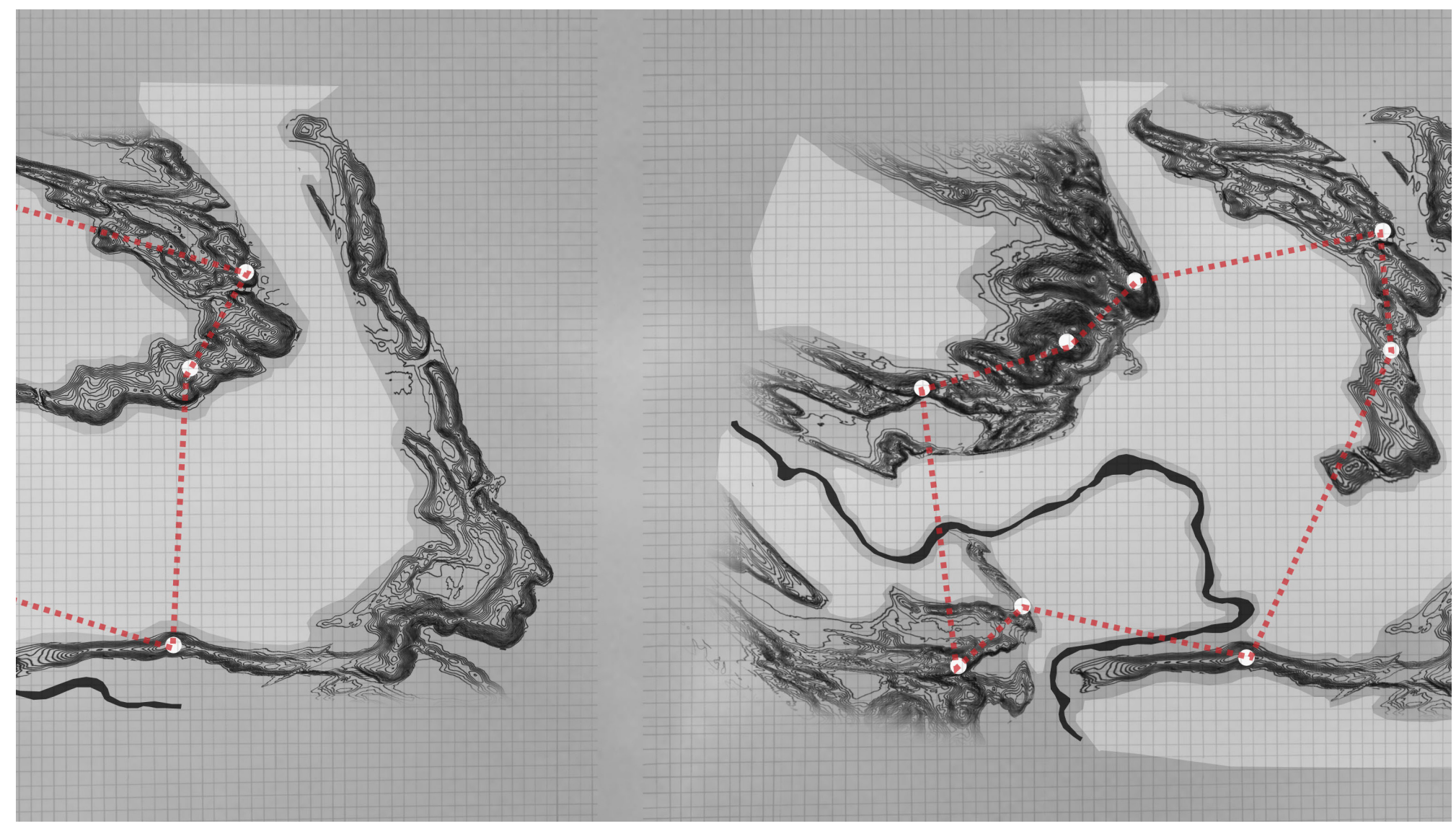

Figure 93 Diagram showing how with slight change the relationship between cores is still preserved 


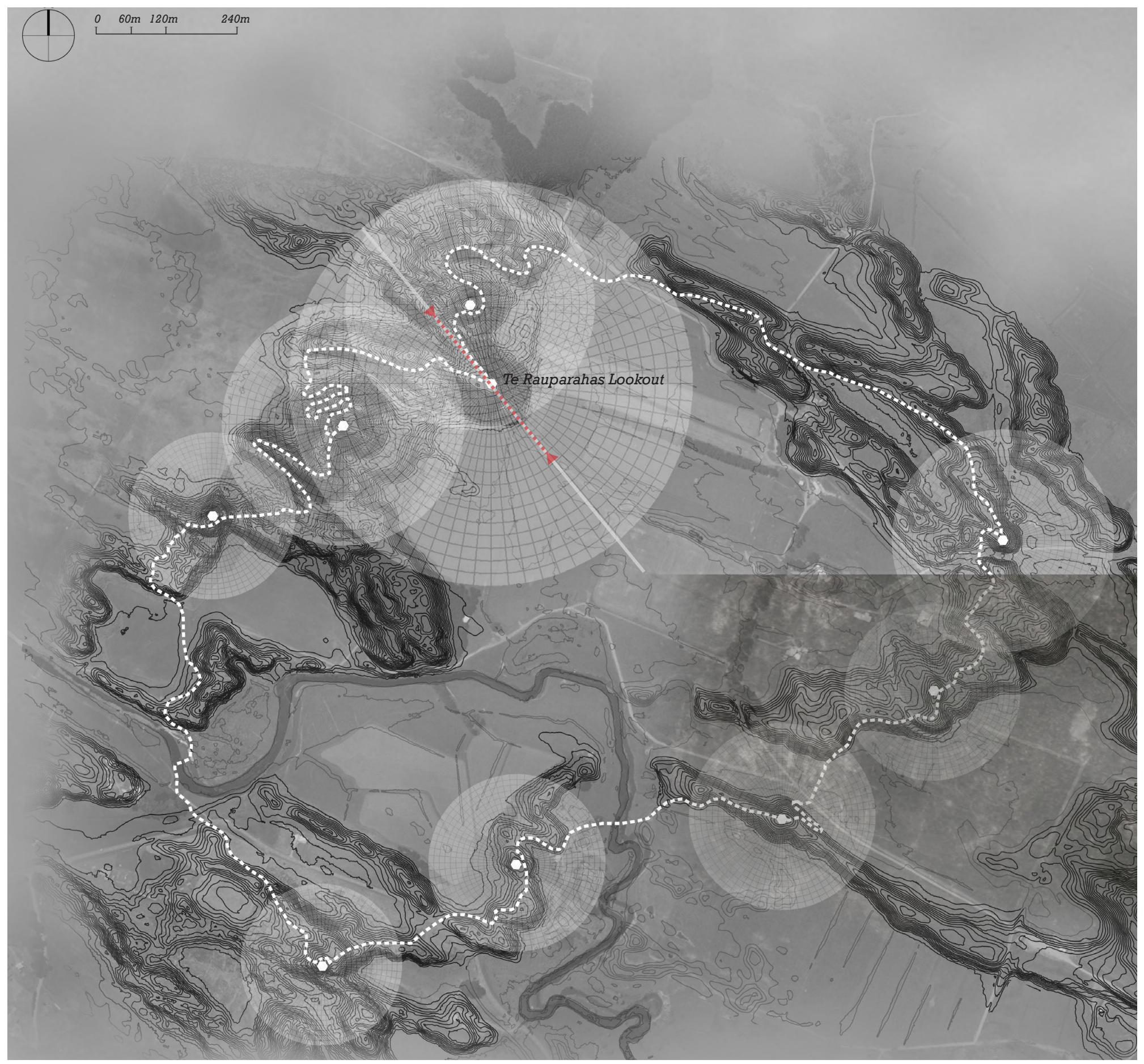


Here, the implemented notion of core is applied to Waikawa, two kilometres inland. This area hosts a number of impressive parabolic dunes and lower ground planes. Cores are situated on notable summits, evenly spaced along the network of remnants. These points join, creating an arrangement which surrounds ideal building land below (Fig.94). From each point a border is formed from which residential areas can extend. Larger points, coupled with vast building land make for a larger periphery. The largest of these is a
30 meter dune, known as 'Te Rauparahas lookout'. This arrangement makes the fabric from which settlement forms. In the event of disaster, such as a tsunami, these points are refuges, remaining safe along a network which link cores together. On an 'everyday' basis these cores provide use to the community, a series of lookouts and a connecting walking track in this case; however they also store vital building material, food, water, and other basic necessities.

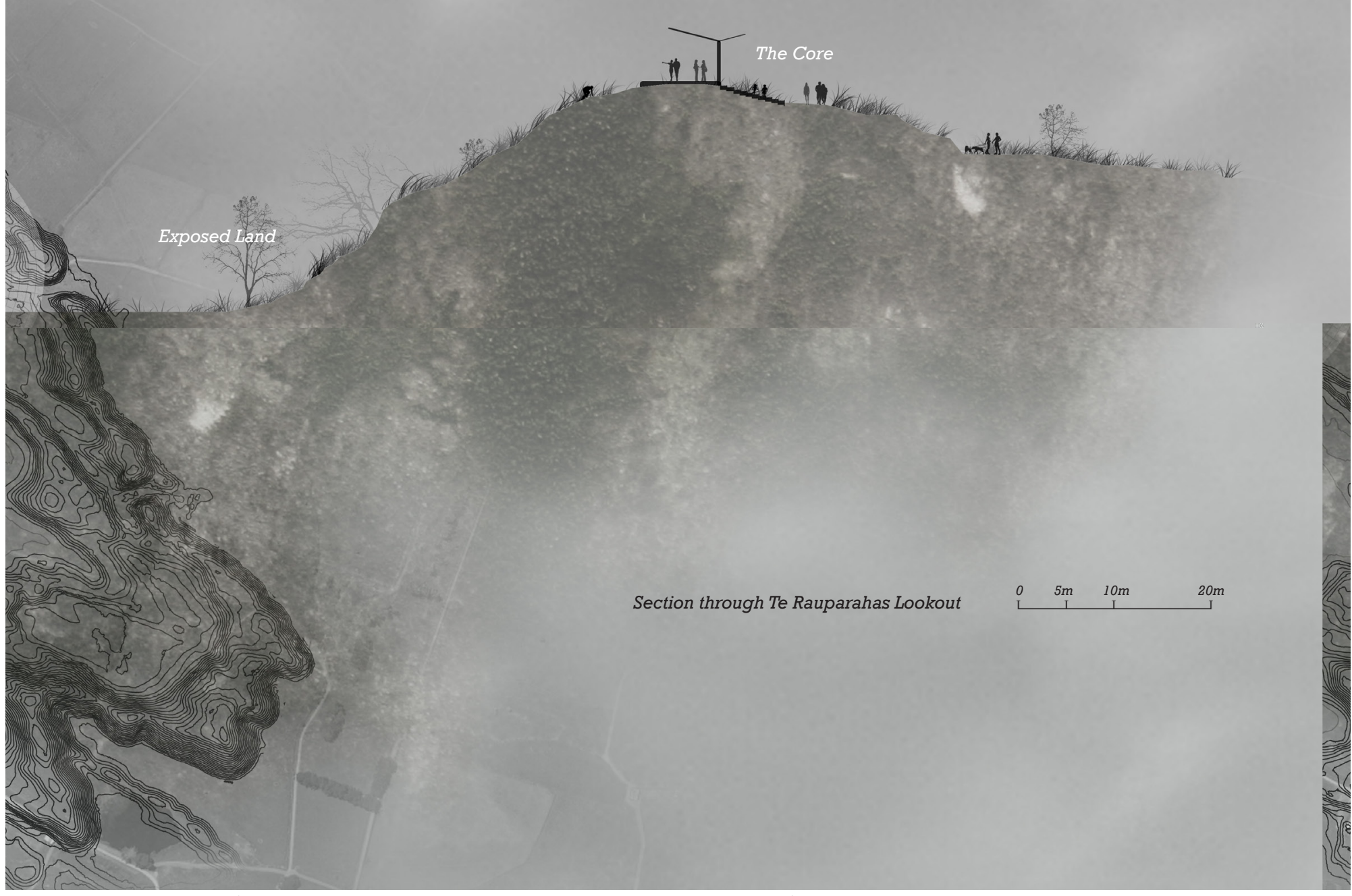

Figure 94 Plan of 'core' arrangement sets up areas which can be settled. Section shows core location as a point of safety, and use as a lookout 
Another possibility to make the cores more useful to the community, would be to use them for nursery space. On some of the more reasonable slopes, it would be possible to grow crops/flax/trees to use as building material. The growth of these along the less formidable slopes would allow acceptable ease of access to cores and protect crops from flooding which occurs at the surface (Fig.95).

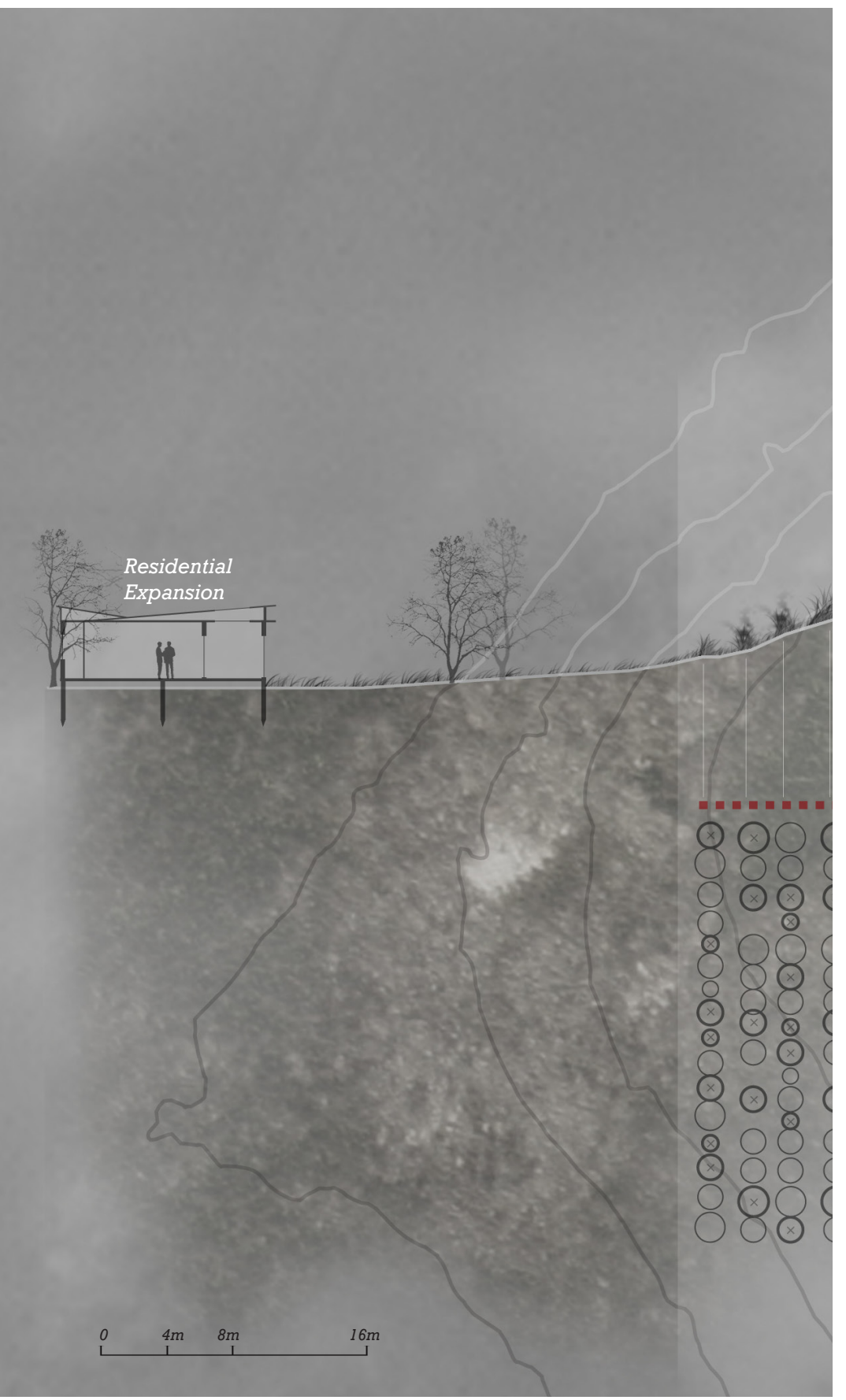




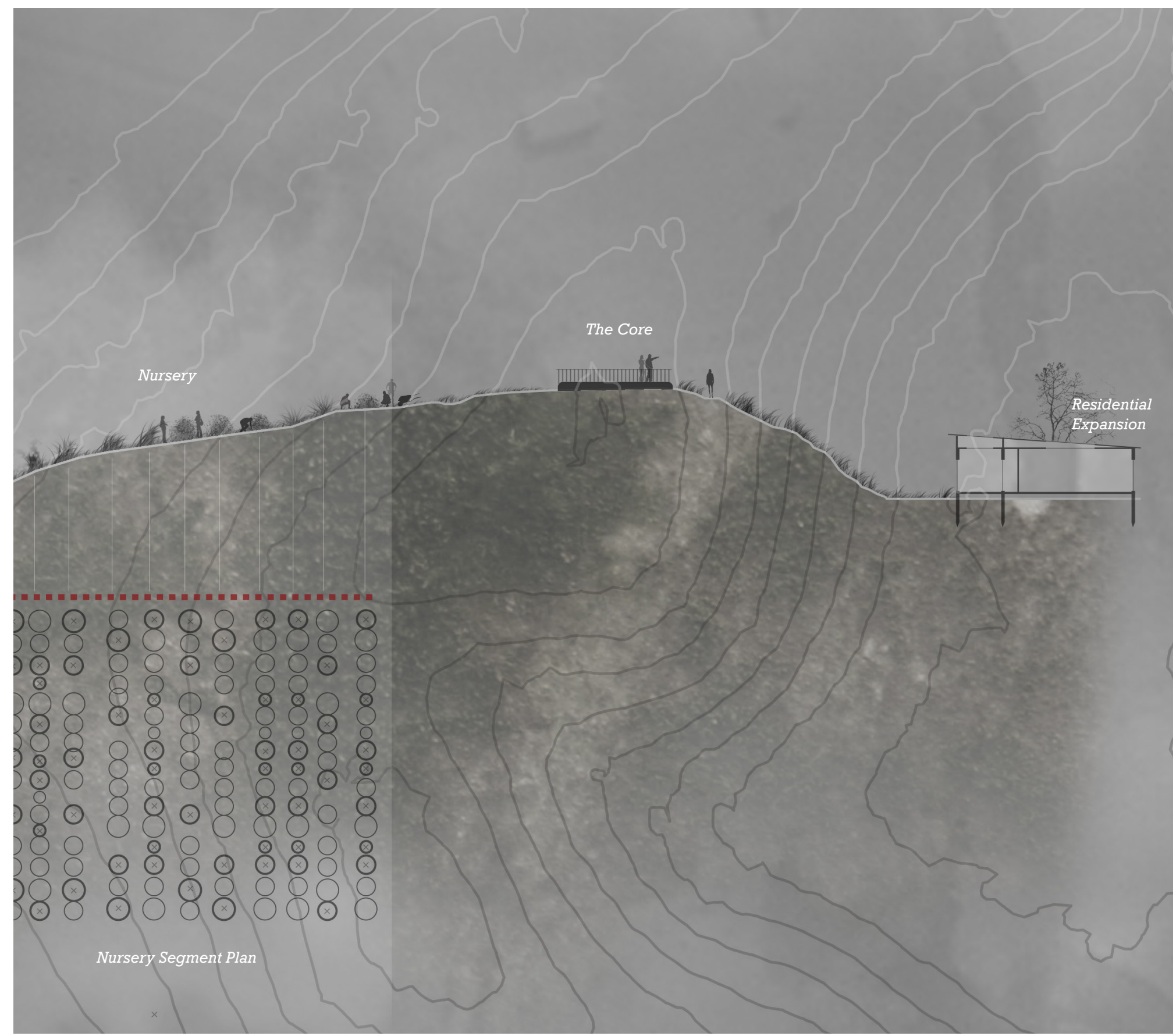

Figure 95 Section through typical parabolic dune. This remnant facilitates a lookout and small nursery 
The appearance of cores is derived from three key drivers. The most fundamental of which is the ability to store essentials such as material, food, and water. Secondly, it must be communally beneficial in ways

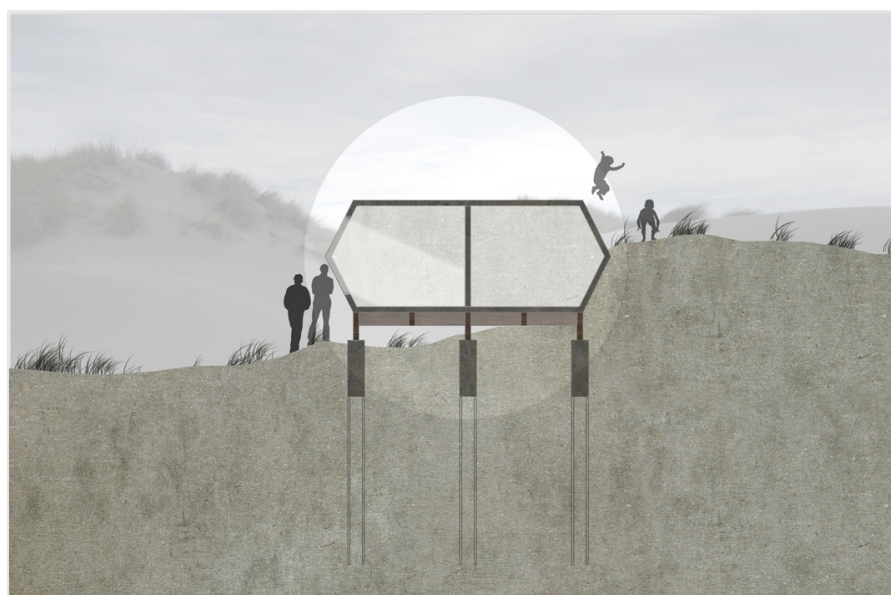

Figure 96 This iteration maximises easily accessed storage space, creating a recognisable form, and providing a surface with potential for acting as a meeting spot. The iteration suffers from lack of height

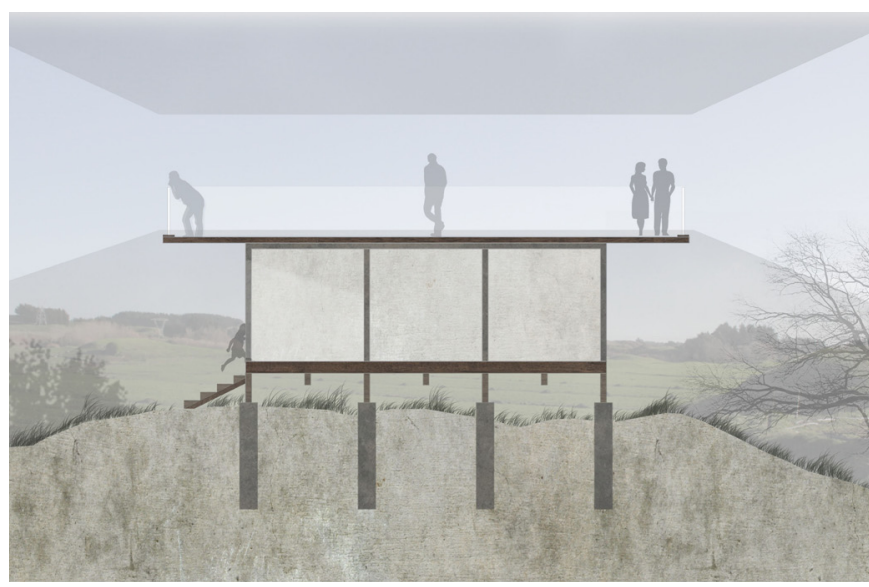

Figure 98 This version keeps storage space at ground plane, while utilising the top surface as a viewing platform. This compromises the structures prominence from afar excluding providing refuge. Finally, a core must act as a landmark, easy to recognise and useful in containing the expanse of residential zones (Fig.96-100).

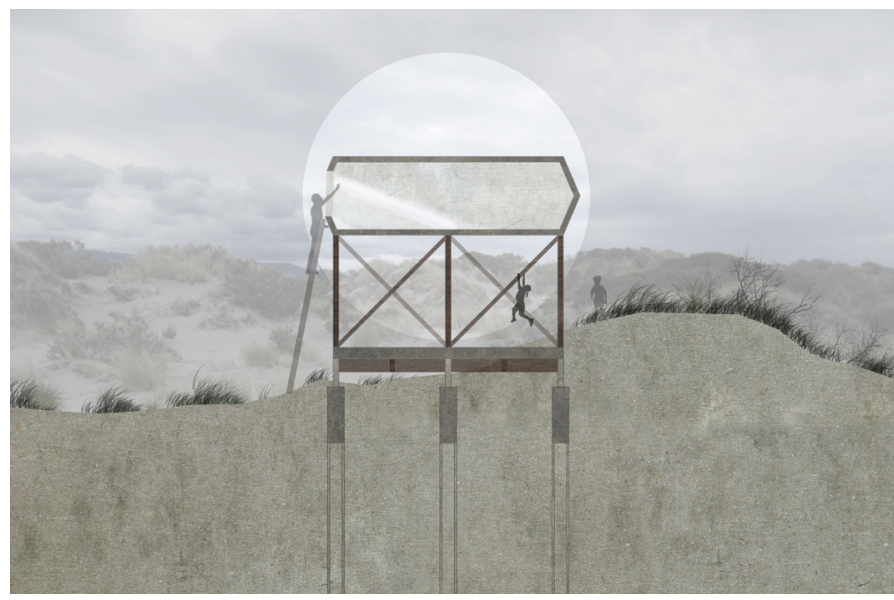

Figure 97 This design maximises visual availability, placing the bold storage space on columns and allowing space beneath for use as a shelter. Greater emphasis on the void would enhance this iterations visual dominance

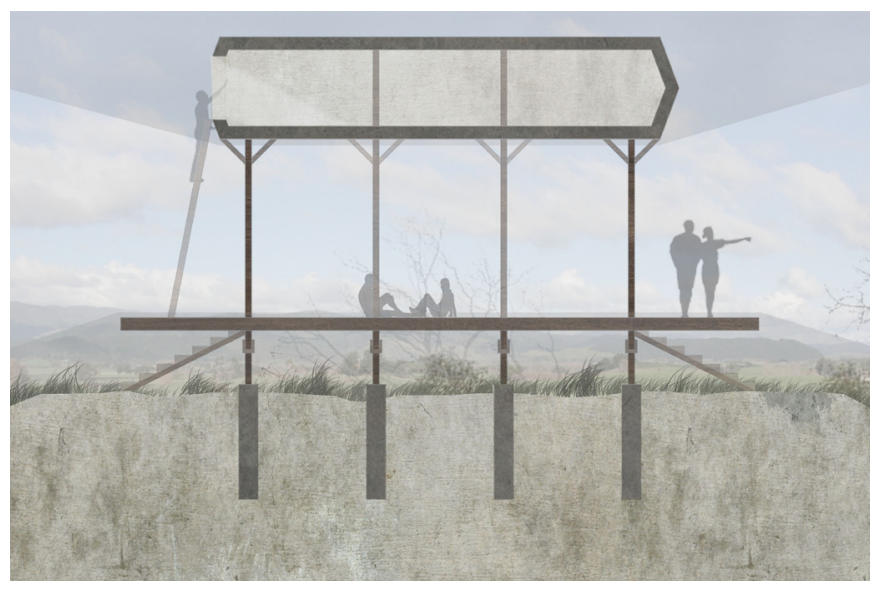

Figure 99 Here, storage is placed at the top, and the void space is emphasised. Above the ground plane a viewing platform is situated which takes advantage of the storage space for shelter. Access to storage is inconvenient 
The 'core' notion is promising as a prospective path of exploration. At a basic level cores are able to store, provide amenity, and act as a landmark. Further research is required to test the ability of these systems to be applied as a fundamental base to widespread settlement. Other uncertainties also need investigation such as, how this network would be established, and what is the logic of settlement expansion from these points.

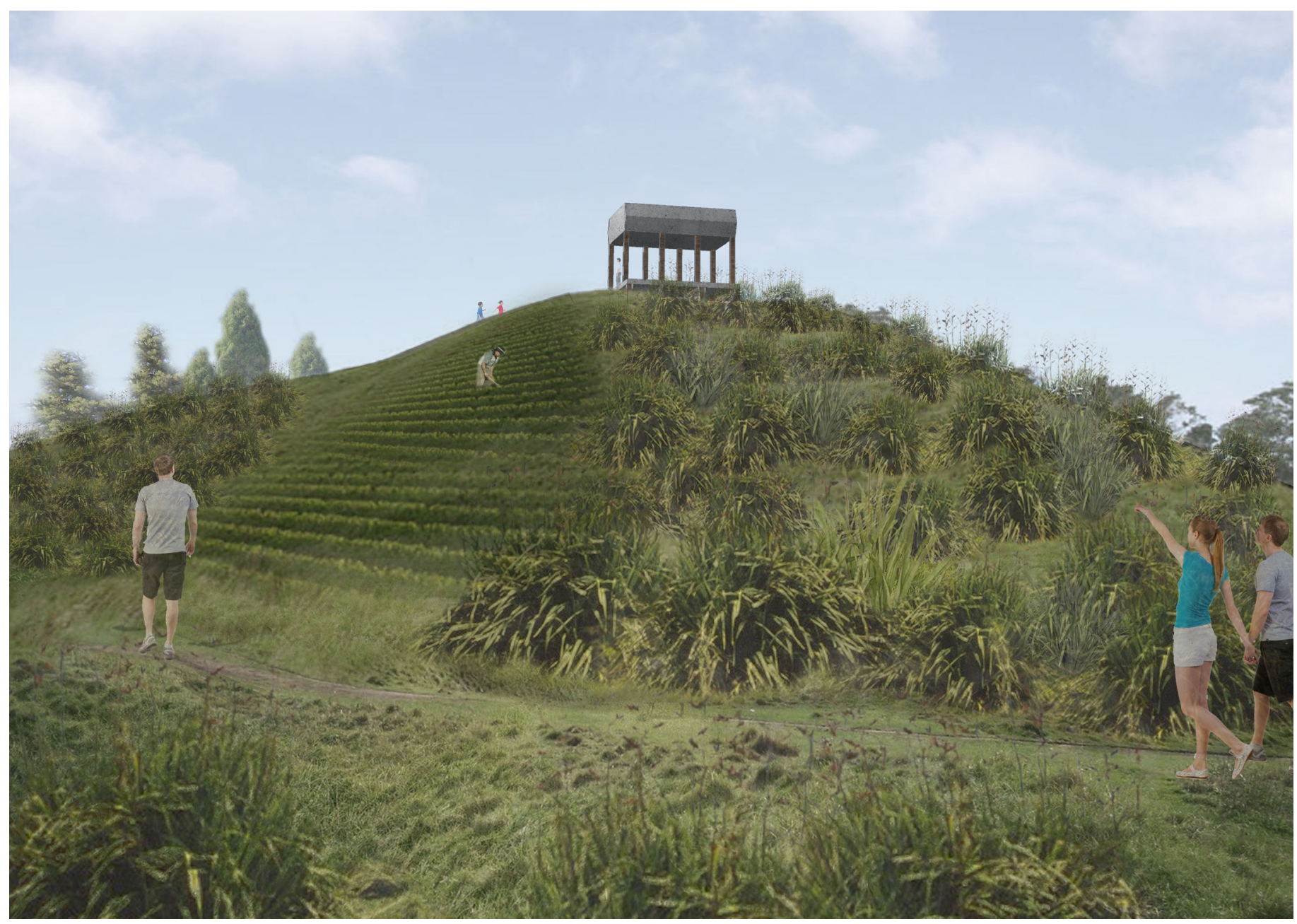

Figure 100 Gestural representation of a typical 'core' functioning as a lookout, storage space, nursery, and landmark 


\section{Design: Core Networks}

This section focuses on the 'logic' of the core network on a large scale. This development dissects the components of the network, exploring their role within the system, and investigates how this system might be implemented. 


\subsection{Of Points, Paths, and Peripheries}

Here, cores are applied on a large coastal scale. The structure of the system can be abstracted into three elements. Points/cores, situated on notable parts of the parabolic dune system, act as safe-houses and recreational zones. Paths run along the remnant network connecting points to one another along a 'safe' linkage, preventing community isolation. Peripheries extend from points, utilising flatter land and housing residents. Points are dispersed along the network, in some areas more densely employed than others, but overall spreading settlement zones, and averting threats which may occur in focal areas. The most Western points act as a starting, and transition point from the current settlement. From here, a new infrastructural network is born, which in time supersedes the old irresponsive fabric. Grounded within the remnant network, this system creates a safe foundation from which settlement can expand. The dispersed nature of points/peripheries creates a greater, evenly spread density, reducing risk from disasters. (Fig.101).

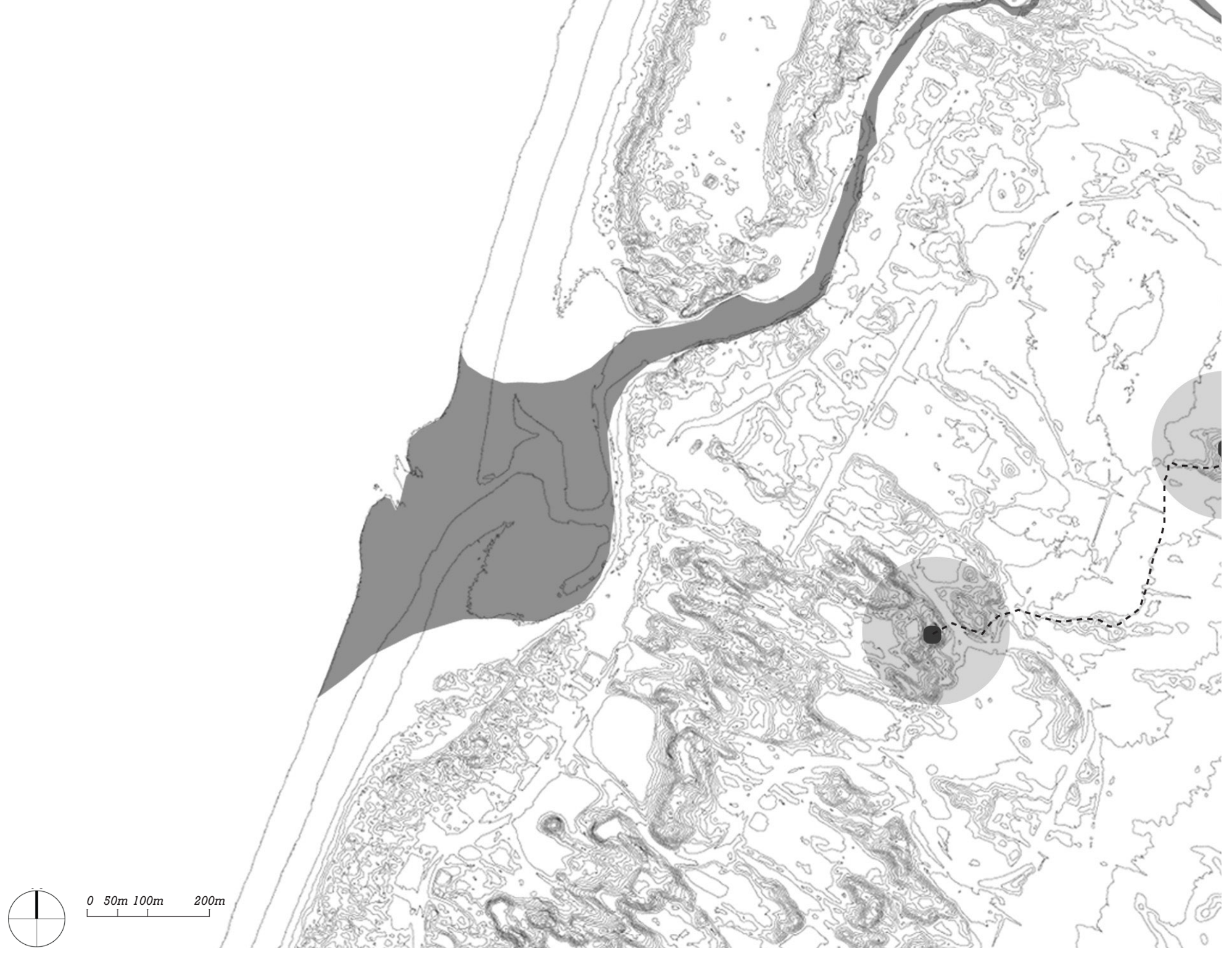




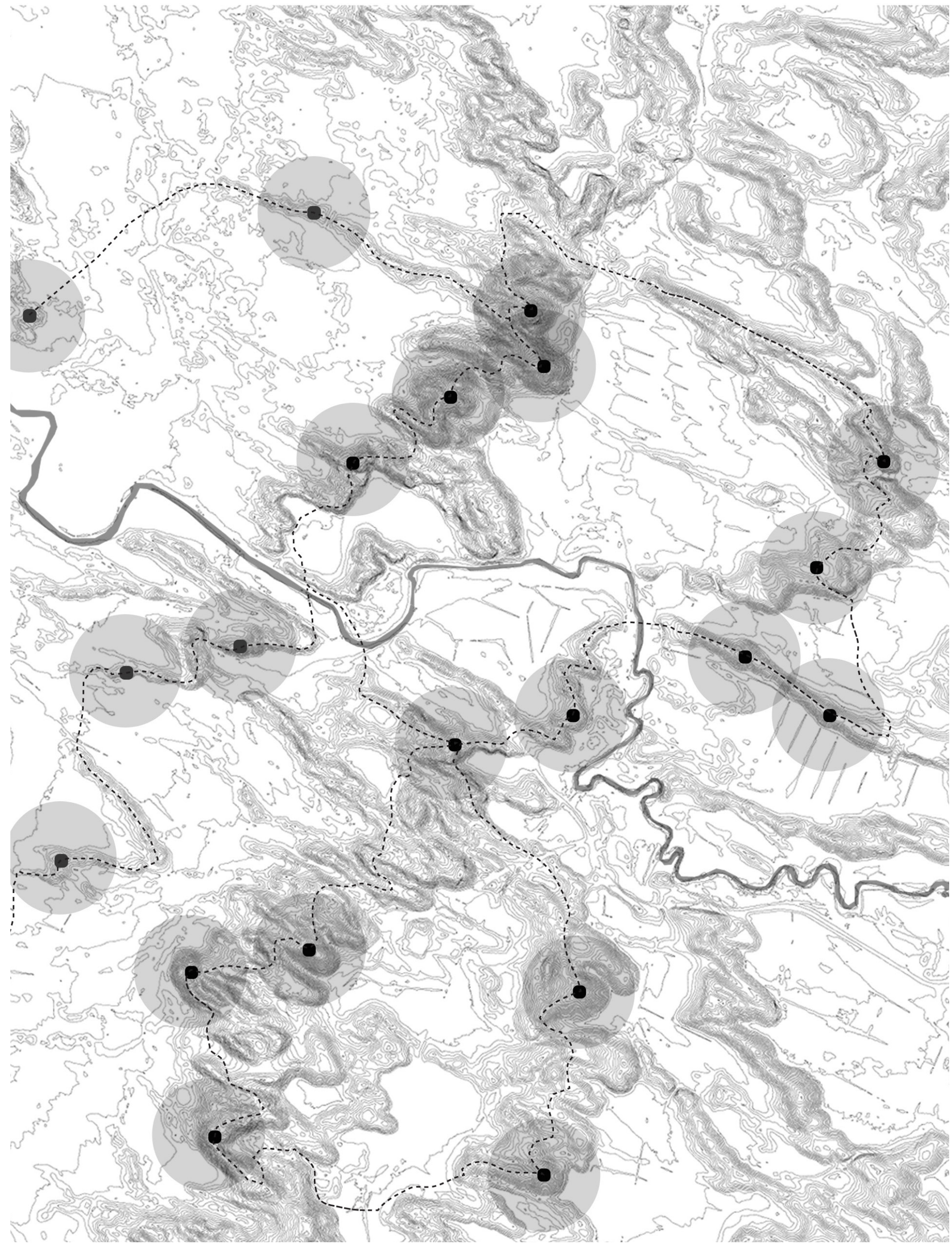


Points: Points are situated on notable high ground, these highly visible landmarks are safe houses for the community and provide amenity. Points are localised to a specific periphery but are connected to each other by paths (Fig. 102).

Paths: Link points together utilising the high ground offered by the remnant system. Paths allow the cores to act as a system and prevent isolation of points in the event of a disaster (Fig. 103).

Peripheries: Peripheries occur around points, expanding outward. Peripheries form the area from which building can occur on reasonably easy land and allow residential areas direct access to points (Fig.104). 


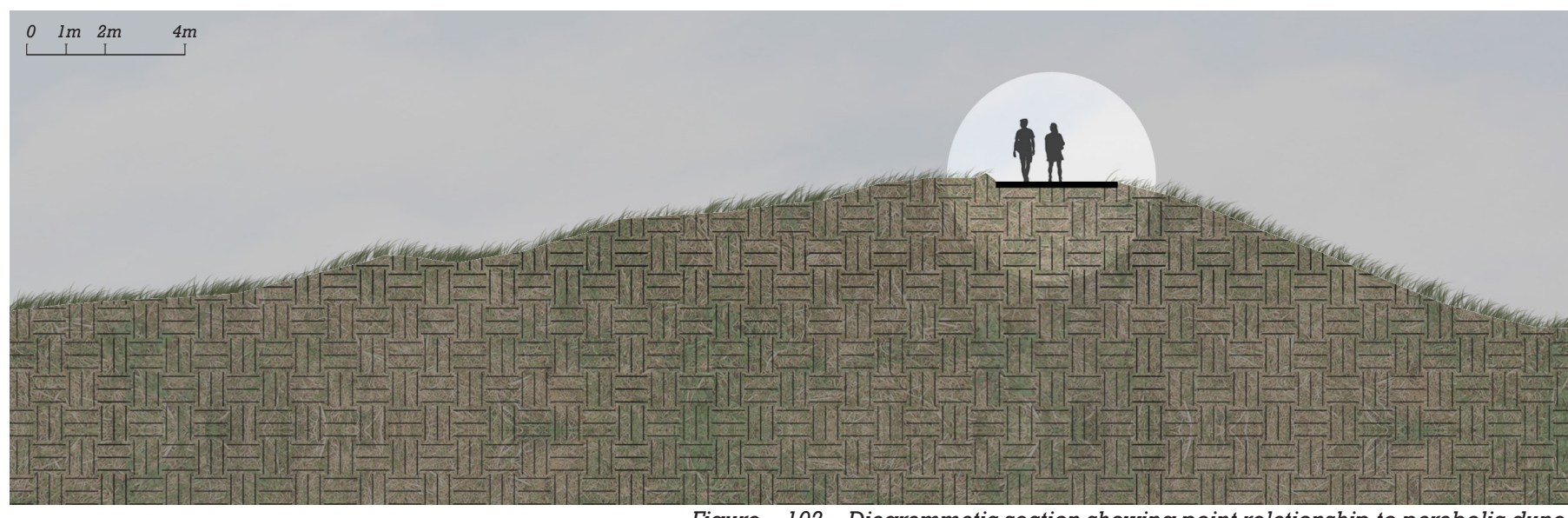

Figure 102 Diagrammatic section showing point relationship to parabolic dune

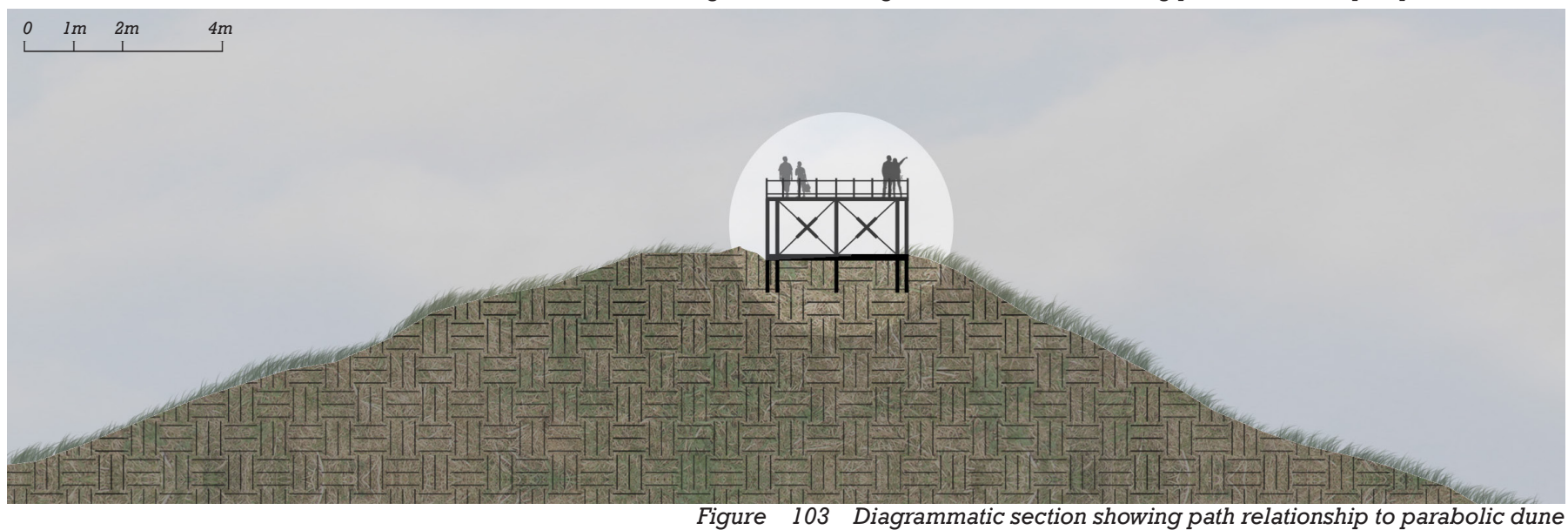
$0 \quad \operatorname{lm} 2 m \quad 4 m$

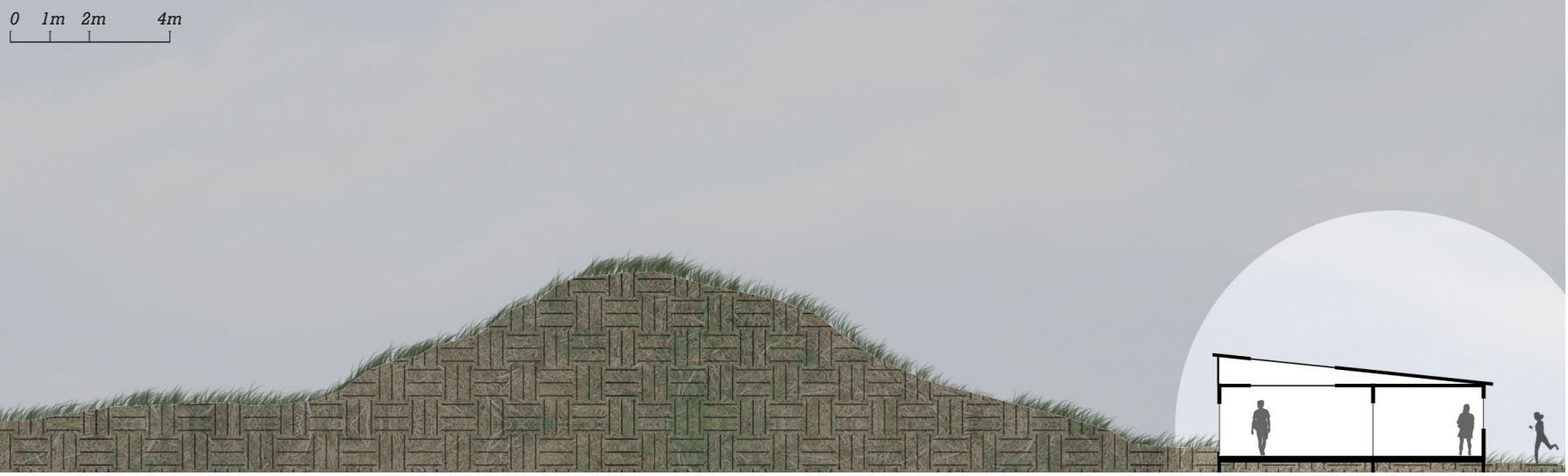




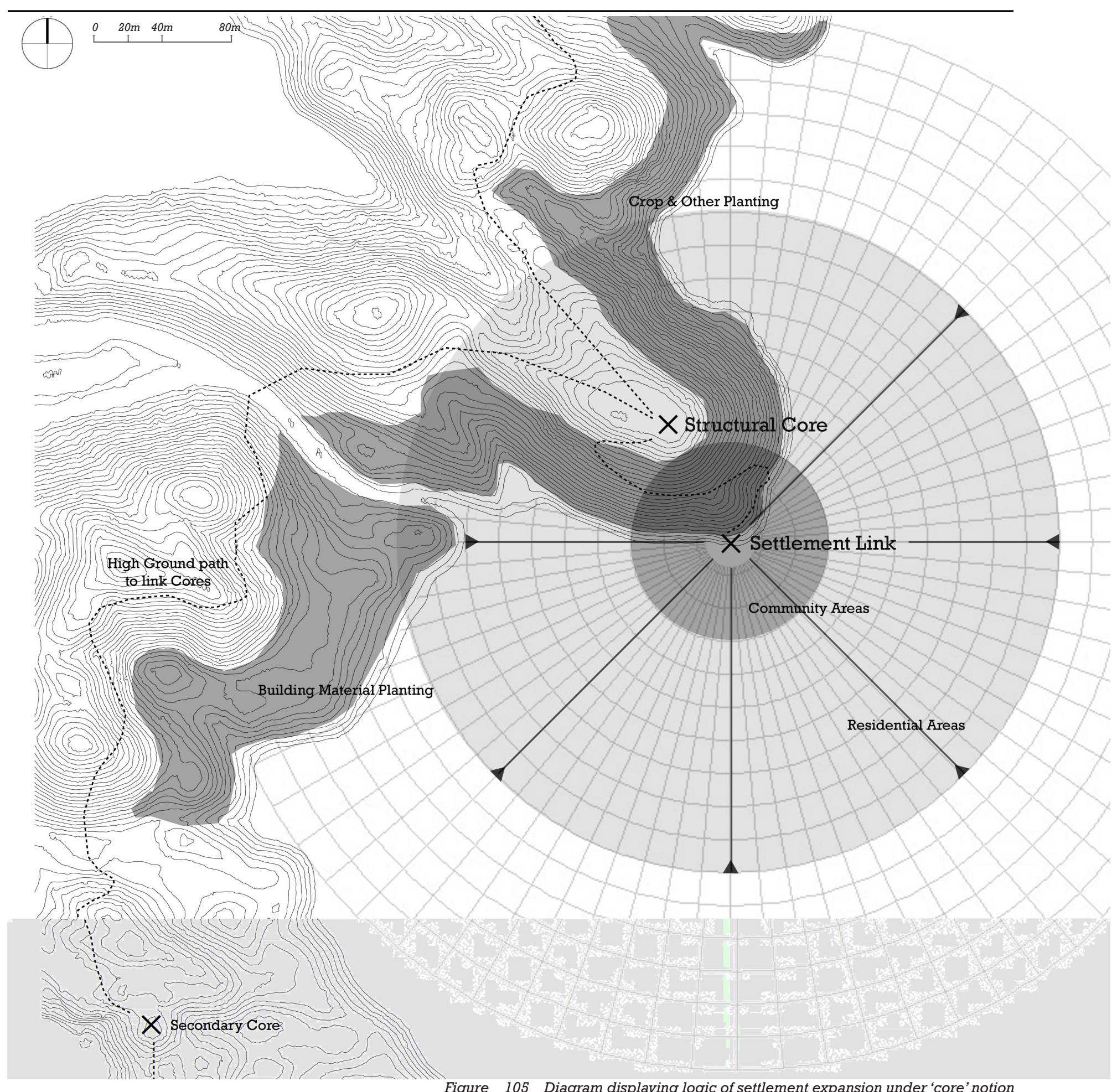

Figure 105 Diagram displaying logic of settlement expansion under 'core' notion 
The logic of settlement extension is based on an initial 'point'. This signifies the birthplace and centre of the community from which other components extend. The core links itself to surrounding building land below, still higher than other flat land. Expansion is managed so residential areas are directly linked to the core, providing equal opportunity/access for residents. Towards the centre, more communal areas are placed, which lead to the pinnacle of the community, the core. The steep land surrounding the core is used to grow crops and material, kept safe from the threats below. Paths meet points and continue along the network linking them together. (Fig. 105). 
Peripheries expand differently according to the feature on which it sits, and the nature of surrounding landform. Variation is potentially large, so it is essential that growth occurs under key principles, which keep the periphery functioning properly. Fundamentally, peripheries must be formed on the basis of clear linkage and access to cores, which act as the hub and refuge. The form of the periphery should respond to the surrounding landform, its application should be derived from cues taken from the context. Sizes of peripheries vary from around 150 to 250 occupants, making these small developments communally stronger. (Fig. 106-108).

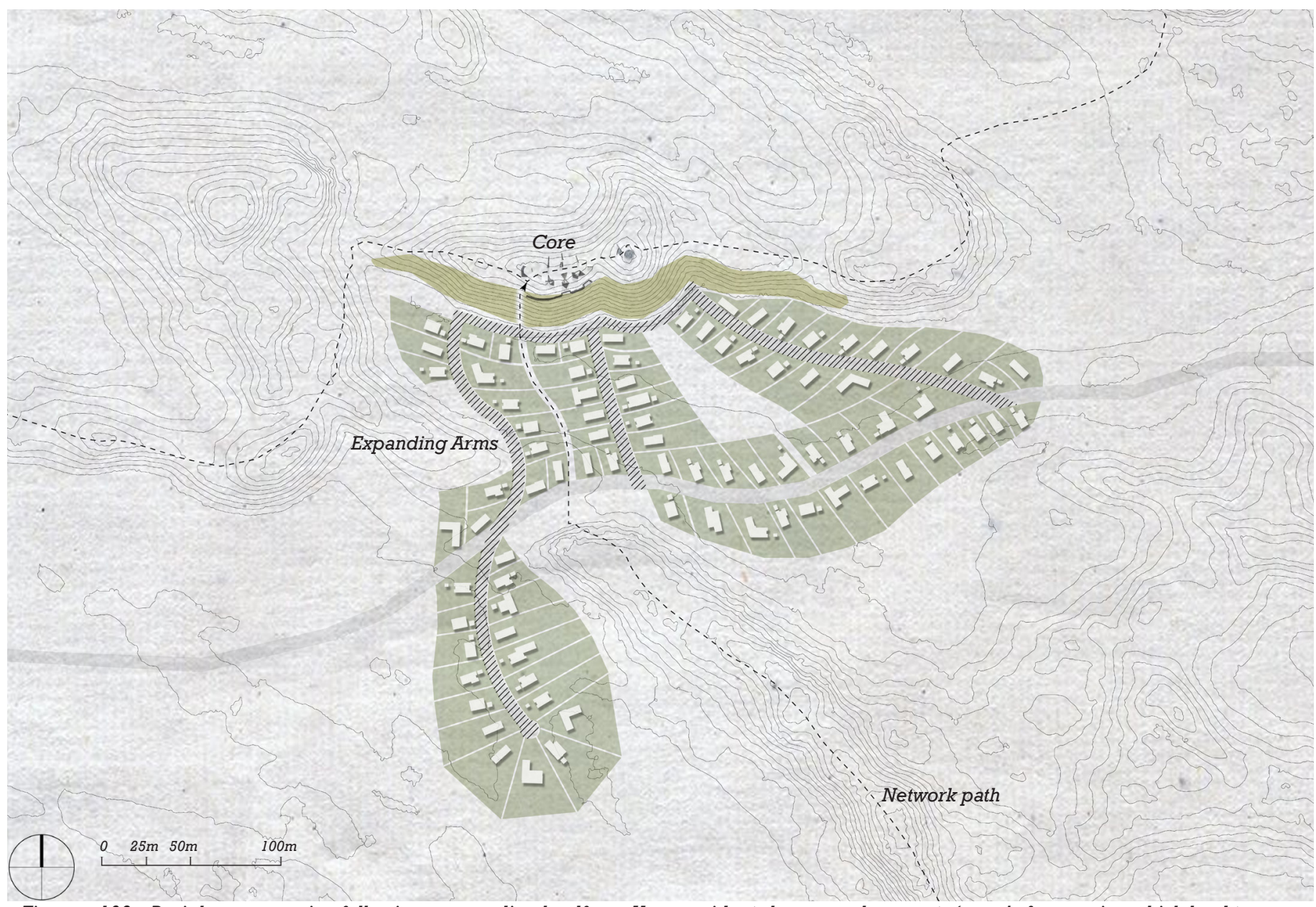

Figure 106 Periphery expansion following surrounding landform. Here, residents have equal access to 'arms' of expansion which lead to access 

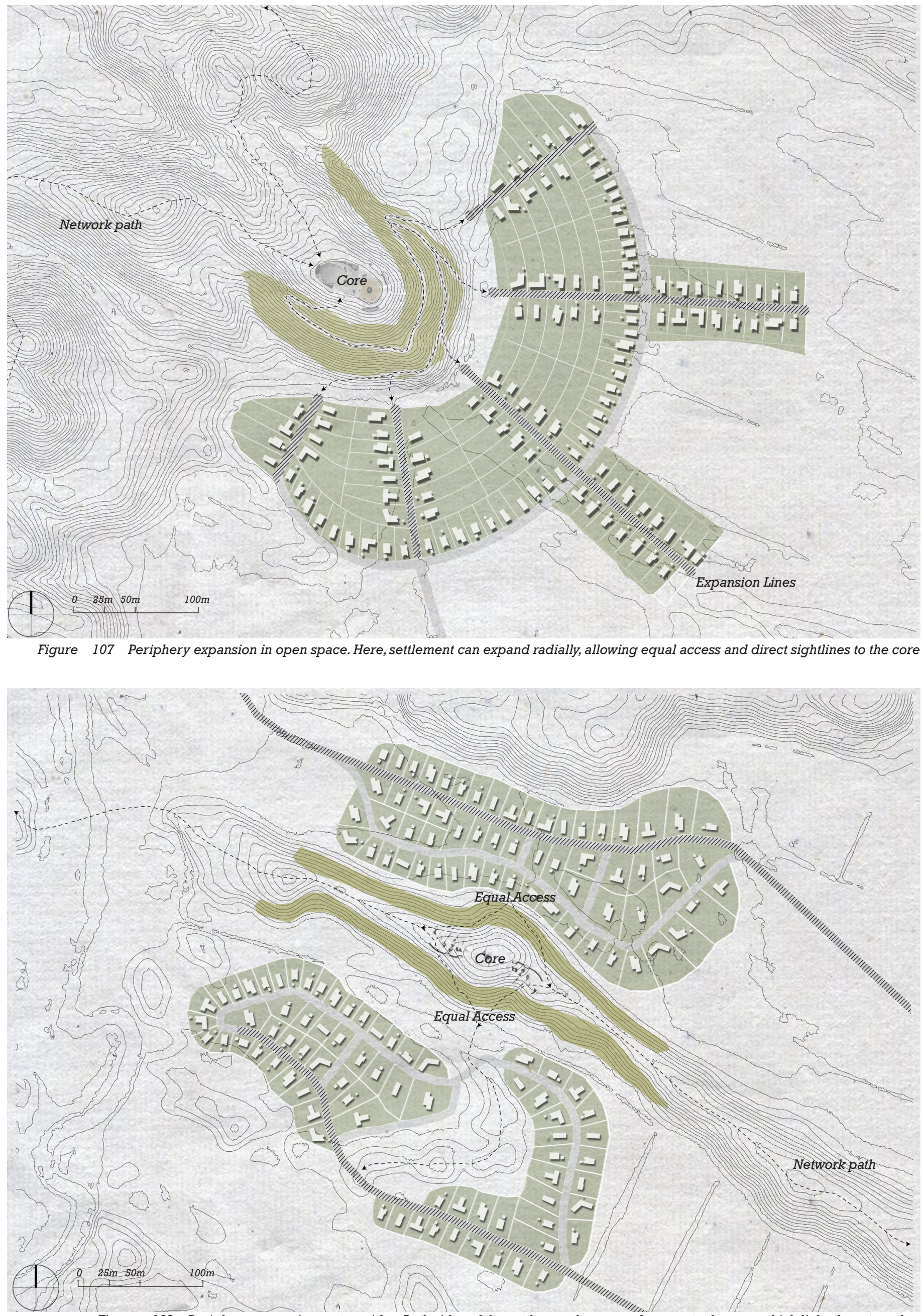

Figure 108 Periphery expansion on two sides. Both sides of the settlement have equal access to the core which links them together 
The parabolic dune network is steep and unruly. Sloped land is poor for farming practices, being difficult to work on, operate machinery, and irrigate. Irrigating these areas can de-stabilise soil and nutrients making the land less rich (Inspiration Green, n.d.). Cattle will not tolerate traversing any more than a $20 \%$ slope in the least slippery conditions, making much of the parabolic dune network unworkable for cattle runs (Chesterton, 2014). The network of cores method resolves this by purchasing this land from current landowners, leaving the flat, easy to work terrain to farming practices. Roads are placed on the shallow edge of these dunes above surface flooding creating a border for settlement/farm edges and preventing segmented farmland. Peripheries connect to roads extending from remnants at one point rather than dissecting farmland. (Fig. 109-110).

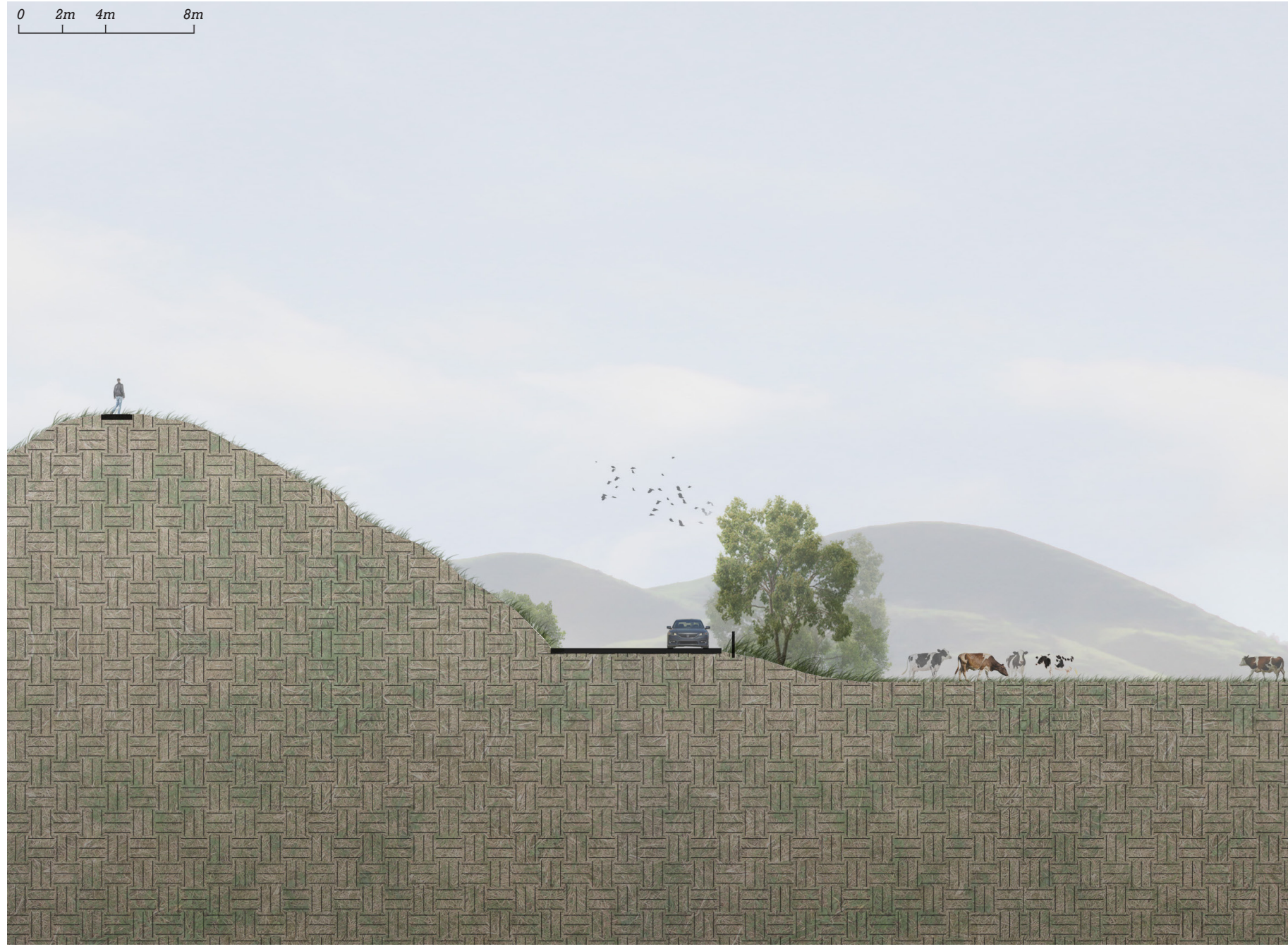

Figure 109 Dune remnant/farmland section shows how farmland occupies most productive land while roads are kept safe from flooding 


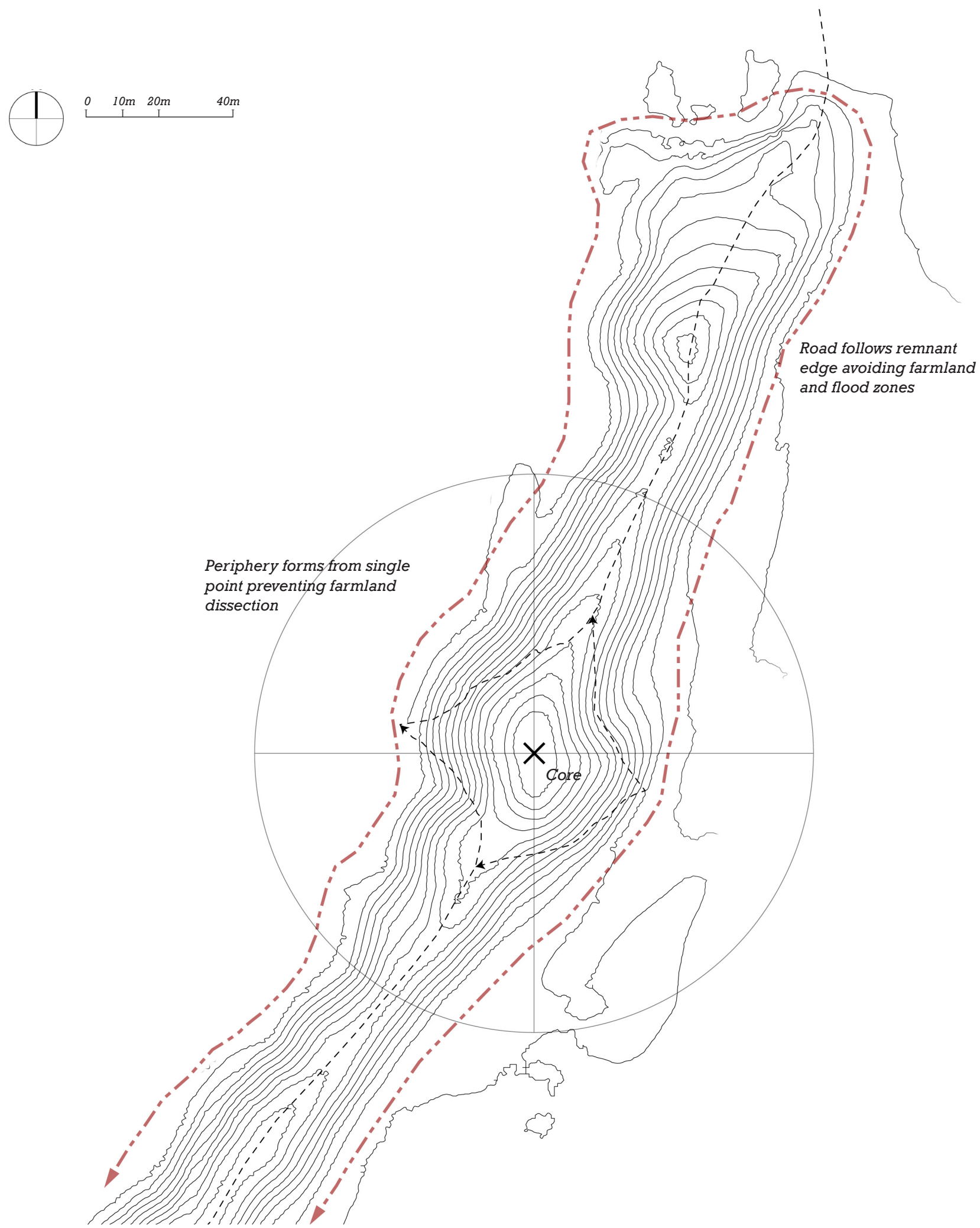

Figure 110 Diagram of road relationship to parabolic dunes - Preventing farmland dissection and tying peripheries to remnants 
It appears, settlements could function under a network following 'core'principles.Implementation would likely begin with the immediate construction of structural centres of cores with the release of small, unprofitable high points owned predominantly by farmers(Fig. 112).
Further land along the parabolic dune network would need to be relinquished by landowners, working in favour for farmers, as the steep, uneven land is hard to work and unprofitable (Fig. 113). When enough land is claimed, points are linked by paths through acquired
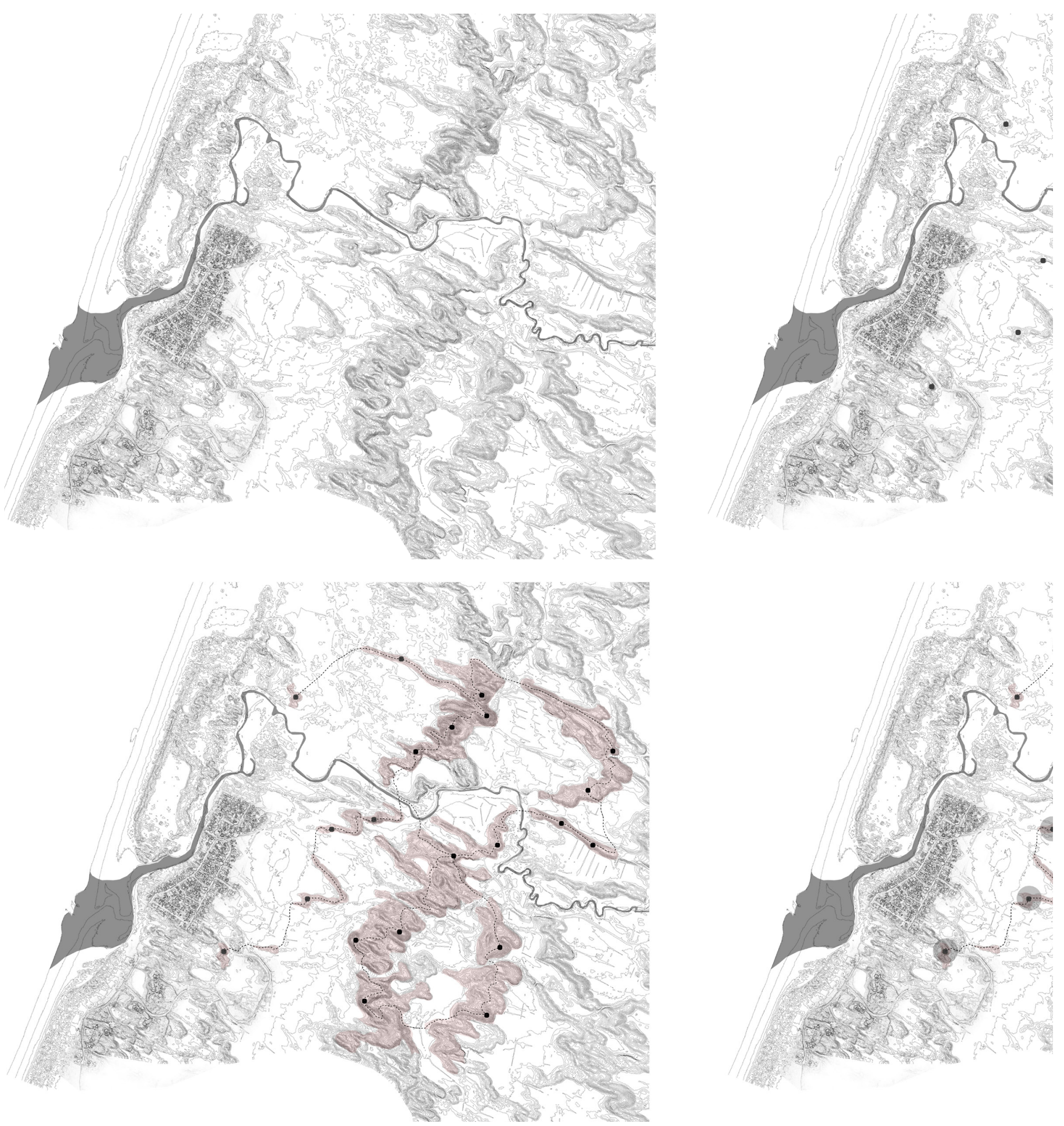
land, forming the infrastructural network of settlement (Fig. 114). From here, incremental development would likely occur; 'cores' closer to roads, the river, and the existing township would be the first to be developed. However as these become more populated, less occupied areas become attractive, and eventually populations are evenly distributed creating a strong, dispersed number of communities (Fig.115-116).
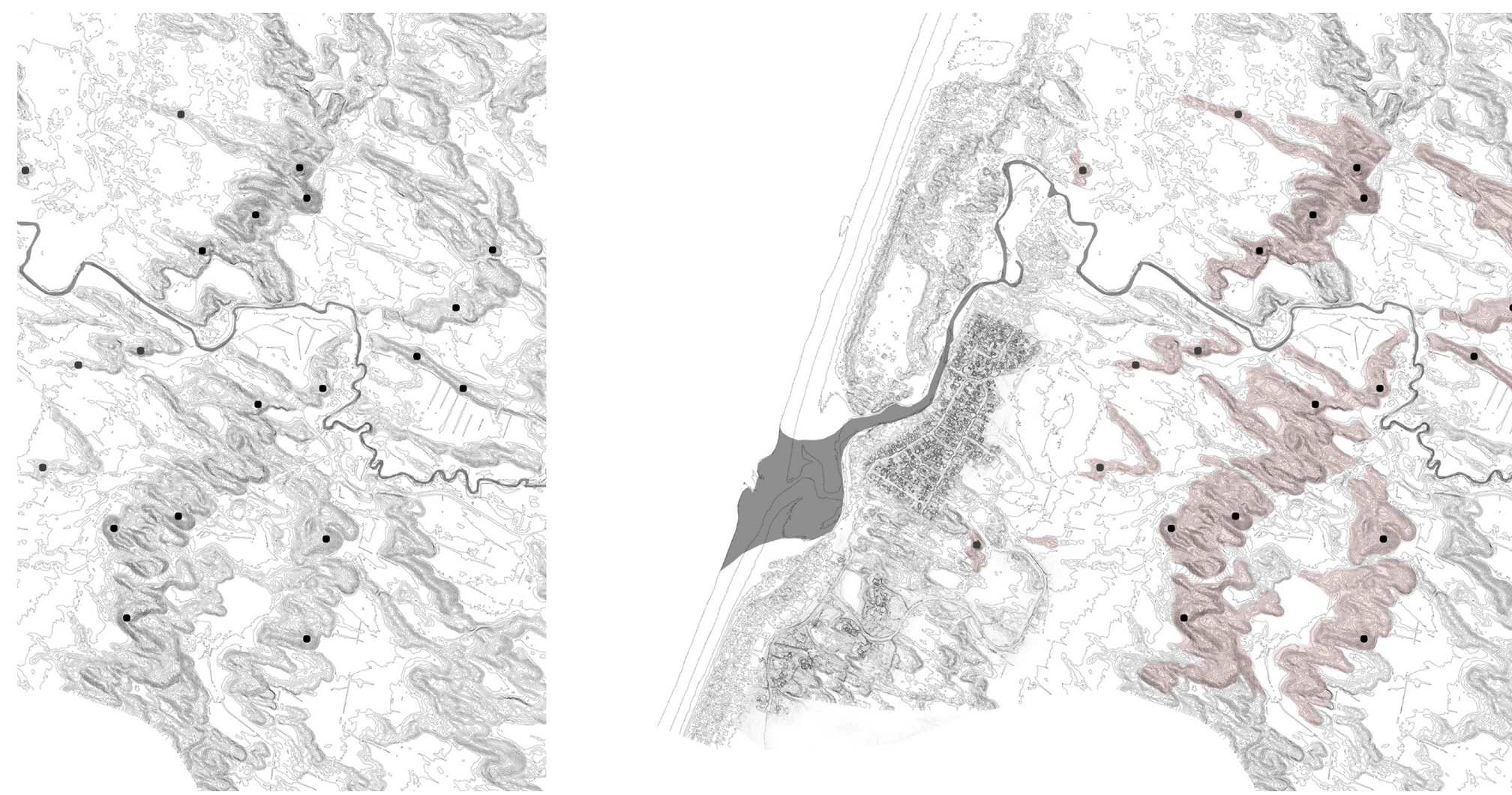

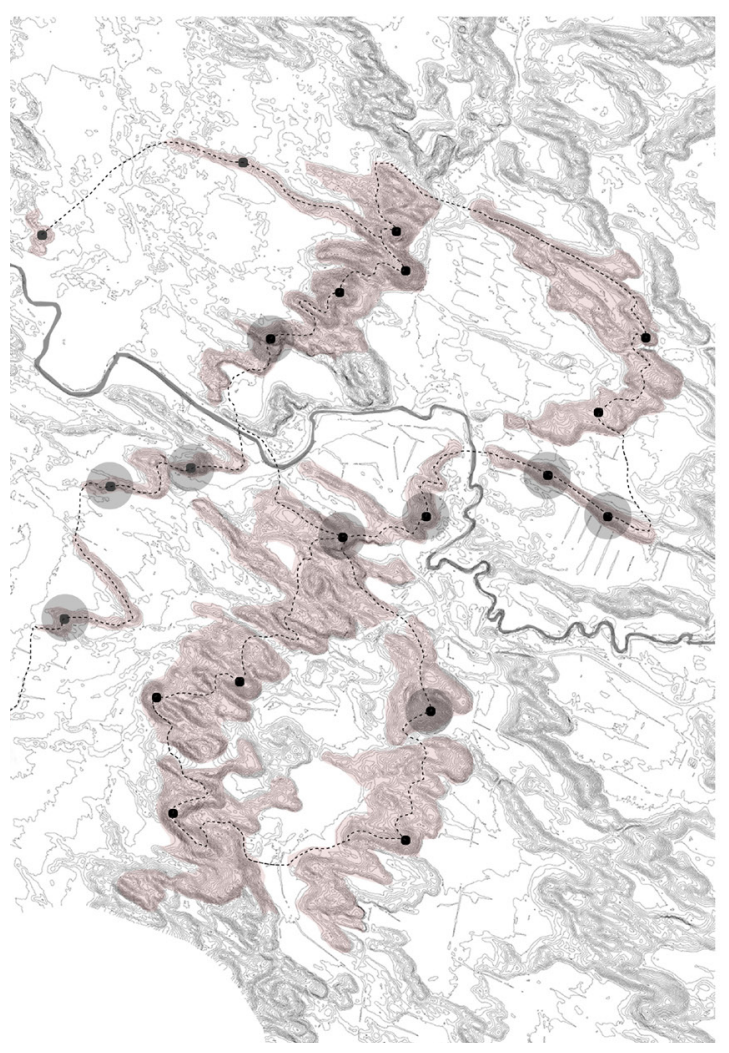

Figure 111 Top Left:Waikawa at present

Figure 112 Top Centre: Structural cores are built using minimal land Figure 113 Top Right:Land occupied by dune remnants is released

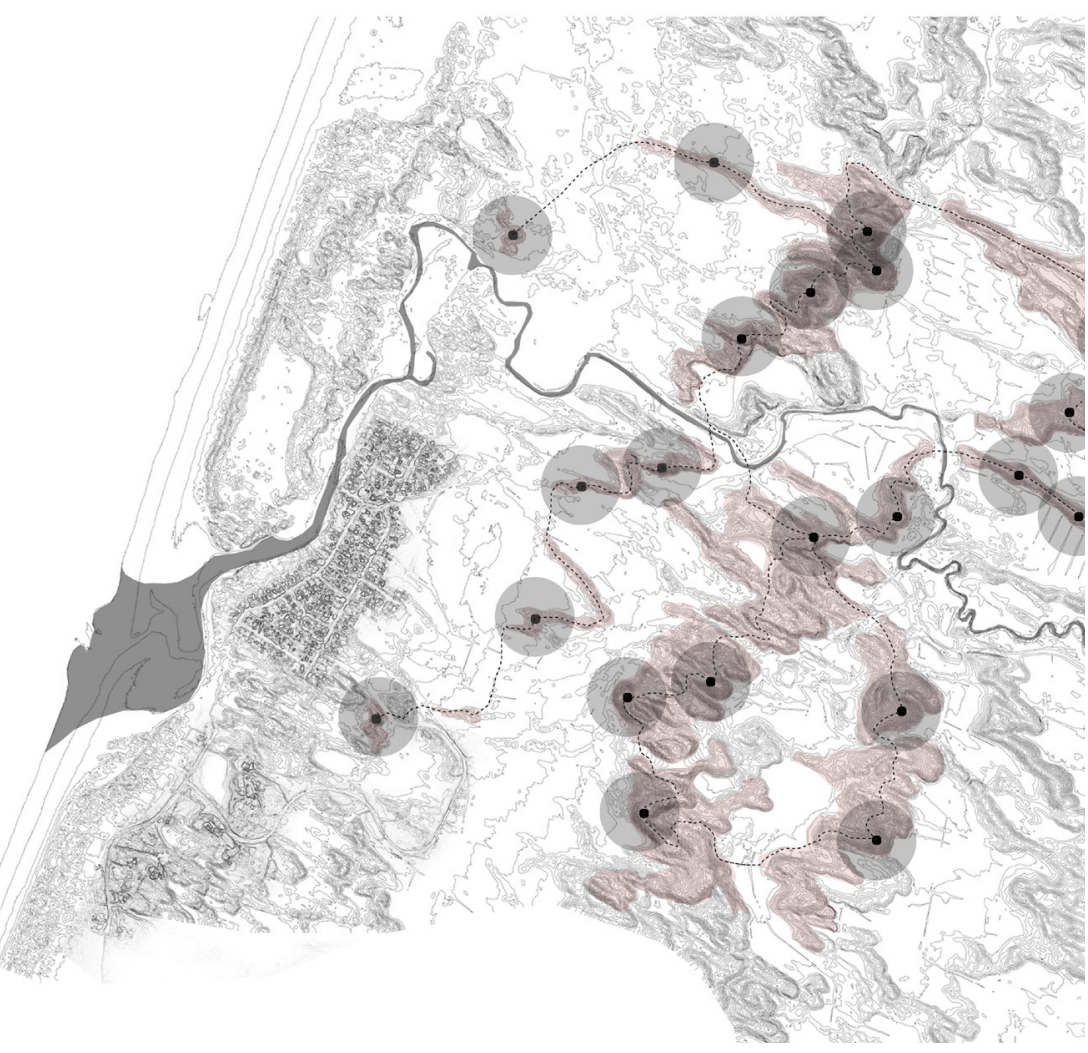

Figure 114 Bottom Left: Points are connected by paths

Figure 115 Bottom Centre: Cores close to road networks, existing settlement and near the river begin to be inhabited

Figure 116 Bottom Right: Eventually communities distribute more evenly across the landscape 
Overlaying a four meter sea level rise reveals the network's resilience. In this rise only one core is compromised. The remainder of the system is intact, with points above the water, and paths in most areas continuing to link communities. Most points still have adequate surrounding space for a periphery. (Fig. 117)

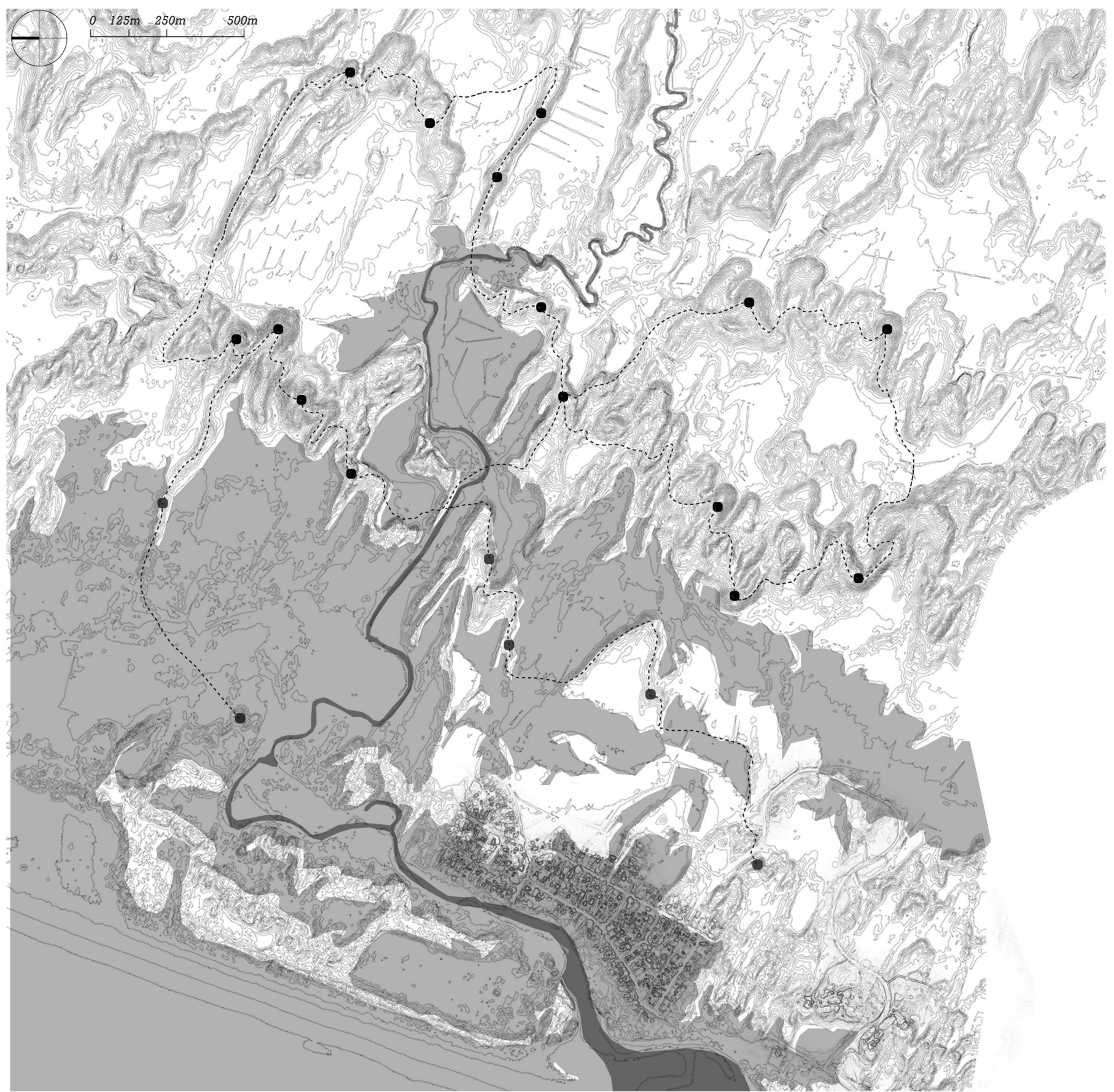


On a large scale, the network functions viably, safeguarding communities, and creating a more responsive coastal identity which respects the relationship between inhabitants and this temperamental landscape. From here it is crucial to explore how each core is diverse, offering different amenities to communities, and avoiding a level of same-ness occurring. What might inform this? 


\section{Design Types: Form and Community}

This segment considers how cores function on a smaller scale. Cores situated in varied contexts should be constructively diverse. How might context inform the form and typologies of amenity? The focus is on community, where these centres are pushed to provide the maximum for residents, offering several opportunities. 
The core occupies the heart of settlements. Aside from functioning as a refuge, they must also tie the community together. Cores should be at the centre of communities, strengthening the link to stable points within the landscape. A number of amenities should be available, which can occur off an applicable platform. The following examples demonstrate the ability of a simple base to allow for a number of amenities. (Fig. 118).

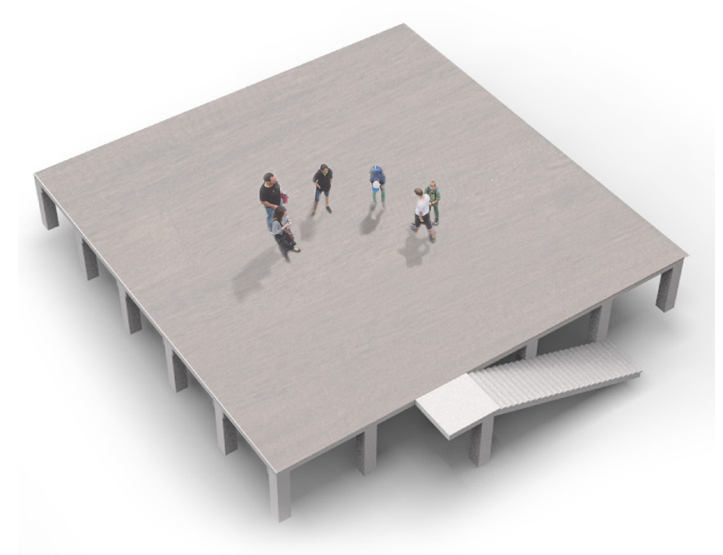

Meeting Space

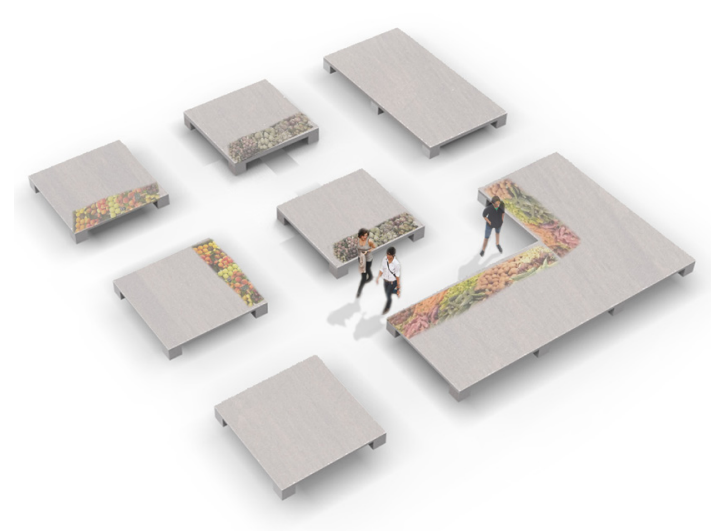

Market Space 


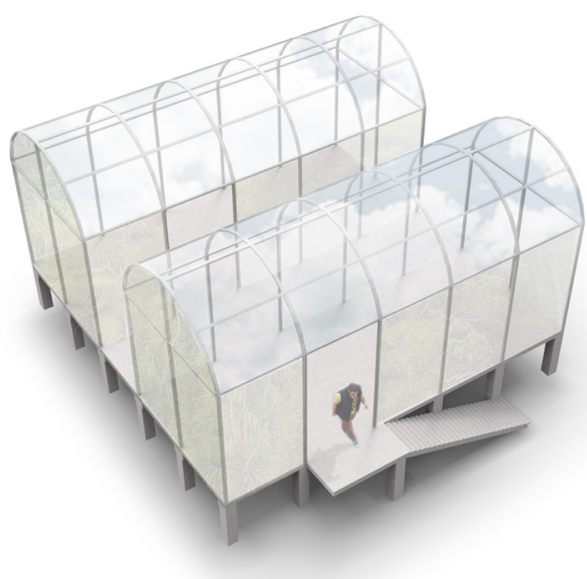

Greenhouse Space

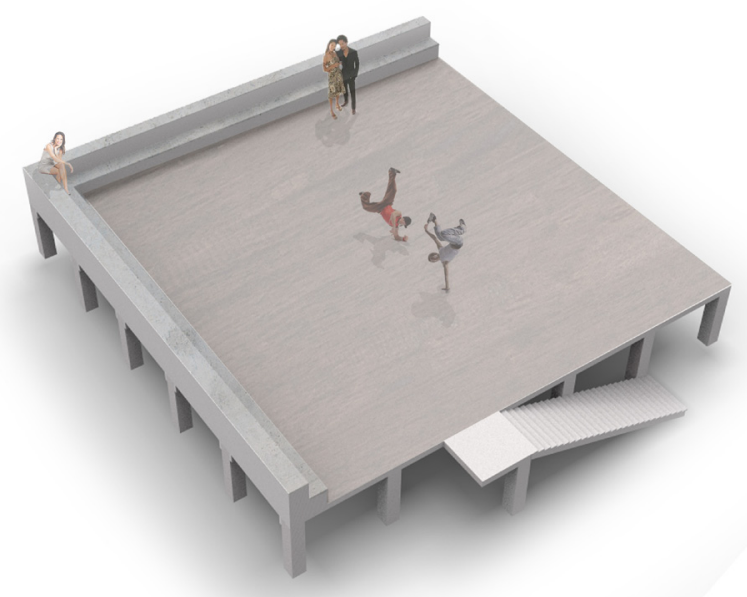

Performance Space

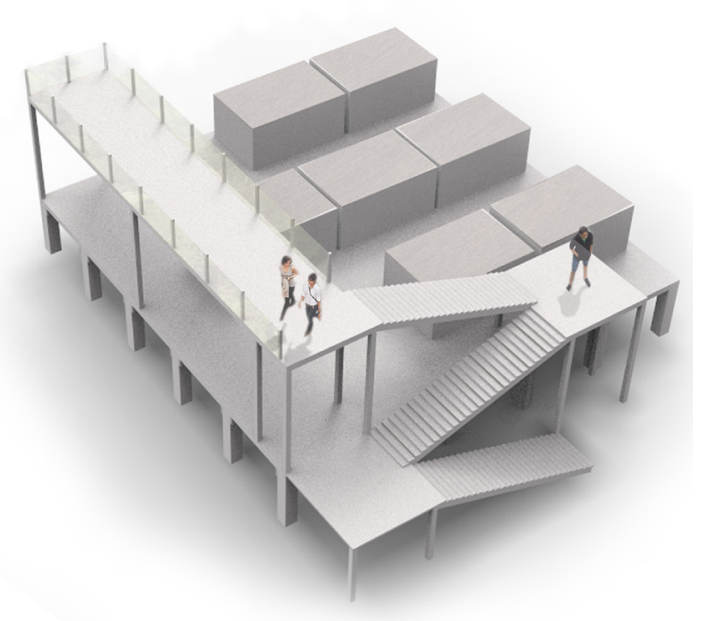

Viewing Space

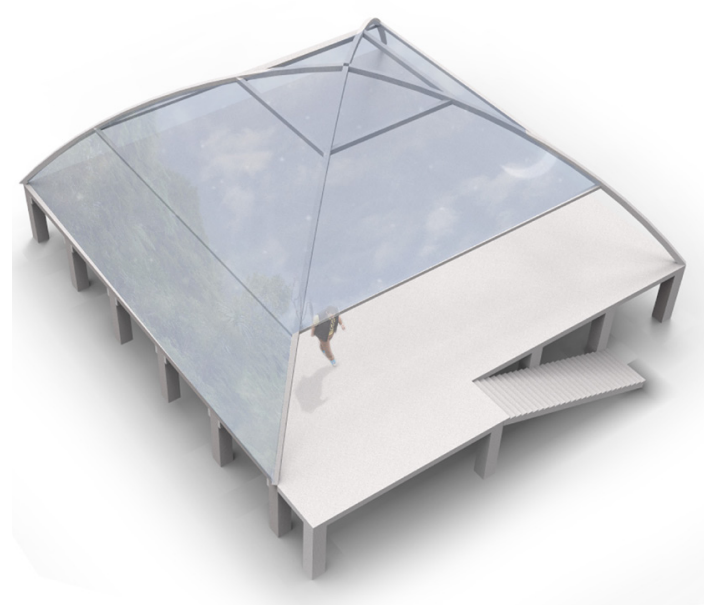

Star Gazing Space 
Varying contexts and forms of structures will permit different activities. This creates a sense of localised uniqueness amongst cores, which can begin to specialise, diversifying the network. Communal pride is an important aspect for the network to function, and a sense of identity allows this. The traction between cores is increased as each localised community can begin to offer neighbouring communities an exchange of produce, or amenity. These examples show how formal change can allow dissimilar amenities to eventuate. (Fig. 19-22)

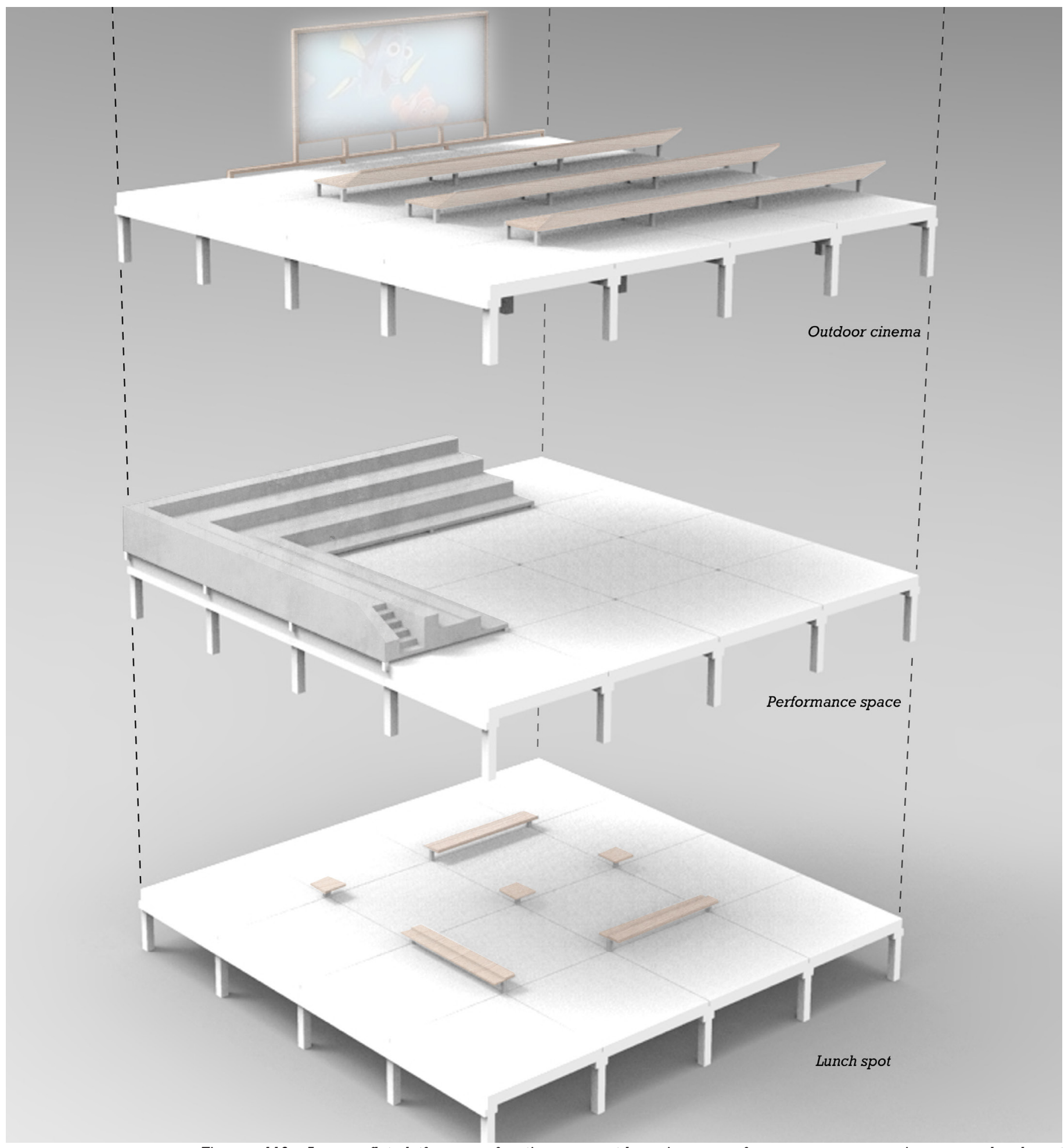

Figure 119 An open flat platform may function as an outdoor cinema, performance space, camping area, or lunch spot 


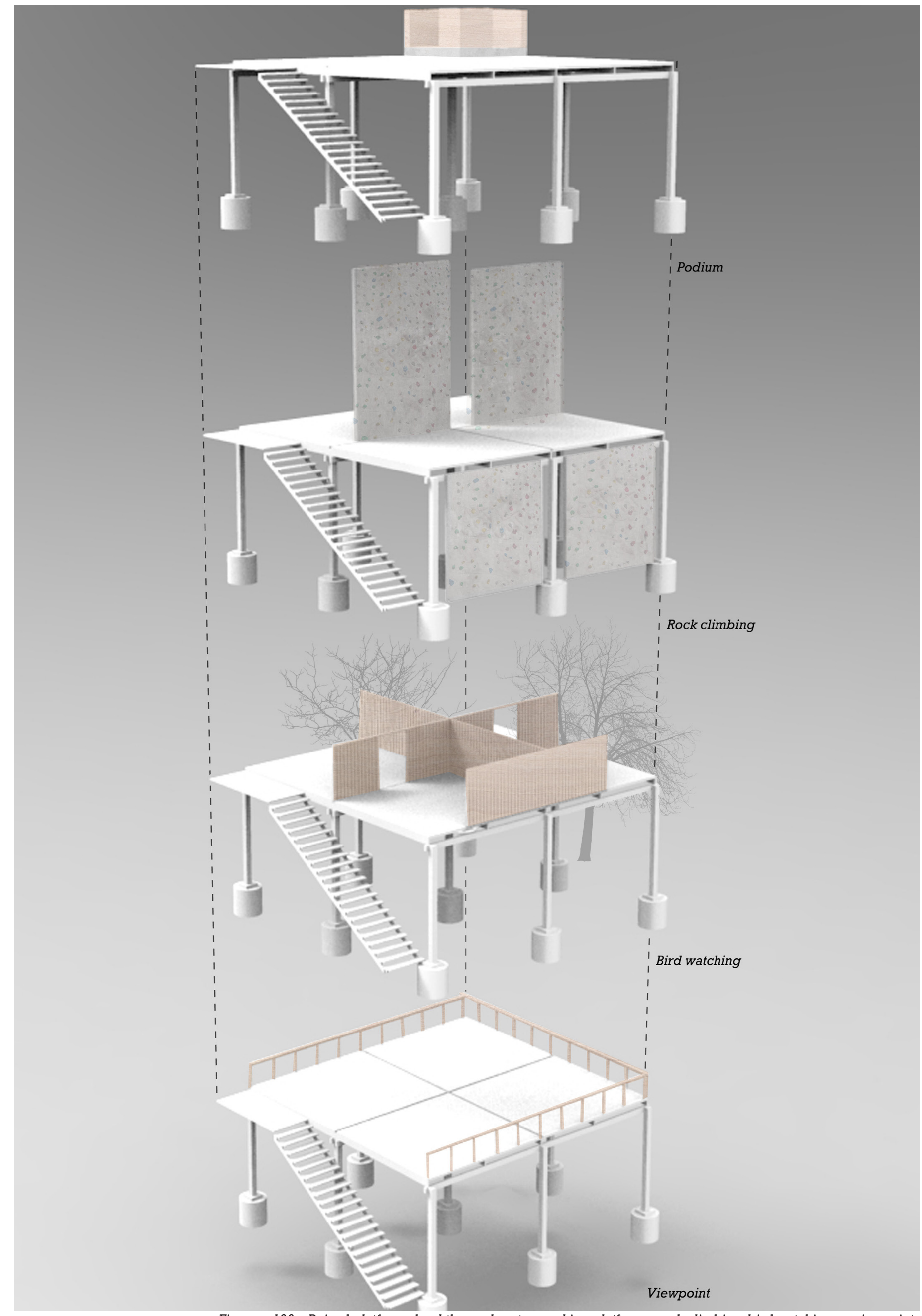

Figure 120 Raised platforms lend themselves to speaking platforms, rock climbing, bird watching, or viewpoints 


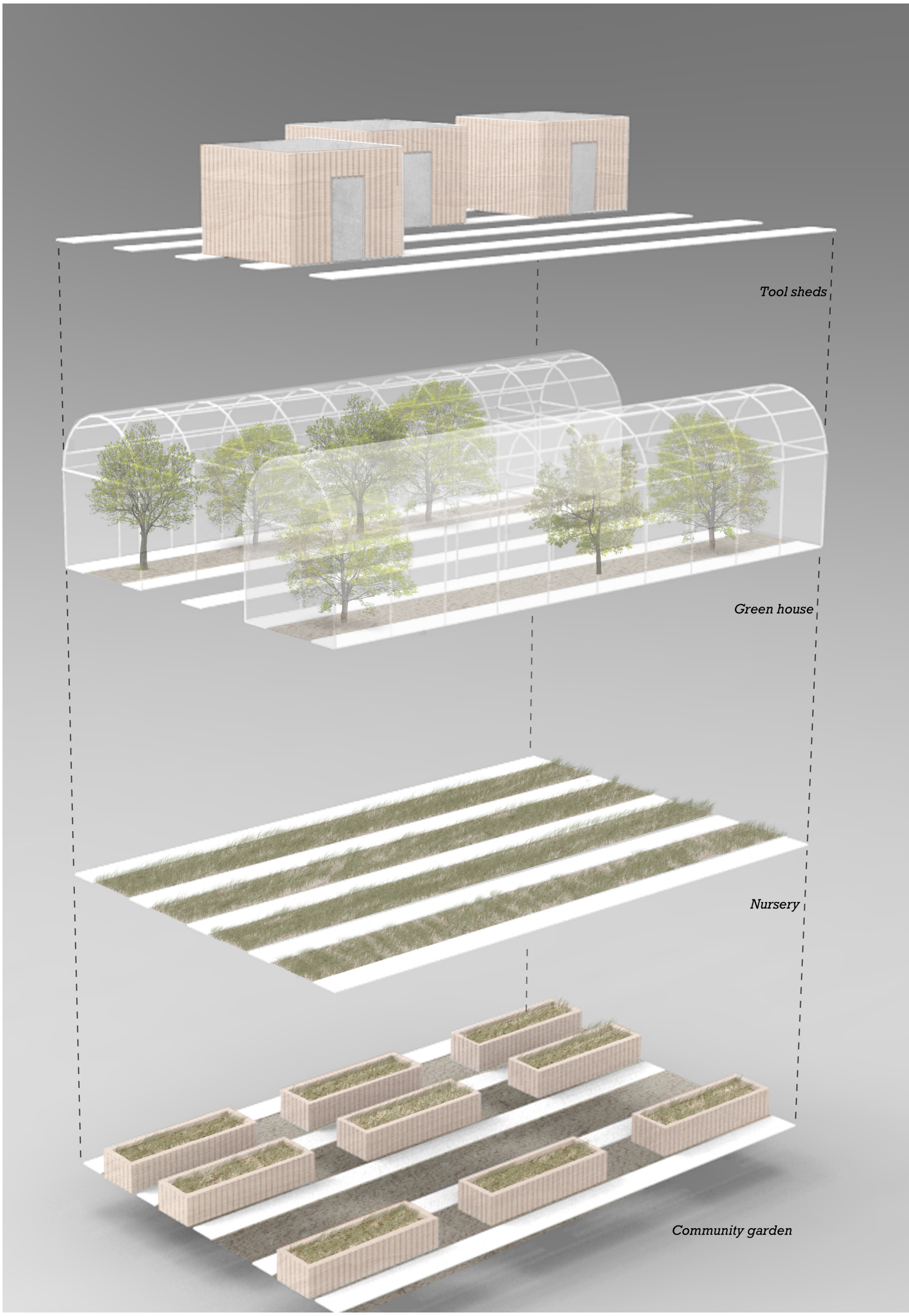




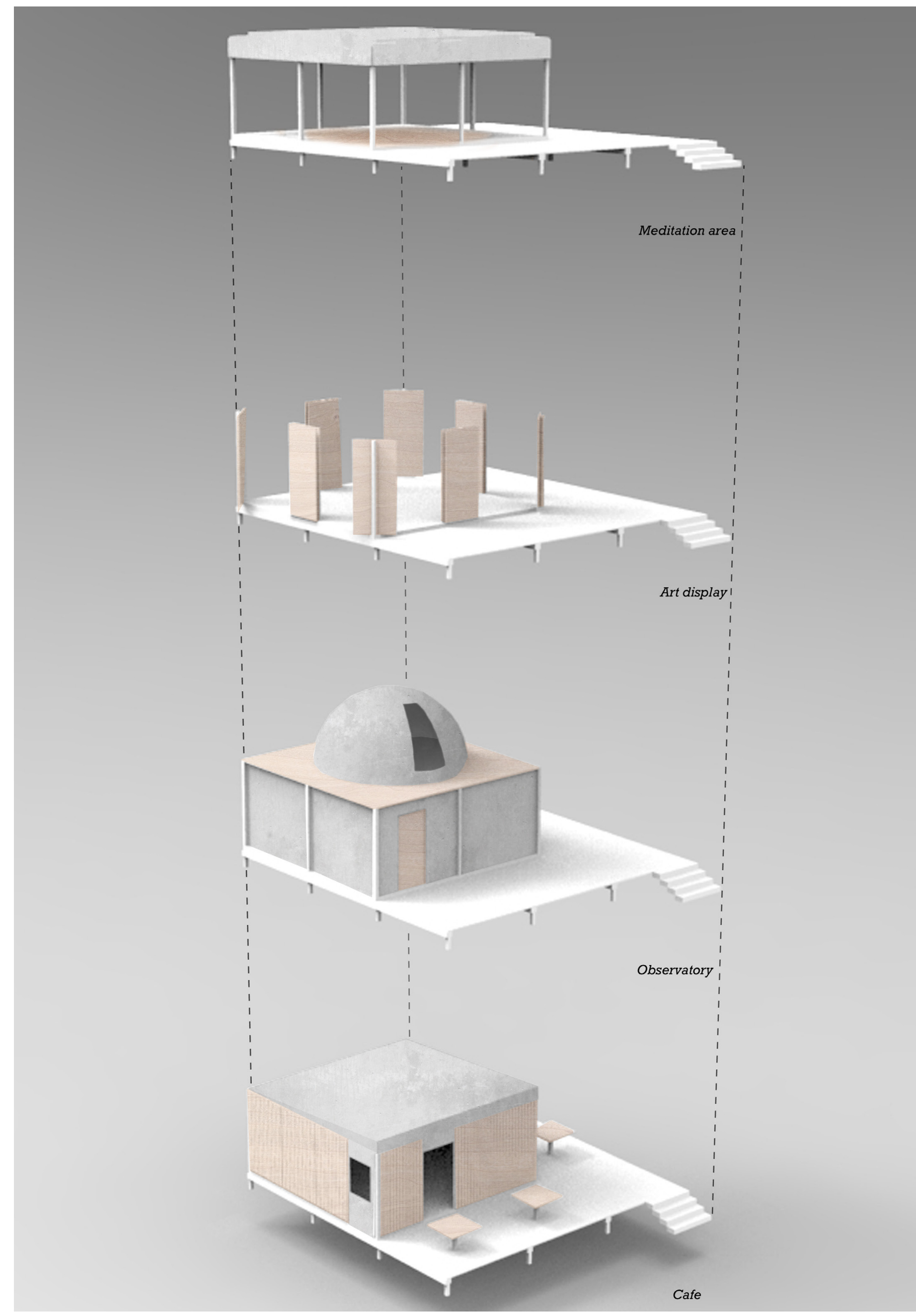

Figure 122 More structural platforms may be used as meditation areas, art displays, observatories, or even a cafe 
It is unproblematic to place activities on a simple base, on site however, the form must be fitting and responsive. This is viewed as complexity from which to draw more diversely informed activities.

Each core attains activities derived from contextual influence, the presence of a nearby river, or placement on a notable highpoint. The form of cores should respond to these drivers, and allow activities to manifest naturally.

"Local distinctiveness is about the continual momentum of social memory, about meaning conveyed and reworked, helping us to feel part of the everyday." (Clifford, 2001)

The core form must balance between its underlying dual functions, as a community amenity hub, and to provide safe refuge and storage.

It is also important to consider the form as a landmark; a form which navigates the equilibrium between becoming a strong reference point and not overpowering the landscape aesthetic. The form must highlight the core location in the landscape, to a degree in which its appearance is emphasised. (Fig. 123). 


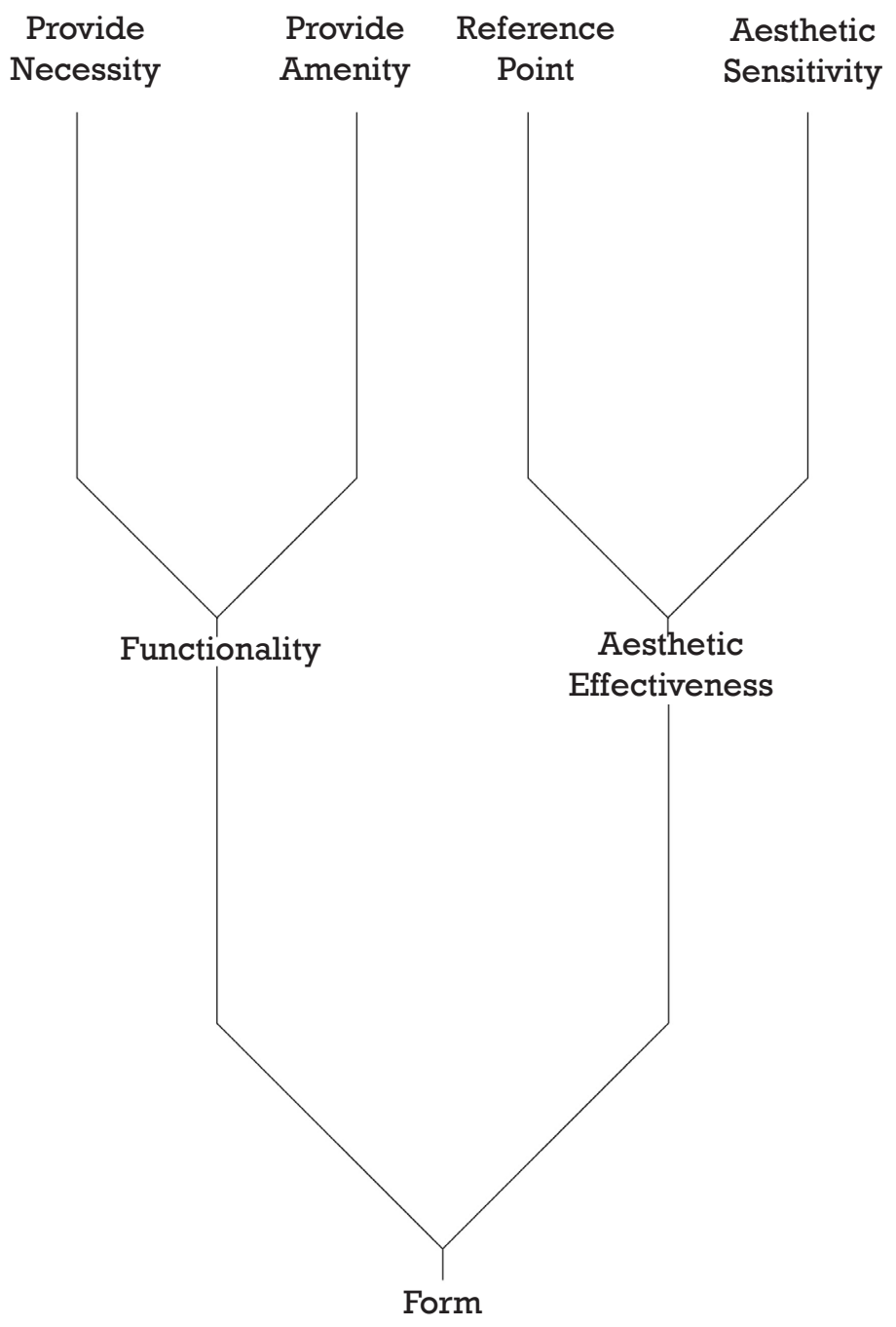

Figure 123 Deriving form 
Final Development 
The test site chosen is a well-established dune lobe named 'Te Rauparahas lookout'. Sitting thirty 30 meters above the surrounding land on a flat plateau and encompassed by steep terrain, it is connected to some of the most pronounced areas of the remnant system. The site sits near existing road networks, forestry, and expansive flat land which prompt application of a larger settlement and community. (Fig. 124) 

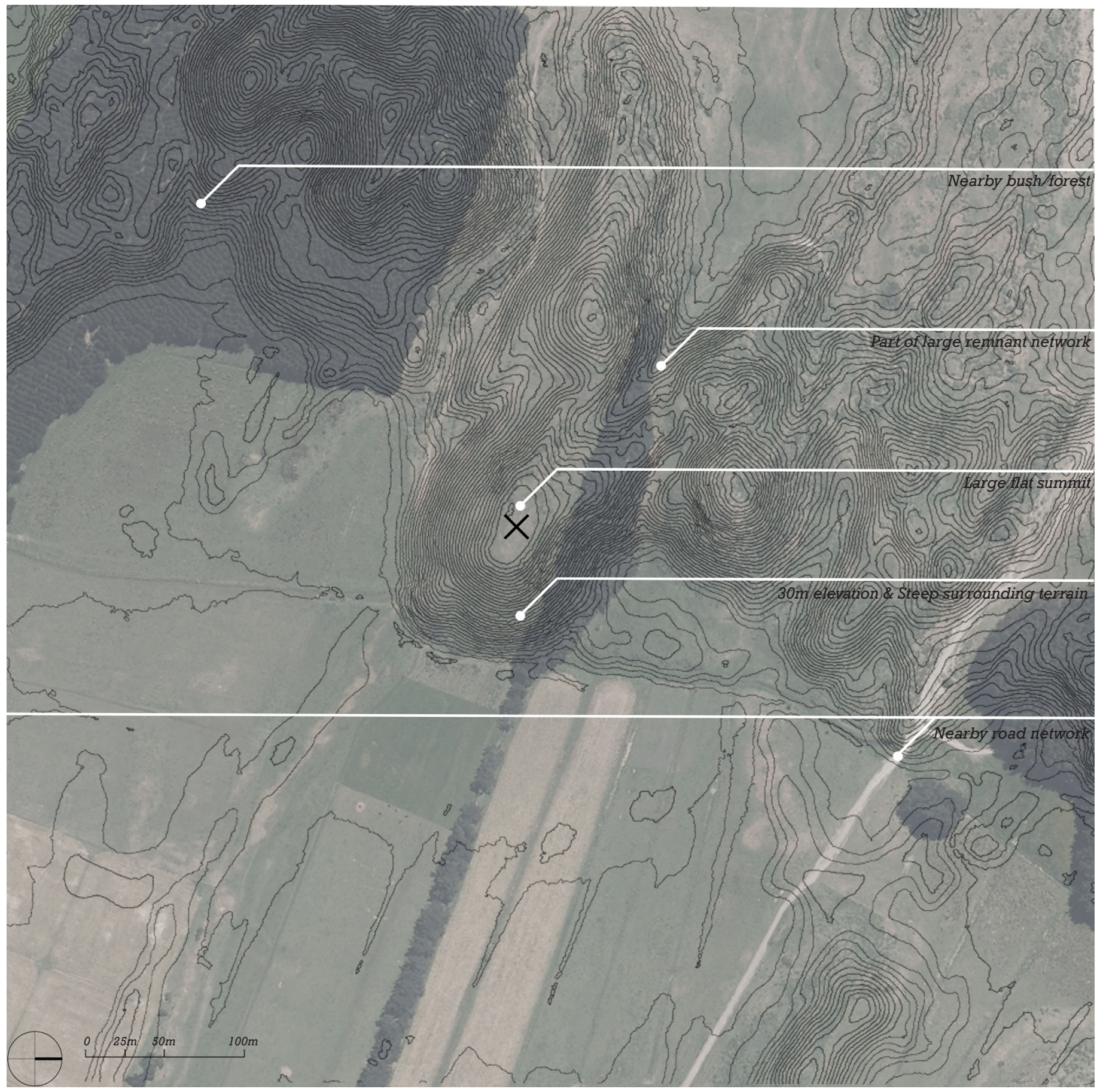

Figure 124 Primary contextual drivers for core 


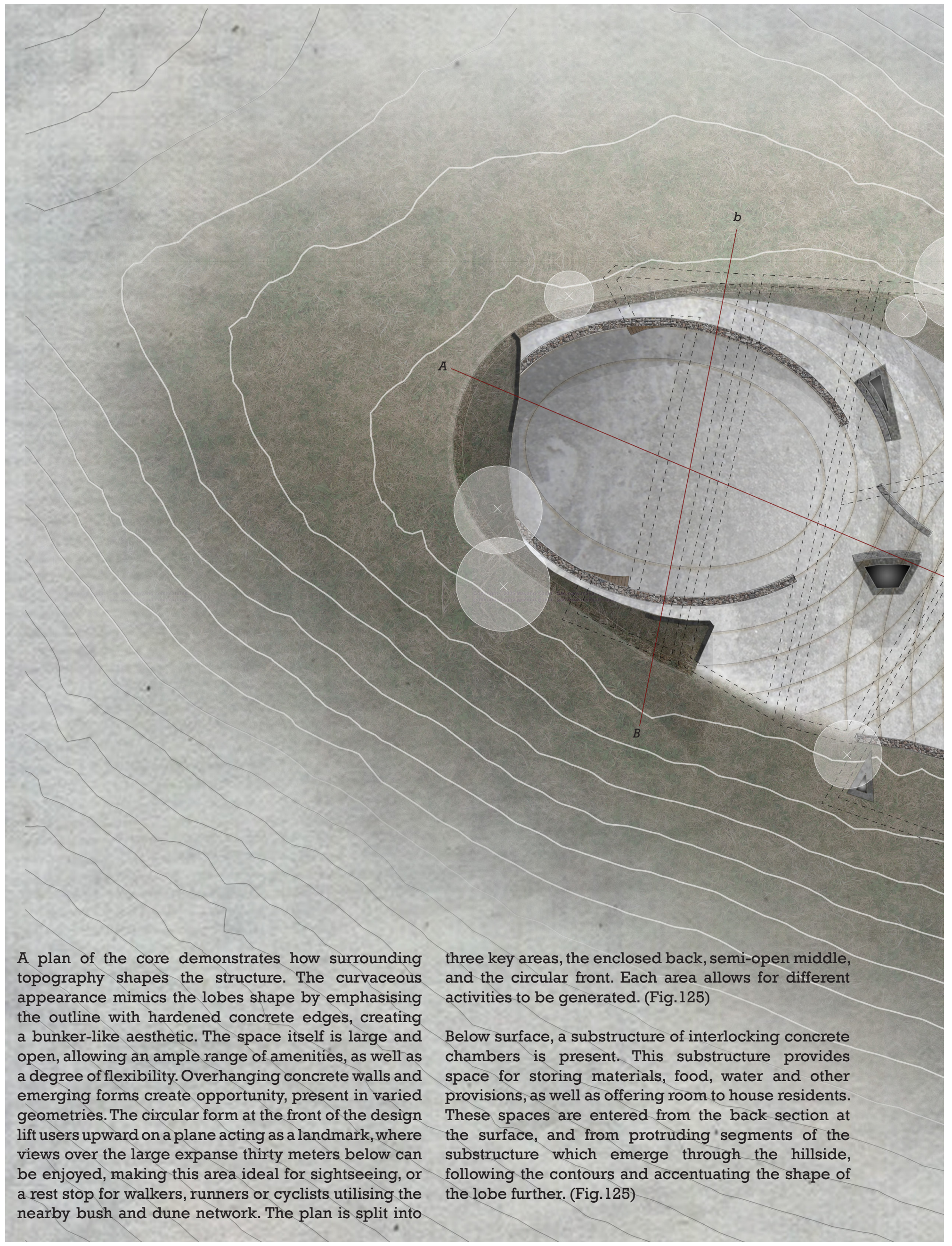




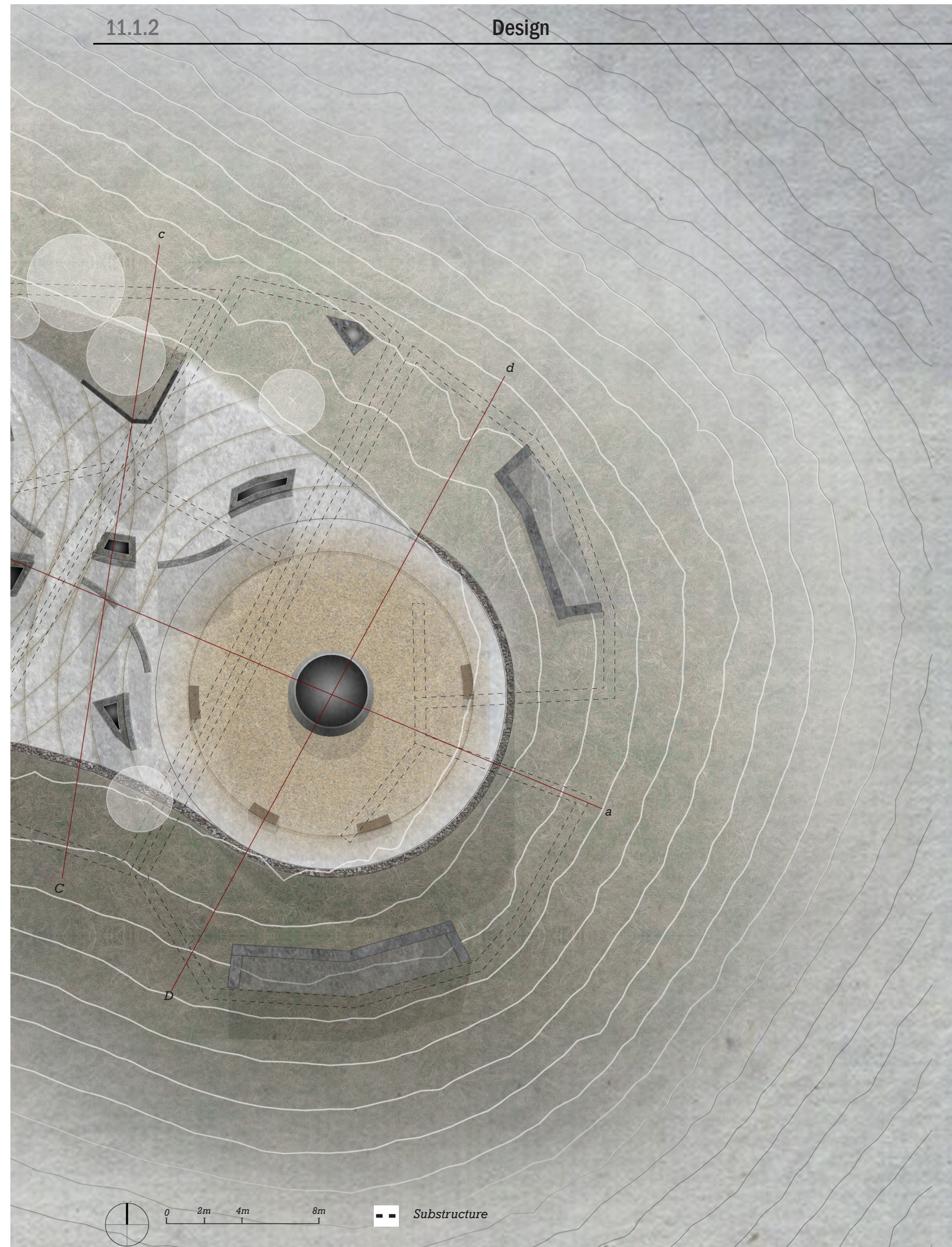


The grade through this longitudinal section displays the emerged-submerged gradient at the surface. The highpoints allow the space to function as lookouts, resting stops or meeting areas, the middle ground lends itself to seating areas, displays, or climbing structures, and the submerged section can act as an outdoor cinema or performance space. The substructure is much sturdier, and aesthetically heavier (Fig.126). These expansive rooms are well connected to the surface with large light wells which illuminate the substructure and connect the two spaces into one legible whole, reminding residents of the cores dualistic nature

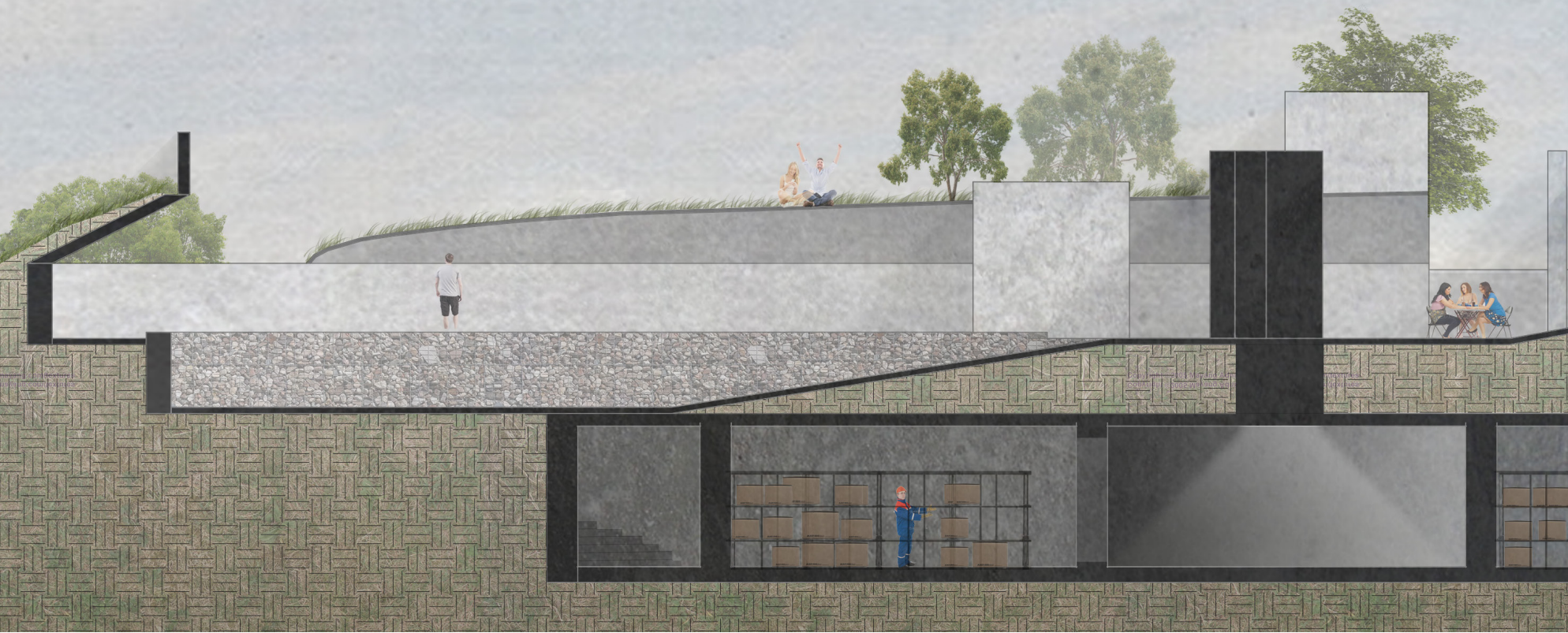

This section shows the encompassment of the cores rear, and its partial submersion into the landscape. The structure follows the landform, and the two seem connected. Access into the substructure is possible from here (Fig. 127). 


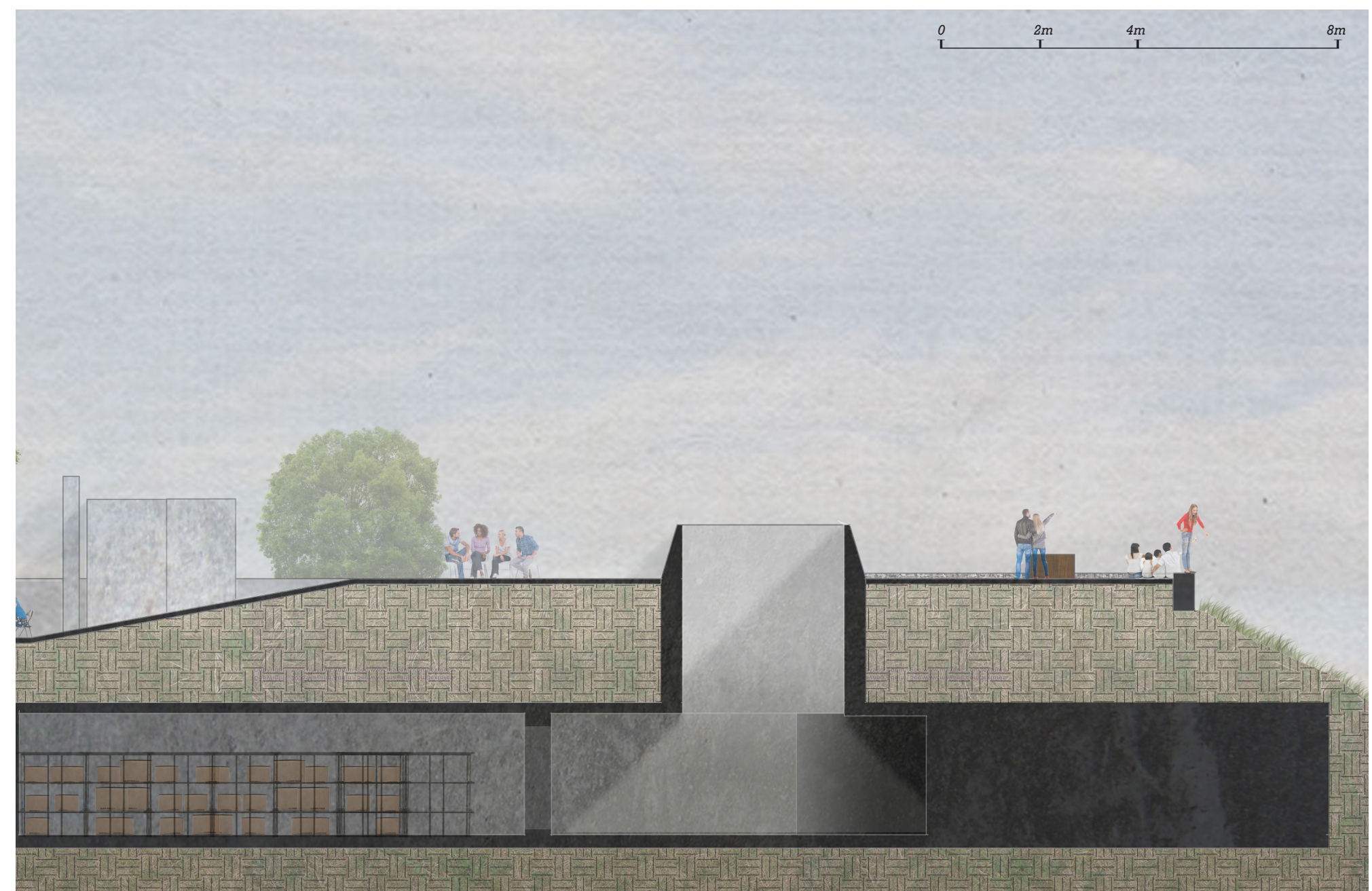

Figure 126 Section Aa: Longitudinal section though surface and substructure of structural core

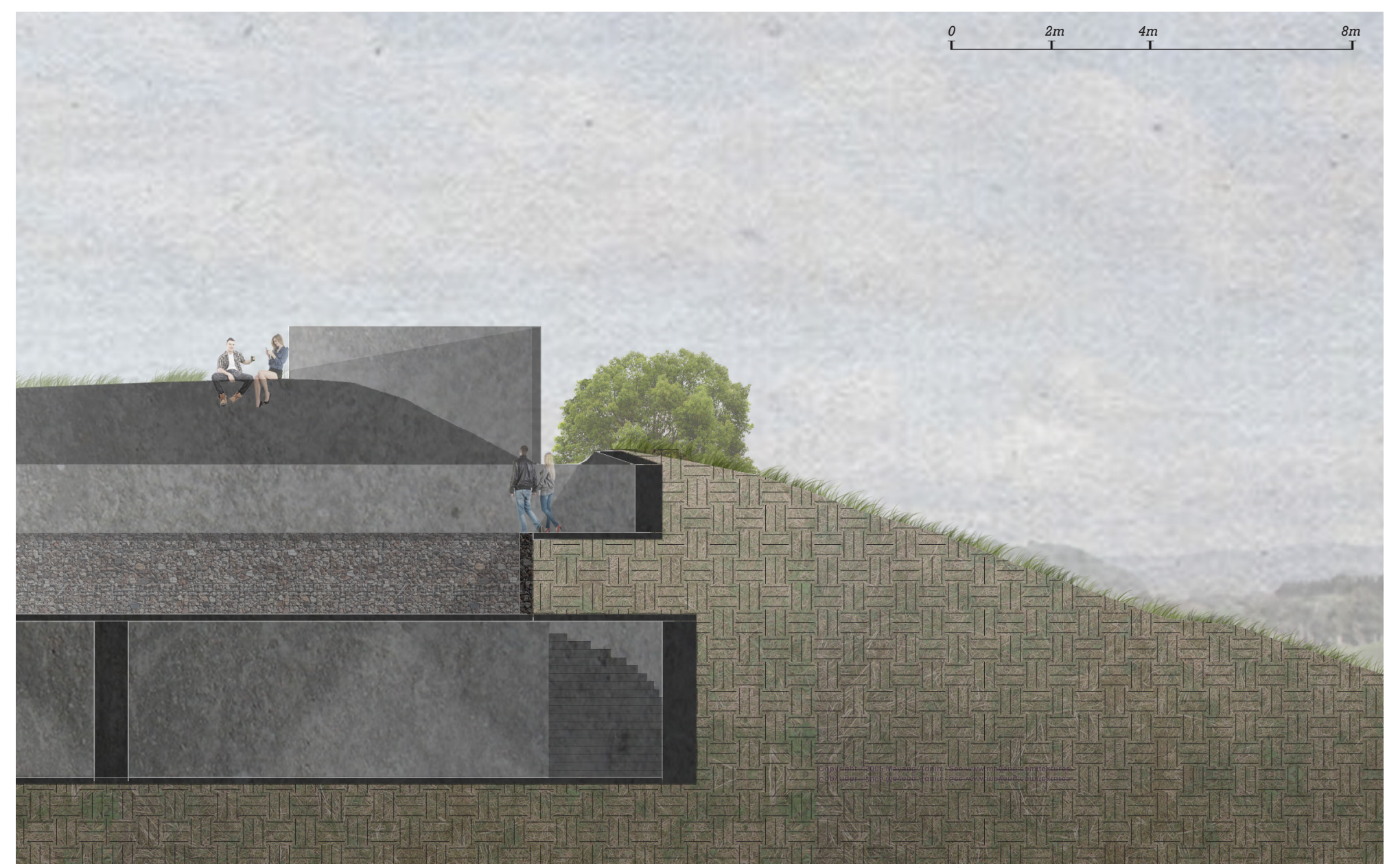


This section further highlights the form of the core, following the surrounding topography. Large concrete walls support soil which conceals the heaviness of the surface structure. Forms project from the ground plane allowing a number of activities to thrive, as well as forming the light wells which reach into the substructure (Fig. 128).

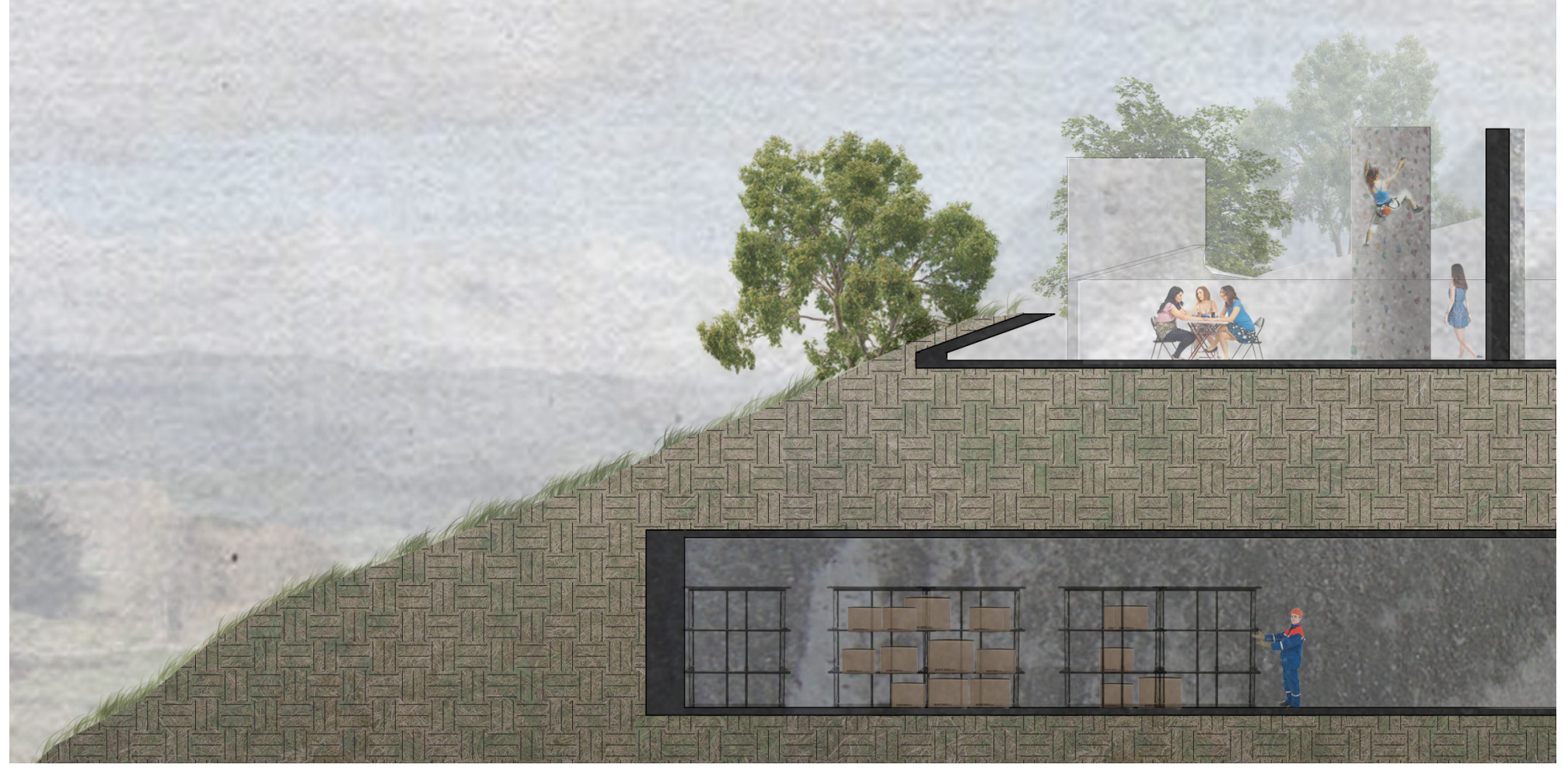

This section is the most open, and indicates the form of the topography. The large light well drastically improves visual quality below and ties the two spaces together (Fig. 129).

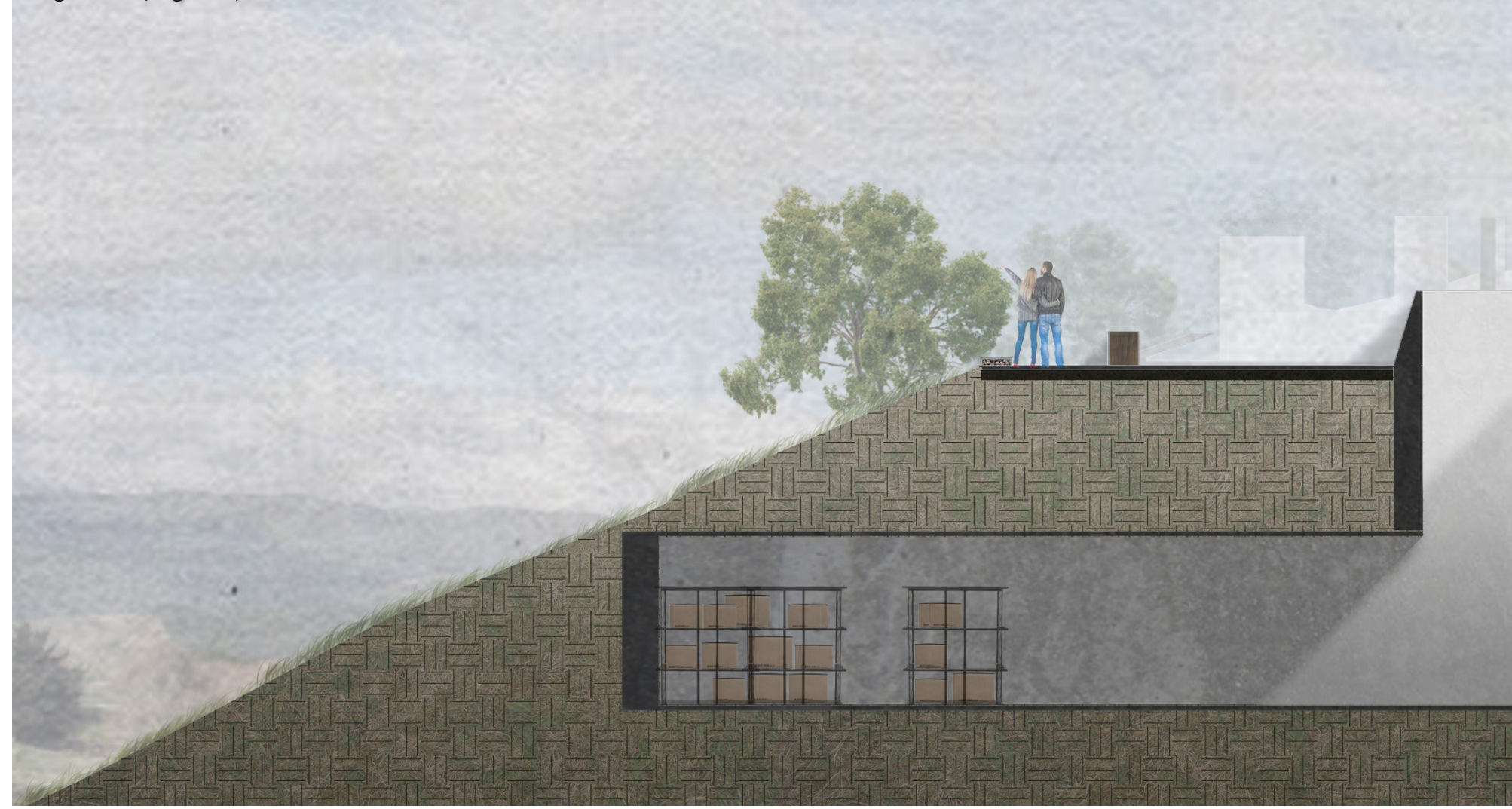


This activity matrix shows some amenities that can be applied to the three principle spaces. The typologies of activities relate to the form of these spaces and in many cases are influenced by the context (Fig.130). 


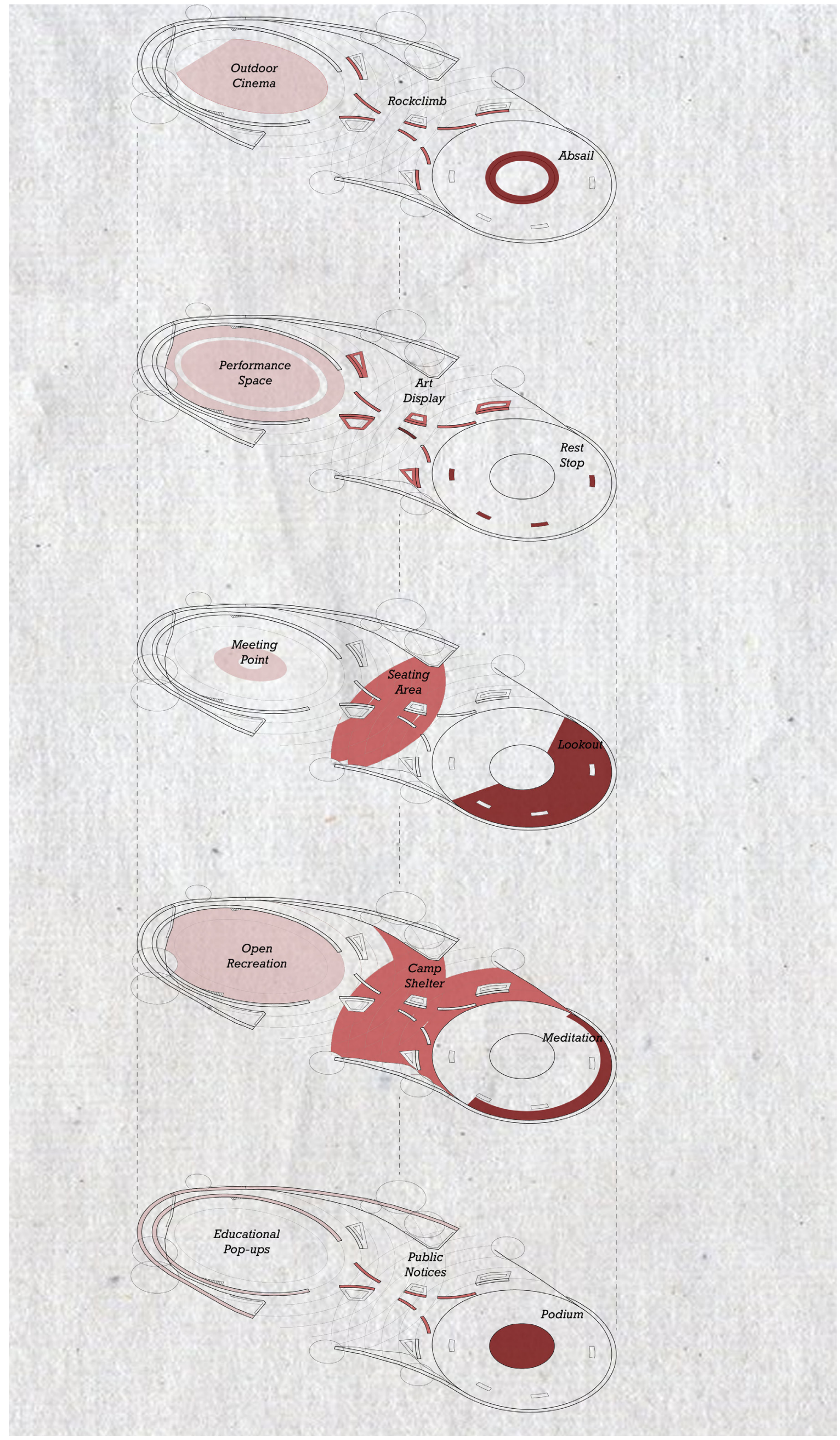

Figure 130 Various areas of the core can be applied to in a diverse manner 


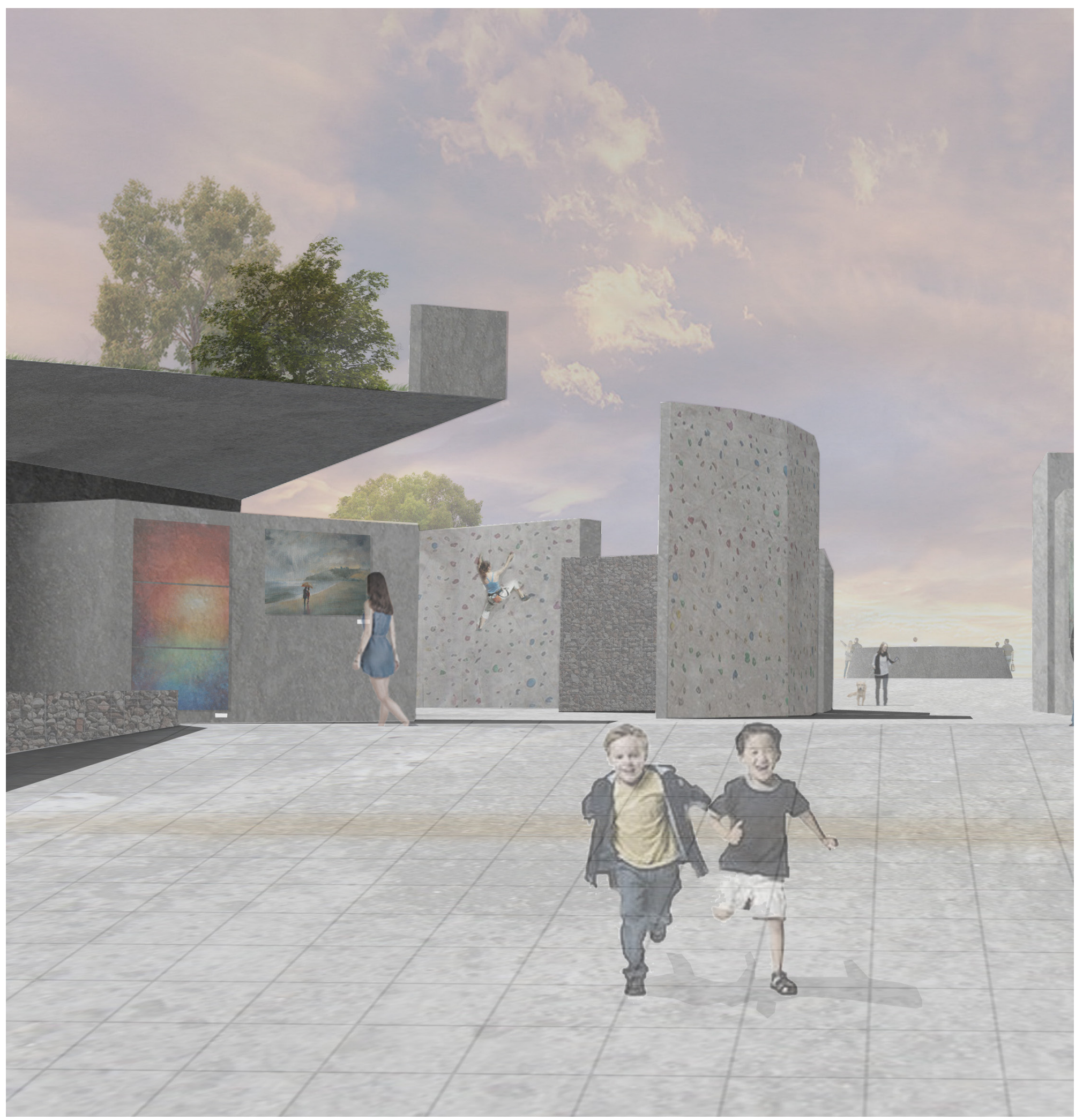




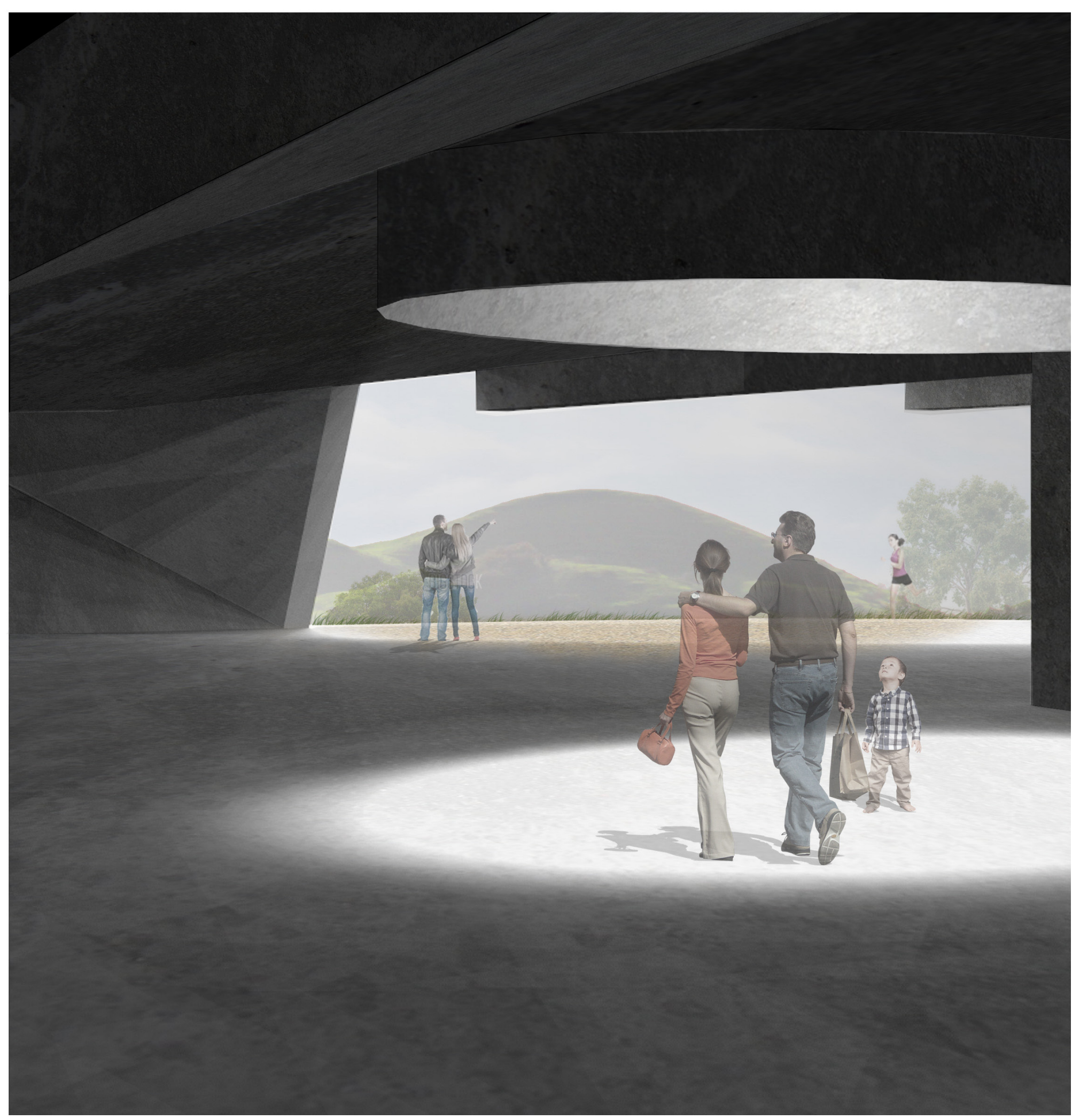




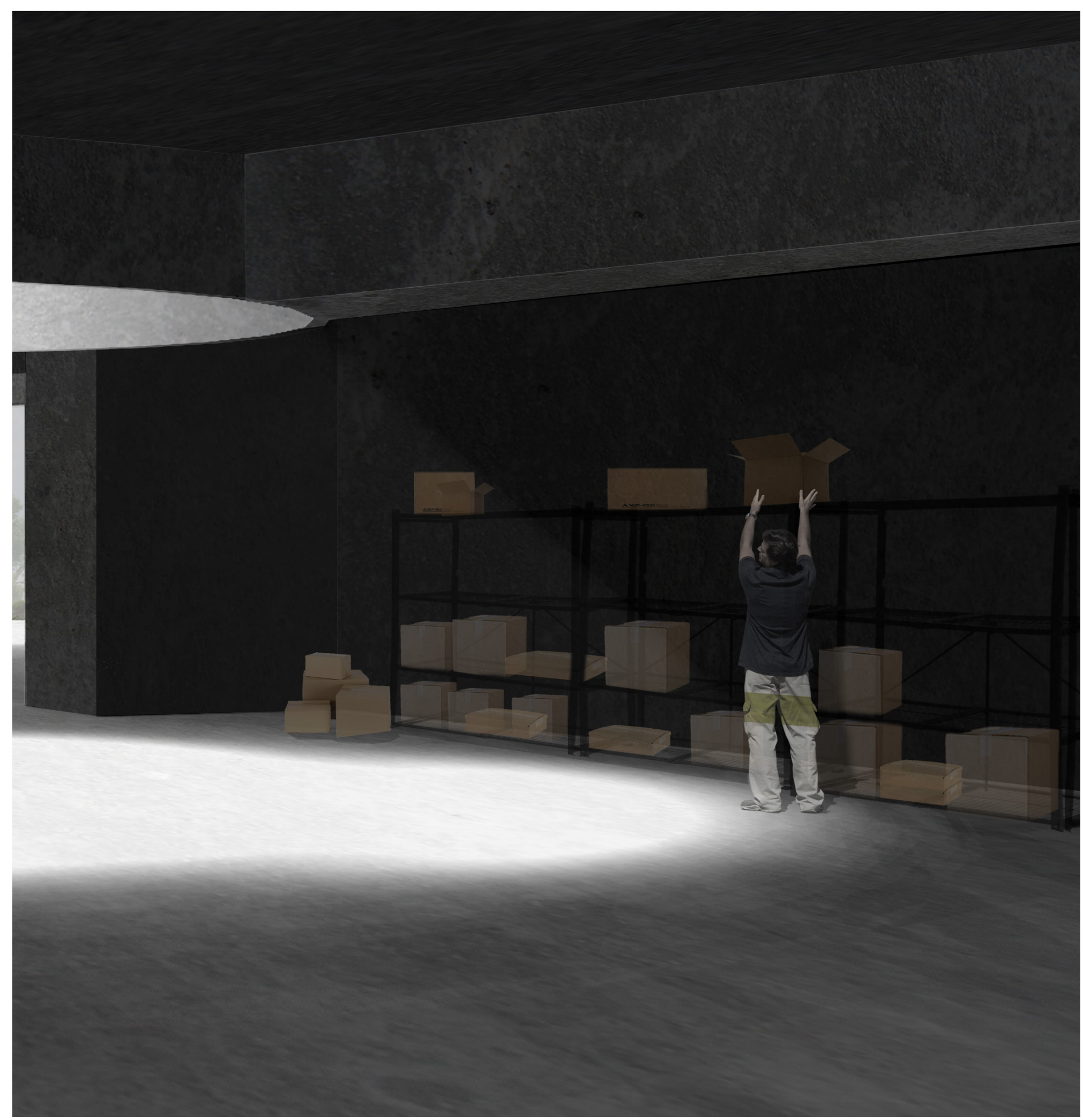

Figure 132 Substructure entrance/exit on slope, and areas for storage 
This second iteration is placed in a less defined location. The dune ridge on which it sits is fifteen meters high, among many in the area of similar form and height. The remnant system is also patchier here, and so flat land is less regular, forming around the parabolic dunes. There is a nearby road, but not a great deal of ideal building space, suggesting a smaller periphery. The largest driver is perhaps the very accessible river situated 150 meters away. (Fig. 133) 


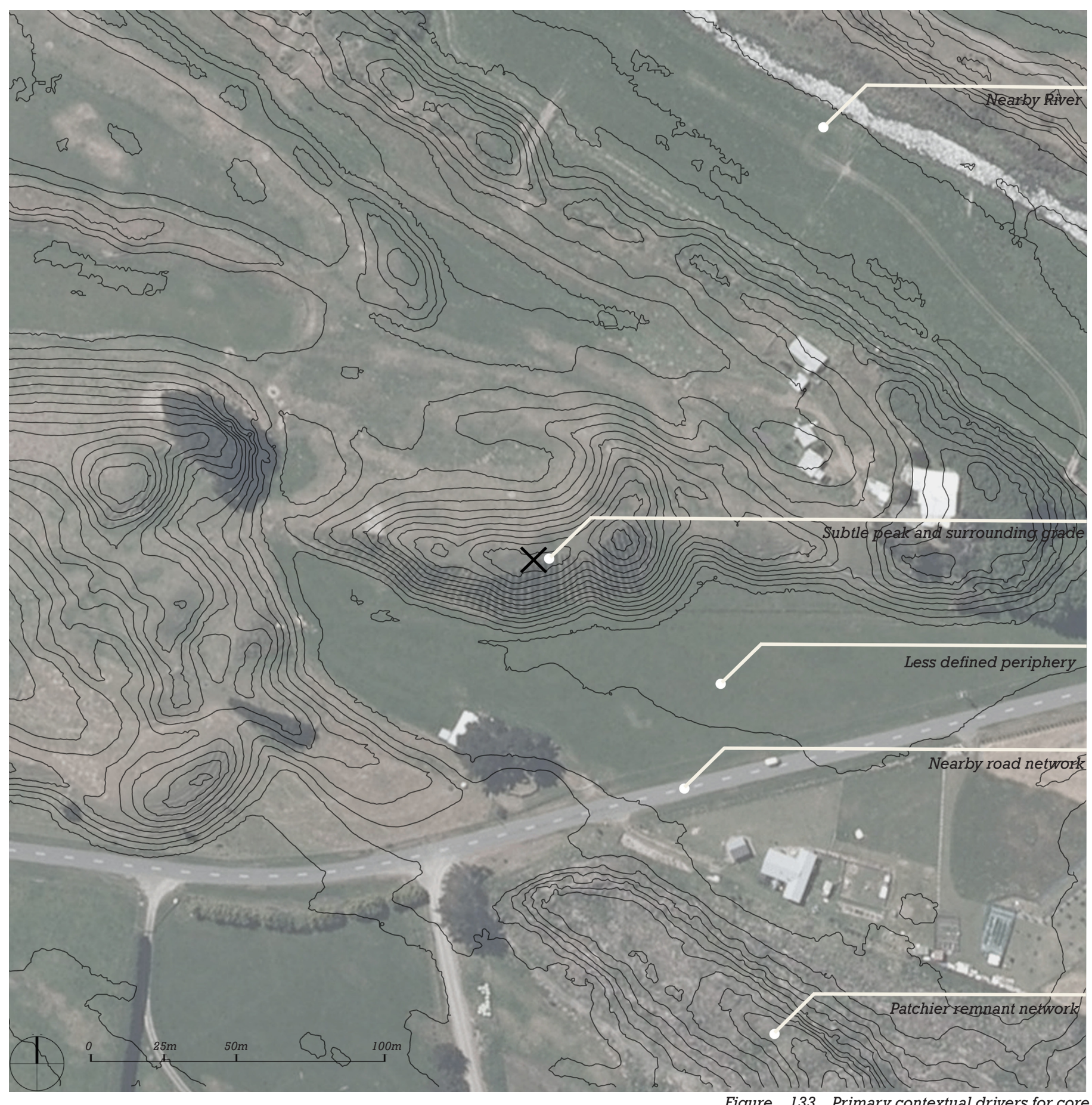

Figure 133 Primary contextual drivers for core 
This core exaggerates the features of topography in a subtle manner not dissimilar to the landscape it inhabits, being less abrupt than the previous iteration. The structure follows the contours highlighting the landform using a similar bunker aesthetic, creating coherence between cores. The surface is open, but unlike the preceding case is less 'built', corresponding to the likely smaller population and more subtle landscape. Elements from the substructure extrude through the surface, and manifest in varied forms, presenting different opportunities. At a glance, these seem disorganised, but on closer examination reveal a pattern. The most southern elements, closer to the settlement are of greater size and form shelters, furniture, and play structures, while the smaller elements on the northern side provide storage for water vessels and equipment, and are orientated towards the river. The most eastern element sits highest, providing elevated views. (Fig.134).

The substructure aligns with the elements on the surface. These chambers store provisions, and grant shelter, though on a smaller scale than the previous model. The substructure is split into three areas for storage/refuge, a corridor connects these together following the topography. Two entrances connect to the corridor and one which leads to the passageway granting access to the surface.The eastern substructure is separated and used to store water. (Fig.134).

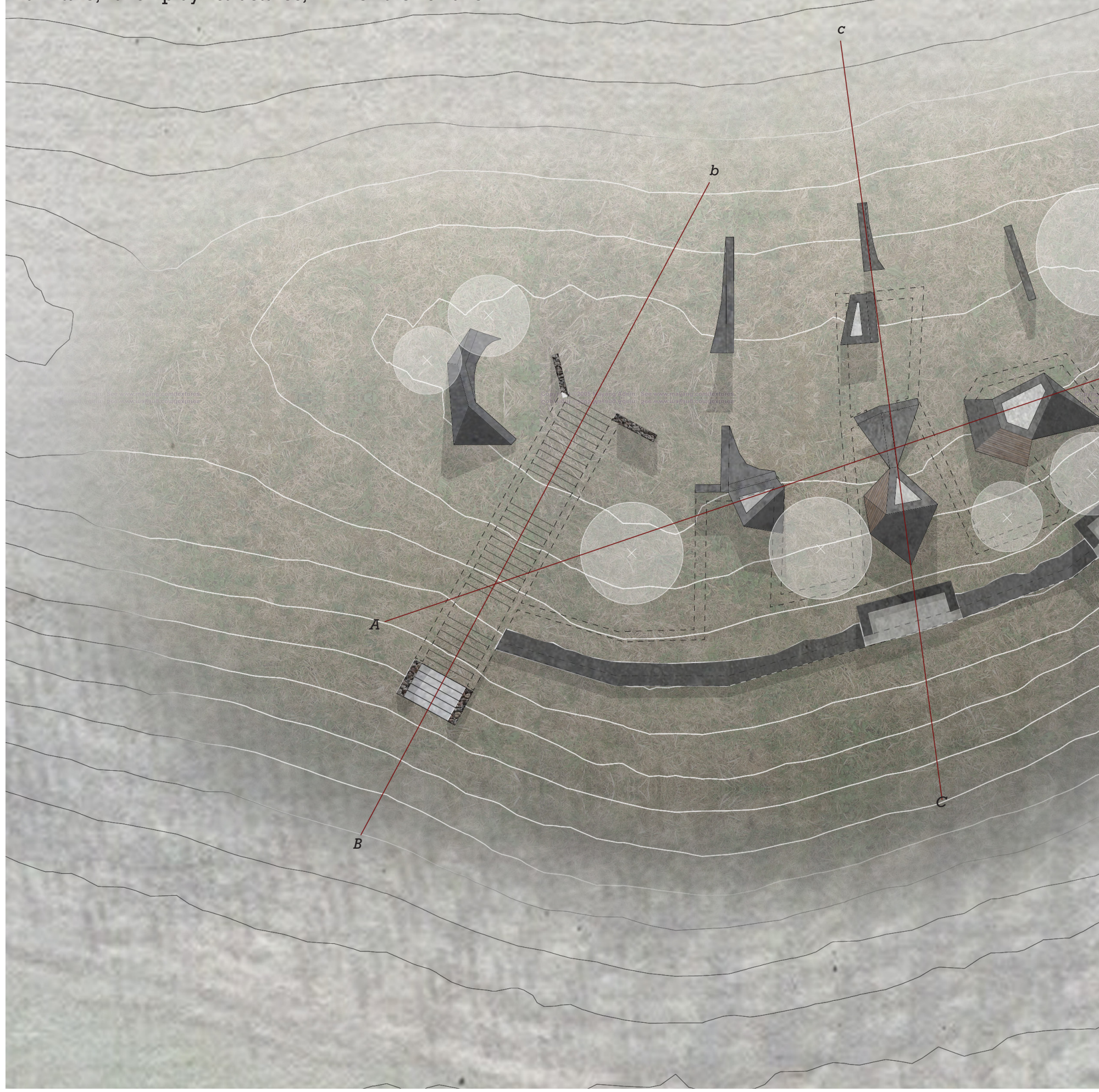


This longitudinal section shows the undulating ground plane. Concrete components of the substructure break through the surface, allowing other materials to be applied, and creating informal seating and other arrangements. The less intrusive nature of the substructure mirrors the modest landscape. Light wells connect the two spaces, and illuminate the substructure. The entrance on the western side dramatizes the experience, as residents wmove up through the earth, emerging at the surface.

The fragmented nature of this core allows segments of the core entity 'safe to fail', meaning that if some chambers can no longer perform as a refuge due to landslides, tsunamis and other events, others are available (Fig. 135).

The rear section displays the drama of approaching the surface through the entrance. The grade of the stairs matches the slope, mirroring it, and allowing soil to be placed on top effectively integrating the structure into the land (Fig. 136).

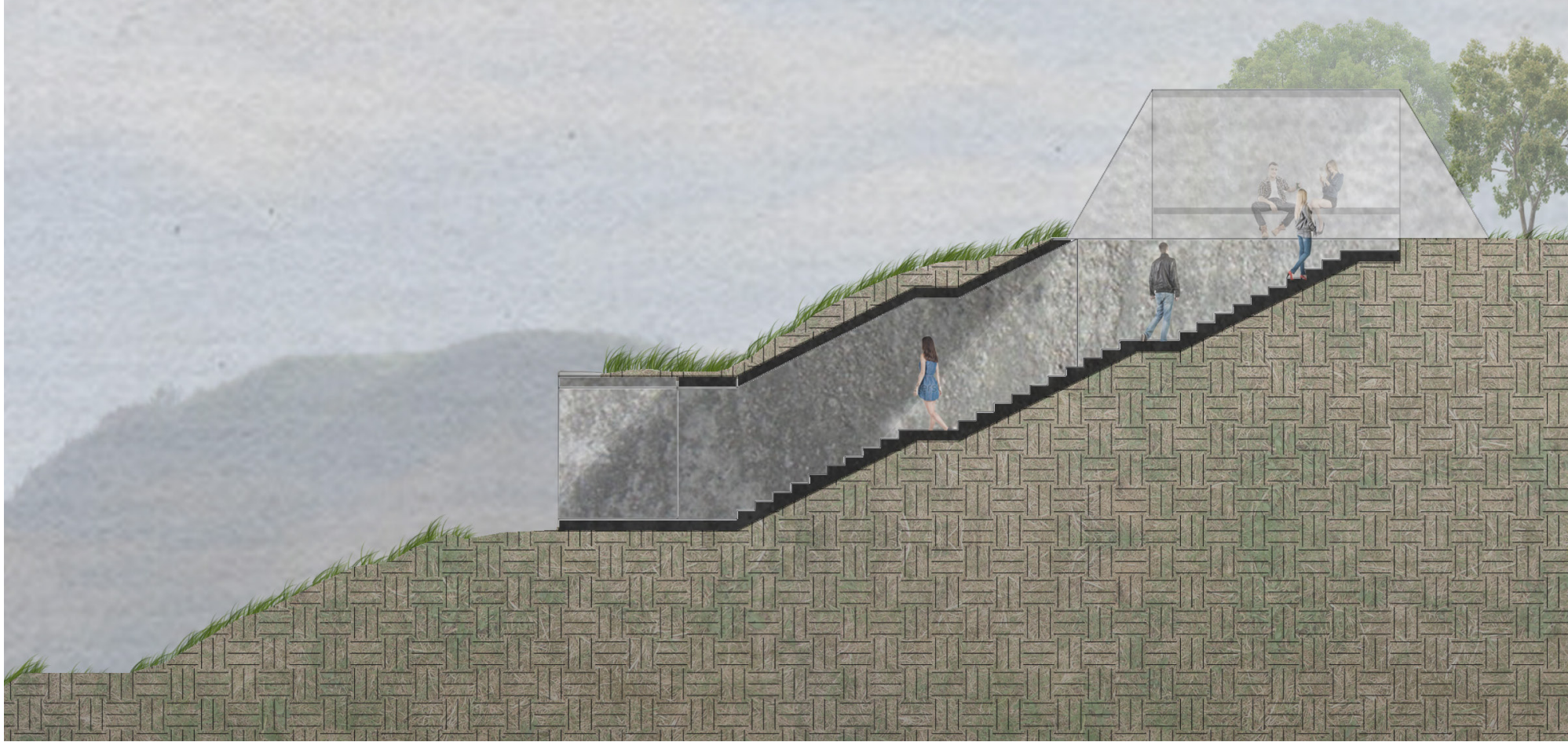


The middle segment cuts through the longest chamber, the substructure is brightened by light wells, and protruding elements create opportunity at the surface. The entrance to the South follows the contours emphasising the topography, while elements at toward the North point towards the river, storing water vessels (Fig. 137).

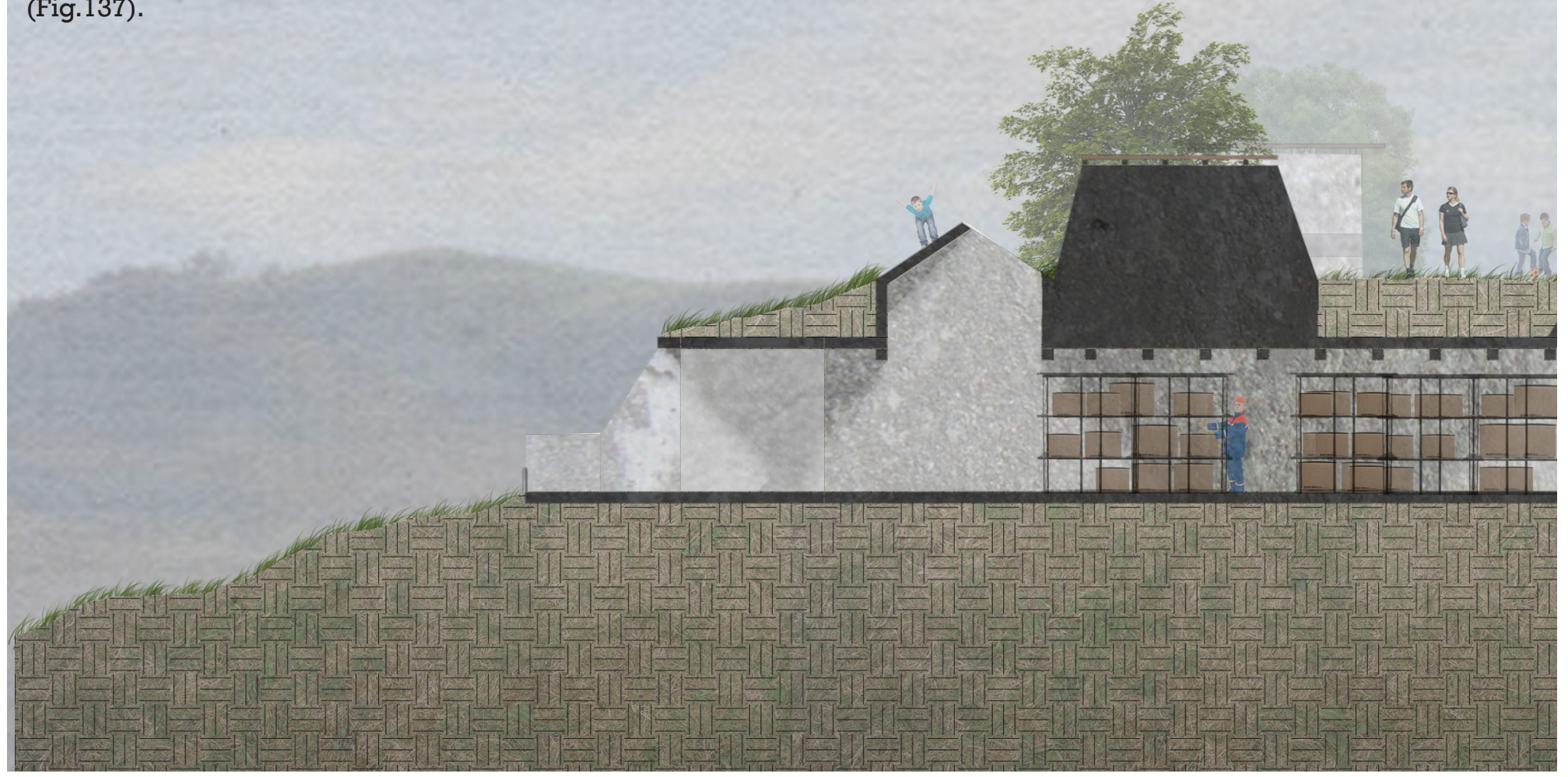

The front section cuts through the isolated eastern structure. This large water tank makes an excellent resting/viewing platform at the surface. Stairs lead to an enveloping passageway around the water tank for access (Fig. 138).

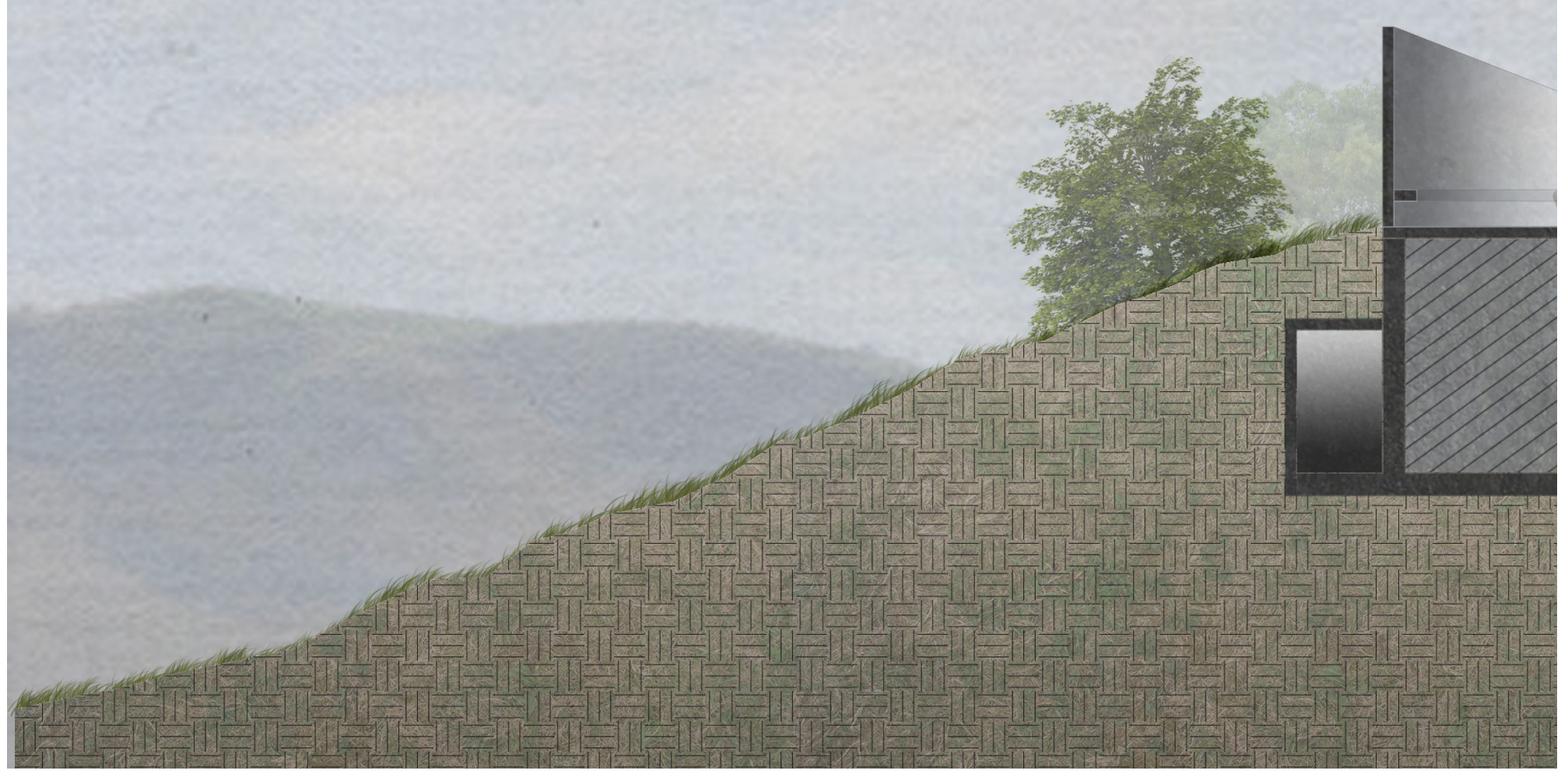


This matrix shows amenities applied to segments of the core. Elements are not as defined as in the previous case, but certain forms lend themselves to particular typologies of application (Fig. 139). 


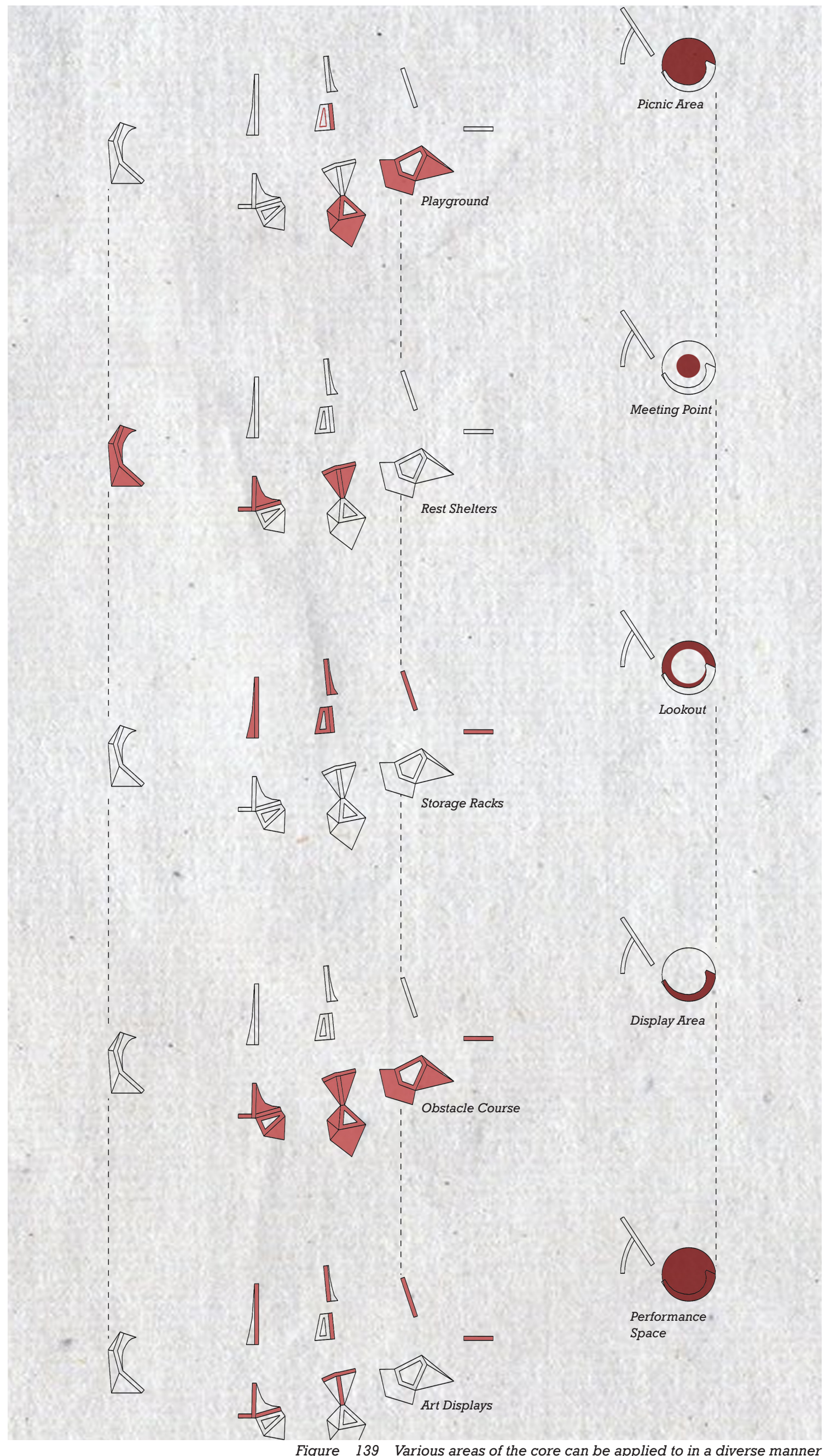




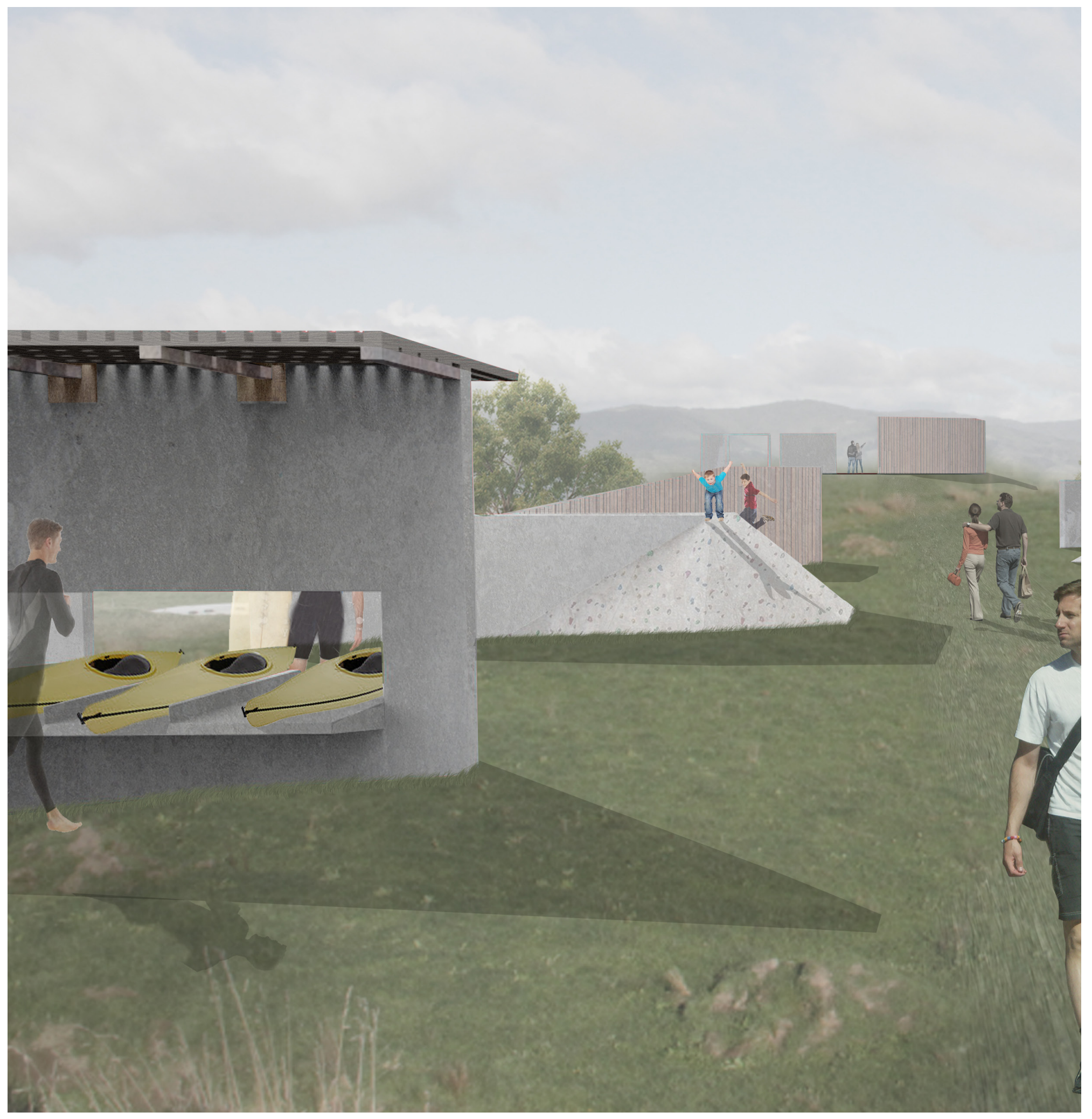




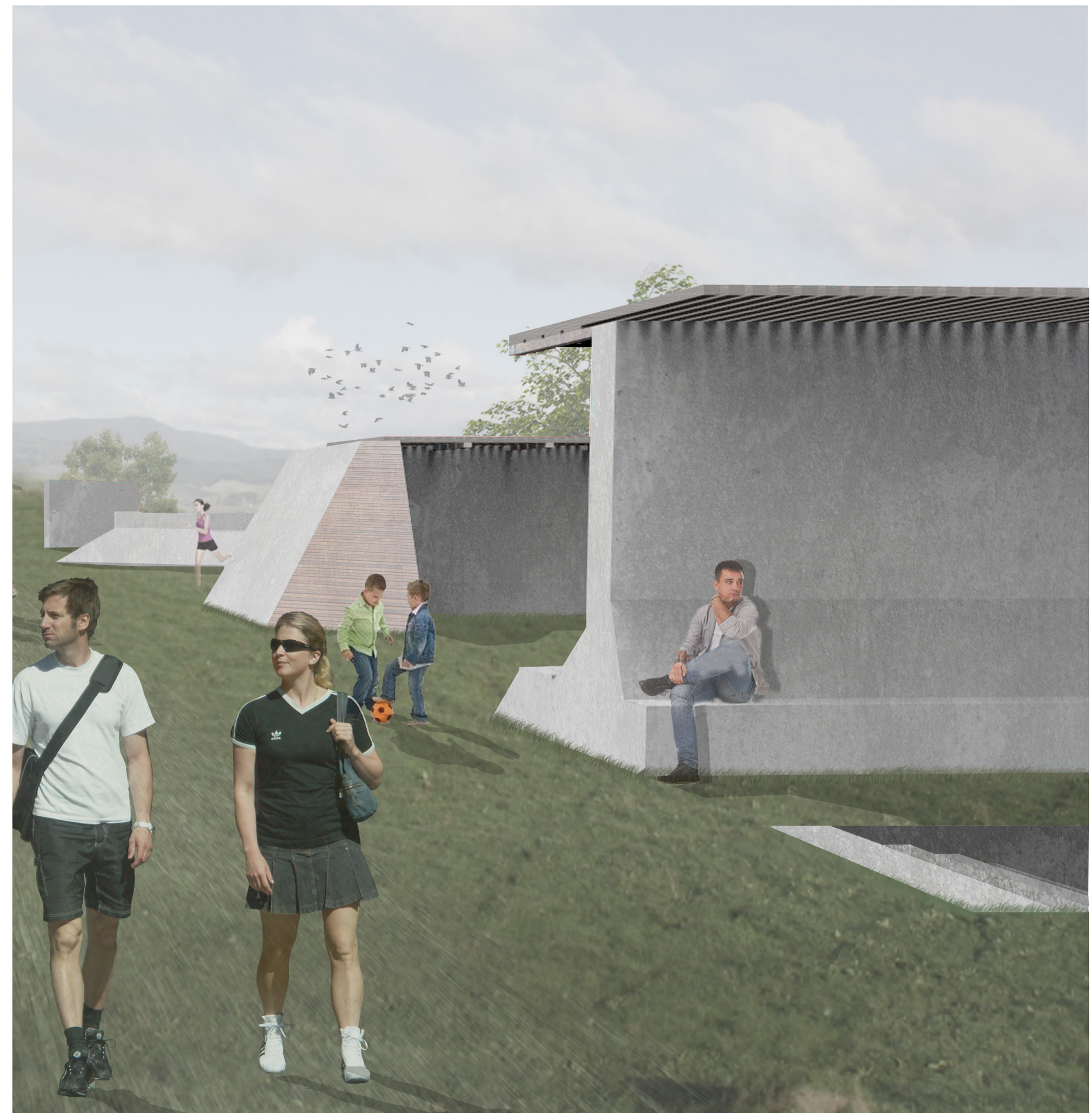

Figure 140 View looking between protruding elements at the surface, offering diverse amenity 


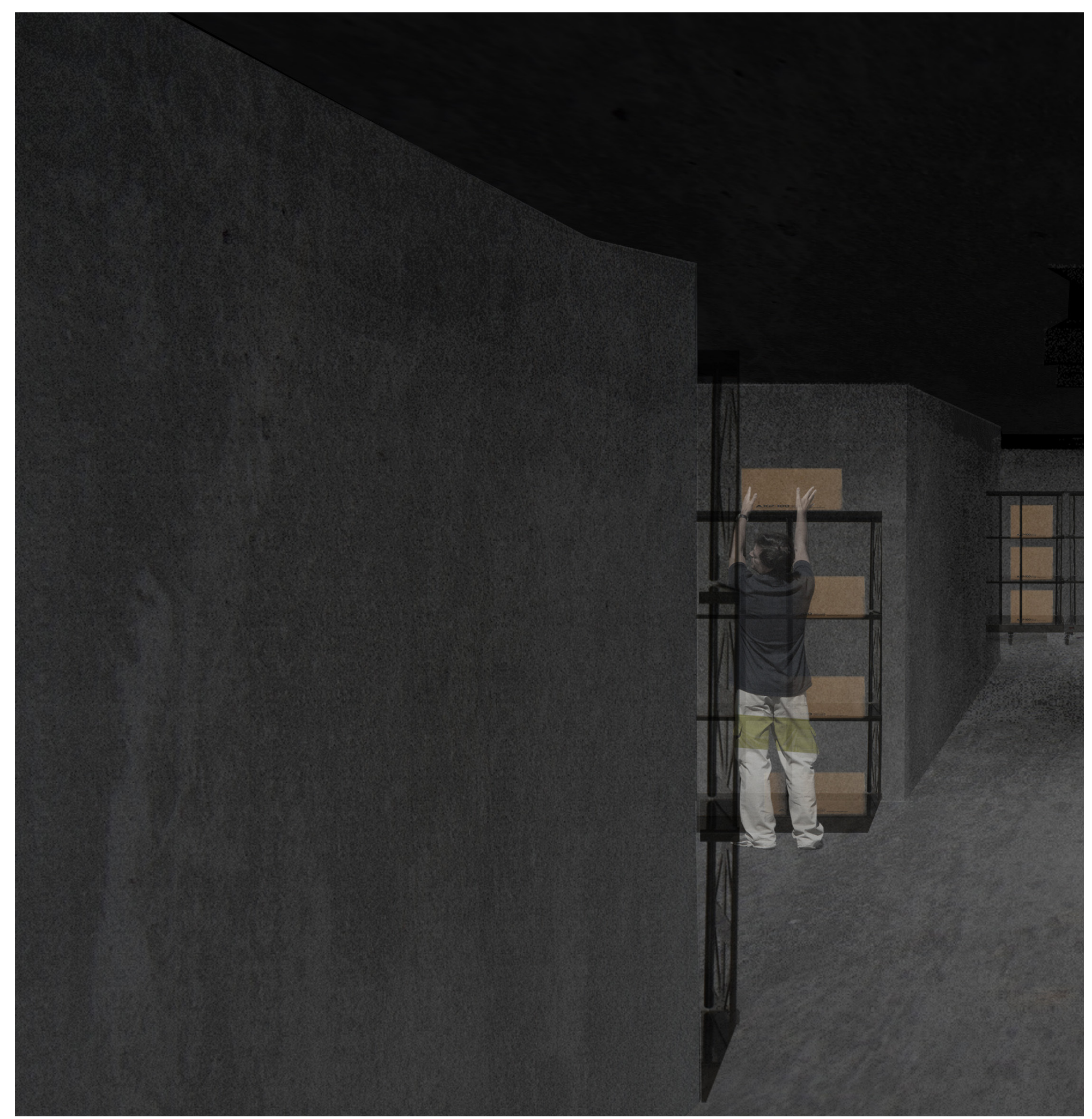




\section{Discussion}

Design research has raised a number of interesting ideas that are worthy of discussion and relevant to disciplines concerned with coastal settlement. 
Foremost, the significance of cores and core networks as a method for settling is much more responsive than that of traditional sprawling, centre-less settlements. This thesis has provided opportunity to investigate repercussions of reworking the way coasts in Horowhenua are settled.

In the case of this design, cores are located in a network which completely conforms to the movements of the land, working in 'tandem' with natural systems present in the landscape. In particular, static members of the landscape were utilised as a way of mediating uncertainty in what is an unruly habitat (Fig.92). The core system accepts that there is a level of unpredictability, but rather than fortifying settlement boundaries and preventing exchange between the landscape and settlements, the core system centres communities on a strong, natural reference point, and allows the periphery to change and adapt on a shorter timescale. This prepares settlements for long term change such as sea level and landform movements, avoids common threats such as river movement, and creates an infrastructural heart to the settlement from which a community can regenerate (Fig. 117).

The design research proposes a network of cores that spreads settlements across the coastal landscape, based on ideal foundations situated high on parabolic dunes. This allows room for growth on ideal building land in a number of areas, unlike many traditional settlements which instead disregard landform, requiring earthwork and disrupting ecosystems and processes. The result of the core system approach provides for a diverse range of settlements linked together, and each with its own unique 'flavour'. There are other benefits of this spread, such as the overall density over the total land being increased, which allows more people to sustainably inhabit the coast. The spread also prevents localised disasters from greatly affecting the entirety of the settlement; simply put these clusters prevent 'putting all one's eggs in one basket'. Overall, the arrangement of the network makes the core system enormously resilient (Fig.101).

The core network does not only make living on the coast much more viable and safe, but also much more responsive. The system is responsive in the fact that it acknowledges the coast as an unsettled landscape, a surface constantly fluctuating and changing. Due to this acknowledgement, application has occurred in a manner which respects this, avoiding most of the predictable changes, basing centres on stable points, and spreading communities to ideal locations. In this way, settlement application under the core system sets up a unique identity for New Zealand coastal settlements based on a response to the landscape, rather than a transplanted one, a system which perhaps belongs elsewhere. This does not imply that the core system is the only way to set up a legitimate New Zealand coastal settlement identity, but shows that through the reworking of the method in which we settle, it is possible to make settlements more true to the landscapes they inhabit. 
Rather than considering roads, grids, blocks, or lines of movement as suitable starting points or foundations for settlements, this design research considered the intangible components, the aspects which are often forgotten in planning, in this case the foundation for settlements was community. Traditionally physical elements are the leading drivers when it comes to planning; roads, open spaces, and residential areas are plotted out, and separated with bold colours, even though these do not relate to what is actually happening on the ground and its systems. Priority is placed into making 'places' efficient and practical. This is of course important, it means traffic congestion is reduced, undesirable industrial areas are mitigated, and arrangements are orderly and legible.

However, in the process of this, intangible qualities such as community are 'put on the backburner' or forgotten. These qualities which are the real definers of what it means to inhabit a 'place' are lost. The process of design in this research led to an intangibly pushed layout of a point and a periphery focused on communities, and so is less detailed in practicalities such as the exact placement of residential zones, or circulation (Fig.105). Setting up a strong community was a way to help the system work on a large scale as well, as keeping residents tied to stable points in the landscape, which could provide amenity and refuge. It is because of this that the core is established first, and not the periphery.

The relationship between the principle ideas of community refuge and amenity were the driving factors which ensured a strong community, and this was strongly linked to the form of the structural core. At the surface of both examples a variety of forms and spaces are presented which provide a diverse range of amenity in application (Fig.130,139).

The striking extruding forms in the centre of the first case for example, allow users to take shelter and offer secluded seating areas, yet could also be applied in a way which allows rock-climbing, gatherings, meetings, informal displays and so on (Fig.131). In contrast, the more open space lends itself to resting spots, viewing platforms, or meeting points, and the most encased areas allow for performance spaces, or gatherings such as outdoor cinema events (Fig.127-129).

Although the design is not the same for each core, the principles which guide it are, and a number of activities can occur here as well. Activities are again related to the immediate context in which the core sits (Fig. 124,133). Interestingly, it is shown here that there is an inherent need to design on the detailed scale, in order for large scale plans to feasibly work. Various detailed forms allow for opportunity that different members of the community can capitalise on, this has eventuated in several complex extrusions of different shapes which lend themselves to certain activities. An example might be the extruding centre elements in the first iteration which at first seems ambiguous but are actually facilitators of wall displays or rock-climbing (Fig.131). Another example would be the north facing elements within the second iteration, though the form seems randomised, in reality they are ideal structures to store water vessels (Fig. 140). 
This thesis has used geomorphology as an indicator for settlement. Typically, settlement is applied utilising patterns and layouts that you might find in an urban planning guide book. Rather than applying these in a 'stamp' like fashion against the grain of the land, it was vital to examine the patterns present on the coast. Though this could be considered more design intensive, the benefits in this case, outweighed this. It was through this analysis that the parabolic dunes were noted as a potential way to set up the infrastructure of a stable coastal settlement. Only when several components of this shifting land were tested and their qualities revealed did it become apparent that this old remnant system could form the base of a responsive, sustainable settlement, a foundation which could mitigate the threats of other movements within the landscape (Fig.60). The placement of the current Waikawa Township displays the inability of poorly planned settlements to respond to coastal movements. This is evident in the several flood episodes, destruction of fore dunes, continual re-alignment of the river mouth, and an inability to protect the community from storm events, earthquakes, tsunamis or even the slow rise of the sea.

The same process of determining stable points based on the geomorphology specific to Waikawa could be easily applied to the entire stretch of the Horowhenua coast as the landscape bears a similar characteristic along this stretch. Analysis similar to the one conducted could indicate stable remnants which are common along the stretch. From here, more networks could be established, guided under the same principles but taking on varied layouts. It is likely that this process is applicable in other areas of New Zealand, and globally. The simple principle of discovering the stable components, from which settlements can be founded, can be applied in many situations. In some cases this might be old remnant dunes, but in other instances other components may be more stable. This would require specific research into the processes of sites, which would necessitate heavy analysis. Ideally this would eventuate in a number of aesthetically varied townships and diverse arrangements, all created under the same guiding principle. 
For an idea like the network of cores to become a reality it is essential to consider the consent and wellbeing of current landowners. How can stakeholders with vested interest in land be made willing to release large portions of land? This question needs answering in order to allow the setup of a core system, if there is an expectation for this to occur on a reasonable timescale. It would be unfair to assume that these land owners (predominantly farmers) who continually utilise and profit off the landscape would be willing to conform. Over a longer time frame an opportunity to purchase land as it becomes available is present, however the time this would take is difficult to estimate. An exchange of similar value is required to protect land owners and to allow the synchronised instalment of the network (Fig.111-116). The exchange that would occur at Waikawa is one which would benefit both parties, the land requested is that of the parabolic dune systems, steep, unruly land not ideal for farming practices. In selling this land the farmer is left with purely workable land, while the core development has gained the most stable land on the coast (Fig.110). Roads can be built close to these remnants, which can now acts as markers for farmers' territories. As development spreads there is also a source of potential buyers who can directly purchase provision, or stock from the farmer, while residents have the benefit of onsite produce. In this sense the farms become part of the coastal system and core network, synergising to form a collectively functioning entity.

This interface between the core system, and land owners such as farmers has the potential to be explored in greater detail. It is possible that there are several opportunities laden within this interface which could be exploited. An example might be how the periphery of settlements which are linked to cores might further assist farming practices. Could for example, peripheries extend near streams, creating buffer zones which prevent the pollution of waterways from farm practices? Or could peripheries perhaps function as filtration zones which clean runoff before it enters water bodies? Questions such as these are worth exploring, they are examples of how synergy of two seemingly different practices can lead to the landscape in its entirety working together in mutual benefit. The way in which the land is purchased is the first step which has been explored, but there is clearly room for further investigation here. 
The form of the core is derived from an amalgamation of contextual requirements. It is not randomised, or based solely on aesthetics, program, or function. Essentially, the form of the core is denoted from three key drivers.

Firstly, form is influenced by attempting to be a point of stability. Cores are situated on the most stable land, and are the refuge to nearby communities. A fragile structure seems to fit conversely to this. The core is designed to last; it is the foundation point of settlements and so must be exceptionally durable and strong. Both examples presented in this thesis display an incredibly sturdy structure which is predominantly constructed with heavy materials such as concrete, and burrowed into the ground plane to protect it. The thick walls of the substructure are comparable to bunkers designed to store and protect materials, provisions and people (Fig. 132,141).

Secondly, the form is derived from community needs. On one hand the core must provide enough variation in form to supply an ample range of activities to a diverse population. The complexity that is present within the examples is designed to manifest a multiplicity of applications. The second case, for example presents several protruding forms which exit the surface. These forms are of varied shape and size and can have different materials applied to them (Fig.140). The forms which reside on the Northern edge for example are excellent places to store water vessels, while on the southern side seating arrangements, shelters, displays, or play structures are all possible with the varied configurations. On the other hand the substructure is much more rigid, organised, and easily legible, because it must be to support storage and act as a safe house. The light wells connect the substructure to the surface, and many of the protruding forms are in fact these light wells. This is an example of where a practicality such as lighting the substructure using light wells, can also present an opportunity on the surface for amenity application (Fig.128). The complexity in form which arose from amenity variation becomes localised and special to residents adding familiarity and distinction between communities. Each element may convey a different meaning to individuals who may choose to apply themselves differently than another user might.

Finally, the form of cores is designed to make them a landmark. The delicate issue with this was to prevent the structure from overwhelming the landscape feature on which it sits, but still be able to be a recognisable safety point. The strategy here, is to use the structure as a way of highlighting the prominent features of the remnant on which it sat. By burrowing the structure into the land and presenting the protruding edges of it around the shape of the localised topography it was possible to emphasize the shape of the dune. The first core example perhaps shows this more plainly, where the circumference of the structure clearly follows the contour lines. Protruding elements of the substructure several meters below also follow their relevant contours (Fig. 125). 
This thesis has challenged the traditional methods of settling and has utilised a landscape architecture led approach as a way to explore more responsive settlements and plans. The design outcome is a summation of several research findings, and a holistic answer to issues in settling coastal landscapes.

Design research has uncovered a number of principles which can be applied when dealing with the coast. These principles are useful to several disciplines, including landscape architecture, but also other planning sectors. Aside from being applied interdisciplinarily these principles have the potential to be applied in foreign landscapes.

In particular, the application of the core notion at Waikawa led to a fabric which avoided coastal threats, allowed coastal processes to continue, built stronger communities, solidified the inhabitation of 'risky' areas, and improved New Zealand's coastal identity.

Using geomorphology as an indicator for settlement created arrangements which were more in tune with patterns and meant that coastal settlement could be stable.

Using community as infrastructure was a defining decision. This intangible response eventuated in a distinctive settlement structure which focused around points, paths and peripheries. To solidify community however, a great deal of detail was invested in the hearts of settlements, showing the importance of designing at multiple scales.
Form was explored as a way to mediate the several expectations for a core, the design outcome attempted to act as a point of stability, perform as a communal hub and refuge, and to act as a landmark to the surrounding periphery.

Design has revealed the importance of coordinating the implementation of a new system with land owners, and discovering how the release of land can somehow benefit the land owner in ways which surpass purely economic value.

Fundamentally, design research has shown that there is potential for coastal settlements in New Zealand, and globally to be re-applied in a manner more in tune with the coastal processes. There is opportunity for settlements to respond to threats and disasters, to promote ecosystem health, to spread/densify the coastal landscape, to create stronger communities, and to create a coastal fabric which references the identity of the landscape.

The thesis is limited in some cases by the need for more scientific data, which in particular might provide more insight into precise movements, and in turn, aid in guiding placement of settlement components.

There is an assumption in the implementation of the core system that, because a beneficial deal exists for land owners, they will take it. The design research does not investigate how a system of cores might function provided that vital land is not acquired, this could be an interesting and rewarding investigation which might 
reveal how the core system might function regardless of whether all required land is seized.

Opportunity in research also lies within interaction between the periphery and the surrounding farmlands. This topic has been left relatively unexplored, investigation into this area may uncover methods in which the periphery and the surrounding land can synergise in mutual benefit. Although possibilities, such as the potential for peripheries to clean farm pollutants, have been mentioned, there is no exploration of how this might eventuate. This area of investigation could prove informative and push the boundaries of farming/settlement interaction.

The dynamic nature of coastal environments and the current application of irresponsive settlements call for a change in how we inhabit these fragile areas. This thesis has argued that there is a need for more responsive settlements which not only react to processes on the coast, but also improve communities, create a more dense and diverse landscape, relate to surrounding practices, and that move towards a 'true' coastal identity. Design research that has occurred here shows that these goals are not only fundamental to sustainable coastal living, but more importantly that they are achievable. 
All unattributed figures are authors own.

Figure 2. Destruction following Tsunami at Rikuzentakata, Japan -Source-http://www.latimes. comworldla-fg-japan-tsunami-before-after-sliderhtmlstory.html

Figure 3. Crumbling cliff at Happisburgh, England -Source-http://www.andrewdunnphoto.com/

Figure 4. Construction of sea wall at Oriental Bay, Wellington, 1930 -Source-http://mp.natlib.govt.nz/ detail/?id=21778\&l=en

Figure 7. The Maritime Youth House deck structure sits above the toxic land beneath -Source-http://www. metamodernism.com/2011/04/04/bjarke-ingels-iiat-warpspeed/maritime-youth-house-copenhagendenmark_0/

Figure 8. Diagram of substitution of toxic land with new deck structure -Source-http://www.archdaily. com/1 1232/maritime-youth-house-plot/

Figure 10. Conceptual section through the Retreating Village mechanics -Source-http://pruned.blogspot. co.nz/2007/09/retreating-village.html

Figure 11. Model shows structures ability to move in response to erosion -Source-http://discovery.ucl. ac.uk/9740/1/9740.pdf

Figure 13. Ha Long Bay's network of connected rafts -Source-http://theclassytraveler.com/ha-long-bayone-of-the-7-natural-wonders-of-the-world/floatingvillage-vietnam/

Figure 14. Floatation devices prop the settlement above the sea -Source-http://www.feedmetravel.com/ vietnam/vung-vieng-floating-village-halong-bay

Figure 16. View along beach spit at Dauphin Island -Source-http://www.toniknox.com/

Figure 17.Typical stilt house at Dauphin Island -Sourcehttp://onegreatjourney.blogspot.co.nz/2009/02/ dauphin-island-storm-damage-end.html

Figure 18. Five kilometre Access Bridge to Dauphin Island -Source-http://www.panoramio.com/ photo/20404172

Figure 20. Interior tunnel system -Source-http://www. caravanmagazine.in/periscope/saving-our-seeds

Figure 21. Storage space inside vaults -Sourcehttp://news.nationalgeographic.com/news/ pictures/2012/07/120702-svalbard-doomsday-seedvault-food-supply/\#/rio-20-seed-bank-svalbardracks_55733_600x450.jpg

Figure 22. Section of Svalbard Global Seed Vault -Source-http://climatechange.thinkaboutit.eu/think4/ post/global_seed_vault_the_food_protector.html

Figure 24. View across Chand Baori structure -Sourcehttp://www.amusingplanet.com/2012/10/chandbaori-step-well-in-rajasthan-india.html

Figure 25. Plan/Section of Chand Baori step well -Source-http://socks-studio.com/2014/03/13/ inhabiting-infrastructures-indian-stepwells/

Figure 27. View along a 'line' connecting the parks 'points' -Source-https://eutouring.wordpress. com/2015/01/16/follies-within-parc-de-la-villette/ 
Figure 28. Exploded plan separates the scheme into 'lines', 'points', and 'surfaces' -Source-https:// landscapelover.wordpress.com/2010/11/30/parc-dela-villett

Figure 29. Diagram showing the various forms follies may acquire -Source-http://plusacne.org/2014/01/03/ la-villette/

Figure 31.View ofvariousapplicationstranspiringwithin the space -Source-http://www.landscapeishankin. blogspot.co.nz/2011/03/blog-post.html

Figure 32. Two students play Ping-Pong using a table based off a pallet module -Source-http://www. landscapeishankin.blogspot.co.nz/201 1/03/blogpost.html

Figure 33. Variation of module form allows for numerous amenities and application -Source-http:// www.landscapeishankin.blogspot.co.nz/201 1/03/ blog-post.html

Figure 36. Map of the former course of the Ohau/ Waikawa River -Source- http://natlib.govt.nz/records /22370716?search\%5Bi\%5D\%5Bcollection \%5D=Adki $n+$ album $+18 \&$ search $\% 5 B i \% 5 D \% 5 B$ subject $\% 5 D=O h a$ u+River\&search \%5Bpath\%5D=items

Figure 37. Historic River courses -Source-http://www. waikawabeach.org.nz/?m=seupfhmjum\&paged=9

Figure 38. Historic River course -Source-http://www. google.co.nz/maps/@-40.6891655,7606a,20y,90h/ data $=! 3 \mathrm{ml} ! 1 \mathrm{e} 3$ ?hl=en

Figure 44. Footbridge before flood events across Waikawa River mouth (1931-1990) -Source-http:// horowhenua.kete.net.nz/en/site/images/7534waikawa-bridge-on-main-road-after-flood1922?view_size=large

Figure 45. Damaged bridge inland along Waikawa River following flood (1920)-Source-http://www. waikawabeach.org.nz/?p=127

Figure 58. Image of parabolic dune study at Cape Cod -Source-The twentieth-century migration of parabolic dunes and wetland formation at Cape Cod National Sea Shore, Massachusetts, USA

Figure 62. Map showing extent of damage from 1855 Wairarapa earthquake. Waikawa (within second ring) is susceptible to landslides, liquefaction and cracking -Source-http://www.teara.govt.nz/en/ interactive/4392/extent-of-shaking-wairarapaearthquake-23-january-1855

Figure 63. Artist's impression of landslide, Wellington, 1855 -Source-http://info.geonet.org.nz/display/ quake/M+8.2+-+8.3,+Wairarapa,+23+January+1855

Figure 64. Site of landslide in 1855 -Source-http://info. geonet.org.nz/display/quake/M+8.2+-+8.3,+Wairara pa,+23+January+1855 
Allen, L., \& Smout, M. (2008). The Retreating Village. London: Bartlett School of Architecture.

Allen, S. (2007). Augmented Landscapes. In M. Smout, L. Allen, \& A. Smout, Pamphlet Architecture 28: Augmented Landscapes (pp. 6-13). New York: Princeton Architectural Press.

Allen, S. (2011). Matters of Surface. In S. Allen, \& M. McQuade (Eds.), Landform Building: Architecture's New Terrain (pp. 363-370). Baden: Lars Muller Publishers.

Amusing Planet. (2012, April 18). Chand Baori Step Well in Rajasthan, India. Retrieved from Amusing Planet: http://www.amusingplanet.com/2012/10/chandbaori-step-well-in-rajasthan-india.html

Beach Modification: Natural Impacts on Beach Morphodynamics. (2000). In A. Short, \& A. Short (Ed.), Handbook of Beach and Shoreface Morphodynamics ( $\mathrm{p}$. 210). Sacrimento: John Wiley.

Bernard Tschumi Architects. (n.d.). Parc de la Villette. Retrieved from Bernard Tschumi Architects: http:// www.tschumi.com/projects/3/

BGS Landslides team. (2014, February 8). Coastal erosion at Happisburgh, Norfolk. Retrieved April 14, 2014, from British Geology Survey: http://www.bgs. ac.uk/landslides/happisburgh.html
Bowring, J. (2010). Eternal Sunshine: The Search for the Spotless Landscape. In J. Stephenson, M. Abbott, \& J. Ruru (Eds.), Beyond the Scene: Landscape and Identity in Aotearoa New Zealand (pp. 78-82). Dunedin: Otago University Press.

Cappelli, L., \& Gaullart, V. (Eds.). (2010). Self Sufficient City. Barcelona: IaaC.

Chesterton, N. (2014). Dealing with Slopes. Taranaki: Veterinary Education Transfer Services Ltd.

Clifford, S. (2001). The Cultural Landscape: For Looking at or Living in? Local Distinctiveness from the Inside Out. London: ICOMOS-UK.

Corner, J. (2003). Landscape Urbanism. In M. Mostafavi, \& C. Najle (Eds.), Landscape Urbanism: A Manual for the Mechanic Landscape (pp. 58-75). London: Architectural Association.

Correa, C. (1989). The New Landscape: Urbanisation in the Third World. Concept Media Ltd.

Dawe, I. (2014). Sand Dunes: Form, Function, Processes. Wellington: Greater Wellington Regional Council.

Department of Conservation. (n.d.). Coastal Sand Dunes Form and Function. Retrieved from Department of Conservation: http://www.doc.govt.nz/publications/ conservation/native-plants/pikao-or-pingao-thegolden-sand-sedge/coastal-sand-dunes-form-andfunction/ 
Dreaver, A. (1984). Horowhenua County and its People: A Centennial History. Wellington: Dunmore Press.

Dunbar, R. (1991). Neocortex Size as a Constraint on Group Size in Primates. Journal of Human Evolution, 469-493.

Forman, S., Sagintayev, Z., Sultan, M., Smith, S., Becker, R., Kendall, M., \& Marin, L. (2008). The twentieth-century migration of parabolic dunes and wetland formation at Cape Cod National Sea Shore, Massachusetts, USA. The Holocene, 765-774.

Global Crop Diversity Trust. (n.d.). Svalbard Global Seed Vault. Retrieved from Svalbard Global Seed Vault: https://www.croptrust.org/what-we-do/svalbardglobal-seed-vault/

GNS Science. (2009). How often do earthquakes occur along the fault? Retrieved from GNS Science: http://www.gns.cri.nz/Home/Learning/ScienceTopics/Earthquakes/Major-Faults-in-New-Zealand/ Wellington-Fault/How-often-do-earthquakes-occuralong-the-fault

Horowhenua District Council. (1997). Waikawa Stream Mouth Management Plan. Wellington: AC Consulting Group Ltd.

Horowhenua District Council. (2008). Horowhenua Development Plan. Wellington: Horowhenua District Council.
Horowhenua District Council. (2012). Surface Water Flooding and River Bank Erosion. Wellington: Horowhenua District Council.

Inspiration Green. (n.d.). Terraced Farms. Retrieved from Inspiration Green: http://www.inspirationgreen. com/terraced-farms.html

Kroll, A. (201 1, January 9). AD Classics: Parc de la Villette / Bernard Tschumi. Retrieved from Archdaily: http:// www.archdaily.com/9232 1/ad-classics-parc-de-lavillette-bernard-tschumi/

Land Information New Zealand. (2014, March 2). LINZ Data Service. Retrieved from Land Infromation New Zealand: https://data.linz.govt.nz/

Landezine. (2011, March 6). DIY Urban Furniture Experiment. Retrieved from Landezine: Landscape Architecture Works: http://www.landezine.com/index. php/2011/03/diy-urban-furniture-experiment/

Landscapelover. (2010, November 30). Parc de la Villette. Retrieved from a landscape lover's blog: https://landscapelover.wordpress.com/2010/11/30/ parc-de-la-villette/

Livingstone, M. (2002). Steps to Water: The Ancient Stepwells of India. Princeton: Princeton Architectural Press.

Lynch, K. (1960). The Image of the City. Cambridge: MIT Press. 
McFadgen, B. (1997). Archaeology of the Wellington Conservancy: Kapiti-Horowhenua. Wellington: Department of Conservation.

MIMOA Community. (n.d.). Maritime Youth House. Retrieved February 20, 2014, from MIMOA: mi modern architecture: http://www.mimoa.eu/projects/ Denmark/Copenhagen/Maritime\%20Youth\%20House

Mostafavi, M. (2003). Landscapes of Urbanism. In M. Mostafavi, \& C. Najle (Eds.), Landscape Urbanism: $A$ Manual for the Mechanic Landscape (pp. 5-21). London: Architectural Association.

Nature Space. (n.d.). Community group bolsters native regeneration in dunes. Retrieved April 21, 2014, from Nature Space: Ecological Restoration in Aotearoa: http://www.naturespace.org.nz/community-groupbolsters-native-regeneration-in-dunes

Oskin, B. (2013, August 22). Japan Earthquake and Tsunami of 2011 : Facts and Information. Retrieved April 14, 2014, from livescience: http://www.livescience. com/39110-japan-2011-earthquake-tsunami-facts. html

Pallasmaa, J. (2009). The Temporal Dimension of Existential Space. In M. Treib (Ed.), Spacial Recall: Memory in Architecture and Landscape (pp. 18-27). New York: Routledge.

Rose, G. (2007). Building in a Restless World. In M. Smout, L. Allen, \& A. Smout, Pamphlet Architecture 28: Augmented Landscapes (pp. 22-34). New York: Princeton Architectural Press.
Russel, J. S. (2011). The Agile City: Building Well-being and Wealth in an Era of Climate Change. Washington, DC: Island Press.

Shepherd, D., \& Shepherd, L. (1999). Bitter Water: A Story of Waikawa. Wellington: Catch 22.

The Economist Newspaper. (2012, March 10). Banking against Doomsday. Retrieved from The Economist: http://www.economist.com/node/21549931

Town of Dauphin Island. (2014). About Dauphin Island. Retrieved from Town of Dauphin Island: http:// townofdauphinisland.org/default.asp?ID=32

Tuan, Y.-F. (2004). Sense of Place: Its Relationship to Self and Time. In T. Mels (Ed.), Reanimating Places: $A$ geography of Rhythms (pp. 46-47). Michigan: Ashgate Publishing Limited.

Waldheim, C. (2006). Landscape as Urbanism. In C. Waldheim (Ed.), The Landscape Urbanism Reader (pp. 35-54). New York: Princeton Architectural Press.

World Monuments Fund. (2012, March 22). An Overview of Ha Long Bay's Fishing Villages. Retrieved from World Monuments Fund: http://www.wmf.org/journal/ overview-ha-long-bay\%E2\%80\%99s-fishing-villages

Zaera-Polo, A. (2003). On Landscape. In M. Mostafavi, \& C. Najle (Eds.), Landscape Urbanism: A Manual for the Mechanic Landscape (pp. 132-134). London: Architectural Association. 
